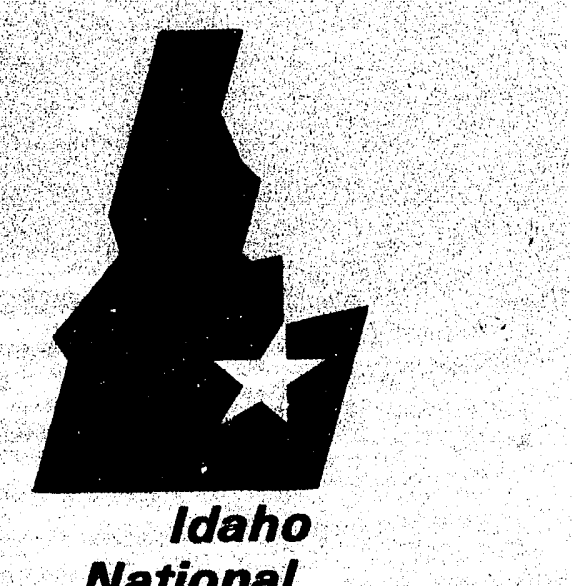

National

\section{Engineering}

Laboratory

Managed by the U.S.

Department

of Energy
EGG-MS- 9617

September 1991

RAPID SOLIDIFICATION PROCESSING OF IRON-BASE ALLOYS FOR STRUCTURAL APPLICATIONS

J. E. Flinn

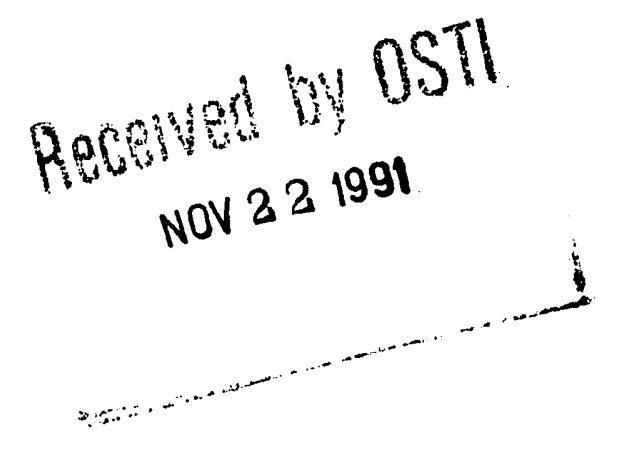

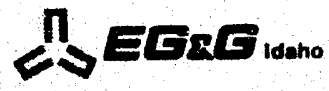

Work performod under DOE Contract No. DE-AC07-761D01570 
This document contains new concepts or the author(s) interpretation of new calculations and/or measurements; accordingly, EG\&G Idaho, Inc. is required by the United States Government to include the following disclaimer:

\section{DISCLAIMER}

This report was prepared as an account of work sponsored by an agency of the United States Government. Neither the United States Government nor any agency thereot, nor any of their employees, makes any warranty, express or implied, or assumes any legal liability or responsibility for the accuracy, completeness, or usefulness of any information, apparatus, product or process disclosed, or represents that its use would not infringe privately owned rights. References herein to any specific commercial product, process, or service by trade name, trademark, manufacturer, or otherwise, does not necessarily constitute or imply its endorsement, recommendation, or favoring by the United States Government or any agency thereol. The views and opinions of authors expressed herein do not necessarily state or reflect those of the United States Government or any agency thereof. 
EGG-MS--9617

DE92 003306

RAPID SOLIDIFICATION PROCESSING OF IRON-BASE ALLOYS FOR STRUCTURAL APPLICATIONS

J. E. Flinn

Published September 1991

EG\&G Idaho, Inc.

Idaho Falls, ID 83415

Prepared for the

Interior Department's Bureau of Mines and for the

U.S. Department of Energy

Under DOE Contract No. DE-AC07-76ID01570 


\section{ABSTRACT}

The response of iron-base alloys to rapid solidification is reviewed with an emphasis on the effects of processing on the microstructure and mechanical property behavior. The processing topics addressed are powder atomization, powder consolidation, joining, and thermal-mechanical exposures. The value of rapid solidification processing (RSP) lies in the ability to promote compositional homogeneity and retention of fine and stable (to high temperatures) microstructures. Achieving the maximum benefit from RSP requires proper application of the basic principles of composition control and rapid crystallization. This investigation has disclosed two very important facets of the RSP approach that can be applied using current technologies. Dissociated oxygen appears to play a significant role in stabilizing microstructural features. In conjunction with oxygen, vacancies trapped during crystallization provide a very stable matrix dispersion for enhanced strengthening. With a fundamental understanding of the response of iron-base alloys to RSP, alloys can be designed that will have substantially better properties and performance than their conventionally processed counterparts. 


\section{ACKNOWLEDGMENTS}

The author is greatly indebted to many colleagues and associates for their contributions to the RSP research on the iron-base alloys. Jung Chan Bae, Joseph V. Burch, Gary L. Fletcher, M. Duane Harper, and Thomas F. Kelly have provided major contributions to the experimental studies and findings. The contributions and discussions provided by J. B. Adams, J. G. Byrne, D. E. Clark, J. S. Dunning, A. W. Erickson, M. E. Fine, W. W. Kim, G. E. Korth, J. C. Rawers, Keesam Shin, G. R. Smolik, C. L. Trybus, P. W. Voorhees, W. G. Wolfer, and R. N. Wright are also greatly appreciated. The author greatly appreciates the efforts provided by Dorothy Cullen, Bob Neilson, Heide Schaefer, Myrtle Taylor, Bobbi Tracy, and Jeff Wright in the preparation of this manuscript.

This work was supported by the Interior Department's Bureau of Mines (under Contract No. J0134035) and the Department of Energy's Advanced Industrial Concept Division through Department of Energy Cuntract No. DE-ACO776ID01570. 
CONTENTS

ABSTRACT

INTRODUCTION

POWDER PROCESSING AND CHARACTERIZATION . . . . . . . . . . . . . . . 3

Atomization Methods.... . . . . . . . . . . . . . . . . 3

Powder Characterization... . . . . . . . . . . . . . 5

Particle Size Distributions .

Particle Microstructure Metallographic Results . . . . . . . . 11

Submicron Microstructural Observations . . . . . . . . . . . . 19

Particle Surface Films . . . . . . . . . . . . . . . 26

Entrained Noble Gases. . . . . . . . . . . . . . 30

Powder Atomization Issues. . . . . . . . . . . . . . . . . 35

POWDER CONSOLIDATION . . . . . . . . . . . . . . . . . . 37

Methods and Parameters . . . . . . . . . . . . . . . 37

Hot Extrusion....................... . 39

Hot Isostatic Pressing . . . . . . . . . . . . . . . . . . 41

Dynamic Consolidation . . . . . . . . . . . . . . . . . . 48

Comparisons Between As-Consolidated Forms . . . . . . . . . . . . . . 53

Some Issues Associated With Consolidation of RSP Powders . . . . . . 56

JOINING OF CONSOLIDATED RSP POWDERS . . . . . . . . . . . . . . . . 57

GTA Welding 57

Capacitor Discharge Welding . . . . . . . . . . . . 59

Electron Beam Welding... . . . . . . . . . . . . . . . 60

Inertia or Friction Welding . . . . . . . . . . . . . . . . . 61

Explosive Joining . . . . . . . . . . . . . . . . . . . . . . 61

Issues Associated with Joining of RSP Iron-Base Alloys . . . . . . . 63

CHARACTERIZATION OF CONSOLIDATED RSP POWDERS . . . . . . . . . . . . 65

Evaluation of Particle Surface Films . . . . . . . . . . . . . . 65

Entrained Noble Gases and Porosity . . . . . . . . . . . . . 69

Microstructure-Submicron Features . . . . . . . . . . . . . 76

Dislocation Behavior .... . . . . . . . . . . . . . . 77

Precipitate Behavior .. . . . . . . . . . . . . . . . 81

Cavity Formation . . . . . . . . . . . . . . . . . . . 86

Microstructure-Grain Size Behavior . . . . . . . . . . . . . . . 94

Powder Processing . . . . . . . . . . . . . . . . 95

Powder Consolidation . . . . . . . . . . . . . . . . 97

Thermal-Mechanical Processing . . . . . . . . . . . . . 97 
Particle Size Effects................... 100

Composition Influences . . . . . . . . . . . . . . 103

Grain Growth Retardation Mechanisms . . . . . . . . . . . 105

Microstructural Issues .................. . 113

Mechanical Behavior . . . . . . . . . . . . . . . 113

Tensile Properties . . . . . . . . . . . . . . . . 113

Creep Properties . . . . . . . . . . . . . . . . . 119

Fatigue Properties . . . . . . . . . . . . . . . . 127

Microstructure-Mechanical Property Correlation . . . . . . . . . 131

Tensile Correlations .................. 131

Creep Correlations . . . . . . . . . . . . . . . . . 138

Fatigue Correlations . . . . . . . . . . . . . . . . . 138

Improved Microstructural Stability and Strengthening by Designed

Rapid Solidification Processing . . . . . . . . . . . . 139

POTENTIAL FOR COMMERCIAL UTILIZATION . . . . . . . . . . . . . 142

Powder Processing . . . . . . . . . . . . . . . . . . 14 2

Powder Consolidation .. . . . . . . . . . . . . . . . . 144

Fotential Product Applications . . . . . . . . . . . . . 146

SUMMARY . . . . . . . . . . . . . . . . . . . . . 148

REFERENCES ............................ 151

FIGURES

1. Inert gas and centrifugal atomization processes . . . . . . . . . 4

2. Particle size distribution for Type $304 \mathrm{SS}, \mathrm{CA} \mathrm{Fe}-20 \mathrm{Ni}-20 \mathrm{Cr}$

with three carbon levels, and $\mathrm{Fe}-40 \mathrm{Ni}$ powders . . . . . . . . . . 8

3. Effect of gas-to-molten metal flow ratio on the mean particle size for argon and helium atomized Type 304 SS powder . . . . . . . . . 11

4. Microstructures of $\mathrm{Fe}-40 \mathrm{Ni}$ powders processed by $\mathrm{CA}$ and VGA methods using different gases . . . . . . . . . . . . . . . . . 13

5. Microstructures of $\mathrm{Fe}-40 \mathrm{Ni}-0.3 \mathrm{Nb}-0.05 \mathrm{C}$ powders processed by $\mathrm{CA}$ and VGA methods using different gases . . . . . . . . . . . . . . 14

6. Microstructures of $\mathrm{CA}$ processed $\mathrm{Fe}-20 \mathrm{Ni}-20 \mathrm{Cr}$ powders, with and without $2 \mathrm{Mo}$, and each with three carbon levels . . . . . 15

7. Microstructures of Type 3C4 SS powders processed by various atomization methods . . . . . . . . . . . . . . . . . 16

8. Microstructures of 50-75 $\mu \mathrm{m}$ powders of six IGA stainiess steels $\quad 17$

9. Dendrite and cell size for various particle sizes of $\mathrm{Fe}-40 \mathrm{Ni}$ and $\mathrm{Fe}-40 \mathrm{Ni}-0.3 \mathrm{Nb}-0.05 \mathrm{C}$

10. Influence of particle size on microstructural fineness for $C A$ processed $\mathrm{Fe}-20 \mathrm{Ni}-2 \mathrm{OCr}$ and $\mathrm{Fe}-20 \mathrm{Ni}-20 \mathrm{Cr}-2 \mathrm{Mo}$ powders with different carbon contents

11. Influence of particle size on microstructural fineness for VGA and CA and IGA processed Type 304 SS powders . . . . . . . . . . . 21 
12. Influence of particle size on retained austenite for VGA, CA, and IGA Type 304 SS powders . . . . . . . . . . . . . . . . . 22

13. TEM of submicron defects in Type 304 SS processed powder particles .......................... . . . 24

14. TEM of IGA Type 304 SS particle showing microtwinning . . . . . . 25

15. TEM of submicron features for an IGA Type 304 SS particle showing a high density of small defects and dislocations . . . . . . . 25

16. Auger depth profiles for IGA processed powder . . . . . . . . . 28

17. Auger depth profiles for CA Type 304 SS powder . . . . . . . . . . 29

18. Influence of particle size on entrained noble gas contents for CA and VGA powders . . . . . . . . . . . . . . . . . . . 31

19. Influence of particle size on entrained helium content and

20. Influence of particle size on entrained hei ium content for various stainless steels processed by IGA using similar parameters . . . . 34

21. Porosity in atomized Type 304 SS 100-150 $\mu \mathrm{m}$ particles . . . . . 34

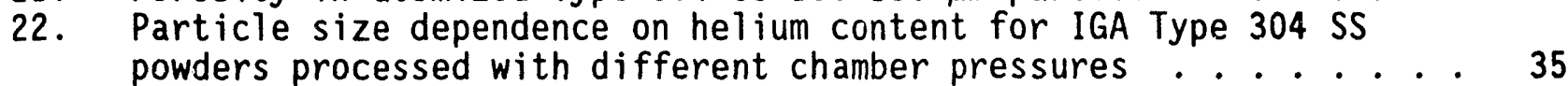

23. Consolidation methods for RSP powders . . . . . . . . . . . 38

24. Microstructure of IGA processed Type 304 SS for various powder particle sizes after hot extrusion...... . . . . . . . . . 40

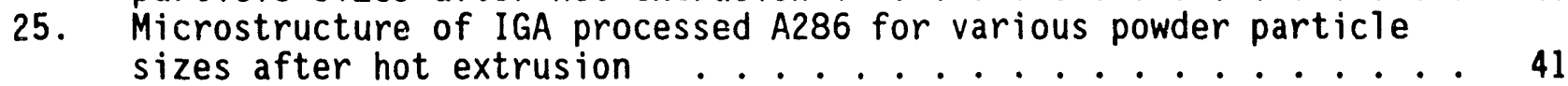

26. Microstructure of $\mathrm{CA} \mathrm{Fe}-20 \mathrm{Ni}-20 \mathrm{Cr}$ powders with different carbon
contents HIPped at 900 and $1100^{\circ} \mathrm{C}$. . . . . . . . . 43

27. Microstructure of $\mathrm{CA}$ Fe-40Ni powders after $\mathrm{HIPping}$ at $207 \mathrm{MPa}$
for $2.5 \mathrm{~h}$ at various temperatures . . . 44

28. Microstructure of $\mathrm{CA}$ Fe-40Ni-0.3Nb-0.05C powders after HIPping
at $207 \mathrm{MPa}$ for $2.5 \mathrm{~h}$ at various temperatures . . . . . . . 45

29. HIPping maps of CA Type $304 \mathrm{SS}, 30-50 \mu \mathrm{m}$ particles. . . . . . . . . 46

30. Experimental and calculated densities for CA Type 304 SS HIPped powders ............................ . . 4 47

31. Elongation results from tensile testing correlated with density for various HIP conditions on CA Type 304 SS powder . . . . . . . 49

32. Test configurations for dynamic consolidation of powders using

33. Optical micrographs of dynamically consolidated $\dot{C} A$ Type $30 \dot{4}$ SS powders ....................... . . 51

34. Influence of peak stress from projectile impacts on average hardness for Type 304 SS powders before and after consolidation $\quad 52$

35. Entrained helium from powder processing after extrusion consolidation of CA Type 304 SS powder............. . . . 54

36. Fracture surfaces of failed tensile specimens for CA Type 304 SS powders consolidated by different methods . . . . . . . . . . .

37. GTA spot weld on CA Type 304 SS extruded powder containing $\sim 8$ appm entrained helium and showing pnrosity in fusion zone . . . . . . .

38. Grain behavior in HAZ for CA Type 304 SS extruded powder and conventionally processed Type 304 SS cladding . . . . . . . . . 58

39. Schematic of capacitor discharge joining . . . . . . . . . . .

40. Microstructure of CA Type 304 SS extruded powder after joining .

41. Test configurations for plate-to-plate and tube-to-tube sheet weids using explosives

42. Bond region of plate-to-plate joint, made using explosives, in CA Type 304 SS consolidated powder 
43. CA Type 304 SS tube explosively joined to a conventionally processed header . . . . . . . . . . . . . . . . . 63

44. Influence of powder particle size on oxygen content for IGA A286 and Type 304 SS after consolidation .. . . . . . . . . . . . . 66

45. Influence of reciprocal particle diameter on total oxygen content for IGA processed stainless steels . . . . . . . . . . . . . . 68

46. Influence of alloy nickel content on oxide film thickness for IGA powders

47. Noble gas contents of iron-base alloy powders before and after

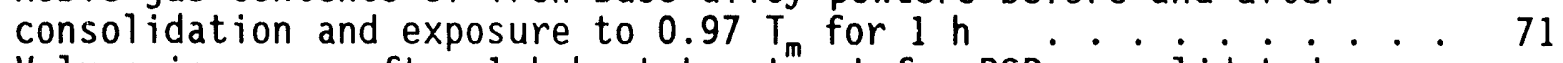

48. Volume increase after $1 \mathrm{~h}$ heat treatment for RSP consolidated iron-base alloy powders containing noble gases . . . . . . . . . 73

49. Porosity for CA Type 304 SS consolidated powder containing $~ 8$ appm of entrained helium after $1 \mathrm{~h}$ heat treatments ........... . 74

50. Ferrite formation around austenite grains after $\dot{i} \dot{h}$ heat treatment $\dot{s}$ for CA Type 304 SS consolidated powders ............ . 76

51. Dislocations for Type $304 \mathrm{SS}$ after $1 \mathrm{~h} 1100^{\circ} \mathrm{C}$ heat treatment . . . 78

52. Influence of $1 \mathrm{~h}$ heat treatments on the dislocation density for $C A$ and IGA Type 304 SS extruded powders and their CPC. . . . . . . . .

53. Influence of $1 \mathrm{~h}$ heat treatments on precipitate features for $C \dot{A}$ and IGA extruded Type 304 SS powders . . . . . . . . . . . . . .

54. Precipitate size distributions for IGA Type 304 SS extruded powder after $1 \mathrm{~h}$ heat treatments .................. 83

55. $8 \mathrm{~nm}$ cavities in CA Type 304 SS extruded powder . . . . . . . . . 87

56. $1.5 \mathrm{~nm}$ cavities in CA Type $304 \mathrm{SS}$ extruded powder after i $\mathrm{h}$ at $900^{\circ} \mathrm{C}$. . . . . . . . . . . . . . . . .

57. $1.5 \mathrm{~nm}$ cavities in CA Type 304 SS extruded powder after i $\dot{h}$ at $1200^{\circ} \mathrm{C}$. . . . . . . . . . . . . . . . . . . . . . . 89

58. $1.5 \mathrm{~nm}$ cavities in CA Type 304 SS HIPped powders after $1 \mathrm{~h}$

59. X-ray sper,trum from $8 \mathrm{~nm}$ cavities in CA Type 304 SS eviruded

60. CA Type $30 \dot{4}^{\circ} \mathrm{SS}^{\circ}$ extruded powder after $1 \mathrm{~h}, 1200^{\circ} \mathrm{C}$ and $1000^{\circ} \dot{h}$,

61. Precipitate size distribution for $\dot{C} A$ Type 304 SS extruded powder

62. Influence of atomization method on grain growth behavior of Type 304 SS consolidated powders . . . . . . . . . . . . . . parameters after HIP consolidation and cold working
63. Influence of $1 \mathrm{~h}$ heat treatments on the grain size for $C P C \mathrm{Fe}-40 \mathrm{Ni}$ and for CA and VGA Fe-40Ni powders with different atomization

64. Influence of $1 \mathrm{~h}$ heat treatments on the grain size for $C P C$ and CA Type 304 SS powders after consolidation by different methods

65. Influence of $1 \mathrm{~h}$ reheat treatments on grain size for extruded CA Type 304 SS and VGA Fe-16Ni-9Cr powders with two thermalmechanical processing

66. Influence of powder particle size on grain size after $\dot{i} \dot{h}$ heat

67. Influence of powder particle size on oxide film, dendrite arm
spacing, and grain size after $1 \mathrm{~h}$ heat treatments for IGA Type 304 SS extruded powders

68. Grain size after $1 \mathrm{~h}$ heat treatments for IGA $\mathrm{Fe}-16 \dot{\mathrm{Ni}}-9 \dot{\mathrm{C}} \mathrm{r}$ extruded powders of different particle sizes and the CPC material. 
69. Influence of powder particle size on grain size for IGA extruded

70. Microstructure of $30-50 \mu \mathrm{m}$ and $100-150 \mu \mathrm{m}$ IGA $\dot{A} 286$ particles after extrusion and heat treatment at $1200^{\circ} \mathrm{C}$ for $1 \mathrm{~h} . . . . . . .105$

71. Grain growth behavior of CA, HIPped, and cold worked $\mathrm{Fe}-40 \mathrm{Ni}$ and $\mathrm{Fe}-40 \mathrm{Ni}-0.3 \mathrm{Nb}-0.05 \mathrm{C}$ powders and their CPC ......... 106

72. Influence of carbon content on grain size for $C A F e-20 \mathrm{Ni}-20 \mathrm{Cr}$ HIPped and cold worked powders and their CPC . . . . . . . . . 107

73. Engineering stress-strain curves at various temperatures after $1 \mathrm{~h}, 1100^{\circ} \mathrm{C}$ heat treatments for CPC and VGA extruded $\mathrm{Fe}-16 \mathrm{Ni}-9 \mathrm{Cr}$ powder

74. Influence of temperature on yield and ultimate tensile stresses for CPC and VGA Fe-16Ni-9Cr extruded powder ............

75. Influence of temperature on total elongation and reduction in area for $\mathrm{CPC}$ and VGA Fe-16Ni-9Cr extruded powder . . . . . . . . . .

76. Engineering stress-strain curves at various test temperatures for CA Type 304 SS extruded powders and CPC after a $1 \mathrm{~h}, 1100^{\circ} \mathrm{C}$ heat treatment.

77. Influence of powder consolidation method on room temperature tensile properties for CA Type 304 SS and CPC after $1 \mathrm{~h}$ heat treatments at 900 and $1100^{\circ} \mathrm{C}$

78. Influence of annealing temperature on room temperature yieid and ultimate tensile stresses for IGA A286 extruded powders of three particle sizes and CPC

79. Influence of powder particle size on yield stress after extrusion consolidation and $1100^{\circ} \mathrm{C}, 1 \mathrm{~h}$ heat treatment on A286 IGA powders with and without a $100 \mathrm{~h} 700^{\circ} \mathrm{C}$ aging treatment .........

80. Influence of test temperature on tensile properties of $A 286$ IGA extruded powder and $C P C$ after $1100^{\circ} \mathrm{C} 1 \mathrm{~h}$ heat treatment and $700^{\circ} \mathrm{C}$ $100 \mathrm{~h}$ aging treatment

81. Influence of powder particle size of extruded IGA Fe-16Ni-9Cr$2 \mathrm{Mo}-1.5 \mathrm{Mn}-1 \mathrm{Si}-0.5 \mathrm{Ti}$ on tensile properties at 24,600 , and $800^{\circ} \mathrm{C}$

82. Stress-rupture behavior for CA and VGA HIPped, cold worked, and heat treated powders

83. Stress-rupture behavior at $600^{\circ} \mathrm{C}$ for $V G A$ and IGA extruded
Fe-16Ni-9Cr and VGA extruded $\mathrm{Fe}-16 \mathrm{Ni}-9 \mathrm{Cr}-5 \mathrm{MO}-2 \mathrm{Cu}$ powders and their CPCs after various heat treatments

84. Stress-rupture behavior at $600^{\circ} \mathrm{C}$ for IGA extruded $\mathrm{A} 286$ powders of different particle sizes and their CPC . . . . . . . . . . . . .

85. Influence of powder pirticle size on stress-rupture behavior at $600^{\circ} \mathrm{C}$ and $195 \mathrm{MPa}$ for Type 304 SS IGA extruded powders and CPC material .. . . . . . . . . . . . . . . . . . . .

86. Creep curves at $600^{\circ} \mathrm{C}$ and $195 \mathrm{MPa}$ for CA Type 304 SS extruded

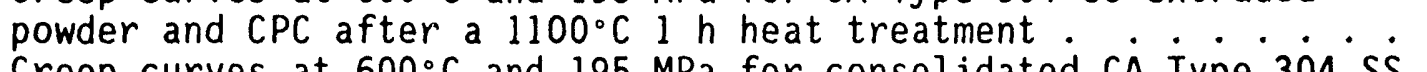

87. Creep curves at $600^{\circ} \mathrm{C}$ and $195 \mathrm{MPa}$ for consolidated CA Type $304 \mathrm{SS}$ powders and CPC with different thermal-mechanical treatments.

88. Room temperature fatigue behavior of CA Type 304 SS extruded powder with comparison to wrought austenitic stainless steels ......

89. Foreign hard particles from prior powder processing caused premature fatigue failure for extruded CA Type 304 SS . . . . . . 129

90. Room temperature fatigue behavior for IGA extruded powders with different partic ${ }^{1}$ e sizes.................... . . 130

91. Influence of grain size on room temperature yield stress . . . . 132 
92. Yield stress dependence on grain size for CA HIPped $\mathrm{Fe}-2 \mathrm{ONi}-20 \mathrm{Cr}$ and $\mathrm{Fe}-2 \mathrm{ONi}-\mathrm{COCr}-2 \mathrm{Mc}$ powders with different carbon contents and their CPCS............................ . 135

93. Influence of grain size on room temperature yield stress for CA Type 304 SS extruded powder and its CPC . . . . . . . . . . . 137

94. Temperature influence on creep obstacle stress for CA Type 304 SS extruded powder and its CPC ............... . 139

\section{TABLES}

1. Powder Atomization of Iron-Base Alloys . . . . . . . . . . . . 6

2. Consolidation Parameters for CA Type 304 SS Powders . . . . . . . 39

3. Mechanical Properties of the "As-Consolidated" Type 304 SS Powder Materials . . . . . . . . . . . . . . . . . . . 55

4. Iron-Base Alloys and Noble Gas Contents After Powder Consolidation .. . . . . . . . . . . . . . . . . 72

5. Quantitative TEM and STEM Examinations on RSP and CPC Alioys $: .77$

6. Influence of Particle Size on Dislocation Density after $1 \mathrm{~h}$, $1100^{\circ} \mathrm{C}$ Heat Treatment for IGA Extruded Type 304 SS Powder . . . . 80

7. Influence of Preconsolidation Particle Size on Precipitate Behavior for Extruded IGA Type 304 SS After $1100^{\circ} \mathrm{C}$ in Heat Treatment

8. Precipitate Observations for $C A$ and $C P C$ Fe-4ONi Alloy Series After $1 \mathrm{~h}$ Heat Treatments

9. Correlation of Grain Sizes Calculated From Dispersion Pinning Model and Measured Grain Sizes for RSP and Extruded Type 304 SS . . 109

10. Correlation of Grain Sizes Calculated From Dispersion Pinning Model and Measured Grain Sizes for RSP Fe-40Ni Alloys and their

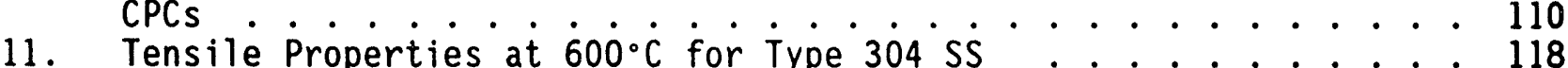

12. Creep Results for Type 304 SS Materials Tested at $600^{\circ} \mathrm{C}$ and $195 \mathrm{MPa}$. . . . . . . . . . . . . . . . . . . . 128

13. Parameters Associated with the Grain Size Influence on Yield Stress for CA Processed Fe-20Ni-20Cr and Fe-20Ni-20Cr-2Mo Alloys and their CPC

Potential End Uses for RSP Iron-Base Alloy Products . . . . . . 147 


\title{
RAPID SOLIDIFICATION PROCESSING OF IRON-BASE ALLOYS FOR STRUCTURAL APPLICATIONS
}

\author{
INTRODUCTION
}

Commercial application of rapidly solidified iron-base alloys has been limited. Two areas of notable success are the production of metallic glasses (amorphous metals) for magnetic applications and tool steels (higher wear resistance, toughness, and strength), which have both benefitted from this technology. However, use of this technology for structural stainless and high strength steels, other than for tooling applications, requires further development. This chapter discusses fundamental research on rapid solidification processing (RSP) of iron-based alloys being conducted primarily at the Idaho National Engineering Laboratory. The goal of this research is to provide the scientific basis for industrial development of RSP technology.

It is common knowledge in the field that RSP promotes chemical homogeneity, fine microstructures, extended solute solubility, and metastable phase development. ${ }^{1,2}$ The latter is the basis for metallic glasses. Chemical homogeneity is apparent in products obtained from powders prepared by melt stream atomization. During solidification, chemical segregation is constrained by particle size and dependent on the solidification rate of the molten droplet. After consolidation of the powders into a monolithic form, chemical segregation is obviously restricted to microscopic levels. The aspect of chemical homogeneity of the product that is not very well understood is the effect of homogeneity and the degree of elemental dissociation in the melt prior to powder atomization. The degree of chemical segregation is related to the microstructural features observed in the atomized powders. Usually these features are fine, micron size, and dependent on the composition and solidification rate of the particles. Spacings between the microstructural features are often measured, and correlation with cooling and solidification rates attempted. Considerably more attention should be given to submicron features of RSP powders. Of particular interest are identifying and cataloging compositional variations, phase development, and defect features such as dislocations and vacancy clusters, e.g., loops or voids. The primary method for such submicron assessments is scanning transmission electron microscopy (STEM), possibly with a position sensitive atom probe. 
The influence of the powder's fine microstructural features on the microstructure and properties/performance of the consolidated powder before and after thermal-mechanical processing also needs to be studied.

The benefits for structural alloys of extended solute solubility and metastable phase development have not received very much attention. Most alloy additions (elemental) to iron are within nominal equilibrium levels of solubility. The properties of these alloys may be significantly enhanced by increasing elemental additions above solubility limits. Metastable phase development has been observed in some iron-base alloys; however, the effect of these phases on structural performance is not obvious.

Although the general benefits of RSP, as discussed above, are commonly perceived, it is the author's opinion they are not well understood in terms of the properties and performance of the end product. Some aspects of RSP that have received very little attention appear to be very important for high temperature microstrictural stability, and corresponding properties, of the consolidated product. Vacancy and impurity trapping, including entrained gases, during the crystallization stage of RSP have been identified as major factors by this study. A goal of the research presented here is to identify and understand these aspects of RSP and thus provide a basis for designing RSP alloys for industrial applications.

This chapter discusses work on several aspects of RSP of iron-base alloys: powder processing, powder consolidation, joining, and their influence on microstructure/properties. In addition, issues that remain to be addressed and the potential for commercial utilization of the RSP technology are reviewed. Most of the information provided here is the result of studies performed during the last six years by the technical staff at the Idaho National Engineering Laboratory in close association with technical team members from Sandia National Laboratory Livermore, the University of Wisconsin (Madison), and the University of Utah. A substantial portion of the information provided has not yet been published in the archival literature, and is referenced accordingly throughout the text. 
This section focuses on atomization methods for prodicing rapidly solidified spherically-shaped particles. Unfortunately, the definition of rapid solidification itself is not easy. In the past it has been rather arbitrarily defined as a cooling rate $\geq 10^{2}{ }^{\circ} \mathrm{C} / \mathrm{s} .{ }^{1-3}$ However, rooling rate is difficult to quantitatively describe or measure since it represents syne gistic interactions of the temperature gradient in the liquid at the solid/liquid interface, recoalescence, and solidification rate. These parameters are very dependent on the alloy composition and the heat extraction process during the cooling cycle. The heat extraction process, in turn, can be very difficult to describe for complex alloy particles having relatively large surface area to volume ratios. Thus cooling rate is difficult if not impossible to quantify directly.

A correlation often encountered in the literature relates the size of the microstructural features observed from polished and etched particle cross sections, e.g., dendritic arm spacings and cellular boundaries, to solidification rate. (It should be noted that the terms 'cooling rate' and 'solidification rate' are used rather indiscriminately.) These microstructural features in rapidly solidified particles are considerably smaller than those observed from controlled tests involving very low solidification rates where temperature monitoring can be used. The solidification rates assigned to the RSP powders thus are the result of a significant extrapolation from the low solidification rates determined experimentally. Since the boundary spacings of the RSP powder appear to provide only qualitative information on the solidification behavior for a given alloy, there will be no attempt to assign cooling or solidification rates to the iron-base alloys examined in this study other than qualitatively, i.e., low versus high.

\section{Atomization Methods}

Several powder atomization methods have acquired either full or nearly full commercial status: rotating electrode, vacuum gas atomization (VGA), inert gas atomization (IGA), and centrifugal atomization (CA). In general, 
their relative cooling rates are in the order listed, with CA having the highest cooling rate. The rotating electrode method relies on high energy deposition on the surface of a rotating work piece. The heat deposited produces localized melting on the work piece, creating molten droplets that are spheroidized as they are flung from the rotating work piece. The chamber is backfilled with a gas, usually inert, such as argon or helium, to provide some convective cooling of the molten droplets. This process produces significantly larger particles than the other atomization processes and was not used in this study.

Vacuum gas atomization involves a pressurized melt. A fine melt stream is pushed up into a transfer tube and coupled with high pressure gas through a nozzle. The melt stream is gas atomized into molten droplets that are blown upwards by the gas into a large, low-pressure chamber. Because of the close coupling of the atomizing gas and molten droplets, some convective cooling occurs.

The inert gas and centrifugal atomization methods (see Figure 1) were used to rapidly solidify the majority of the materials in this study. The IGA process is similar in principle to the VGA method. A fine melt stream is atomized and convectively cooled by gas (usually argon or helium) as it passes through a nozzle. The molten droplets are blown down into a chamber that is
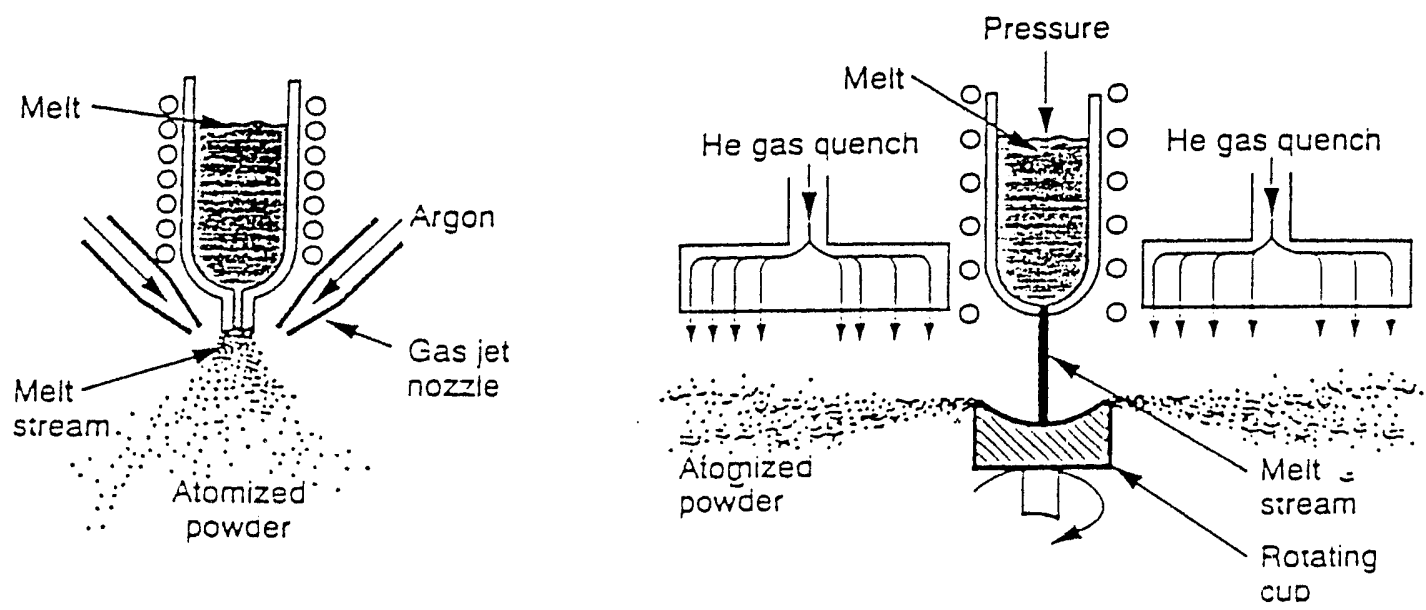

Figure 1. Inert gas (left) and centrifugal (right) atomization processes. 
usually backfilled with the atomizing gas, generally to less than 1 atm. The convective cooling associated with the IGA process is significantly higher than that of VGA.

Centrifugal atomization involves the impingement of a fine, metered melt stream onto a high velocity rotating cup. As the melt contacts the rotating cup it is broken up into fine molten droplets by the centrifugal action. The droplets are convectively cooled by relatively high velocity gas, usually helium, as they are thrown from the cup.

Limited studies were performed to investigate the effects of a range of atomization parameters. The primary parameters in the VGA and IGA processes are melt superheat, atomizing gas, and gas to molten metal flow ratio. The degree of superheat depends on whether the melt stream is poured directly through the nozzle from a tundish or through a transfer tube from a crucible. With a trarsfer tube a higher superheat is needed to reduce the tendency for freeze-off at the nozzle/pour tube interface. In this work, the superheat above the alloy's melting point ranged from 150 to $250^{\circ} \mathrm{C}$ and the atomizing gas was either helium or argon, although nitrogen could have been used. The atomizing gas to molten metal flow ratio in VGA and IGA is a function of the melt stream size, nozzle pressure, and the atomizing gas. This raiio is very important for controlling the particle size distribution. CA involved superheats of $-100^{\circ} \mathrm{C}$ and a cup speed of $\sim 25,000 \mathrm{rpm}$. A limited study was done on the effect of varying the amount of gas (helium) used to convectively cool the particles.

\section{Powder Characterization}

The iron-base alloys investigated were predominately austenitic ( $f(c)$, although some study was done on ferritic (bcc) and precipitation hardenable alloys. The alloys investigated and atomization methods used are shown in Table 1. Four of the alloys have commercial compositions, the remaining are experimental. 
Table 1. Powder Atomization of Iron-Base Alloys

\begin{tabular}{|c|c|c|}
\hline \multirow{2}{*}{$\begin{array}{c}\text { Alloy } \\
\text { (compositions in wt\%) }\end{array}$} & \multicolumn{2}{|c|}{ Atomization } \\
\hline & Method & Gas \\
\hline Type 304 SS (Fe-18Cr-10Ni-1.3Mn-0.5Si-0.05C) & $\begin{array}{l}\text { VGA } \\
I G A \\
C A\end{array}$ & $\begin{array}{l}\text { Ar } \\
\text { Ar \& He } \\
\mathrm{He}\end{array}$ \\
\hline Type PH 13-8(Mo) SS (Fe-13Cr-8Ni-2.4Mo-1.1Al-0.03C) & IGA & $\mathrm{He}$ \\
\hline Type $430 \mathrm{SS} \quad(\mathrm{Fe}-16.6 \mathrm{Cr}-0.2 \mathrm{Ni}-0.5 \mathrm{Mn}-0.3 \mathrm{Si}-0.03 \mathrm{C})$ & IGA & $\mathrm{He}$ \\
\hline $\begin{array}{l}\text { Type A286 (Fe-24Ni-14Cr-2.3Ti-1.2Mo-0.2Al-0.17Si-0.1Mn- } \\
0.05 \mathrm{C})\end{array}$ & IGA & $\mathrm{He}$ \\
\hline $\mathrm{Fe}-16 \mathrm{Ni}-9 \mathrm{Cr}-0.04 \mathrm{C}$ & IGA & Ar \\
\hline $\mathrm{Fe}-16 \mathrm{Ni}-9 \mathrm{Cr}-1.5 \mathrm{Mn}-0.05 \mathrm{C}$ & VGA & Ar \\
\hline $\mathrm{Fe}-16 \mathrm{Ni}-9 \mathrm{Cr}-5 \mathrm{Mo}-2 \mathrm{Cu}-1.5 \mathrm{Mn}-0.05 \mathrm{Si}-0.06 \mathrm{C}$ & VGA & Ar \\
\hline $\mathrm{Fe}-16 \mathrm{Ni}-9 \mathrm{Cr}-2 \mathrm{Mo}-1.5 \mathrm{Mn}-1.0 \mathrm{Si}-0.5 \mathrm{Ti}-0.05 \mathrm{C}$ & IGA & $\mathrm{He}$ \\
\hline $\mathrm{Fe}-11 \mathrm{Ni}-9 \mathrm{Cr}-1.8 \mathrm{Mn}-1.0 \mathrm{~S} i-0.03 \mathrm{C}$ & CA & $\mathrm{He}$ \\
\hline Fe-20Ni-20 Cr (three carbon levels: $0.005,0.04$, and 0.14 ) & CA & $\mathrm{He}$ \\
\hline $\begin{array}{l}\text { Fe-20Ni-20Cr-2Mo (three carbon levels: } 0.005,0.06 \text {, and } \\
0.14 \text { ) }\end{array}$ & $C A$ & $\mathrm{He}$ \\
\hline $\mathrm{Fe}-40 \mathrm{Ni}$ & $\begin{array}{l}\text { VGA } \\
C A\end{array}$ & $\begin{array}{l}\mathrm{Ar} \& \mathrm{He} \\
\mathrm{He}\end{array}$ \\
\hline $\mathrm{Fe}-40 \mathrm{Ni}-0.3 \mathrm{Nb}-0.05 \mathrm{C}$ & $\begin{array}{l}\text { VGA } \\
C A\end{array}$ & $\begin{array}{l}\text { Ar \& He } \\
\mathrm{He}\end{array}$ \\
\hline
\end{tabular}

The iron-base alloy powders produced by the four processing methods described above are predominantly spherical. The powders from the rotating electrode and CA processing methods show very little evidence of satellites or smaller particles attached to larger ones, whereas the VGA and IGA methods show some degree of satellite attachment. This behavior is not unexpected since the rotating electrode and $C A$ methods have very little molten droplet/particle interaction after atomization. However, the turbulence in the gas plume of the VGA and IGA processes offers more opportunities for interaction. 
Characterization of the powders included particle size distribution, particle microstructure (primarily optical examinations, although limited studies have addressed submicron microstructural features for the Type 304 SS powders), surface films, and entrained noble gases and related porosity. Results from these assessments are presented and discussed below.

\section{Particle Size Distributions}

The particle size distributions were determined from a mechanical screening of the atomized powders. A vibratory-rotap system with screen sizes of $<10,>10$ to $<20,>20$ to $<30,>30$ to $<50,>50$ to $<75,>75$ to $<100,>100$ to $<150,>150$ to $<300$, and $>300 \mu \mathrm{m}$ was used. Typical results, in terms of cumulative weight fraction for average particle sizes, are shown in Figure 2. The two different nozzle configurations used for IGA produced substantially different gas to moltel metal flow ratios. The median particle sizes are 31 and $54 \mu \mathrm{m}$ for the high and low flow ratios, respectively. Both IGA powders had significantly smaller particle size distributions than the CA processed powders (Figure 2a).

The Fe-20Ni-20Cr alloy with three carbon levels was centrifugally atomized. It is apparent from Figure $2 b$ that the carbon content had very little influence on the particle size distribution.

The influence of the atomization gas used for VGA processing and cooling gas flow rate for $\mathrm{CA}$ processing of $\mathrm{Fe}-40 \mathrm{Ni}$ powders is shown in Figure $2 \mathrm{C}$. For this alloy series, VGA with helium yielded significantly smaller particles than VGA with argon. The three helium flow rates for the CA processed $\mathrm{Fe}-40 \mathrm{Ni}$ powders show very similar particle size distributions. This should be expected since me1t breakup into the molten droplets by the centrifugal force from the rotating cup occurs before cooling with helium.

The particle size distribution is significantly affected by the powder processing parameters. Although a systematic study has not been reported for iron-base alloys, one can speculate on the important parameters. The degree of superheat temperature at the instant of atomization would be expected to 


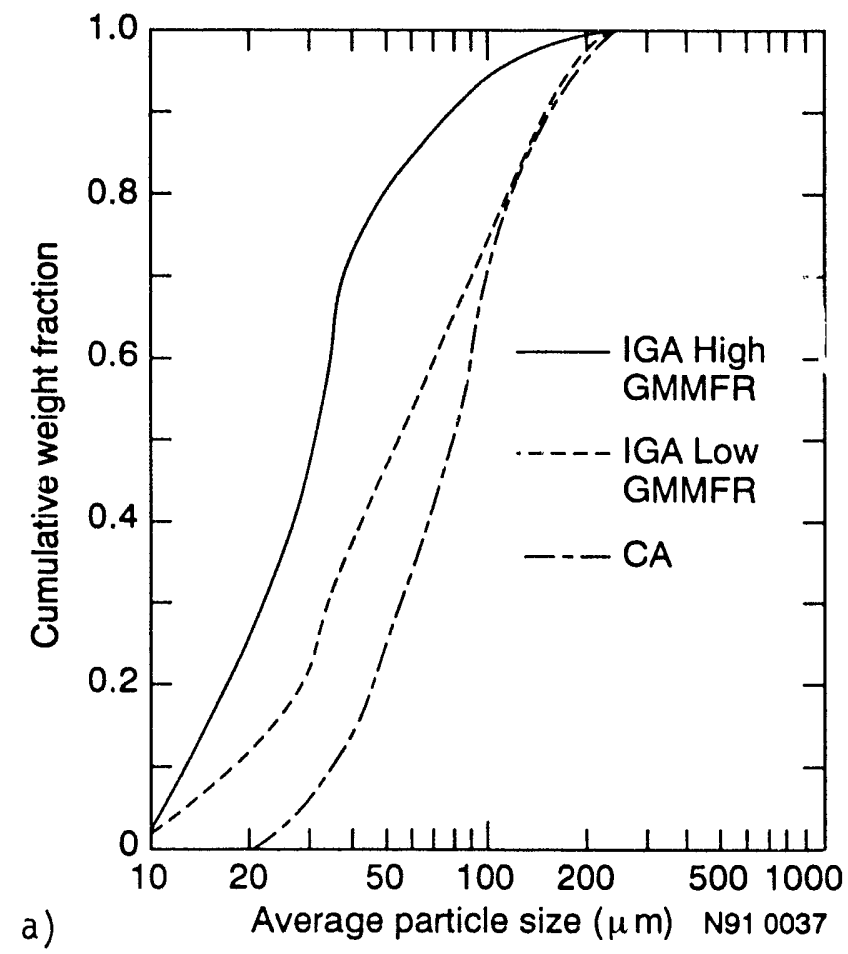

a)

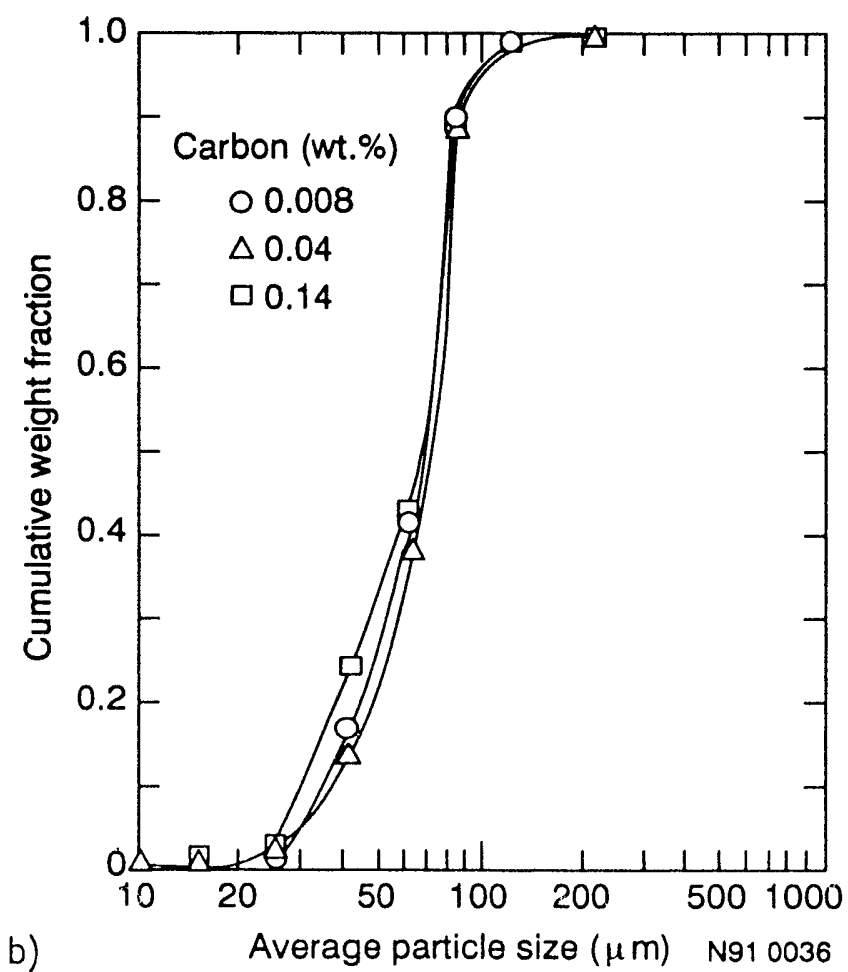

Figure 2. Particle size distribution for (a) Type $304 \mathrm{SS}$, (b) CA Fe-20Ni-20Cr with three carbon levels, and (c) Fe-40Ni powders. (Note: For Type 304 SS, GMMFR represents gas to molten metal flow ratio. For $\mathrm{Fe}-40 \mathrm{Ni}$, data in parentheses are gas flow rate in $\mathrm{kg} / \mathrm{s}$.) 


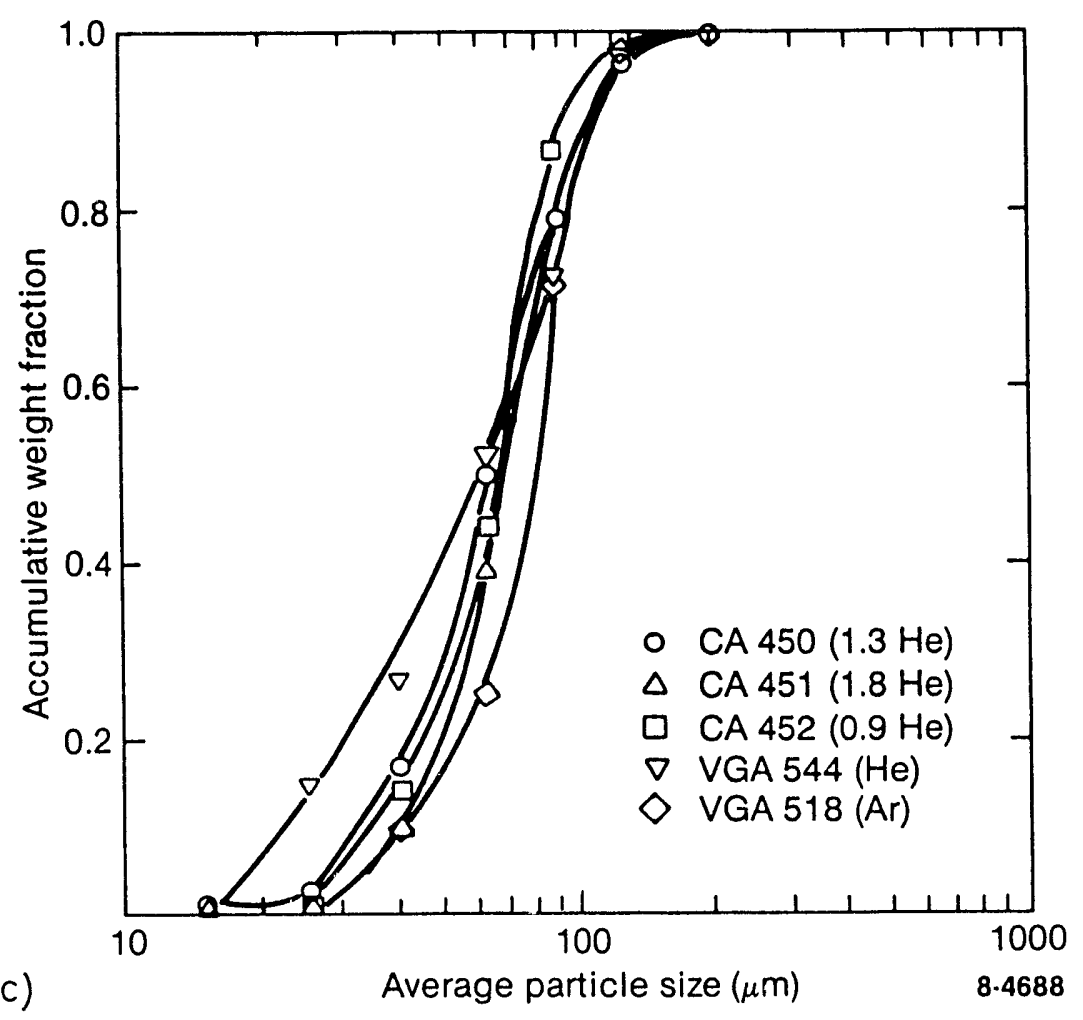

Figure 2. (Continued)

affect the particle size distribution. Increasing the superheat temperature decreases the viscosity of the molten metal, which should reduce surface tension and allow the molten metal stream to be broken into finer droplets.

The particle size distribution for the CA process is largely controlled by the speed of the rotating cup. A larger fraction of finer particles would be expected from higher rotating velocities. However, it must be recognized that there are practical limits to the speeds that can be achieved by the cup.

The VGA and IGA processes rely on focused (nozzle) gas interaction with a metered (size control) melt stream. Two configurations are commonly associated with these processes, close coupling and distant or "free-falling" coupling. For close coupling, the gas interacts with the melt stream as it exits the pour tube, i.e., the gas from the nozzle is immediately coupled with the molten metal. Close coupling produces a low pressure at the interface that creates an aspiration effect, pulling the melt stream from the pour tube. Although the details of close-coupling atomization are not clearly understood, 
it appears that the initial breakup of the melt stream forms primarily larger droplets in the near vicinity of the nozzle/pour tube interface. These larger droplets disintegrate as they enter the plume region of the particle stream. Analytical models that address the two-phase flow characteristics of the melt stream/gas interaction at the nozzle-pour tube interface, as well as in the mixing region of the plume where the particles are still molten, are needed.

For "free-falling" coupling, the gas interacts with the melt stream at some distance away from the pour tube. This technique is more common for commercial processing of metallic powders. The gas-to-molten metal interaction appears to be less effective than in the close-coupling methor, but the probability for freeze-off at the melt/pour tube exit is reduced.

The IGA studies have shown that the particle size distribution can be shifted toward smaller particles by increasing the atomizing gas-to-molten metal flow ratio. Figure 3 illustrates the effect of this parameter for IGA processing of Type 304 SS using argon and helium. ${ }^{4}$ The obvious way to increase this ratio is to increase the gas pressure and/or reduce the melt stream size; however, the best way is through nozzle design to increase the effective interaction of the gas with the melt stream. The two IGA particle size distributions shown in Figure 2 a were produced with the same melt metering orifice and gas pressure but different nozzles. Better gas/molten metal interaction was achieved by changing the nozzle design.

To produce very fine particles, gas atomization methods can be coupled with gases that expand during atomization. These gases, which are usually reactive, are injected into the melt or melt stream and rapidly expand in the molten droplets, causing further disintegration into finer droplets. This approach provides unique opportunities for producing high yields of fine particles, providing there are no adverse effects from the entrained reactive gases remaining in the particles on the properties of the consolidated alloy. 

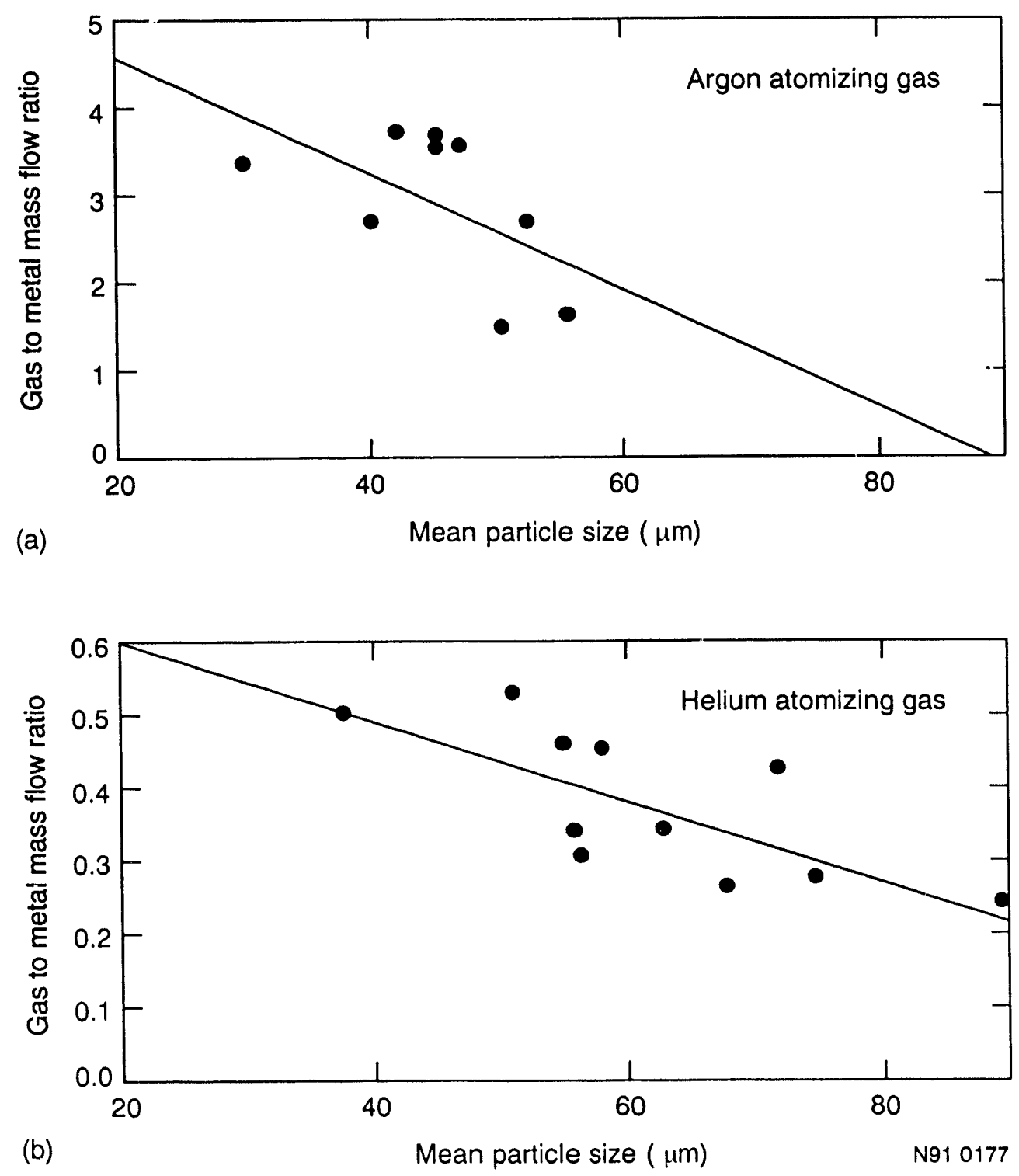

Figure 3. Effect of gas-to-molten metal flow ratio on the mean particle size for argon and helium atomized Type 304 SS powder.

\section{Particle Microstructure Metallographic Results}

Evaluations of particle microstructures are based primarily on optical microscopy examination of polished and etched particle cross sections. The microstructural features (morphology) and corresponding fineness provide an indication of the atomization and cooling effects obtained during powder processing. Iron-base alloy powders processed by VGA, CA, and IGA are 
discussed to show apparent influences from alloy composition, as weil as atomization and cooling parameters.

An evaluation has been performed on VGA and CA processed Fe-40Ni with and without $\mathrm{Nb}$ and $\mathrm{C}$ additions. ${ }^{5}$ Optical micrographs of $>50$ to $<75 \mu \mathrm{m}$ particles shown in Figure 4 represent a powder processing series on the Fe-40Ni binary. The series of $\mathrm{CA}$ processed $\mathrm{Fe}-40 \mathrm{Ni}$ powders had a predominantly dendritic morphology (Figures $4 \mathrm{a}$ and $\mathrm{b}$ ). The dendrite arm spacing is larger for the nitrogen cooled (Figure 4b) than helium cooled particles (Figure 4a). Three different helium flow rates were used for the $C A$ powder batches, but flow rate had little influence on the dendrite arm spacing. The VGA particles show a microstructure morphology that is predominantly cellular for both helium and argon (Figures $4 c$ and $4 d$, respectively). It should be noted that the helium run provided a smaller cell structure than the argon run. This should be expected since helium would provide higher convective cooling. The shape of the particles shown il, Figure 4 was influenced by the powder containment chamber. A relatively large chamber was used for the VGA processing, and the particles are predominantly spherical and possess satellites, although they are not evident from Figures $4 c$ and $4 d$. The $C A$ powders were processed in a small diameter chamber and show very significant irregularities in shape. The particle irregularity is probably dise to high velocity collision with the chamber wall after crystallization nas occurred.

Adding small amounts of $\mathrm{Nb}(0.3 \mathrm{wt} \%)$ and $\mathrm{C}(0.05 \mathrm{wt} \%)$ to the $\mathrm{Fe}-40 \mathrm{Ni}$ binary alloy did not appear to affect the microstructure morphology for this series of powder processing parameters. The CA processed powders are predominantly dendritic and the VGA powders show a cellular microstructure (Figure 5). However, these microstructural features are significantly finer than those of the relatively pure binary (without the $\mathrm{Nb}$ and $\mathrm{C}$ additions) processed by VGA. For this alloy also, the particles processed by $C A$ in a small chamber were, in general, irregular in shape.

Mechanically screened particles, $>50$ to $<75 \mu \mathrm{m}$, of a CA alloy series involving $\mathrm{Fe}-20 \mathrm{Ni}-20 \mathrm{Cr}$ and $\mathrm{Fe}-20 \mathrm{Ni}-20 \mathrm{Cr}-2 \mathrm{Mo}$, each with three carbon levels, are shown in Figure 6 . These powders were all processed using the same cup 


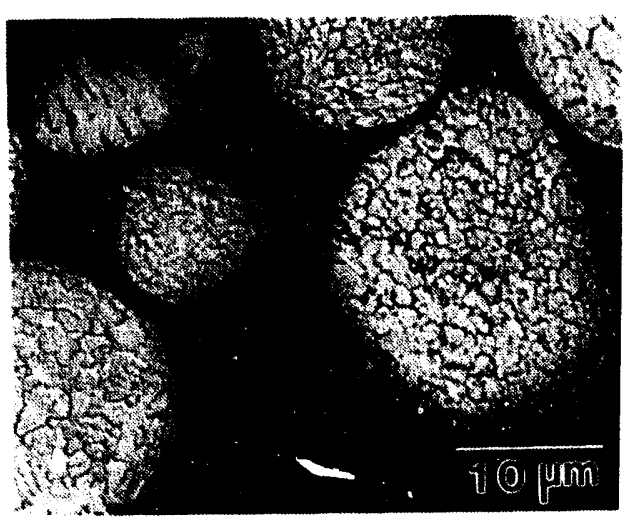

(a) CA helium

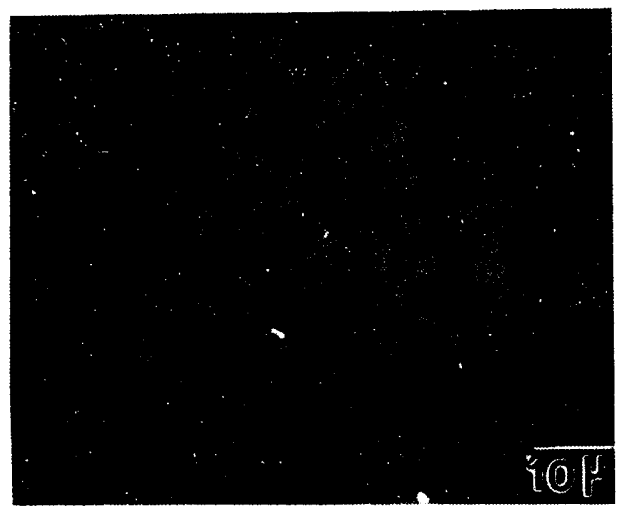

(c) VGA helium

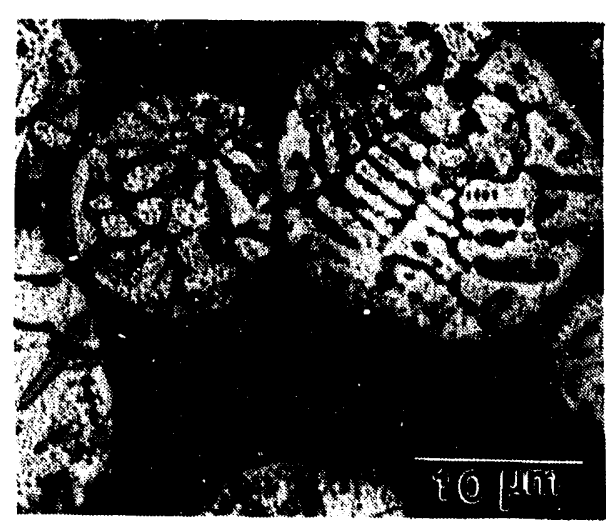

(b) CA nitrogen

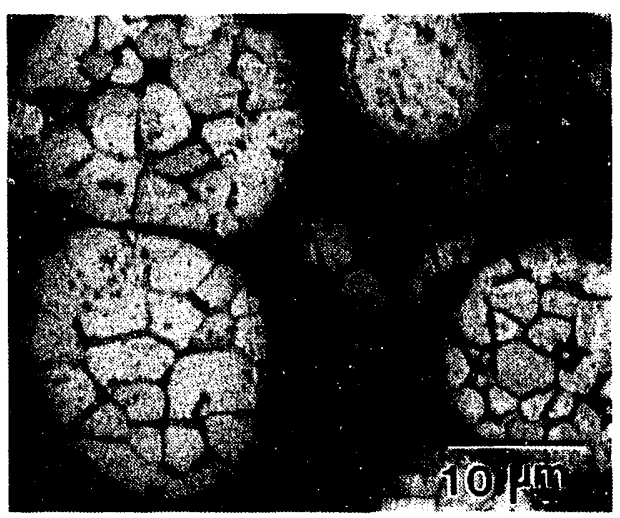

(d) VGA argon

Figure 4. Microstructures (optical) of $\mathrm{Fe}-40 \mathrm{Ni}$ powders $(30-50 \mu \mathrm{m})$ processed by $C A$ and VGA methods using different gases.

speed $(24,000 \mathrm{rpm})$, superheat $\left(-100^{\circ} \mathrm{C}\right.$ above melting), and helium flow rate for convective cooling. The same chamber was used for processing these powders as was used for the $\mathrm{Fe}-40 \mathrm{Ni}$ series. The powders for the six alloys have dendritic microstructures. In general, the dendrite arm spacing decreases

- with increasing carbon content as well as with the addition of 2 wt\% of Mo. Microstructures of Type 304 SS powders processed by VGA, CA, and IGA are shown in Figure 7. The VGA processed powder (using argon) has a cellular morphology, which appears to be the more common morphology for the lower solidification rate VGA process. Both the CA (helium cooled) and IGA (helium and nitrogen atomized and cooled) powders show much finer and nearly 


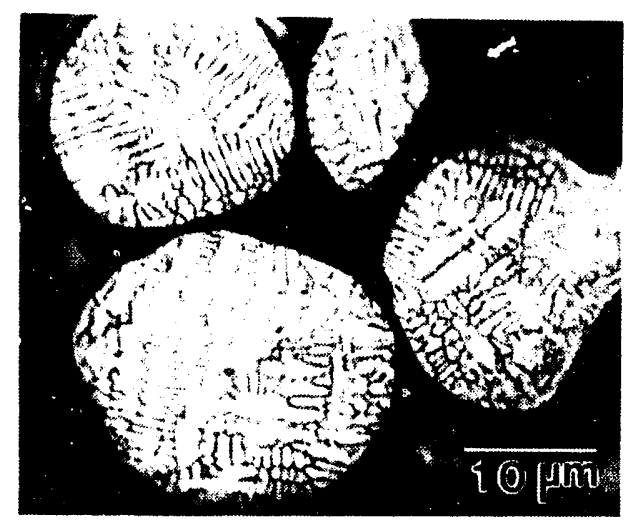

(a) CA helium

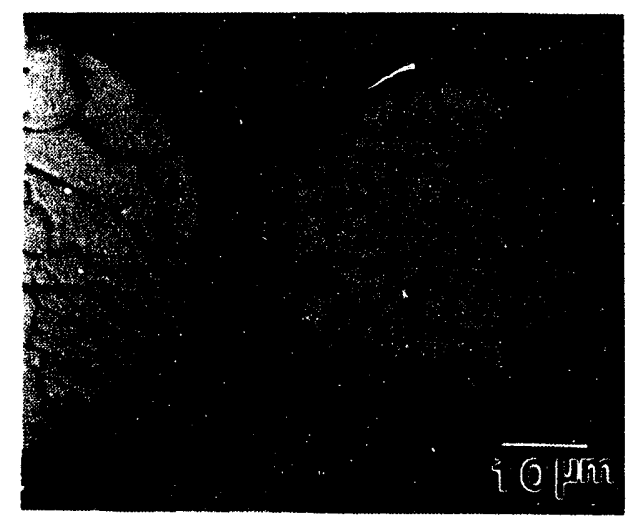

(c) VGA helium

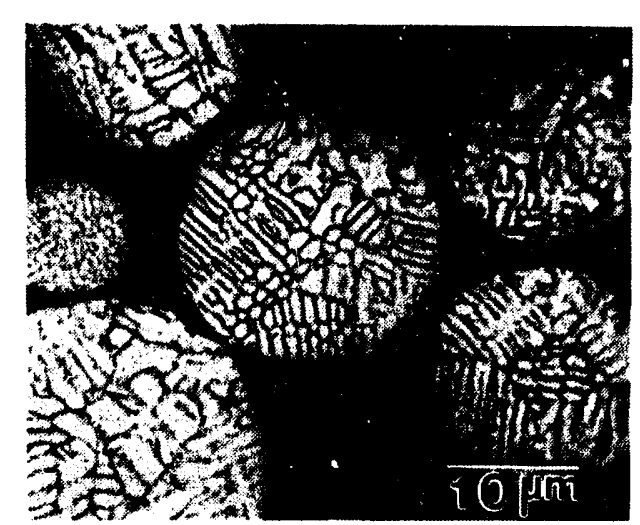

(b) CA nitrogen

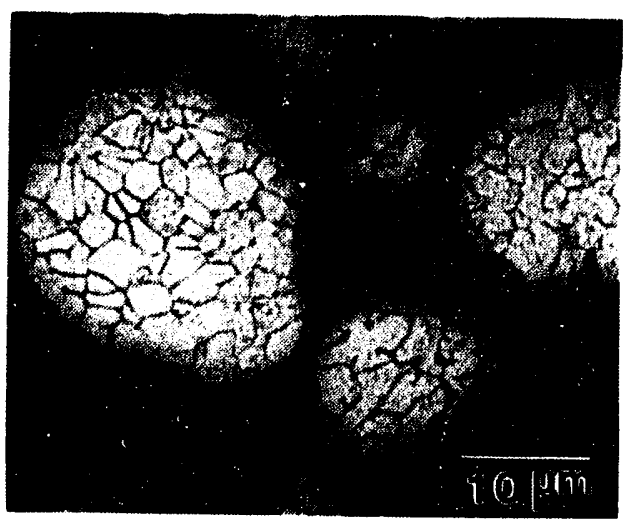

(d) VGA argon

Ficure 5. Microstructures (optical) of Fe-40Ni-0.3Nb-0.05C powders $(30-50 \mu \mathrm{m})$ processed by CA and VGA methods using different gases.

equivalent microstructures. It is evident (Figures $7 b, 7 c$ and $7 d$ ) that their microstructures are predominantly dendritic.

Microstructures of a series of stainless steel powders processed by IGA are shown in Figure 8 . These powders were all atomized with helium, had nearly equivalent nozzle pressures and superheats, and the photomicrographs are of the same size fraction, i.e., $>50$ to $<75 \mu \mathrm{m}$. The influence of alloy composition on the solidification microstructure morphology and fineness of Type PH 13-8 (Mo), Fe-16Ni-9Cr-2Mo-1.5Mn-1Si-0.5Ti-0.05C, and the features is clear. The solidification microstructures for Type 304 SS, A286 are 


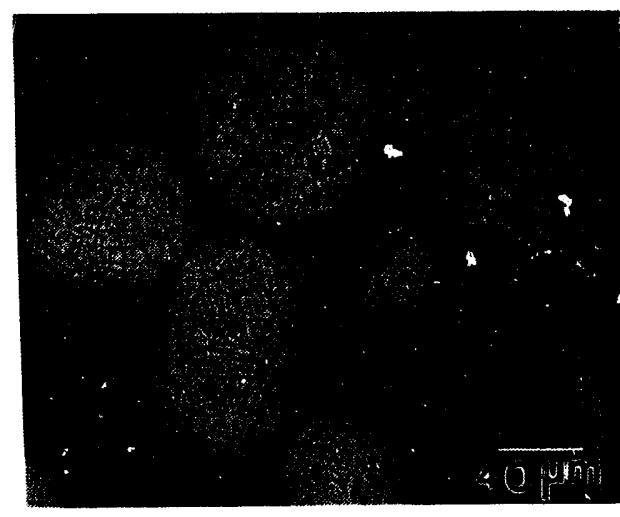

(a) $0.008 \mathrm{C}$

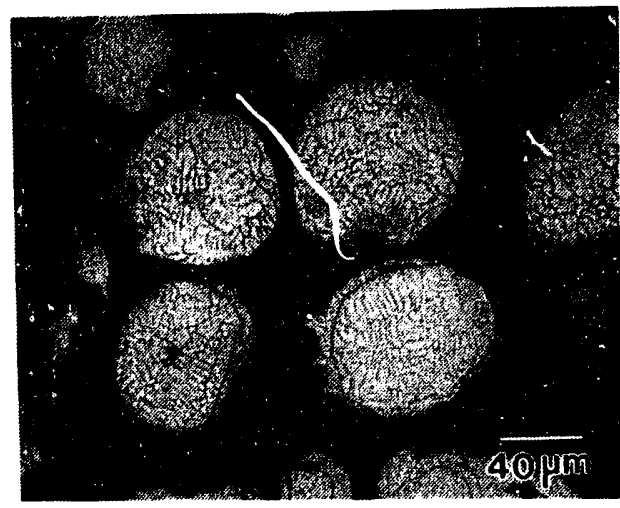

(c) $0.04 \mathrm{C}$

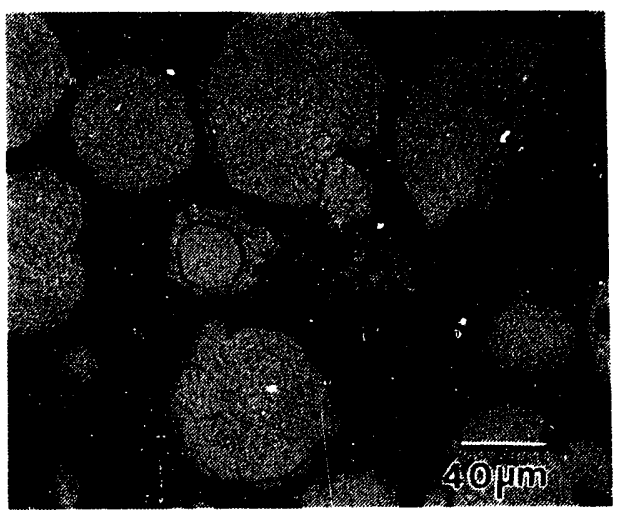

(e) $0.14 C$

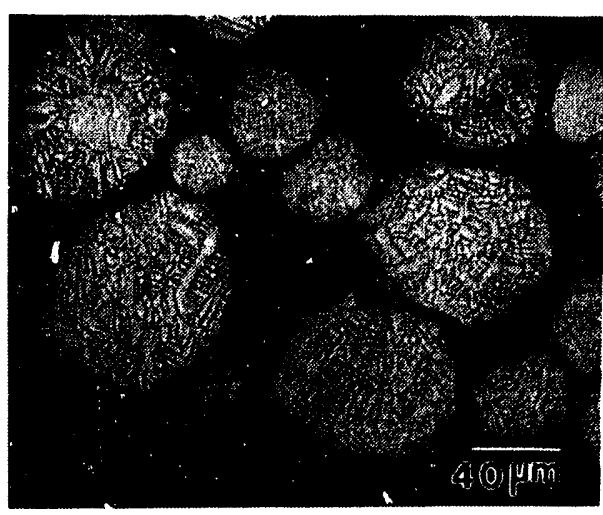

(b) $2 \mathrm{Mo}-0.005 \mathrm{C}$

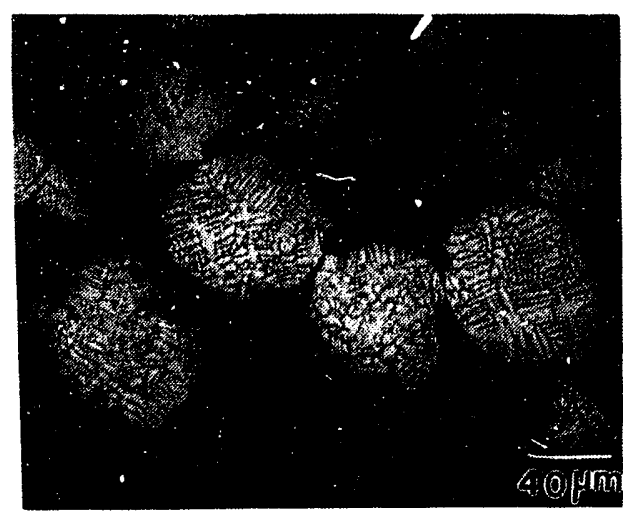

(d) $2 \mathrm{Mo}-0.06 \mathrm{C}$

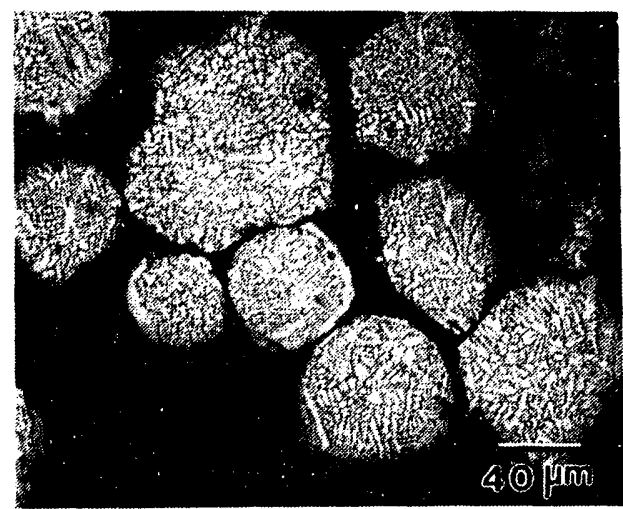

(f) $2 \mathrm{Mo}-0.14 \mathrm{C}$

Figure 6. Microstructures of CA processed (helium) Fe-20Ni-20 Cr powders, with and without 2 Mo, and each with three carbon levels. 


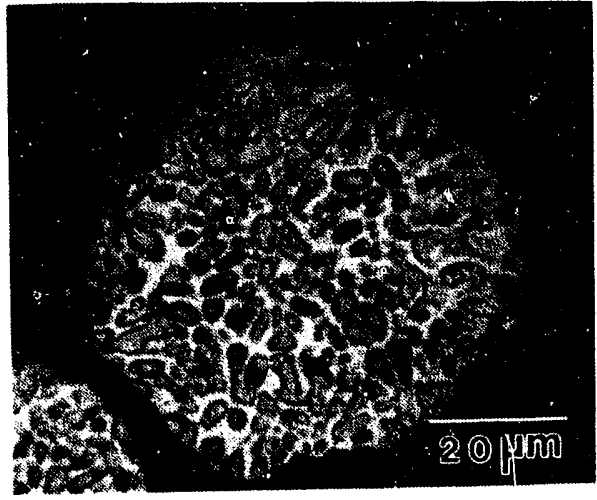

(a) VGA argon

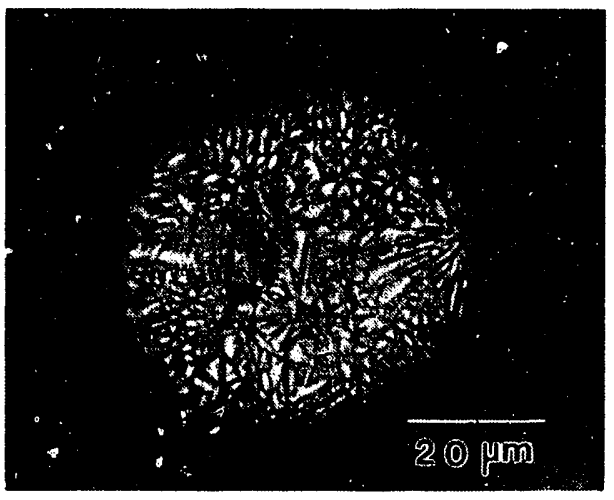

(c) IGA helium

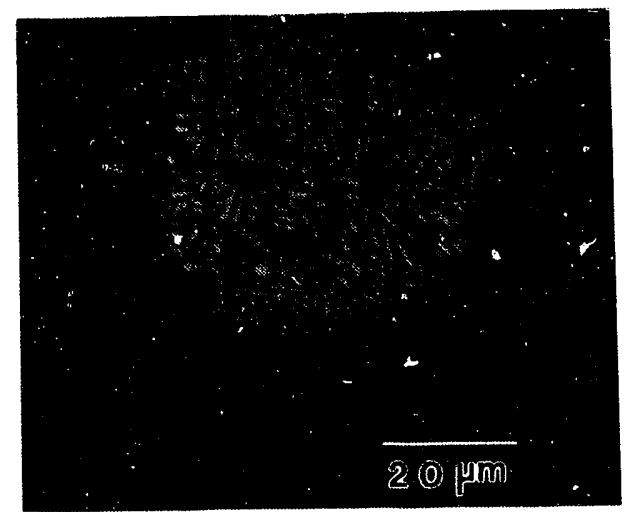

(b) CA helium

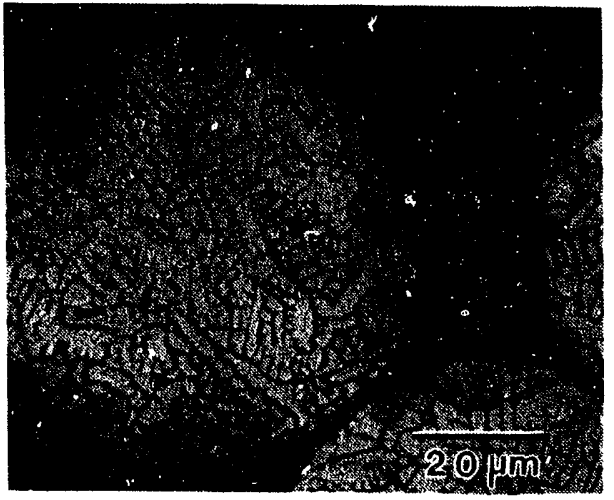

(d) IGA nitrogen

Figure 7. Microstructures of Type 304 SS powders processed by various atomization methods.

dendritic, whereas for $\mathrm{Fe}-16 \mathrm{Ni}-9 \mathrm{Cr}-0.04 \mathrm{C}$ it is cellular. The Type $430 \mathrm{SS}$ shows an apparent large grain morphology with some substructure in the grains.

The fineness of the microstructural features of the particles, such as those shown in Figures 4 through 8 , can be estimated from 1 inear intercept measurements. The boundary measurements (either cellular or dendrite arm spacings) for the relatively pure Fe-40Ni binary alloy in a range of particle sizes are shown in Figure 9a. As would be expected, the boundary spacings increase with increasing particle size. The results (Figure 9a) reflect the influence of the atomization method. As noted earlier (Figure 4), VGA 


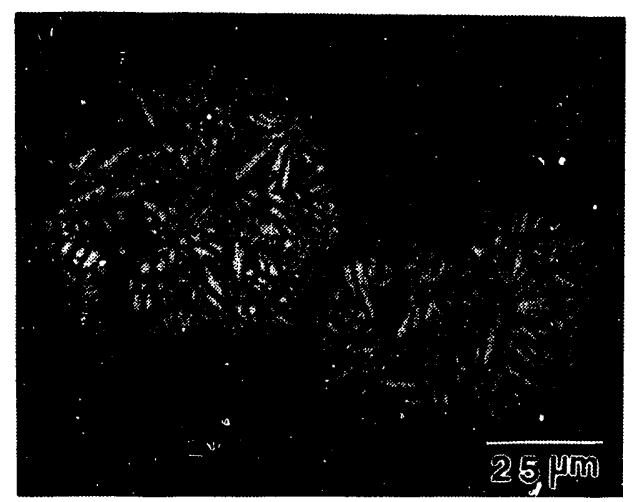

(a) Type 304 SS

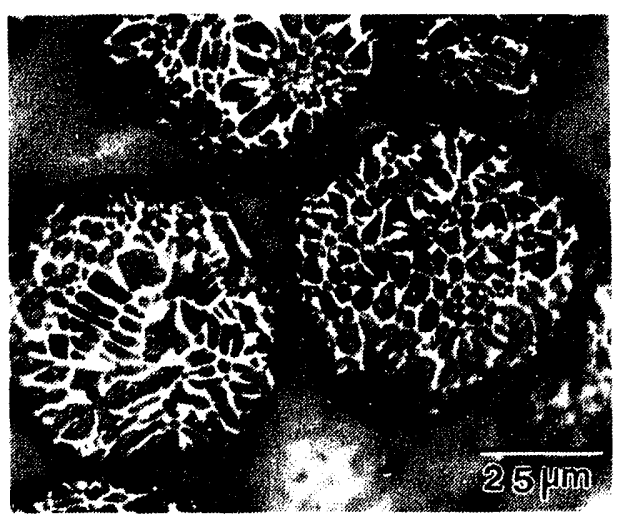

(c) $\mathrm{Fe}-16 \mathrm{Ni}-9 \mathrm{Cr}$

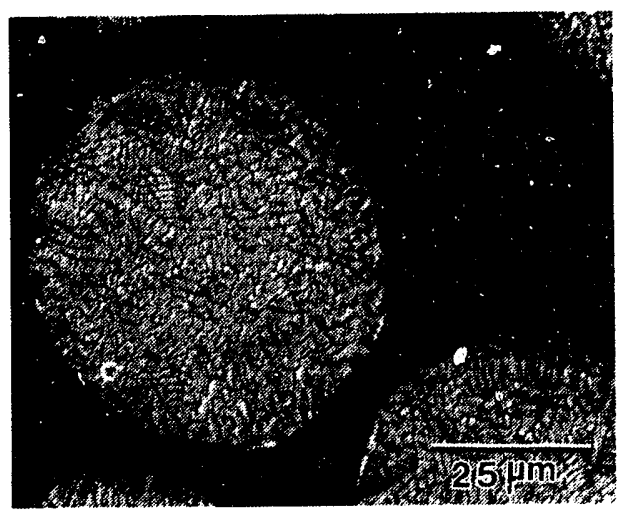

(e) A286

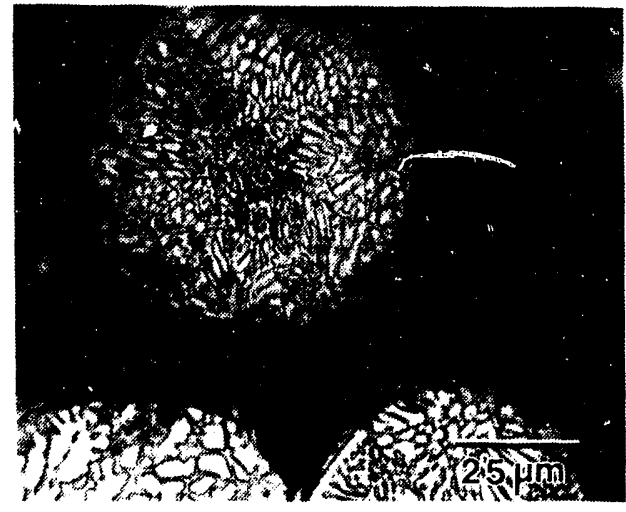

(b) $\mathrm{PH} 13-8$ (Mo)

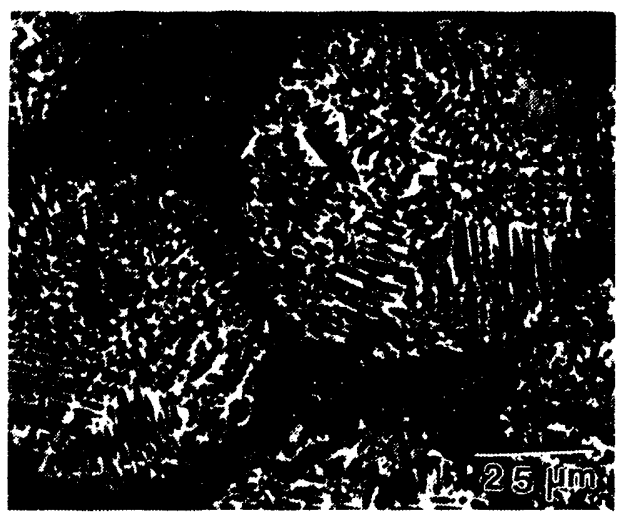

(d) $\mathrm{Fe}-16 \mathrm{Ni}-9 \mathrm{Cr}-2 \mathrm{Mo}-1.5 \mathrm{Mn}-0.5 \mathrm{Ti}$

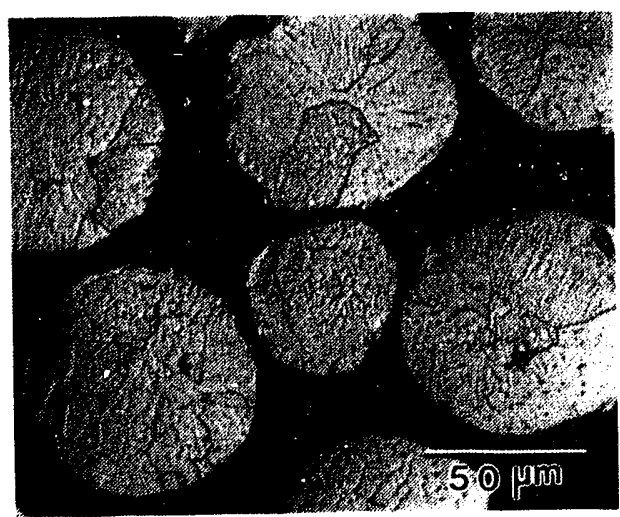

(f) $430 \mathrm{SS}$

Figure 8. Microstructures of 50-75 $\mu \mathrm{m}$ powders of six IGA stainless steels. 


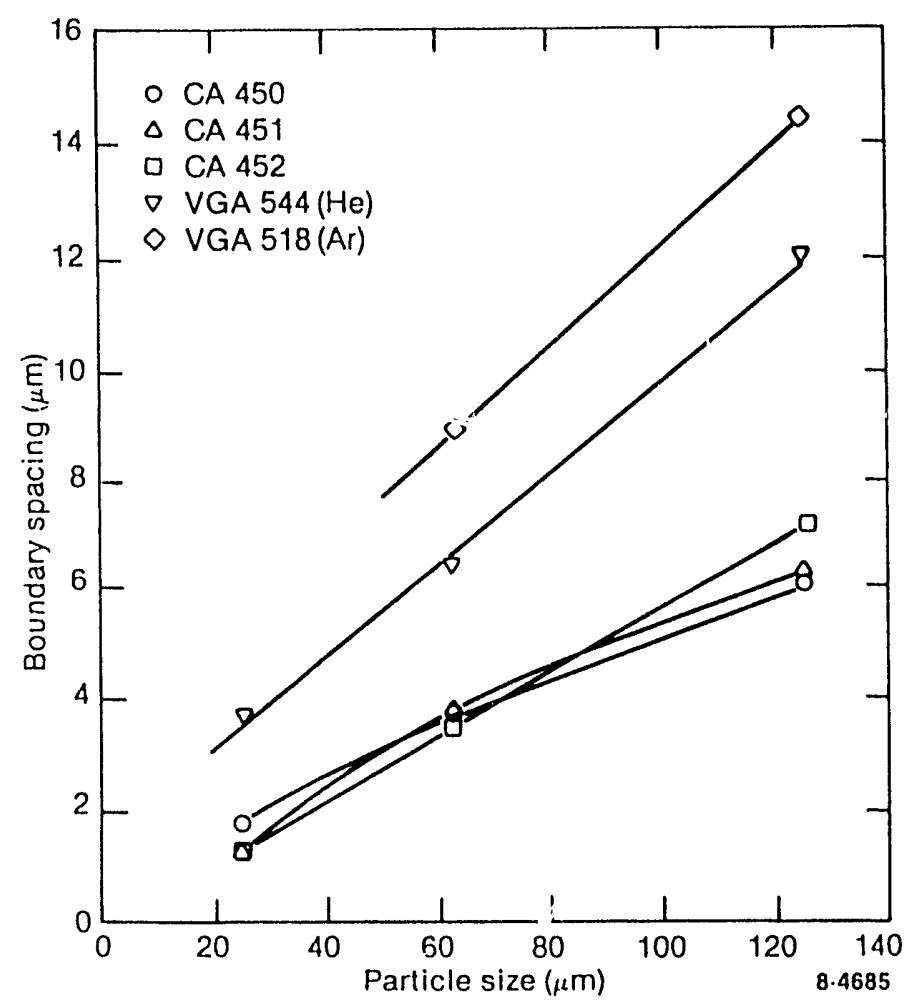

(a) $\mathrm{Fe}-40 \mathrm{Ni}$

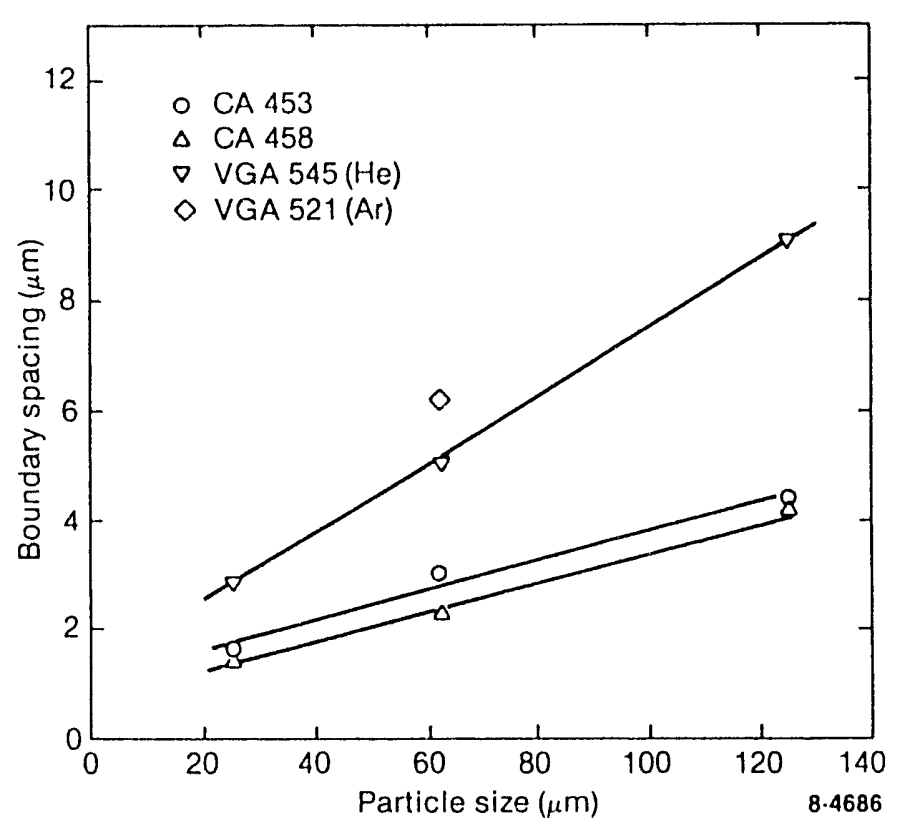

(b) Fe- $40 \mathrm{Ni}-0.3 \mathrm{Nb}-0.05 \mathrm{C}$

Figure 9. Dendrite (CA) and cell size (VGA) for various particle sizes of Fe$40 \mathrm{Ni}$ and $\mathrm{Fe}-40 \mathrm{Ni}-0.3 \mathrm{Nb}-0.05 \mathrm{C}$. 
produces a coarser microstructural morphology than does $C A$. It is apparent that VGA using helium, rather than argon, results in a finer cell size in the particles. The different helium flow rates used to convectively cool the $C A$ powders did not have a significant effect on dendrite arm spacings. Although not shown in Figure 9a, the nitrogen-cooled powder run had larger dendrite arm spacings than the powders cooled with flowing helium. The results shown in Figure $9 \mathrm{~b}$ are from the $\mathrm{Fe}-40 \mathrm{Ni}$ powder series that contained small additions of $\mathrm{Nb}$ and $\mathrm{C}$. The same atomization influences are noted as for the relatively pure Fe-40Ni binary. However, the $\mathrm{Nb}$ and $\mathrm{C}$ additions produse significantly smaller microstructural features, compared to the binary alloy.

The microstructural measurements for the $\mathrm{CA} \mathrm{Fe}-20 \mathrm{Ni}-20 \mathrm{Cr}$ with and without 2 wt\% Mo, each with three carbon levels, are shown in Figure 10 . The influences of Mo and carbon content on dendrite arm spacing vary with particle size; however, the general trend indicates that these additions reduce the arm spacing. The powder processing parameters (i.e., superheat, cup speed, and helium flow rate for convective cooling) were equivalent for these six alloys.

The influences of particle size and powder atomization method on solidification microstructures for Type 304 SS are shown in Figure 11. As noted earlier (Figure 8 ), VGA resulted in a cellular morphology, whereas IGA and $C A$ produced a predominantly dendritic microstructure. The boundary spacing for the VGA powder (cellular) is considerably larger than those of the IGA and CA powders, indicating a much lower solidification rate. The dendrite arm spacings are somewhat comparable for the IGA and CA powders, al though the results for the IGA suggest that its solidification rate may be slightly higher than that of the CA powders.

\section{Submicron Microstructural Observations}

Submicron features have received very little attention. Examinations at this level require analytical electron microscopy and, in particular, TEM/STEM, which requires that the powder specimen be sufficiently thin to permit electron transmission. The preparation of powder specimens for 


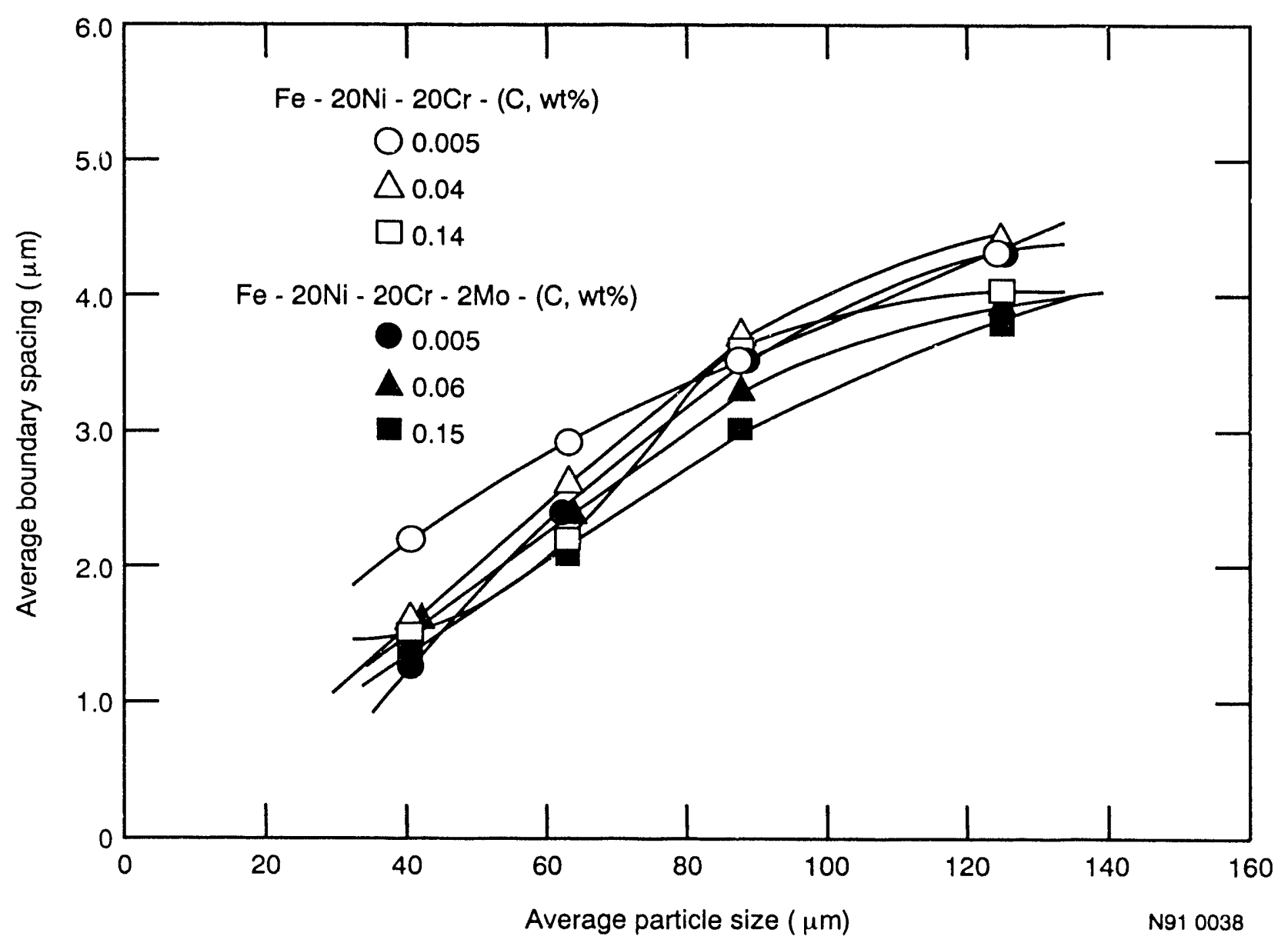

Figure 10. Influence of particle size on microstructural fineness for $C A$ processed $\mathrm{Fe}-20 \mathrm{Ni}-2 \mathrm{OCr}$ and $\mathrm{Fe}-20 \mathrm{Ni}-20 \mathrm{Cr}-2 \mathrm{Mo}$ powders with different carbon contents.

TEM/STEM examination usually involves a composite foil of powder particles embedded in a matrix material. For the Type 304 SS powders, the embedding medium was electroplated nickel, and the samples were thinned by dimpling and ion milling. ${ }^{6,7}$ A rather thorough TEM/STEM examination of the CA and VGA Type 304 SS powders emphasizing the microstructure/substructure features associated with solidification ${ }^{7}$ and the submicron defects ${ }^{8}$ has been reported. Recently, TEM studies have been performed on IGA processed Type 304 SS. ${ }^{9}$

In conventional processing, Type 304 SS initially solidifies as primary delta ferrite (in equilibrium). With subsequent cooling, the alloy transforms into a two phase region, austenite (fcc)-delta ferrite (bcc) phase field, and 


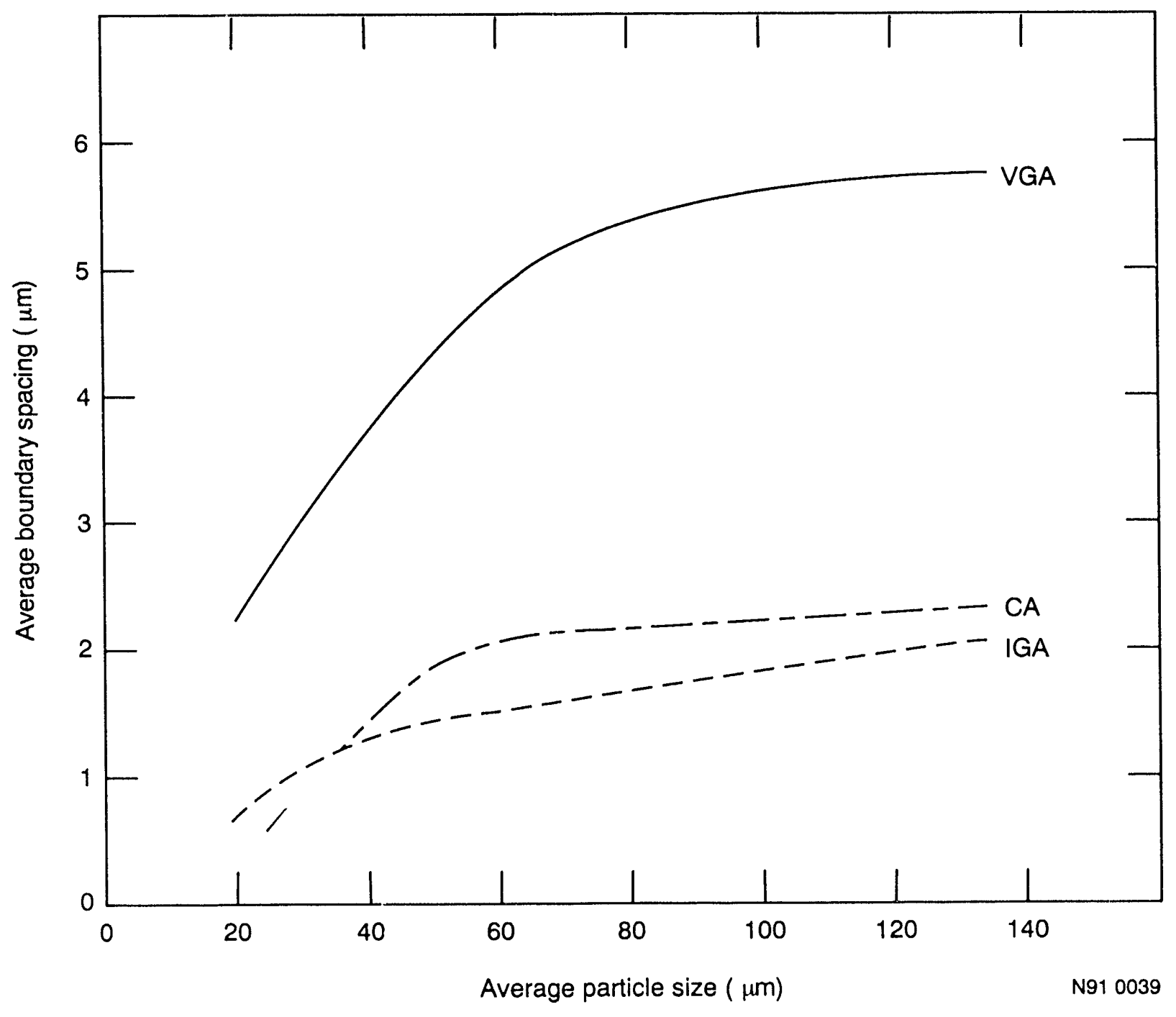

Figure 11. Influence of particie size on microstructural fineness for VGA (cellular) and CA and IGA (both dendritic) processed Type 304 SS powders.

then enters into the austenite phase field commonly observed at room temperature. ${ }^{10-12}$ When these phases are observed in the atomized powders, their origins require careful consideration, i.e., is the phase derived from the solidification stage, more accurately described as the crystallization stage, or is it a product of solid state phase transformations during subsequent cooling to room temperature. X-ray diffraction studies were performed on the VGA, CA, and IGA powders to determine the particle size influence on the relative amounts of $f c c$ (austenite) and bcc (delta ferrite) present. These results are shown in Figure 12. For the VGA powder, the 


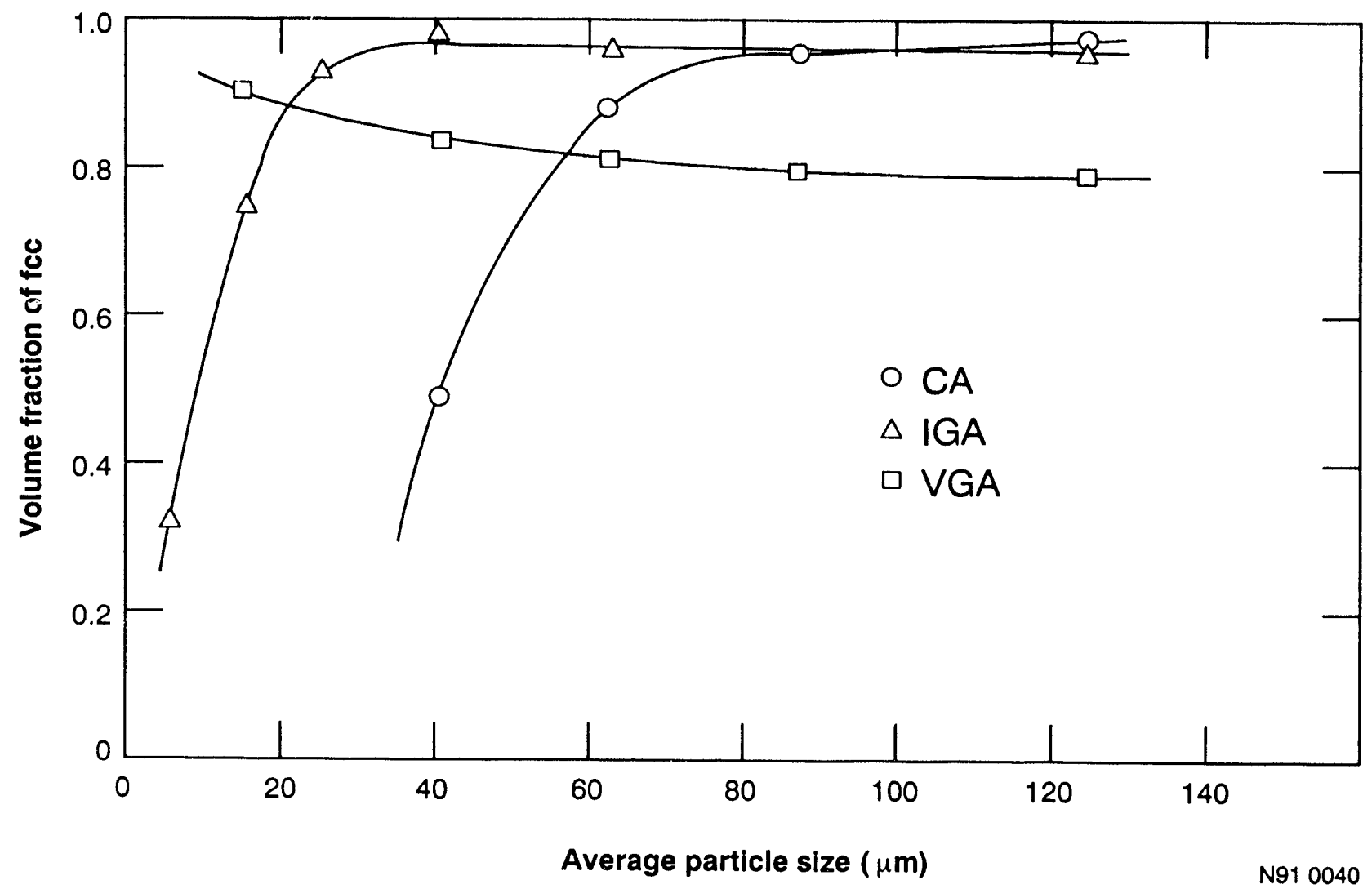

Figure 12. Influence of particle size on retained austenite for VGA, CA, and IGA Type 304 SS powders.

the segregation of nickel and chromium would be relatively large since the amount of the $\mathrm{fcc}$ phase decreases with increasing particle size. Evidence provided by TEM/STEM examinations shows significant compositional partitioning of $\mathrm{Cr}$ and $\mathrm{Ni}$ at the cell wall ${ }^{7}$, with chromium enriched at the cell walls and nickel enriched in the cell core (matrix) regions. This observation raises the question of whether the two-phase behavior occurs during crystallization of the molten droplet or is an outcome of the solid-state transformation during further cooling of the solid particle. Alternative crystallization phases are strongly dependent on the degree of undercooling rather than the cooling rate. ${ }^{6,13}$ The degree of undercooling should increase with decreasing particle size. Furthermore, the probability that a droplet will contain potent nucleation sites decreases sharply with decreasing particle size. ${ }^{6}$ VGA powders are expected to possess a relatively low degree of undercooling during crystallization. A bcc structure would be expected to nucleate in the small 
VGA droplets and an fcc structure in the larger droplets. In both structures, solidification rate is fairly low. During cooling of the particles after crystallization, the smaller particles would transform from bcc to fcc if the chromium content of the bcc phase was not high enough to stabilize it. A transformed fcc structure would be expected to dominate the smaller particles. For the larger VGA droplets more potent nucleation sites would occur and the primary crystallization phase would be fcc with chromium-rich bcc phase at the cell wall. Since the solidification rate is lower for the large droplets than the small ones, a larger degree of segregation would occur. If the chromium segregation is compositionally large enough, it should stabilize the cell walls as bcc and prevent the solid-state transformation to fcc during cooling of the solidified particle. As a result, a higher volume fraction of delta ferrite would be expected with increasing particle size, as is shown in Figure 12 .

The influence of undercooling is more important for the CA powders. For the smaller droplets, it is expected that bcc, rather than fcc, nucleates preferentially with higher degrees of undercooling and, if accompanied by high cooling rates, would be retained down to room temperature. The larger CA droplets would solidify primarily as fcc due to the presence of more potent nucleation sites with less undercooling. X-ray evaluation of the CA Type 304 SS particles shows $\mathrm{Cr}$ and $\mathrm{Ni}$ segregation at the dendrite walls, but the compositional levels are significantly lower than those observed for the VGA powders. ${ }^{7}$ This appears to be primary fcc dendritic solidification after cooling through the solid-state transformation. As a result, there would be less compositional se!rregation with decreasing particle size, and, therefore, the increasing bcc content shown in Figure 12 must be due to the presence of bcc as a crystallization phase.

The results shown in Figure 12 suggest that the degree of undercooling was significantly lower for the IGA than for the CA Type 304 SS powders. The crystallization-derived bcc phase has been shifted to much smaller particle sizes for the IGA powder. However, it should be noted that the IGA solidification rates appear to be higher than those of the CA processed powder as was shown in Figure 11. 
Examination of the three types of 304 SS powders for submicron defect features has provided some very important observations. ${ }^{8,9}$ A typical TEM image for a CA Type 304 SS particle is shown in Figure 13. The perimeter of the particle shows some relatively large defects that have a black and white contrast (Figure 13a). These defects have been identified as Frank loops, ${ }^{8}$ and must be of the vacancy type formed during particle cooling. Formation of interstitial loops during quenching is not likely due to energy considerations. The interior of the particle (Figure 13b) contains numerous stacking faults and small defects $\leq 3 \mathrm{~nm}$ in size. The small defects have not been conclusively identified as large vacancy clusters (voids) or solid phase precipitates. Their size borders on the detection limit of energy-dispersive $x$-ray analysis. For the VGA Type 304 SS particles, a typical TEM microstructure is shown in Figure 13c. For the slower cooled VGA particle, there was no evidence of Frank loops or stacking faults. However, there are the numerous small defects $\leq 3 \mathrm{~nm}$.

TEM/STEM studies on the IGA Type 304 SS powder particles have disclosed some interesting submicron features with some similarities to, but also some

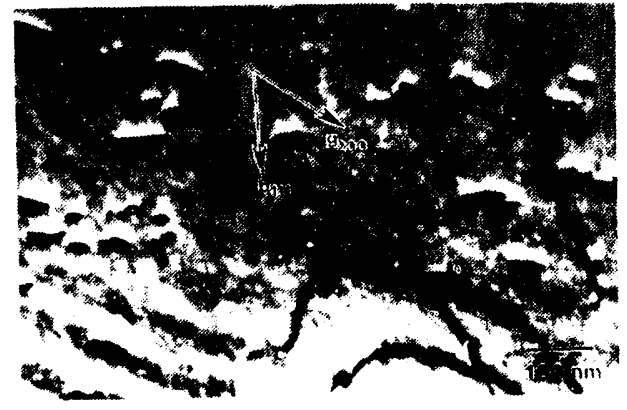

(a) CA particle perimeter

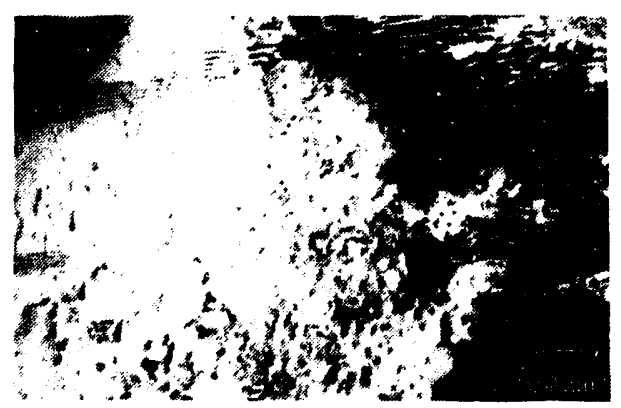

(b) CA particle interior

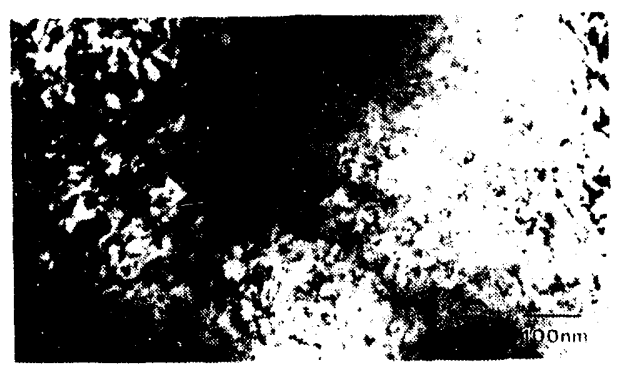

(c) VGA particle

Figure 13. TEM of submicron defects in Type 304 SS processed powder particles. 
pronounced differences from, the CA and VGA processed powders. 9 The particles contain numerous twins (Figure 14). The twins do not relate to any known martensitic behavior, since they retain a fcc character. Also observed in the IGA 304 SS powders are high dislocation densities (Figure 15) and a large number of small defects whose image characteristics are similar to those shown in Figures $13 a$ and $13 b(C A)$ and $13 c$ (VGA). The microstructures shown in Figures 14 and 15 were typical of a wide range in particle sizes.

The Type 304 SS powders processed by CA, VGA, and IGA appear to have a submicron feature in common--the small black and white contrast defects $\sim 3 \mathrm{~nm}$ in size. They appear to be relatively independent of cooling rate and,

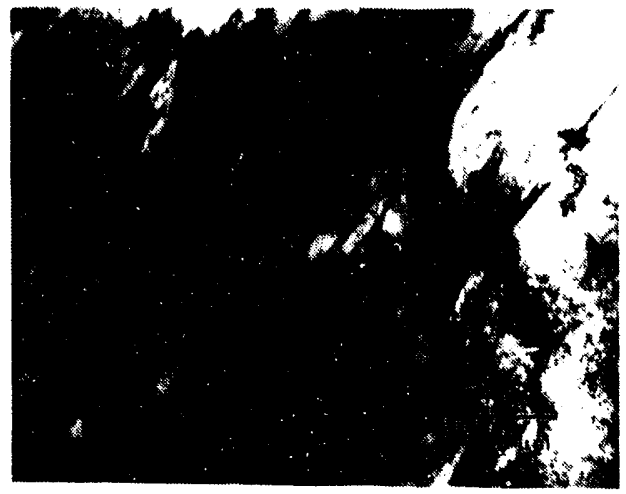

Figure 14. TEM of IGA Type 304 SS particle showing microtwinning.

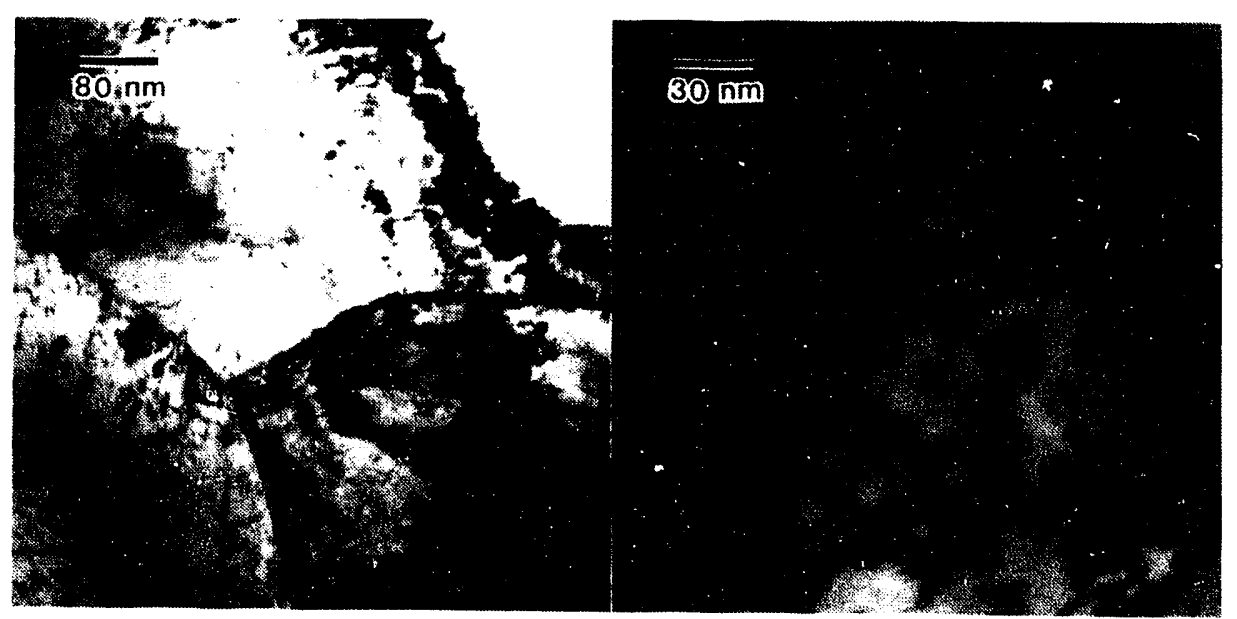

Figure 15. TEM of submicron features for an IGA Type 304 SS particle showing a high density of small defects (left) and dislocations (right). 
a) though not confirmed, they are probably precipitates. The twin features and the relatively high dislocation densities appear to be unique to the IGA Type 304 SS powders. The vacancy loops and dislocation stacking faults observed in the CA powder indicate that a supersaturation concentration of vacancies has been trapped during $C A$. The difficulty with both the optical microscopy microstructure and the submicron features observed for the three atomized Type 304 SS powders is the inability to use them to arrive at a quantitative understanding of fundamentals associated with the cooling rates. Further studies are certainly required to develop fundamental correlations with the microstructural behavior, powder atomization parameters, and cooling of the molten droplets. The ultimate goal is to establish the relationship between the powder processing parameters, the powder microstructure, and the microstructure and properties that evolve during and after powder consolidation. This would permit rapid solidification processing by design, which is required to realize the full potential of RSP.

\section{Particle Surface Films}

Atomized powders always possess surface films, mostly oxides. An obvious concern with surface films on the particles is their influence on the consolidated product. This section discusses the surface films; their effect on the consolidated powder is addressed in some detail in a later section.

Molten droplets, with their large combined surface area, are effective getters for any residual oxygen and carbon in the atomization chamber. Evacuation and bake-out of the chamber prior to powder atomization initiation will, in principle, reduce the oxide film thicknesses on the particles. The purity of the atomizing gas (i.e., argon, helium, or nitrogen) would also be expected to influence the surface film buildup. Atomizing gas that is recirculated/reused would be of higher purity after being used several times due to the cleansing/gettering nature of the hot particles. Most atomization practices do not attempt to purify the gas prior to atomization or to recirculate it due to the expense. As a result, powders atomized with most commercial grades of gas will have a surface film. Again, the surface film thickness that can be tolerated will depend on the performance requirements of 
the powder after consolidation. Commercial grade gas was used to produce the RSP powders in this research.

Analysis of surface films on the particles is not a trivial task. Two techniques that have been used in the past are fusion mass spectroscopy for oxygen and Auger sputtering spectroscopy. Auger spectroscopy, which has been used in powder characterization at the INEL, has provided useful information; however, the technique has some severe limitations. A significant amount of time is required to analyze one particle, limiting the ability to examine a statistical representation of a powder batch. Also, obtaining quantitative information, such as sputtering rate correlations with film thickness and film composition, requires a set of standards for calibration.

Some results that illustrate the value of Auger spectroscopy are shown in Figure 16 for IGA processed Type 304 SS and A286 powder. These Auger electron spectroscopy (AES) profiles show that the times for sputtering through the oxide (primarily iron-base) film appear to be independent of particle size, implying that the oxide film thickness is independent of particle size, i.e., constant. This suggests that the oxide film development is very rapid since the small particles should have cooled faster than the large ones. The AES profile in Figure 16C shows that for A286 a major metallic component of the oxide film is titanium. This suggests that during powder atomization and cooling a significant amount of titanium has migrated (segregated) to the particle surface.

AES has also provided information on the effects of exposing the powder to air after atomization. The profiles shown in Figure 17 were taken from CA Type 304 SS powders that were exposed during handling to an inert atmosphere, to relatively low humidity air, or to high humidity air. Comparison of the AES sputtering times and profiles for the three conditions indicates that the oxide films on the particles are quite stable and not influenced by the air exposures, i.e., the oxide films developed during atomization, not during subsequent handling. Studies on CA and VGA processed Fe-40Ni powders had 


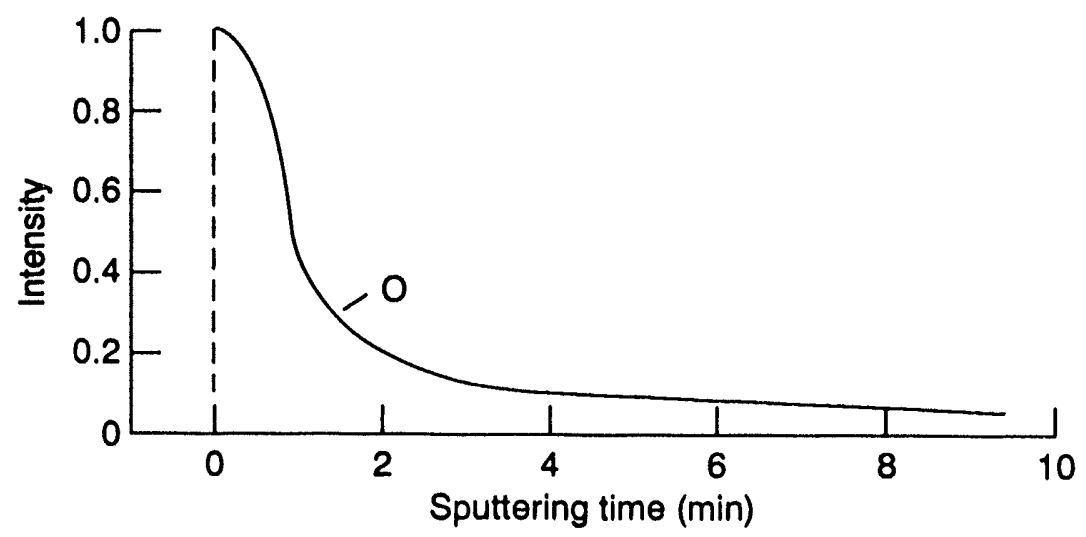

a) IGA 304 SS particles, $>20$ to $<30 \mu \mathrm{m}$

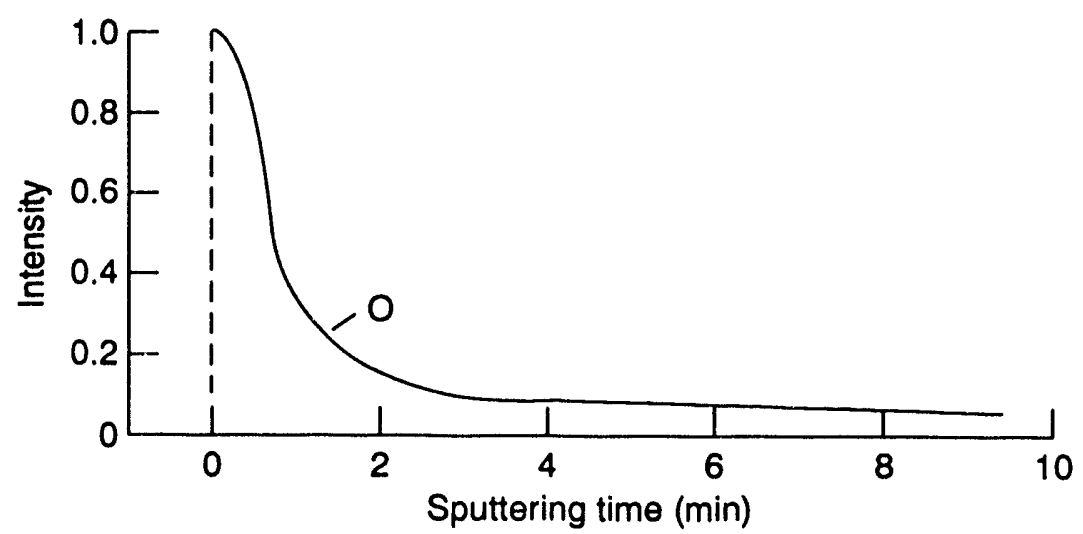

b) IGA 304 SS particles, $>100$ to $<150 \mu \mathrm{m}$

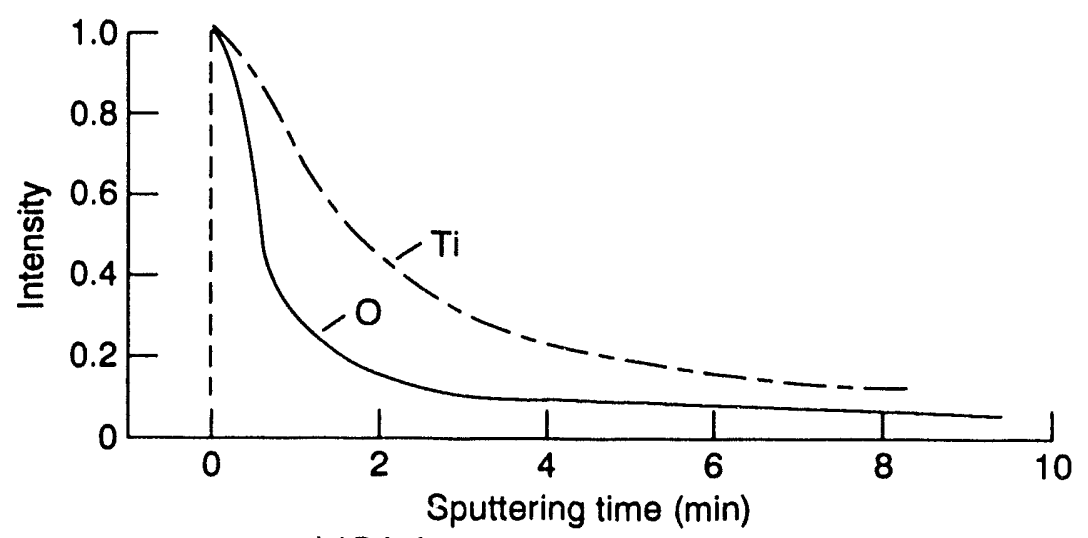

c) IGA A286 particles, $>30$ to $<50 \mu \mathrm{m}$

N91 0041

Figure 16. Auger depth profiles for IGA processed powder.

similar results. Thus, for the iron-base alloy powders, air exposure is permissible and, except for some caution regarding other forms of 

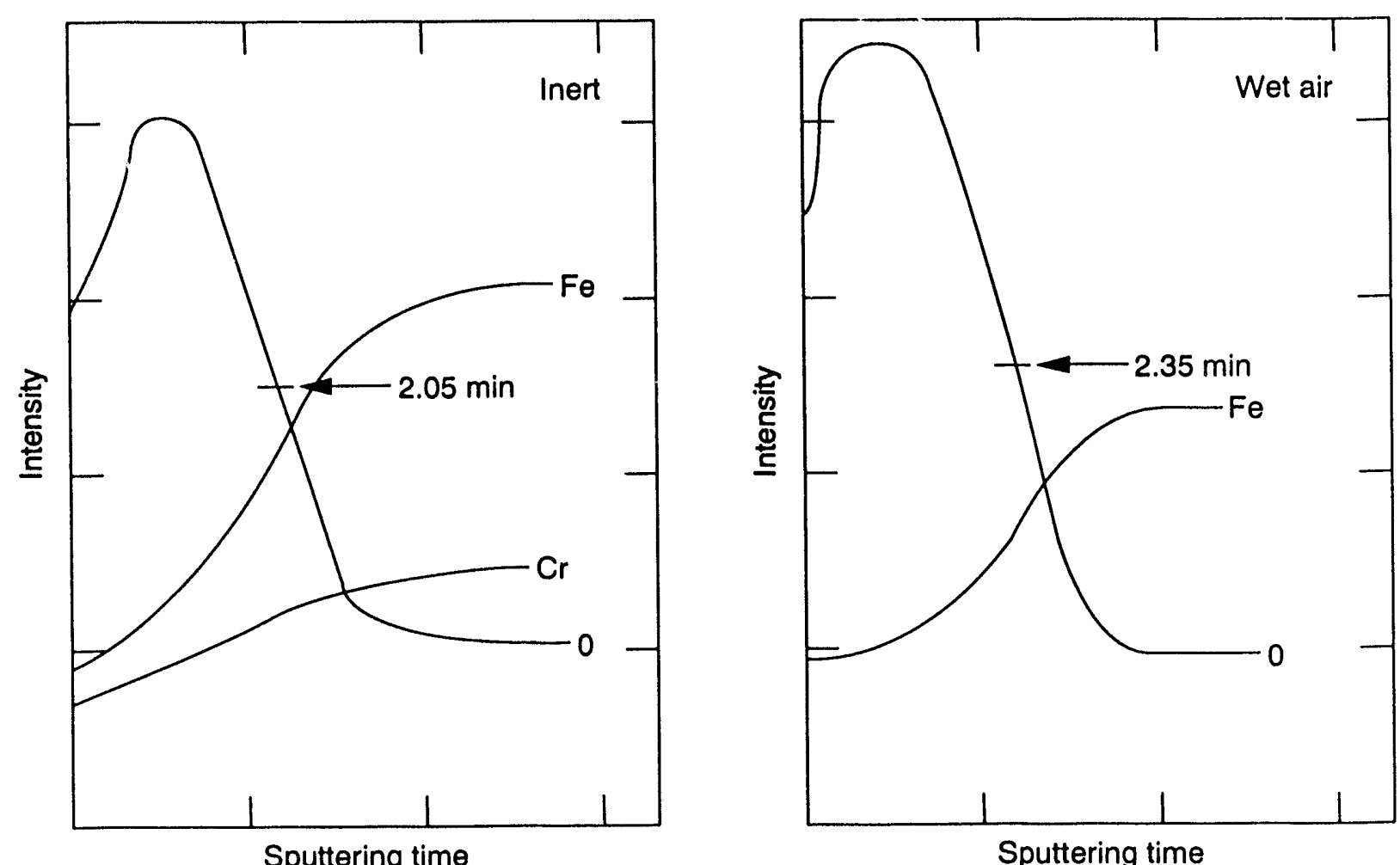

Sputtering time

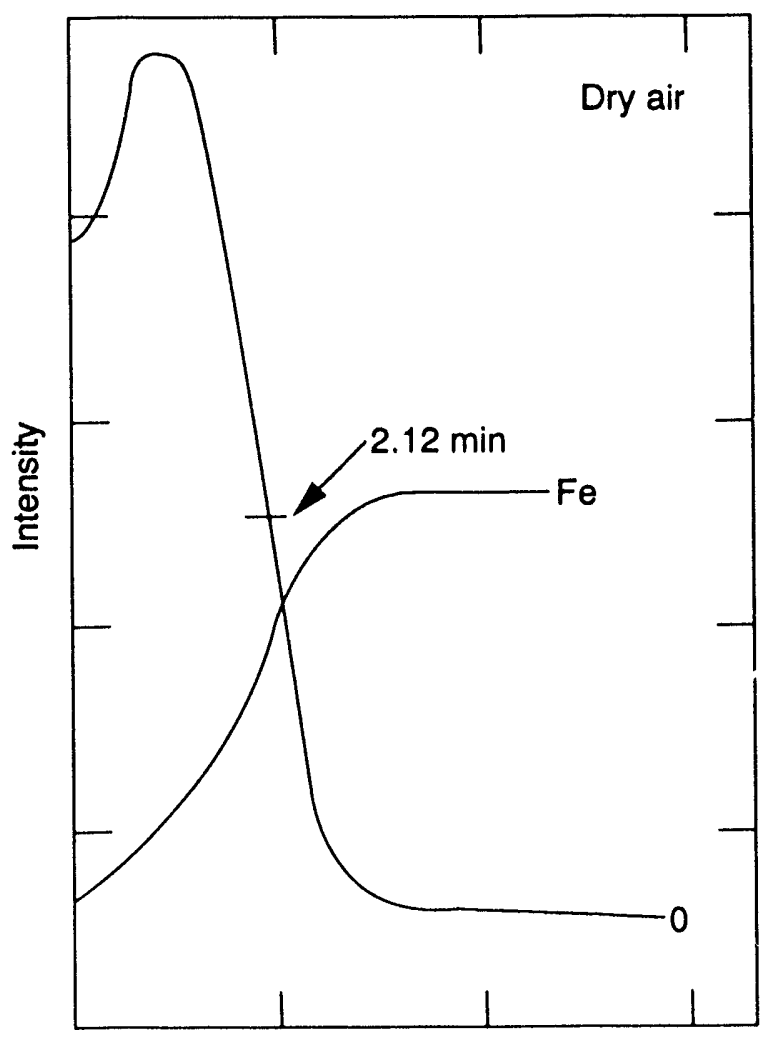

Auger sputtering profiles for centrifugally atomized 304 stainless steel powder; sputtering rate $\approx 1 \mathrm{~nm} / \mathrm{s}$

Sputtering time

Figure 17. Auger depth profiles for CA Type 304 SS powder. 
contamination, glove box/inert gas blanket handling of the powders dics not appeär to be necessary.

\section{Entrained Noble Gases}

The use of noble gases in powder atomization, whether for melt stream breakup and/or convective cooling of the molten droplets, inevitably results in some entrainment of the gas in the particles. The obvious concern with entrapped noble gases is porosity, particularly for applications requiring high temperature exposures. This issue is addressed later.

Analysis for noble gas concentrations, i.e., helium or argon, was performed by fusion mass spectrometry. ${ }^{14}$ The entrained noble gas was not released until the specimen melted; therefore, degassing treatments on the powders at temperatures below the alloy's melting point will not reauce the amount of entrained gas. The entrained noble gas levels were dependent on particle size, Figures 18 and 19. The noble gas concentrations shown in Figure 18a for $\mathrm{Fe}-40 \mathrm{Ni}$ powders indicate some parametric influences from powder atomization. ${ }^{5}$ The CA powders represent three runs with all atomization parameters identical except the flow rate of helium used for convective cooling, which was $0.9(452), 1.3(450)$, and $1.8(451) \mathrm{kg} / \mathrm{s}$. The VGA powders, 518 and 544, were processed with argon and helium, respectively. Initially, the entrained gas content increases rapidly with particle size, but an apparent saturation in gas content at some intermediate particle size cccurred for most of the alloy batches. These results for the $\mathrm{Fe}-40 \mathrm{Ni}$ powders do not show a definitive corr: lation with the processing parameters. For example, the CA Fe-40Ni (450) contains nearly twice as much helium as batches using higher (451) and lower (452) helium flow rates for convective cooling. Although no quantitative porosity measurements were made for the various particle sizes and processing parameters, metallographic observations of polished cross sections indicate that the pore size and number of particles containing pores increase with increasing particle size. Also, for the $\mathrm{CAFe}-$ $40 \mathrm{Ni}$ series, the pore sizes for particles of a given particle size fraction 

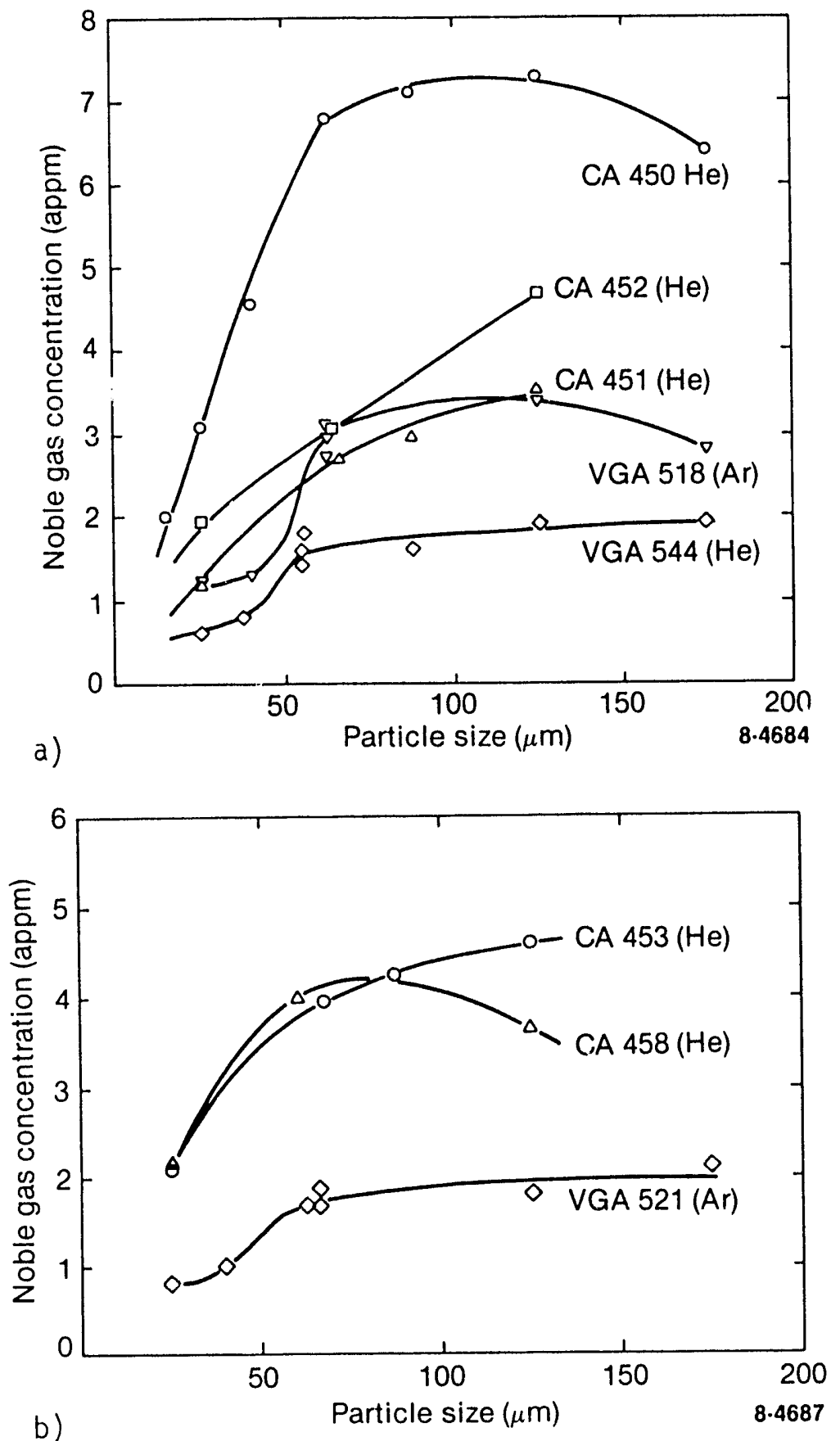

Figure 18. Influence of particle size on entrained noble gas contents for CA and VGA powders.

were comparable; however, the number of particles containing pores appeared to increase with increasing helium content. 


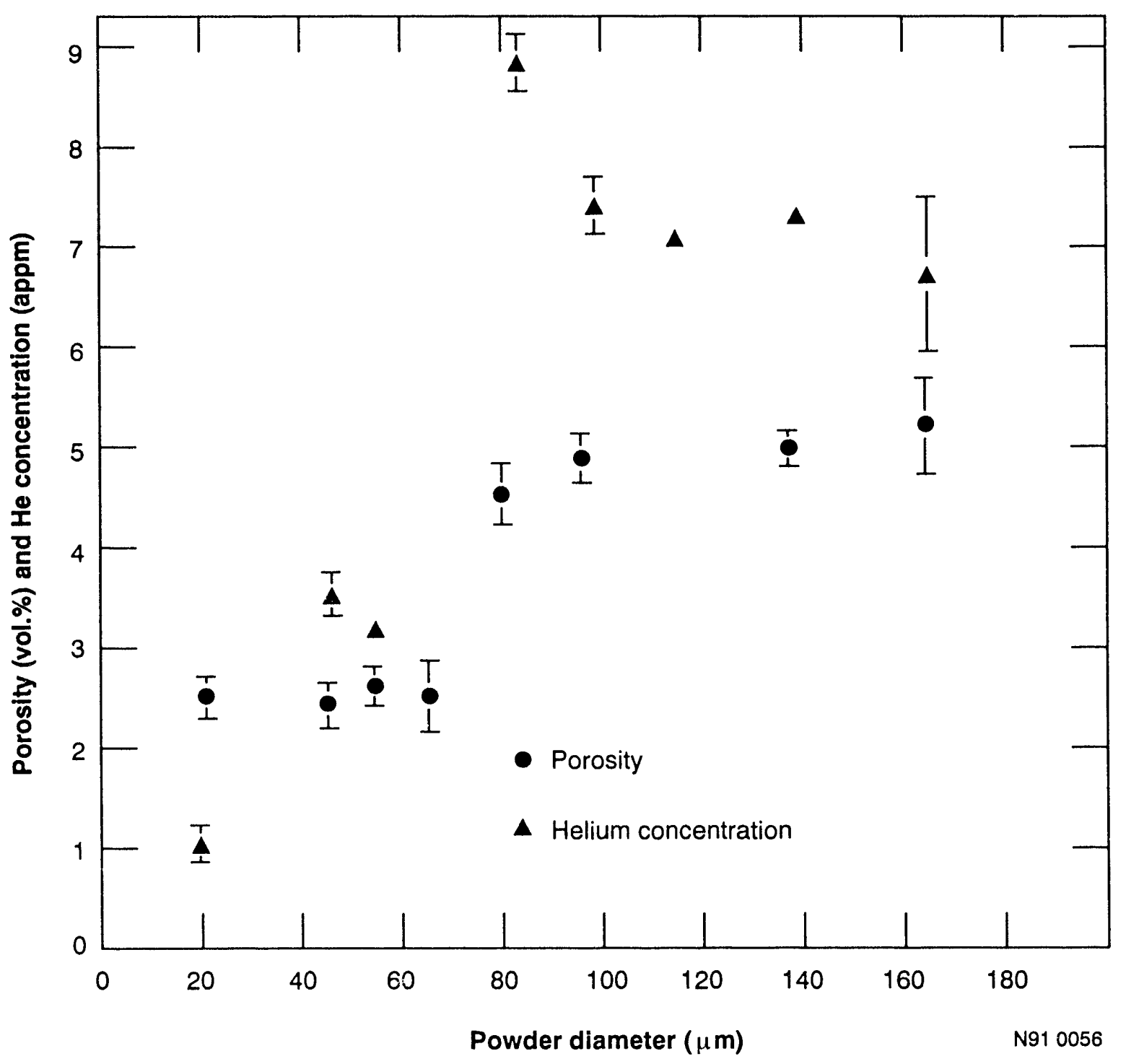

Figure 19. Influence of particle size on entrained helium content and porosity for CA Type 304 SS powders.

The porosity correlation with entrained noble gas content is more evident in Figure 19 for CA processed Type 304 SS. For this comparison, pycnometer density measurements were used. ${ }^{15}$ The two measurements show that the majority of the helium is entrained as porosity. The amount of helium entrained in the lattice cannot be resolved from these measurements. Although there are no known measurements on equilibrium solubility of noble gases in metals, such as the iron-base alloys examined in this study, a recent theoretical treatment by Wolfer et al. ${ }^{16}$ shows that the equilibrium solubility of helium in nickel is 
over five orders in magnitude lower, even in the liquid state, than the entrained helium levels shown in Figures 18 and 19.

IGA of the powders using helium reduced the entrained gas levels considerably, see Figure 20. The micrographs in Figure 21 for $100-150 \mu \mathrm{m}$ particles of CA and IGA Type 304 SS powders show that the porosity is much lower for the IGA particles; although the pores sizes are similar, fewer particles contain pores.

The mechanism of gas entrainment during atomization is not entirely understood; however, it is likely that the gases are mechanically entrained during the formation of the molten droplets. ${ }^{5}$ Such a process is consistent with the observed particle size dependence. The gas flow's interaction with the forming and cooling droplets has to be a primary factor. Some recent results on IGA processing of Type 304 SS using helium show that the tank gas pressure in the atomization chamber can have a significant effect on entrained gas level. ${ }^{17}$ These results, shown in Figure 22, are consistent with those reported by Siddall for IGA processing of nickel-base alloys using argon. ${ }^{18}$ Porosity evaluations on particles of the same size fraction from the two chamber pressure tests showed that pore size distributions were nearly equivalent; however, the number of particles containing pores was significantly larger for the higher chamber pressure. ${ }^{17}$

The effect of entrainment of the atomizing gas on porosity in the consolidated powder is of concern. For powders containing noble gases such as helium and argon, consolidation of the powders produces very small high pressure bubbles. These high pressure bubbles are susceptible to growth and possible coalescence when exposed to high temperatures. This bubble growth may be a problem in joining parts made from the consolidated powders. Porosity evolution after powder consolidation will be examined in some detail later in this chapter. 


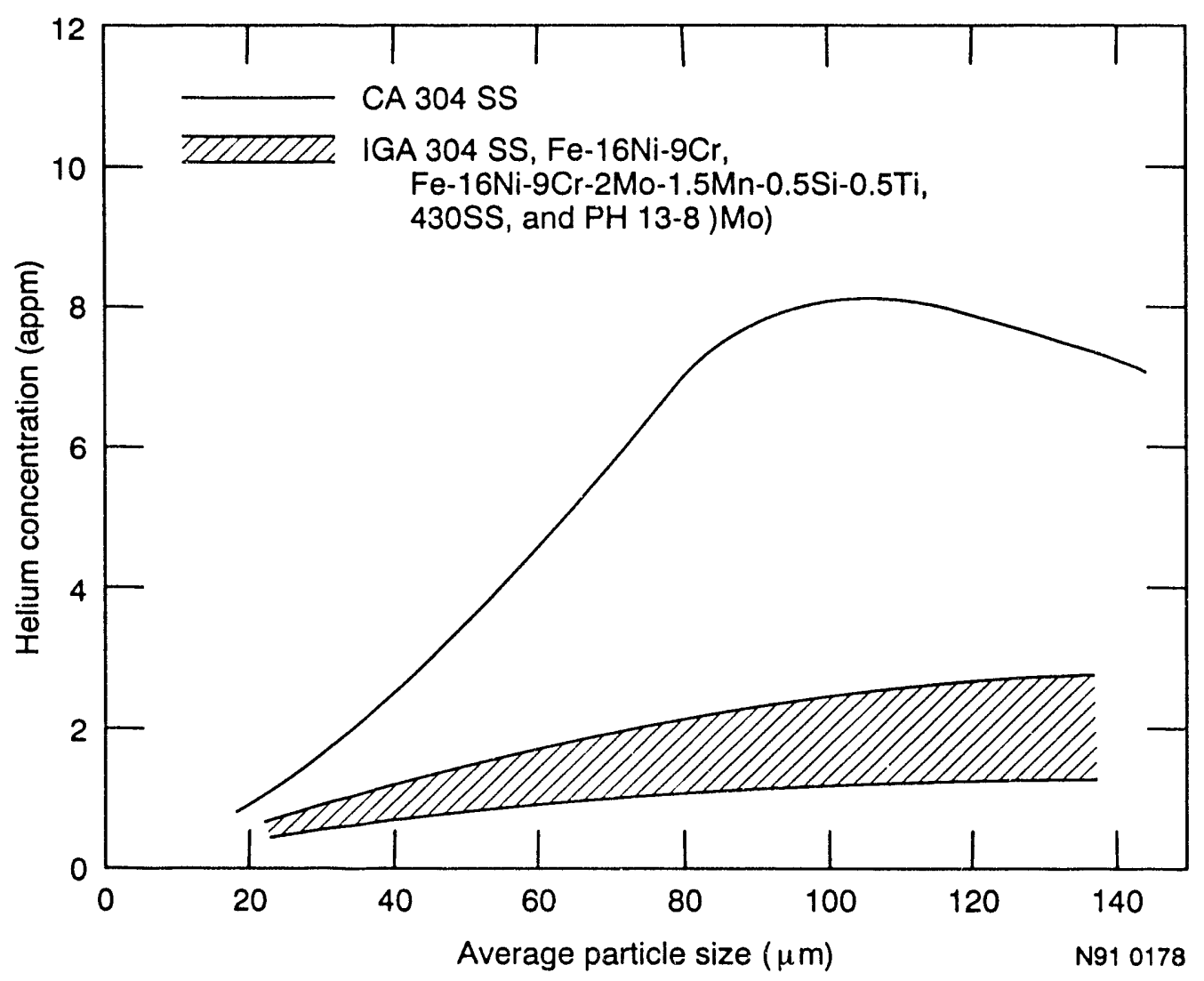

Figure 20. Influence of particle size on entrained helium content for various stainless steels processed by IGA using similar parameters.

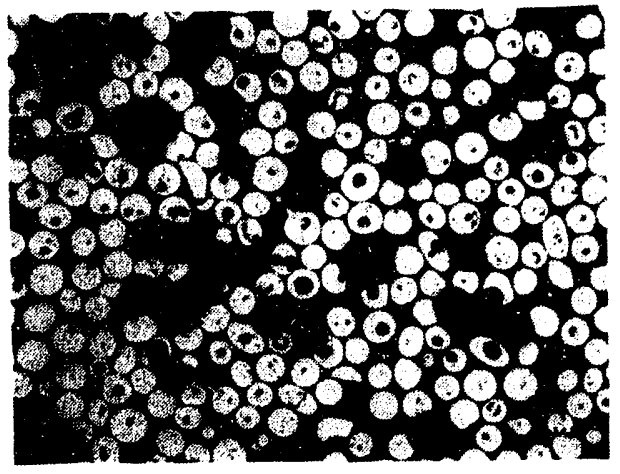

$C A(H E=8$ APPM $)$

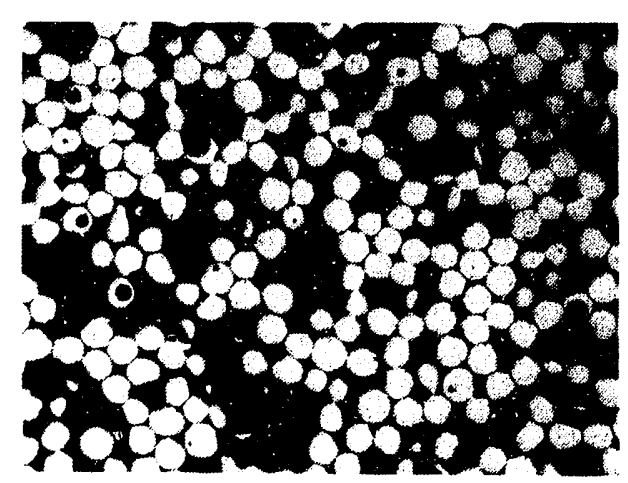

IGA $(\mathrm{HE}=1.8 \mathrm{APPM})$

Figure 21. Porosity in atomized Type 304 SS 100-150 $\mu$ m particles. 


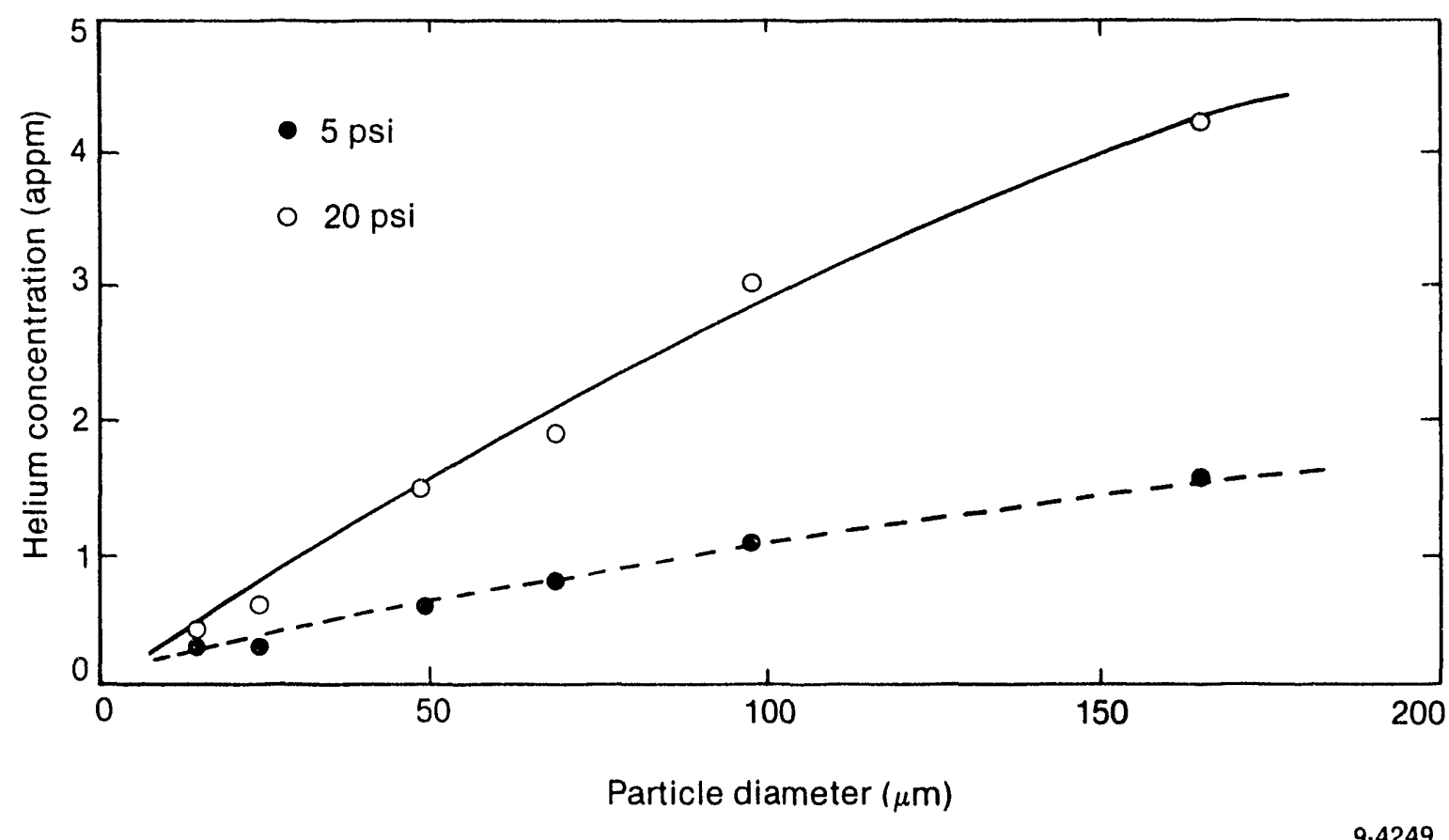

Figure 22. Particle size dependence on helium content for IGA Type 304 SS powders processed with different chamber pressures.

\section{Powder Atomization Issues}

Although the characterization of the atomized iron-base alloy powders has been quite thorough, some relevant issues remain. The issues that, in the author's opinion, remain to be resolved are summarized below.

1. Identification of Important Powder Characteristics. Which powder characteristics affect the microstructure and properties or performance behavior after powder consolidation? Furthermore, can controlling RSP of powders, through control of melt chemistry, melt stream breakup into fine droplets, and effective cooling to provide high crystallization rates, enable design of superior iron-base alloys? These questions will be further addressed later in this chapter when the observations on the behavior of the consolidated powders are discussed. 
2. Powder Processing Performance and Economics. These aspects represent the bottom line for industrial use of the RSP technology. RSP must consistently produce very high yields of high quality powders with minimum levels of contamination (e.g., surface films, foreign particles, and entrained insoluble gases). In addition, the expendable items associated with powder processing should be minimal or recyclable. Also, the end-use performance must be considered. For example, is the performance and reliability of an RSP-derived product sufficiently greater than that of its conventional counterpart to justify the cost? This question can only be answered by the end users. 
POWDER CONSOLIDATION

In general, the powders from RSP have little value until consolidated into a useful form such as a part or component. At the INEL, considerable effort has been devoted to the consolidation behavior of atomized iron-base alloy powders. The research effort was aimed at developing a more fundamental understanding of particle deformation, interaction, and bonding, rather than the fabrication of parts/components for certain applications. As a result, very little attention was given to near-net-shape forming of parts from the powders. The studies primarily addressed the influence from extrinsic parameters such as pressure (stress), temperature, and time on powder consolidation. An additional variable was particle size. The results from the study are summarized below.

\section{Methods and Parameters}

In this chapter, the following definition for powder consolidation is used: powder consolidation is a process or processes where full densification occurs and total bonding of the particles is achieved. The latter allows a distinction between consolidation and compaction; compaction of the powders to full density could occur without adequate particle bonding.

The more extensive study on powder consolidation was performed on CA processed Type 304 SS powders using primarily a "grab" distribution with a particle size range of $>20$ to $<150 \mu \mathrm{m}$ and median particle size of $80 \mu \mathrm{m} .{ }^{19}$ The consolidation methods were hot extrusion, hot isostatic pressing (HIPping), and dynamic consolidation using projectile impacts and explosives. Schematics that illustrate several of the techniques are shown in Figure 23, and the associated parameters used in the study are given in Table 2.

Initially, there was some concern regarding the influence of temperature and time at temperature on microstructural stability and its primary association with rapid solidification processing. This provided an incentive to keep the consolidation temperatures low, and the primary justification for investigating dynamic consolidation. It is evident from Table 2 that the 

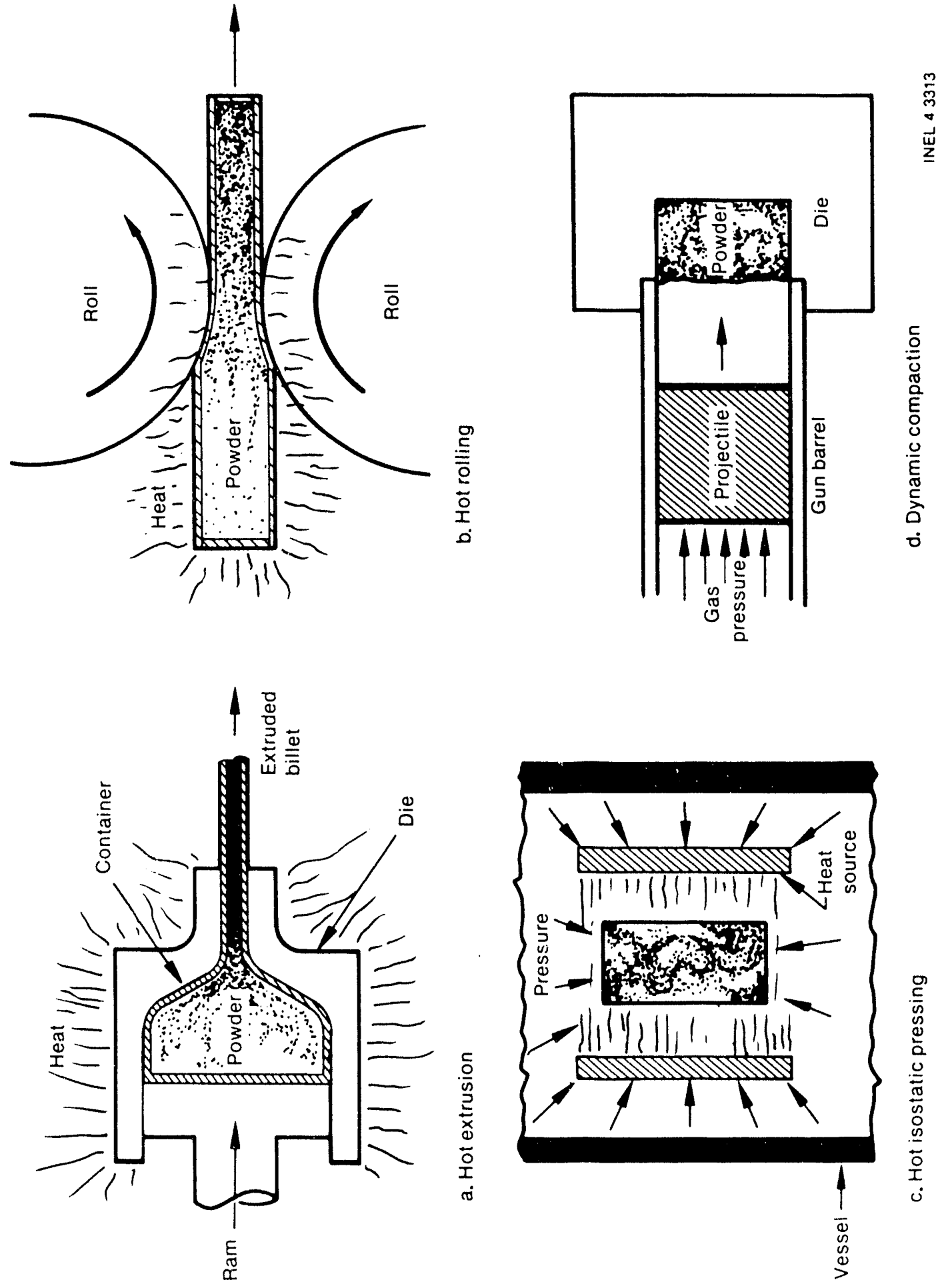

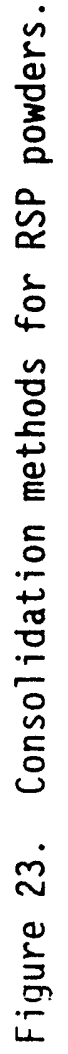


Table 2. Consolidation Parameters for CA Type 304 SS Powders

\begin{tabular}{|c|c|c|c|c|}
\hline $\begin{array}{l}\text { Consol idation } \\
\text { Method }\end{array}$ & $\begin{array}{l}\text { Product } \\
\text { Form }\end{array}$ & $\begin{array}{l}\text { Pressure } \\
\text { or Stress } \\
(\mathrm{MPa}) \\
\end{array}$ & $\begin{array}{l}\text { Temperature } \\
\left({ }^{\circ} \mathrm{C}\right)\end{array}$ & $\begin{array}{l}\text { Load Duration } \\
(\mathrm{s})\end{array}$ \\
\hline HIPping & $\begin{array}{l}\text { Plate } \\
\text { and rod }\end{array}$ & 34 to 207 & 900 to 1100 & $\begin{array}{l}3.6 \times 10^{3} \text { to } \\
3.6 \times 104\end{array}$ \\
\hline Extrusion ${ }^{a}$ & Bar & $\sim 2,800$ & 900 & -1 \\
\hline Dynamic & Plate & 15,000 & $400^{b}$ & $10^{-5}$ \\
\hline \multicolumn{5}{|c|}{ b. Calculated bulk temperatures. } \\
\hline
\end{tabular}

parameters investigated cover a very wide range and should provide an effective consolidation assessment. The consolidation response of other ironbase alloy powders was included in the evaluation, but not to the extent of the CA Type 304 SS powders. Pertinent results from these other powders will be included in the following sections.

\section{Hot Extrusion}

Extrusion consolidation of the iron-base alloy powders involved filling stainless steel or mild steel cans with powder to tap density, heating under vacuum for degassing, and hermetically sealing them. In all cases, the powder-filled cans were heated at $900^{\circ} \mathrm{C}$ for 0.5 to $1 \mathrm{~h}$ and then extruded using extrusion ratios of either 8 to 1 or 10.5 to 1 . Without exception, the consolidated iron-base alloy powders showed a very fine grain, recrystallized microstructure with little evidence of porosity or particle boundaries. Some typical as-extruded microstructures that are parallel to the extrusion direction (i.e., longitudinal) are shown in Figures 24 and 25 for Type 304 SS and A286 IGA extruded powders with different initial particle size fractions. For the Type 304 SS extruded powders (Figure 24) there appears to be no influence from particle size on the recrystallized microstructure. The series 


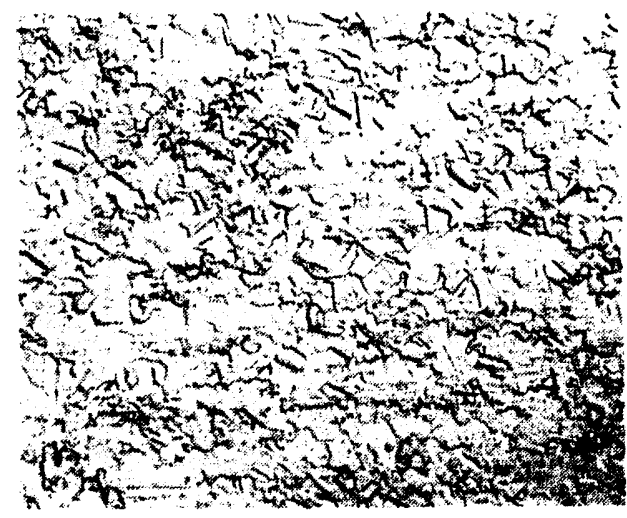

(a) $>10$ to $<30 \mu \mathrm{m}$

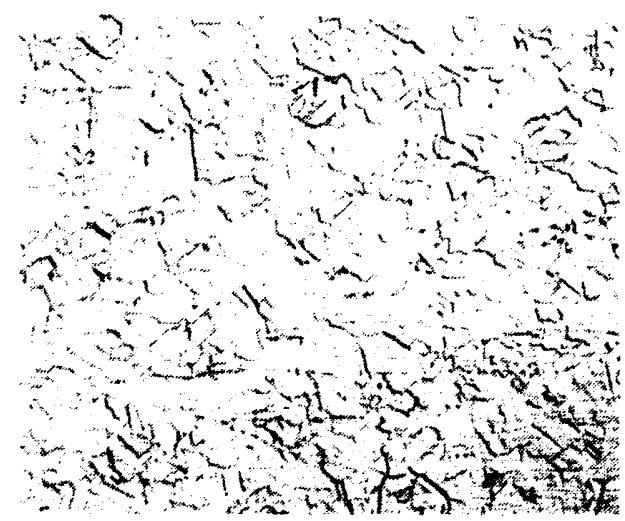

(c) $>50$ to $<75 \mu \mathrm{m}$

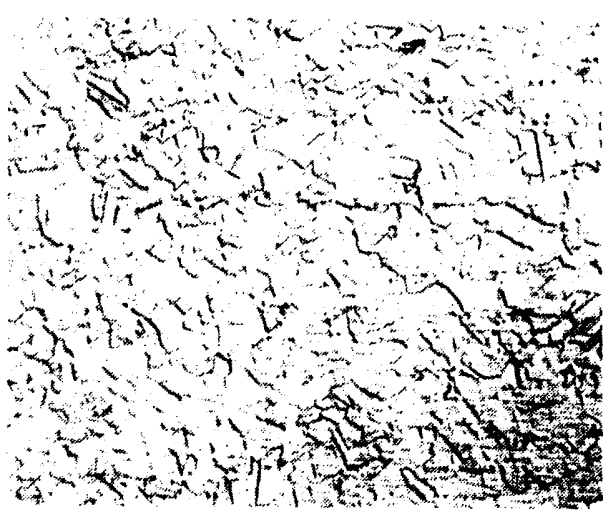

(b) $>30$ to $<50 \mu \mathrm{m}$

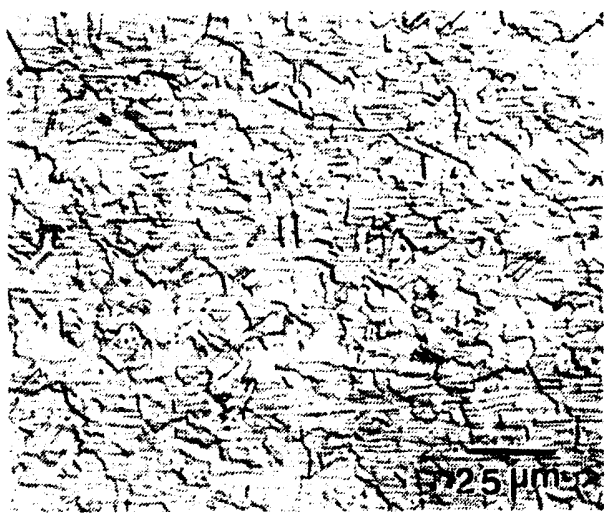

(d) $>100$ to $<150 \mu \mathrm{m}$

Figure 24. Microstructure (longitudinal plane) of IGA processed Type 304 SS for various powder particle sizes after hot extrusion.

of A286 extruded powders shows an apparent recrystallized microstructure in which the grains increase in size with the increasing size of the particles. In addition, there is evidence of banding from the formation of titanium-rich oxide films on the particles after atomization (see Figure 16c). It is apparent from Figure 25 that the band width increases as the size of the particles used in the extrusions increases.

The current investigation has not established temperature and extrusion ratio limits for the iron-base alloy powders. However, a $900^{\circ} \mathrm{C}$ preheat and extrusion ratios of $\geq 8$ to 1 have yielded products that are of high quality 


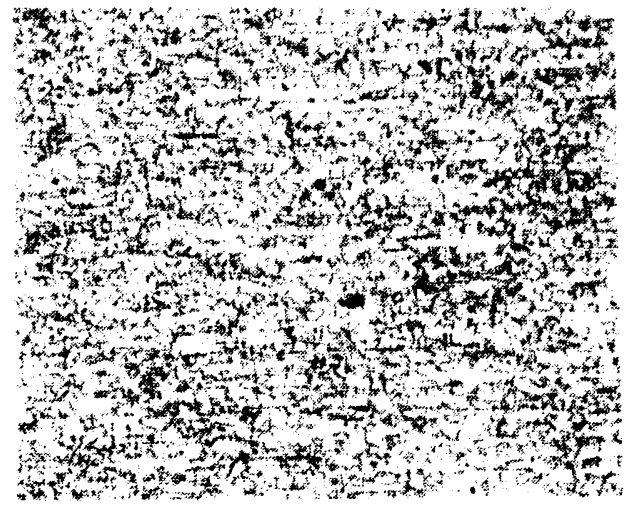

(a) $>10$ to $<30 \mu \mathrm{m}$

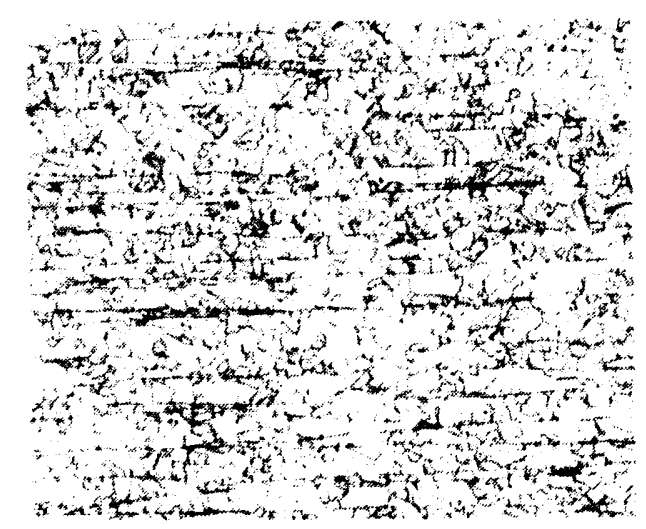

(c) $>50$ to $<75 \mu \mathrm{m}$

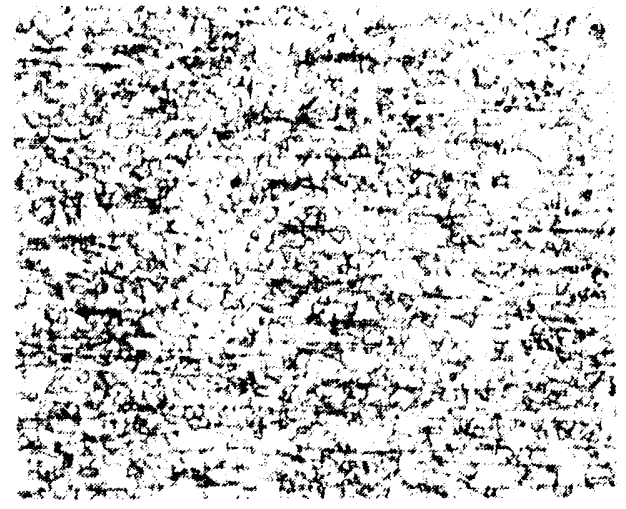

(b) $>30$ to $<50 \mu \mathrm{m}$

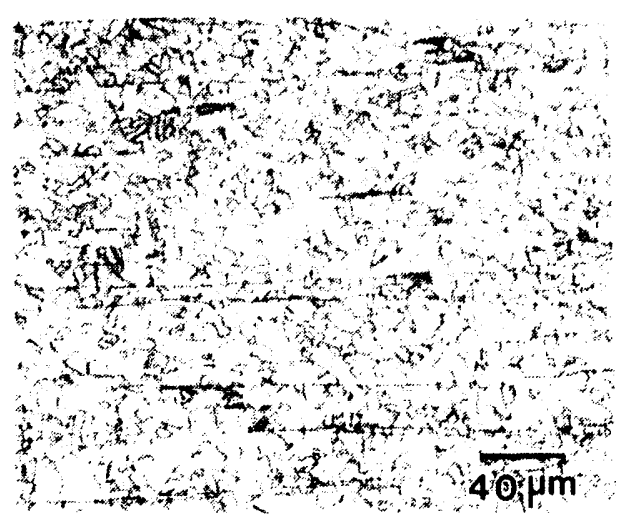

(d) $>100$ to $<150 \mu \mathrm{m}$

Figure 25. Microstructure (longitudinal plane) of IGA processed A286 for various powder particle sizes after hot extrusion.

from a consolidation standpoint. These products possess the desired densification and particle bonding, and have converted the solidification microstructure of the powder into a fine-grained recrystallized microstructure.

\section{Hot Isostatic Pressing}

HIPping was used to consolidate many of the alloy powders shown in Table 1 into plates for heat treatment and subsequent microstructure and mechanical property evaluations. For consolidation into plates, rectangular 
stainless steel cans were filled with powder, degassed at $\sim 250^{\circ} \mathrm{C}$, and hermetically sealed. The HIP parameters included a pressure of $207 \mathrm{MPa}$ (30 ksi) applied at temperature for $2.5 \mathrm{~h}$. Depending on the alloy, two temperatures were used, 900 and $1100^{\circ} \mathrm{C}$. The as-HIPped microstructures showed very little evidence of porosity for either temperature. However, the $900^{\circ} \mathrm{C}$ HIP temperature showed retention of the solidification microstructure associated with particles after powder processing. The $1100^{\circ} \mathrm{C} \mathrm{HIP}$ temperature produced a fully recrystallized microstructure with only occasional evidence of the particle boundaries. Examples of the microstructure for the two HIP temperatures are shown in Figure 26 for a CA processed $\mathrm{Fe}-20 \mathrm{Ni}-20 \mathrm{Cr}$ alloy with three carbon levels. An interesting feature for the series HIPped at $900^{\circ} \mathrm{C}$ is that recrystallization has been initiated in the region of the particle boundaries, indicating that these regions are ones of high strain. Not all of the other alloys showed recrystallization being initiated at $900^{\circ} \mathrm{C}$.

In order to better understand HIP consolidation of the iron-base alloy powders, studies were also performed using powder-filled and hermetically sealed stainless steel tubes. This configuration produced rod/cylindrical shaped specimens for evaluation. Some examples from a study of CA processed $\mathrm{Fe}-40 \mathrm{Ni}$ and $\mathrm{Fe}-40 \mathrm{Ni}-0.3 \mathrm{Nb}-0.05 \mathrm{C}$ powders involving a $207 \mathrm{MPa}$ pressure applied for $2.5 \mathrm{~h}$ at four different temperatures are shown in Figures 27 and 28 . For both alloys, a "grab" particle size distribution was used. The influence of HIPping temperature on microstructural evolution is similar for the two alloys. At $900^{\circ} \mathrm{C}$, massive recrystallization has been initiated between the particles. The powders for both alloys were noted earlier as containing a significant amount of porosity. The $900^{\circ} \mathrm{C}$ HIP treatment appeared to close the pores, since very little porosity was observed after HIPping. The $1000^{\circ} \mathrm{C} \mathrm{HIP}$ exposure still shows a high population of fine recrystallized grains for both alloys. At $1100^{\circ} \mathrm{C}$, a relatively uniform grain size dominates the microstructure. The average grain size after the $1200^{\circ} \mathrm{C}$ HIP exposure is $<20 \mu \mathrm{m}$ for the two alloys shown in Figures 27 and 28.

A detailed HIPping study was performed on the CA Type 304 SS powder using the powder-filled stainless steel tube configuration. The purpose of the study was to determine the influence of the HIPping variables, as well as 


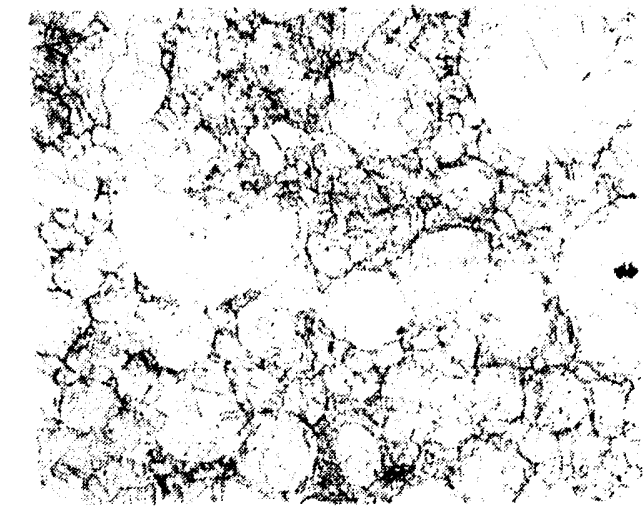

(a) $900^{\circ} \mathrm{C}, 0.008 \mathrm{C}$

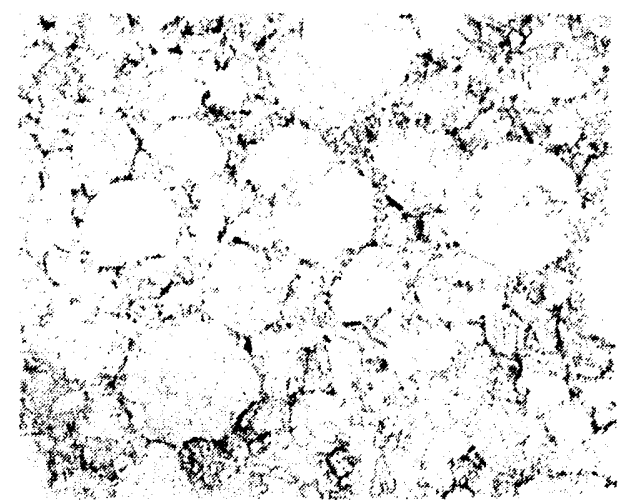

(c) $900^{\circ} \mathrm{C}, 0.06$

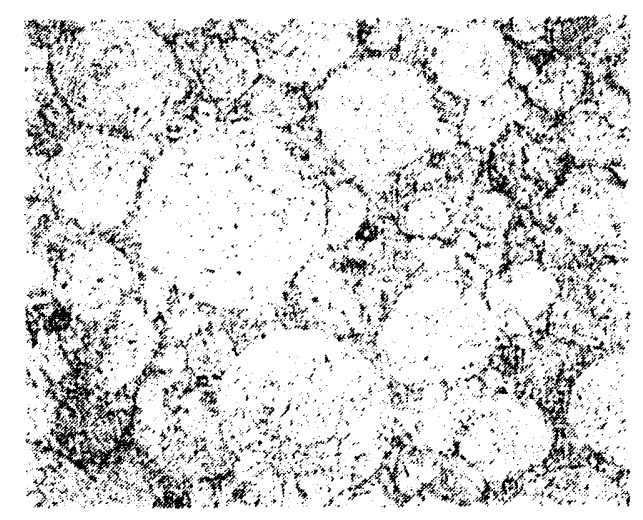

(e) $900^{\circ} \mathrm{C}, 0.14 \mathrm{C}$

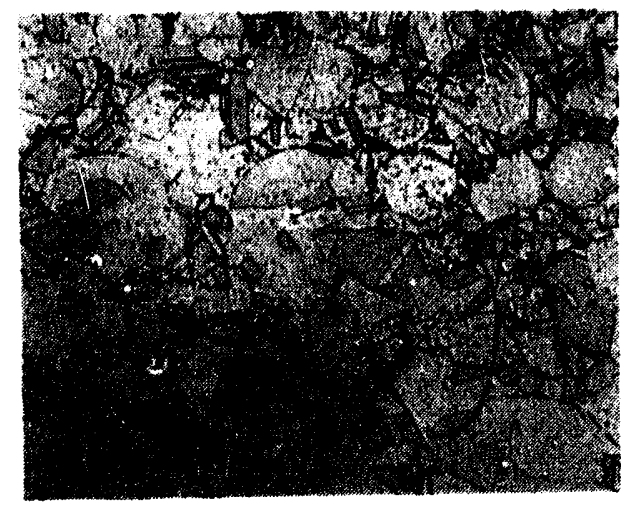

(b) $1100^{\circ} \mathrm{C}, 0.008 \mathrm{C}$

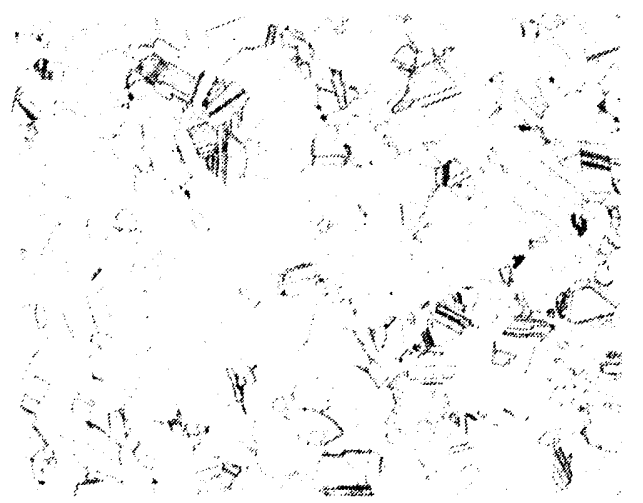

(d) $1100^{\circ} \mathrm{C}, 0.06 \mathrm{C}$

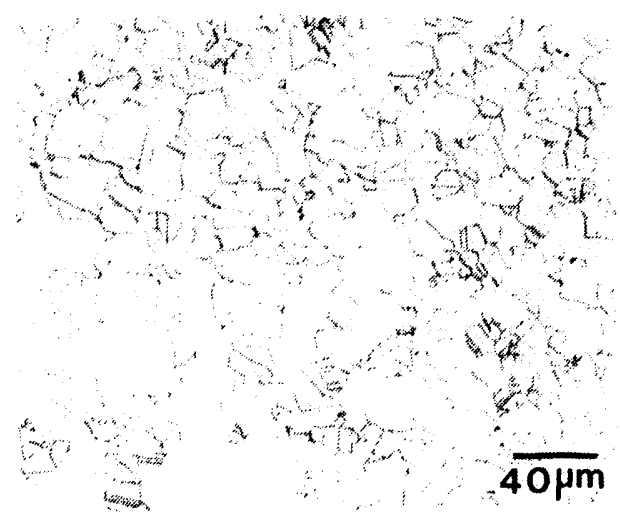

(f) $1100^{\circ} \mathrm{C}, 0.14 \mathrm{C}$

Figure 26. Microstructure of $\mathrm{CA} F-20 \mathrm{Ni}-20 \mathrm{Cr}$ powders with different carbon contents HIPped at 900 and $1100^{\circ} \mathrm{C}(207 \mathrm{MPa}, 2.5 \mathrm{~h})$. 


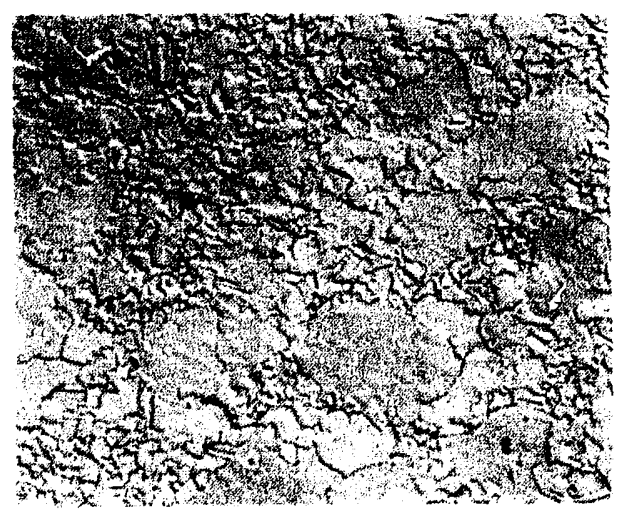

(a) $900^{\circ} \mathrm{C}$

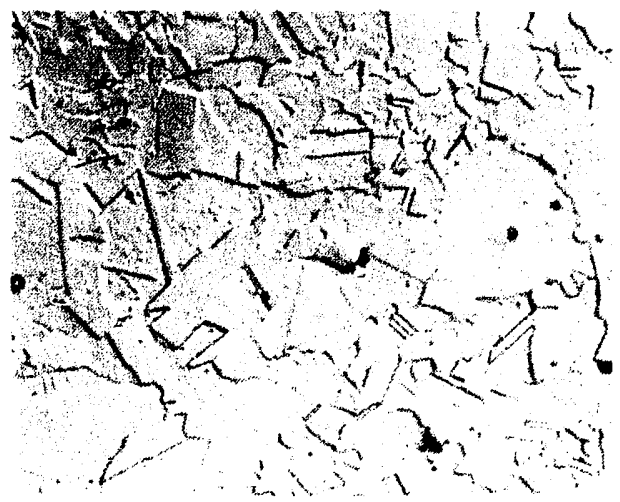

(c) $1100^{\circ} \mathrm{C}$

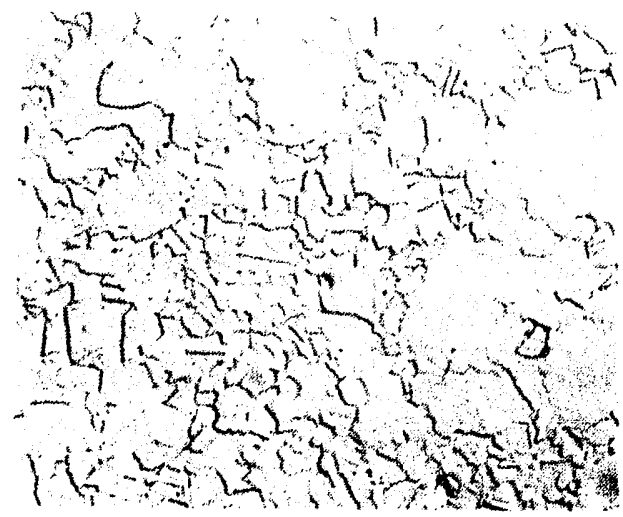

(b) $1000^{\circ} \mathrm{C}$

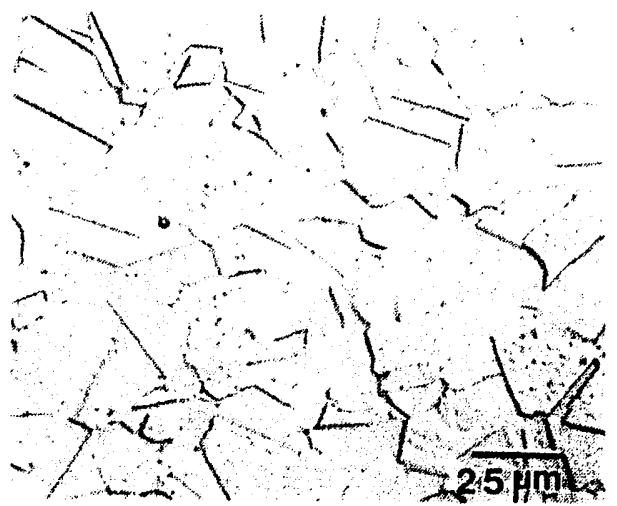

(d) $1200^{\circ} \mathrm{C}$

Figure 27. Microstructure of CA Fe-40Ni powders after HIPping at $207 \mathrm{MPa}$ for $2.5 \mathrm{~h}$ at various temperatures.

particle size, on densification and particle bonding. ${ }^{20,21}$ In addition, the densification behavior was compared to phenomenological models proposed for HIPping of spherical powders. 22,23 The HIPping parameters used for the study involved pressures of 35 and $103 \mathrm{MPa}$ ( 5 and $15 \mathrm{ksi}$ ), temperatures of 900 and $1100^{\circ} \mathrm{C}$, and times under full load and temperature of 0.5 to $10 \mathrm{~h}$. Two particle size fractions were examined, $>30$ to $<50 \mu \mathrm{m}$ and $>100$ to $<150 \mu \mathrm{m}$.

Following the procedure given by $\mathrm{Hell}^{23,24}$, hot isostatic pressing maps were obtained for the Type 304 SS powder and the associated parameters. HIPping maps corresponding to the 30 to $50 \mu m$ particie size and pressures of 35 and $104 \mathrm{MPa}$ are shown in Figure 29. For the low pressure tests (35 MPa), 


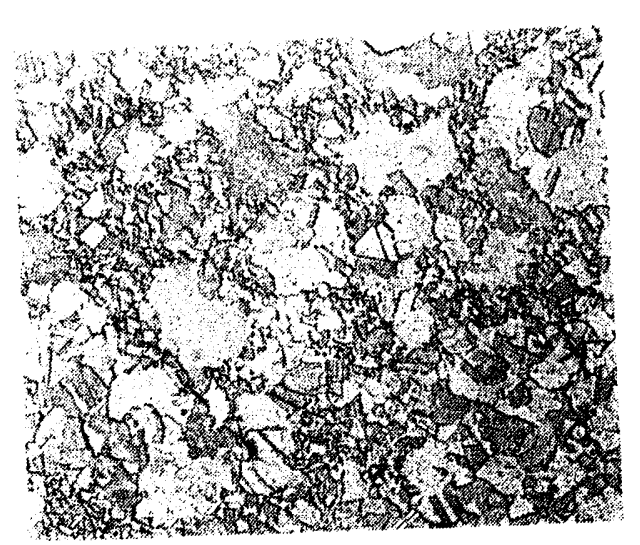

(a) $900^{\circ} \mathrm{C}$

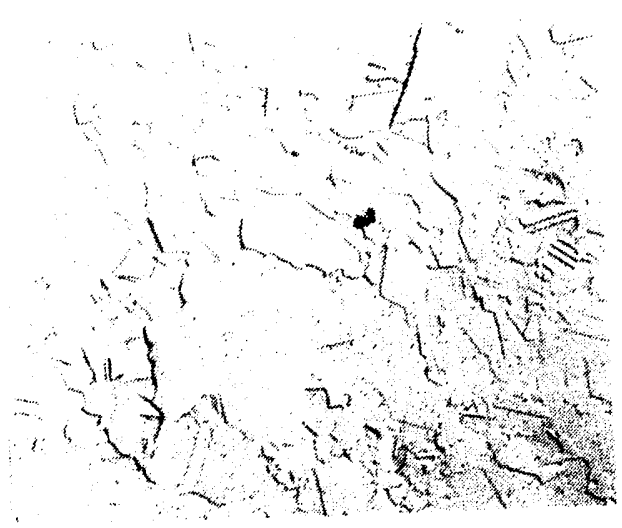

(c) $1100^{\circ} \mathrm{C}$

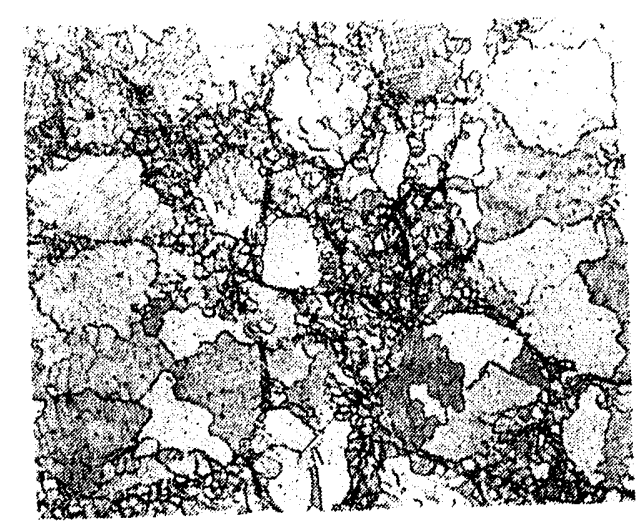

(b) $1000^{\circ} \mathrm{C}$

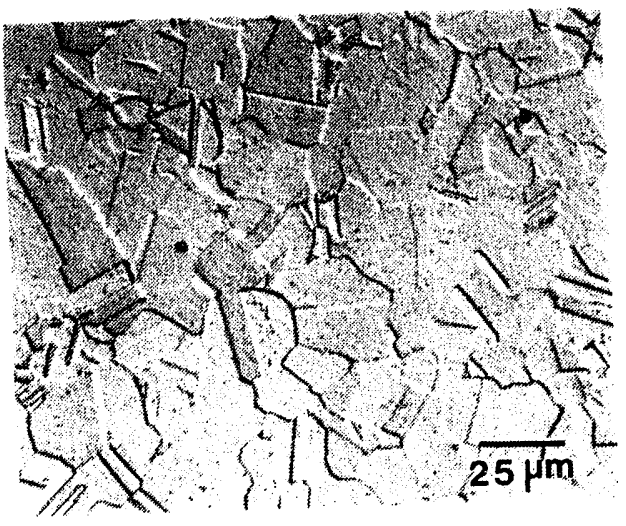

(d) $1200^{\circ} \mathrm{C}$

Figure 28. Microstructure of $\mathrm{CA} \mathrm{Fe}-40 \mathrm{Ni}-0.3 \mathrm{Nb}-0.05 \mathrm{C}$ powders after HIPping at $207 \mathrm{MPa}$ for $2.5 \mathrm{~h}$ at various temperatures.

densification is predominantly controlled by the Nabarro-Herring/Coble (NH/C) creep behavior (Figure 29a). However, at the higher pressure (104 MPa), power 1 aw creep contributes substantially to densification. A comparison between the calculated densities (Figure 29) and the immersion densities of CA HIPped Type 304 SS powders is shown in Figure 30 . The measurements are in reasonable agreement with the calculations and show that pressure and temperature have the most influence on densification. Particle size has a modest influence on densification at equivalent pressures and temperatures, with the smaller particle size $(>30$ to $<50 \mu \mathrm{m}$ ) showing more densification than the larger. 


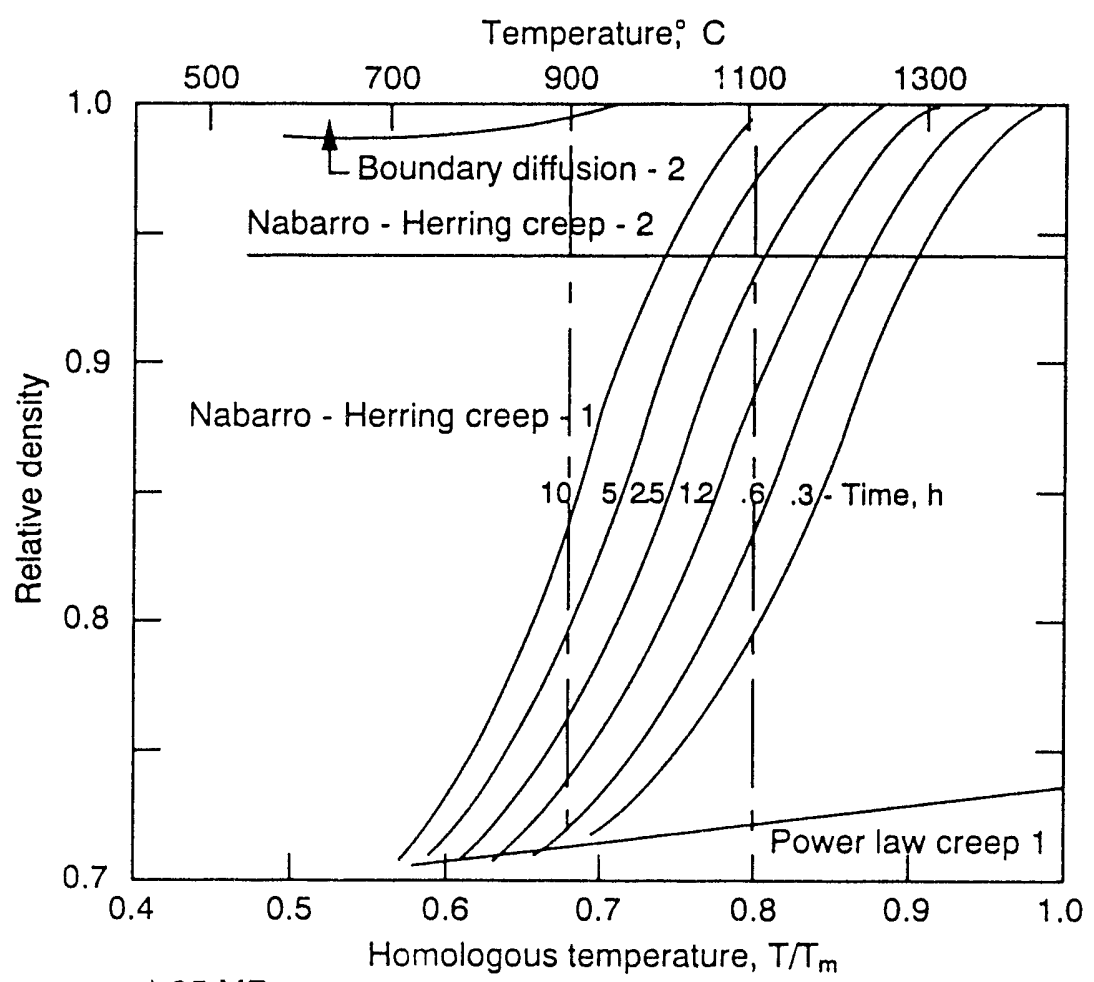

a) $35 \mathrm{MPa}$ pressure

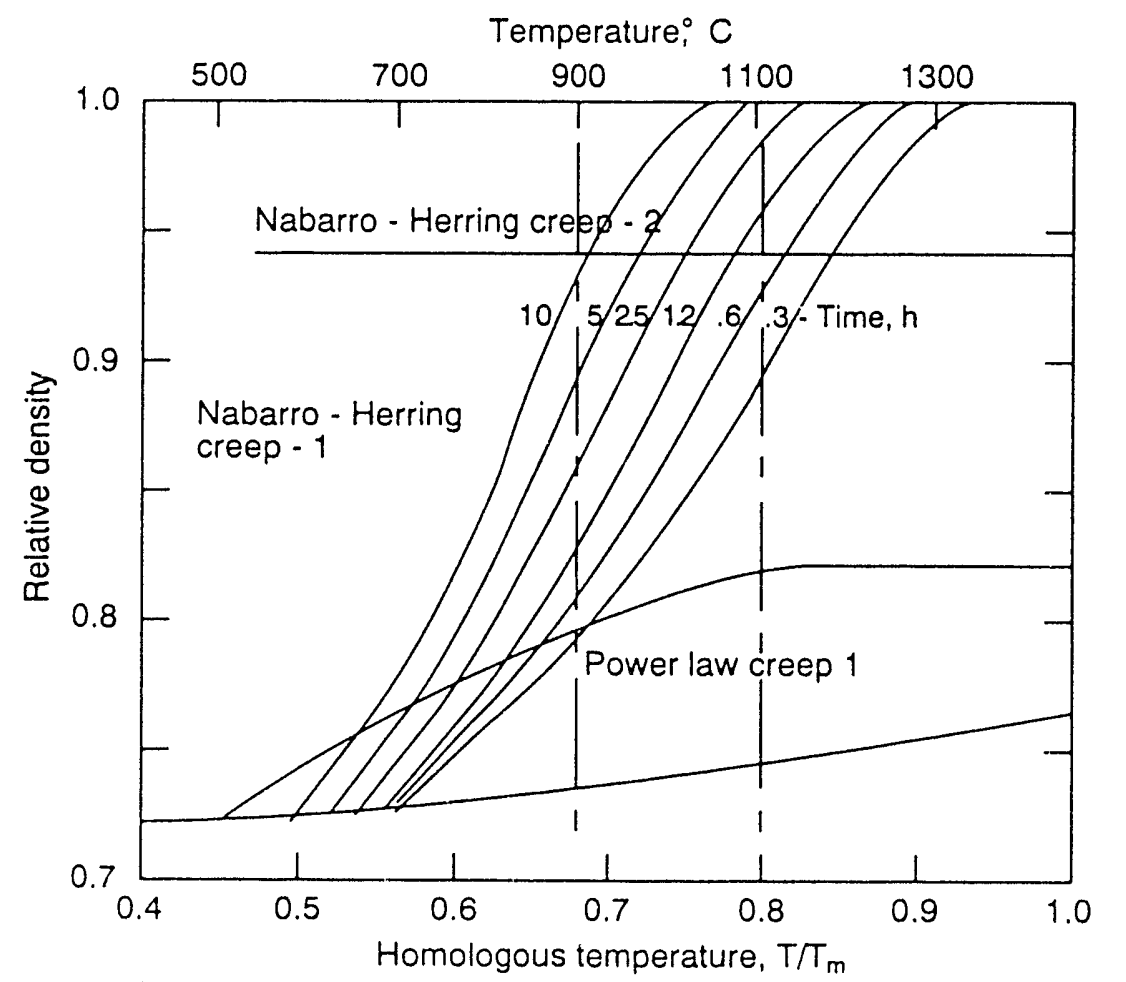

b) $104 \mathrm{MPa}$ pressure

N91 0043

Figure 29. HIPping maps of CA Type 304 SS, 30-50 $\mu \mathrm{m}$ particles. 


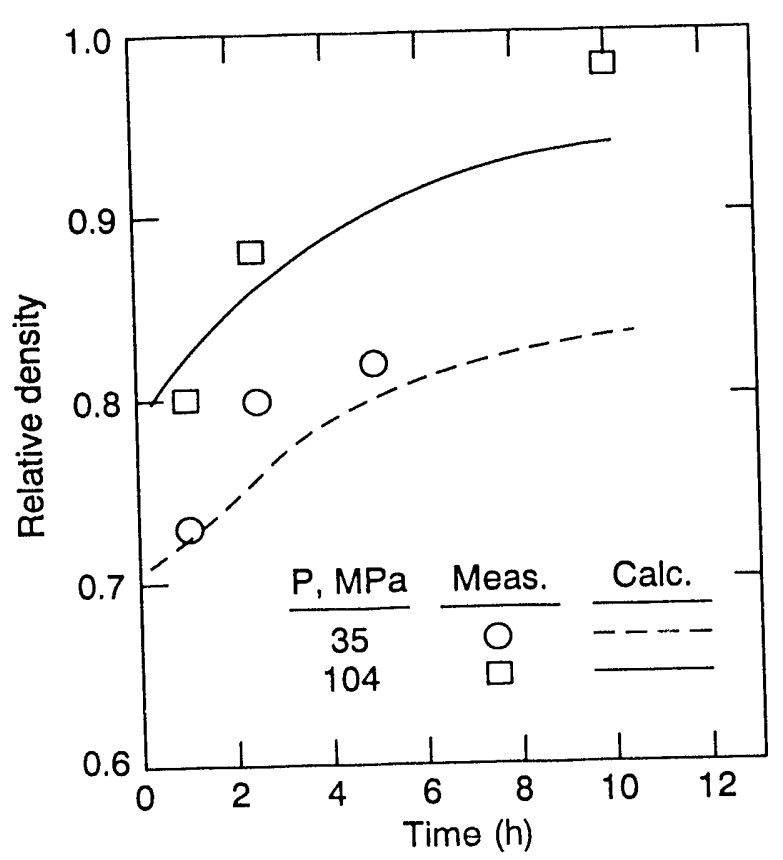

a) $30-50 \mu \mathrm{m}, 900^{\circ} \mathrm{C}$

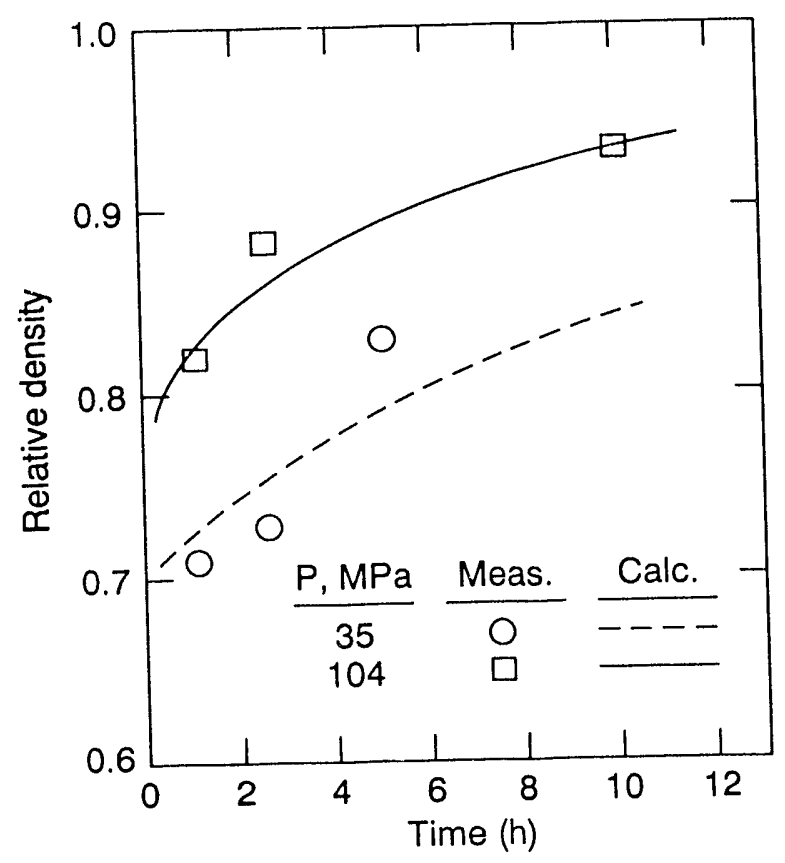

c) $100-150 \mu \mathrm{m}, 900^{\circ} \mathrm{C}$

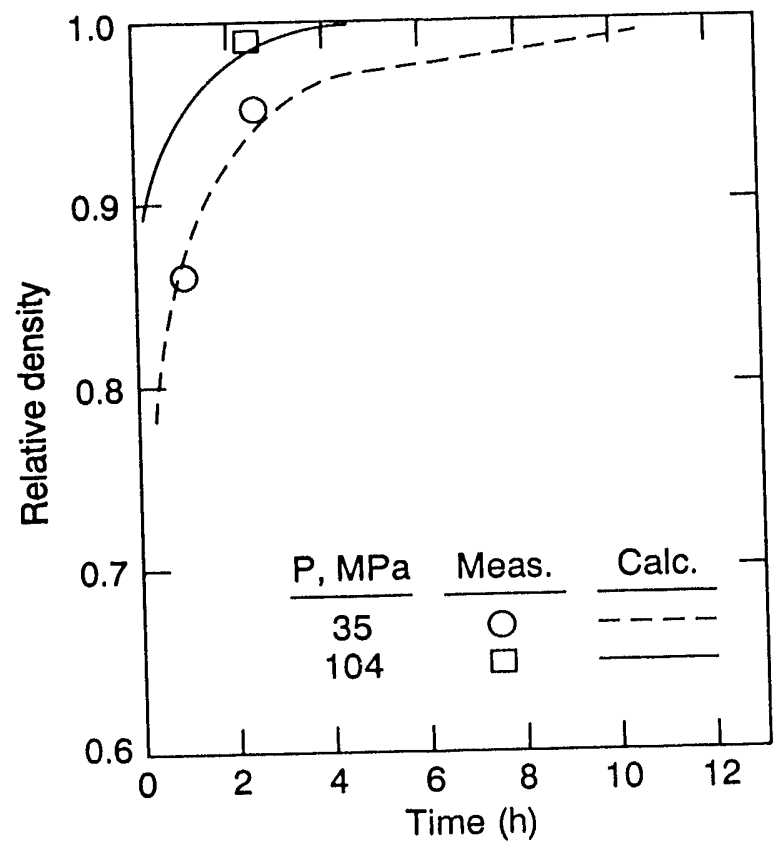

b) $30-50 \mu \mathrm{m}, 1100^{\circ} \mathrm{C}$

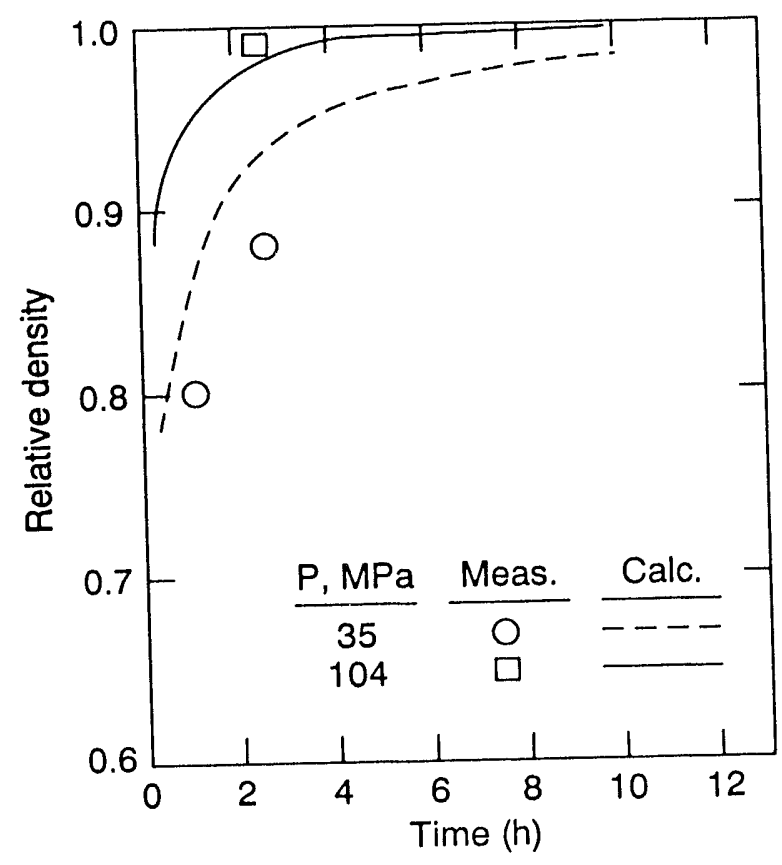

d) $100-150 \mu \mathrm{m}, 1100^{\circ} \mathrm{C} \quad \mathrm{N} 910044$

Figure 30. Experimental and calculated densities for CA Type 304 SS HIPped powders.

The densification maps for HIPping (Figure 29) provide no information regarding particle bonding, which is a necessary condition for powder 
consolidation. Tensile tests were performed on the HIP series of Type 304 SS specimens; in particular, the specimen elongation to failure was examined. The elongation results from the tests and correlations with relative density are shown in Figure 31. The HIPping tests performed at $1100^{\circ} \mathrm{C}$ show bonding indications that appear to be relatively insensitive to pressure and particle size (see Figure 31a). However, limited data are available to substantiate this finding. The $900^{\circ} \mathrm{C}$ HIP test specimens show a discernable dependence on particle size for the higher pressure specimens (Figure $31 \mathrm{~b}$ ). Also, in Figure $31 \mathrm{~b}$ a substantial influence from the HIP pressure (104 versus $35 \mathrm{MPa}$ ) is evident.

Although the above study provided some useful information on densification and particle bonding, the value of the results in providing criteria for HIP consolidation of RSP iron-base alloy powders was limited. For structural applications, powder consolidation should be complete (i.e., full densification and particle bonding). However, the microstructural features or characteristics associated with the as-atomized powders that are important to preserve during the consolidation step have not been identified. As a result, current efforts are concentrated on keeping pressure high (e.g., $207 \mathrm{MPa})$, temperature relatively low (e.g., $900^{\circ} \mathrm{C}$ ), and exposure times modest (e.g., 1-3 h). From the alloys examined in this study, HIP consolidation using tris parametric approach has provided adequate consolidation (full densification and good particle bonding). The microstructure, after consolidation, of the CA Type 304 SS powders that were HIPped at $207 \mathrm{MPa}$ for $2.5 \mathrm{~h}$ at $900^{\circ} \mathrm{C}$ showed very little evidence of recrystallization. The dendritic morphology of the powders was retained. Adequate particle bonding was observed, as indicated by a $43 \%$ total elongation from tensile testing of "as-HIPped" specimens.

\section{Dynamic Consolidation}

Comparison between consolidation parameters shows a potential benefit from dynamic consolidation through a retention of relatively low bulk temperatures (see Table 2). This could be important for alloys whose microstructure and corresponding properties are sensitive to temperature. An 


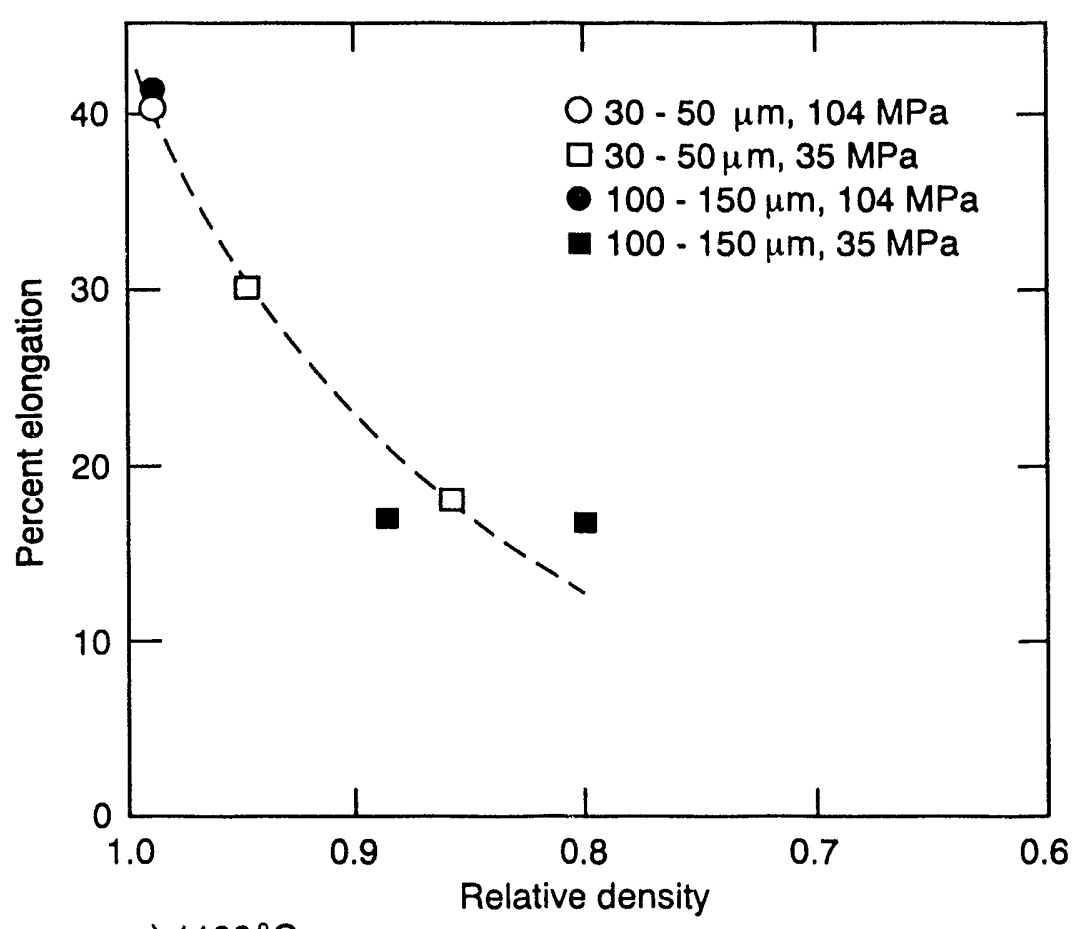

a) $1100^{\circ} \mathrm{C}$

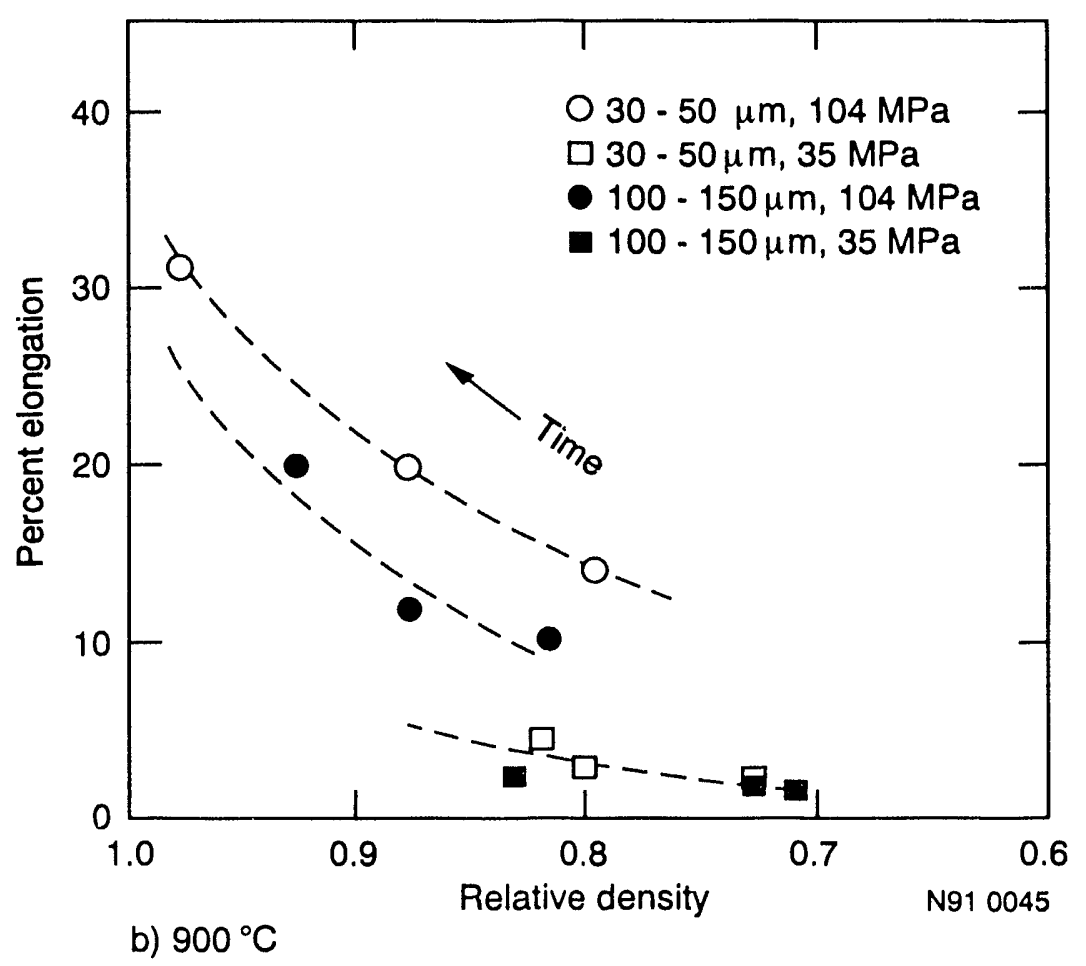

Figure 31. Elongation results from tensile testing correlated with density for various HIP conditions on CA Type 304 SS powder. 
extensive study has been performed on the dynamic consolidation behavior of iron-base alloy powders. Two methods have been employed to investigate the particle interaction, deformation, and bonding characteristics: explosives ${ }^{25-28}$ and high velocity projectile impacts. ${ }^{29}$

Cover plates and flyer plates were the two experimental arrangements used for the explosive consolidation tests. The two configurations are shown in Figure 32. The four rectangular, off-center and off-diagonal, powder cavities in the target $\mathrm{plate}$ and the use of spall plates/momentum traps for trapping lateral and tensile waves enabled fuse-bonded, crack-free monoliths to be produced for examination and testing. For this configuration, peak stresses near $15 \mathrm{GPa}$ and with an $-10 \mu \mathrm{s}$ duration were obtained, which produced four small monolithic plates $-3.5 \times 5.1 \times 0.4 \mathrm{~cm}$ thick per shot. ${ }^{28}$ These monoliths were suitable for fabrication into tensile specimens for bond strength testing as well as for microstructure examinations.

Detonation of the explosive produces a very high stress wave in the cover plate that is transmitted to the powder inside the cavities. The particles move downward (see Figure 32), interact, and deform to fill the void space between the particles. Adiabatic heating, attributable to the
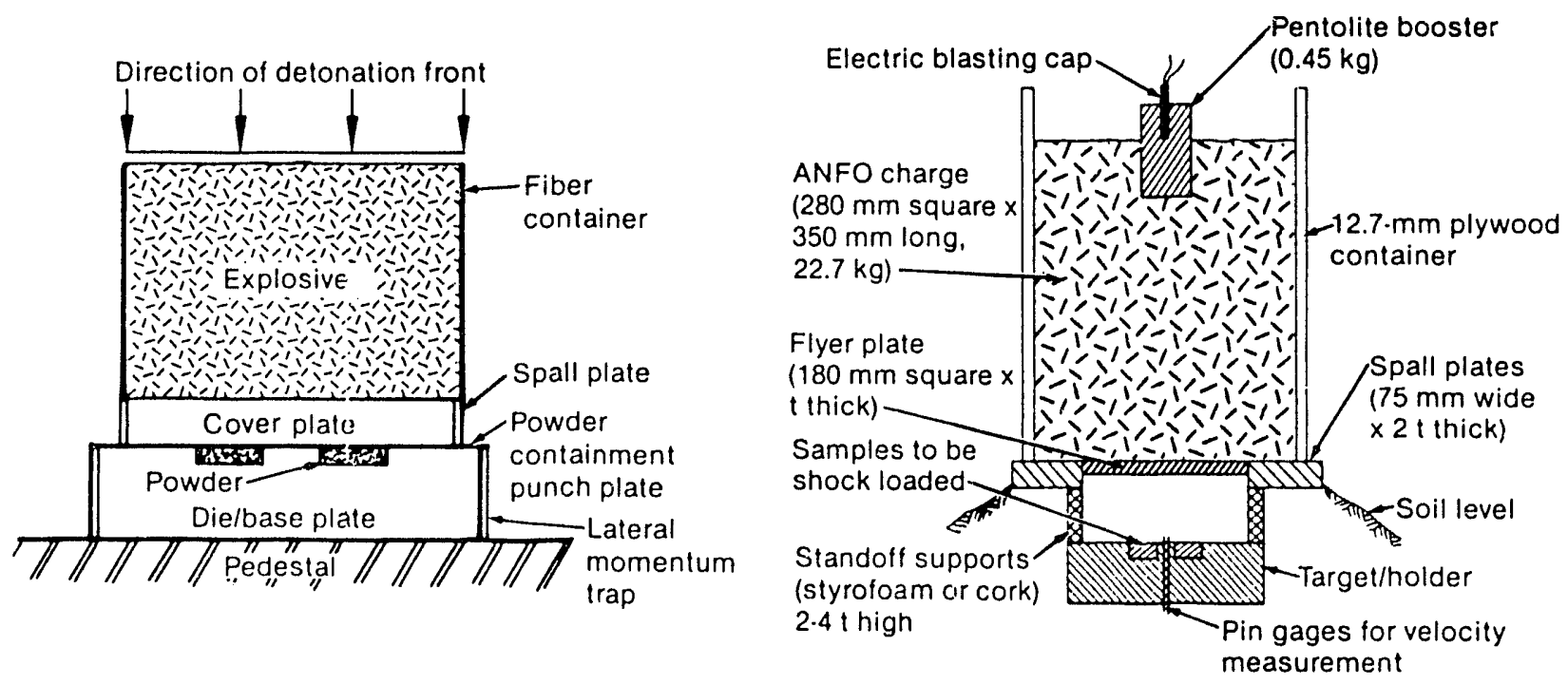

Figure 32. Test configurations for dynamic consolidation of powders using explosives. (Left, cover plate; right, flyer plate) 
deformation rate and deformation associated with the particle extrusion into the void regions, is the primary source of heat generated in the dynamic process. Some examples of the particle deformation/flow characteristics from specimen cross sections are shown in Figure 33. The "tails" associated with the particle deformation to fill the interstitial regions of the particles correspond to the direction of the stress wave. Interparticle friction appears to play a minor role in heating the particle interfaces. The high deformation rate regions produce localized temperatures that can exceed the alloy's melting temperature. ${ }^{28,29}$ These regions represent a very small fraction of the total volume of the particles. Heat from the high deformation regions is readily extracted by the bulk of the particles, thereby keeping the average or effective temperature of the corsolidated powder monolith to relatively low levels.

Full density is observed for the dynamic consolidation processes; however, the interparticle bonding around the particles is graded, ranging from localized fusion bonding (high deformation/particle extrusion regions) to solid state bonding (lateral particle surface regions) to mechanical abutment (leading surface region). The next section will discuss how graded bonding associated with dynamic consolidation still provides substantial strength.

During dynamic consolidation, particle interaction is limited to nearest neighbors. ${ }^{28}$ This behavior could be effectively used for composite consolidation of dissimilar powders. Comparison of dynamically consolidated
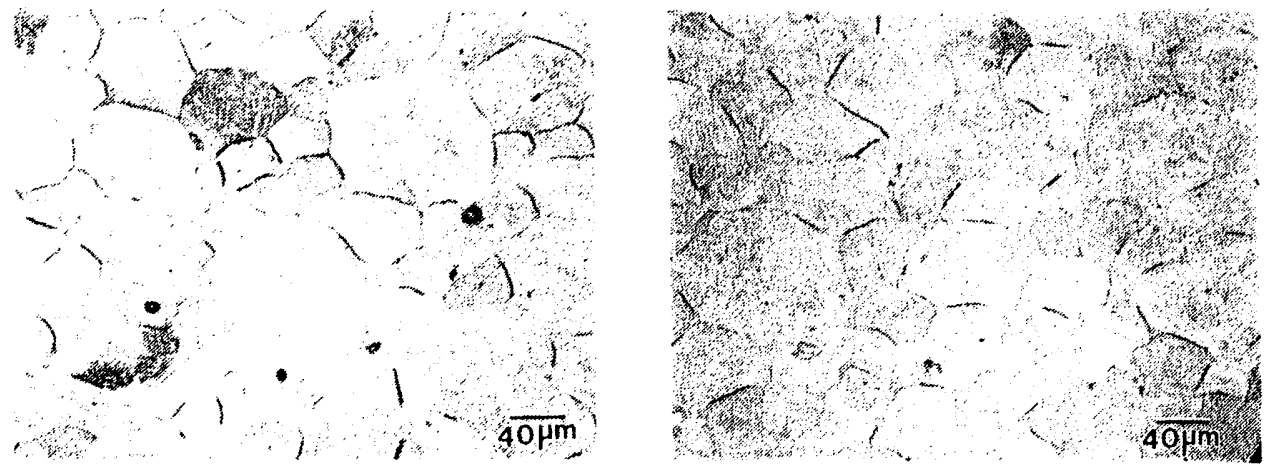

Figure 33. Optical micrographs of dynamically consolidated CA Type 304 SS powders. 
large (e.g., 100 to $150 \mu \mathrm{m}$ ) and small particles shows evidence of a larger volume fraction of regions where melting occurred in the large particles. ${ }^{28}$ This behavior is consistent with the very high degree of deformation and deformation rate associated with the regions of particle extrusion to fill the void/interstitial regions between the particles--which provide the high localized heat generation.

Dynamic consolidation studies have been performed on CA and VGA Type 304 SS powders using projectile impacts from a gas gun. ${ }^{29}$ These studies used a similar, but dimensionally reduced, quad-cavity die target arrangement (Figure 32). A range of peak stresses was obtained using various projectile velocities. Dynamic load duration for the tests was 2 to $3 \mu \mathrm{s}$. Characterization of the powder specimens showed that they had obtained full densification and adequate particle bonding. Hardness measurements on the specimen cross sections parallel to the direction of the projectile impact were uniform across the specimen. Some localized variations were observed in the regions where melting occurred, i.e., high deformation/deformation rate powder extrusion regions. The influence of peak stress (projectile velocity) on hardness is shown in Figure 34 , where a peak hardness near the $15 \mathrm{GPa}$ peak

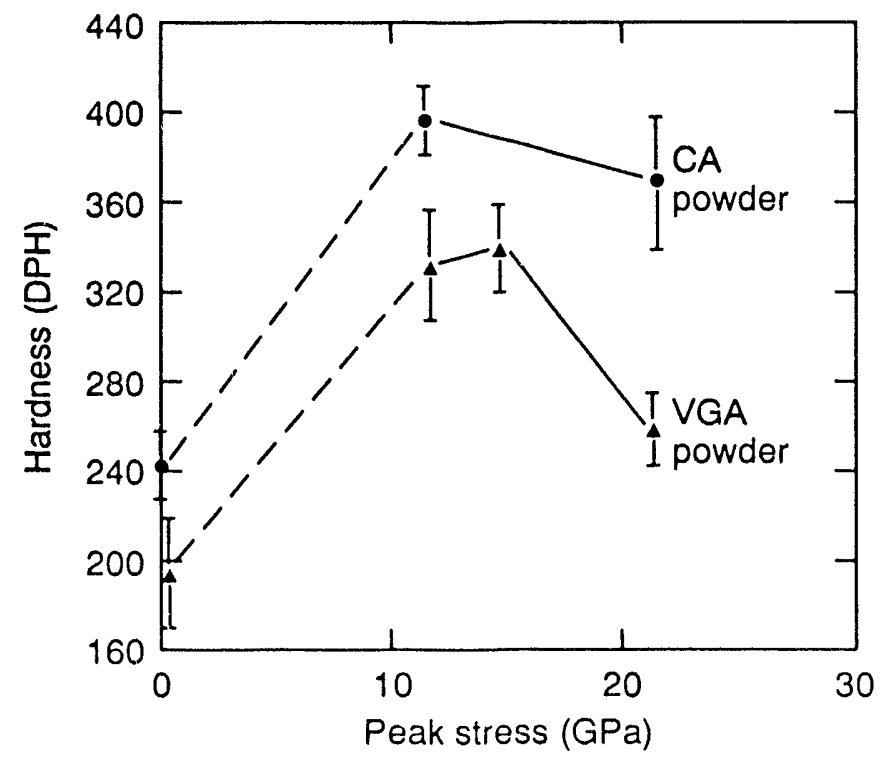

N91 0055

Figure 34. Influence of peak stress from projectile impacts on average hardness for Type 304 SS powders before and after consolidation. 
stress level is observed. This stress is comparable to the calculated peak stress obtained from the dynamic consolidation studies using explosives. The hardness decline for the highest velocity (stress) impact (Figure 34) is associated with higher temperatures being generated from the impact. Increasing the projectile velocity increases the deformation rate of the particles, and increases temperature. The $21.1 \mathrm{GPa}$ tests have provided sufficient heat to cause some recovery of the consolidated powder specimens. Evidence for recovery was obtained from microscopy and $x$-ray diffraction. Although bond strength tests were not performed on these specimens, the $15 \mathrm{GPa}$ test provides the best combination for dynamic consolidation and shock hardening.

\section{Comparisons Between As-Consolidated Forms}

It is very important to establish the influence of the method used for powder consolidation on microstructure and properties. These correlations will be examined later in considerable detail for the consolidated powders after heat treatments. "As-consolidated" powders were characterized to provide a baseline for the RSP alloys after heat treatments.

For the consolidation studies, containerization of the powders was required. For extrusion and HIPping, the powder-filled cans (filled to tap density levels) were degassed and hermetically sealed. The powders used for most of the consolidation assessments were of a "grab" distribution. A concern inherent to this type of distribution is nonhomogeneous settling of the particle sizes prior to consolidation. Entrained helium analysis was used to assess particle settling. Specimens were removed along the entire length of a bar of extruded CA Type 304 SS powder and analyzed for helium content. Final results showed no apparent evidence of settling (see Figure 35 ). Although similar tests were not performed on the HIPped and dynamically consolidated CA Type 304 SS powders, or the other consolidated alloy powders, the results shown in Figure 35 are considered representative. As mentioned earlier, the consolidation behavior of CA Type 304 SS powders was studied fairly extensively compared to the other iron-base alloy powders shown in 


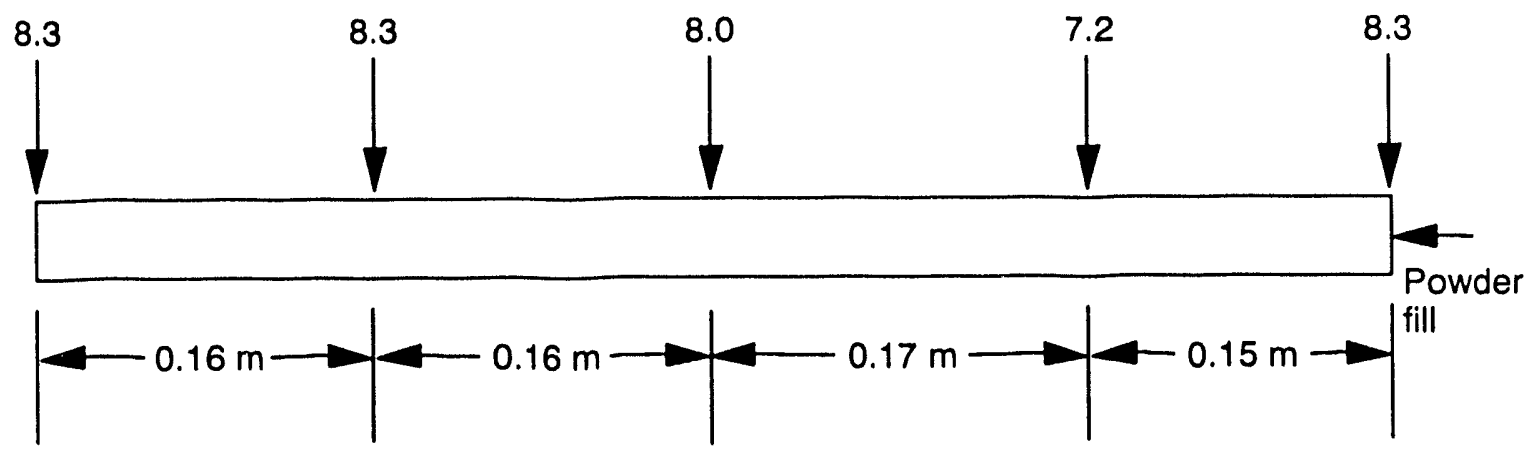

N91 0181

Figure 35. Entrained helium (appm) from powder processing after extrusion consolidation of CA Type 304 SS powder.

Table 1. Hardness and tensile properties were evaluated for the "asconsolidated" Type 304 SS powders; the results are shown in Table 3. Also included in the evaluation was HIPped powder after cold-rolling $50 \%$ (thickness reduction). It is evident that the mechanical properties reflect the temperatures associated with the consolidation. The fracture surfaces of the failed tensile specimens are shown in Figure 36 . The extruded material shows ductile-transgranular failure; this observation is supported by the rather high ductilities shown in Table 3 . The other consolidated materials show failure primarily along the particle boundaries.

Bonding has occurred along the particle perimeters in both HIPped and dynamically consolidated materials; however, bording from HIPping is fairly extensive and encompasses the entire perimeter of the particles. The bond strength and ductility would possibly be higher if HIPping had produced significant recrystallization.

Bonding in the dynamically consolidated material is graded around the particle perimeters as indicated in Figure $36 \mathrm{~d}$. Bonding ranges from localized fuse-welding in the melted regions, which experienced extensive particle extrusion, to mechanical abutment, where very little particle deformation occurred. The low ductility of the dynamically consolidated specimens shown in Table 3 is expected because plastic flow is restricted to the softer, but relatively thin, melted and recrystallized zones associated with the high 
Table 3. Mechanical Properties of the "As-Consolidated" Type 304 SS Powder Materials

\begin{tabular}{|c|c|c|c|c|c|}
\hline $\begin{array}{c}\text { Consol idated } \\
\text { Form } \\
\end{array}$ & $\begin{array}{l}\text { Hardness }^{a} \\
\text { (DPH) } \\
\end{array}$ & $\begin{array}{r}0.2 \% \\
\text { Offset } \\
(\mathrm{MPa}) \\
\end{array}$ & $\begin{array}{l}\text { U1timate } \\
(\mathrm{MPa})\end{array}$ & $\begin{array}{c}\text { Total } \\
\text { Elongation } \\
(\%)\end{array}$ & $\begin{array}{c}\text { Reduction } \\
\text { in Area } \\
(\%) \\
\end{array}$ \\
\hline Extruded $^{b}$ & 205 & 340 & 743 & 60 & 78 \\
\hline HIPped & 203 & 303 & 642 & 42 & 38 \\
\hline $\mathrm{HIP}+\mathrm{CW}^{\mathrm{c}}$ & 420 & 1235 & 1315 & 13 & 39 \\
\hline Dynamic & 405 & 1072 & 1083 & 0.9 & 0.5 \\
\hline $\begin{array}{l}\text { a. } 200 \mathrm{~g} \text { load } \\
\text { b. Parallel t } \\
\text { c. Parallel t }\end{array}$ & $\begin{array}{l}\text { extrusion } \\
\text { rolling di }\end{array}$ & $\begin{array}{l}\text { ection. } \\
\text { tion. }\end{array}$ & & & \\
\hline
\end{tabular}

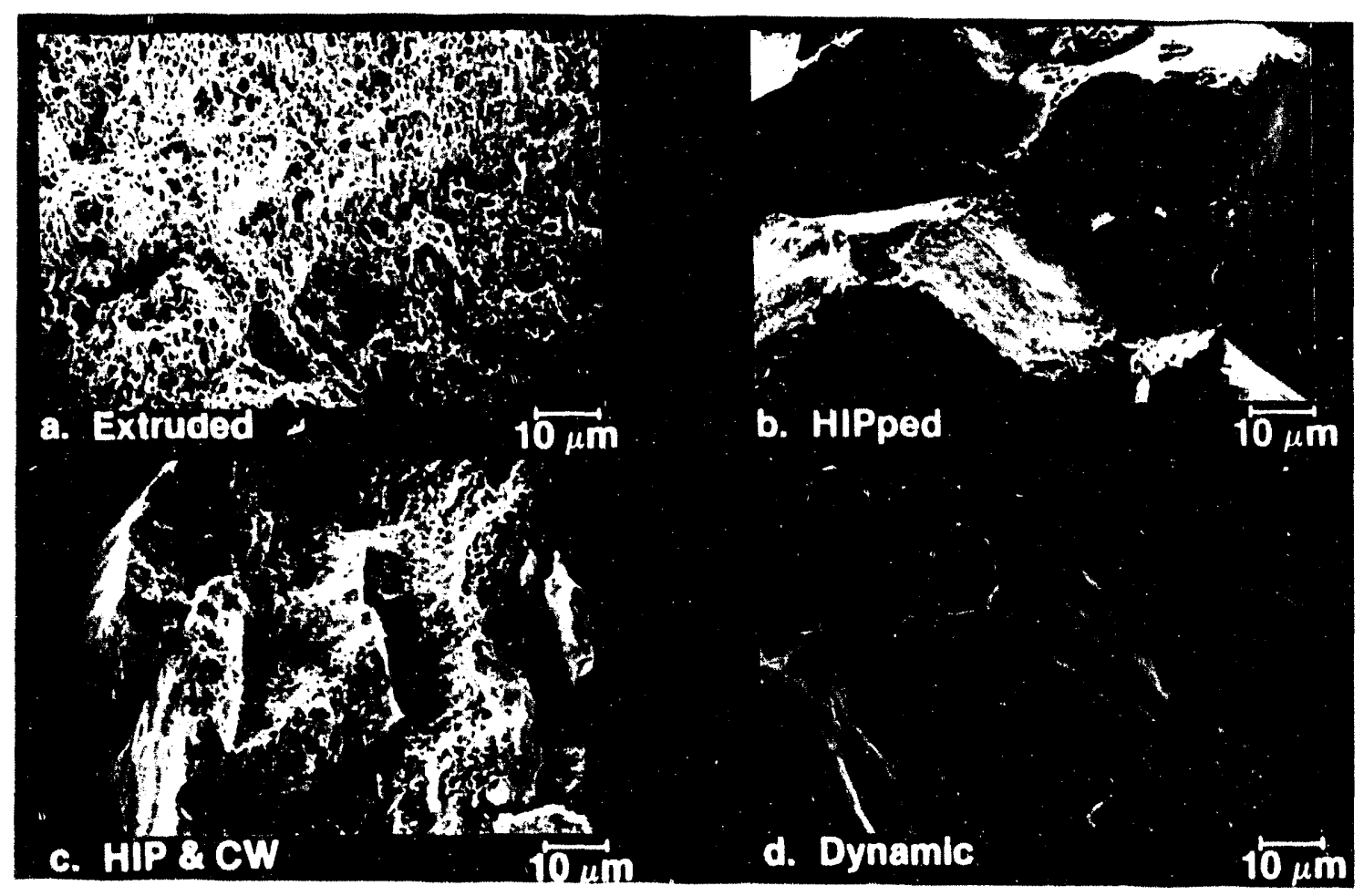

Figure 36. Fracture surfaces of failed tensile specimens for CA Type 304 SS powders consolidated by different methods. 
deformation regions between the shock-hardened particles. The dynamically consolidated powder material displays good bond strength, particularly because the load bearing regions undergoing plastic deformation represent a very small portion of the bulk specimen. The results in Table 3 show that the shockhardening is nearly comparable to that of the HIPped powder after cold rolling $50 \%$.

\section{Some Issues Associated With Consolidation of RSP Powders}

The powder consolidation studies focused primarily on the particle deformation, interaction, and bonding behavior of the RSP iron-base alloy powders. The consolidation parameters were selected to produce fully dense (i.e., no porosity) monolithic forms, with good bond strengt.hs between particles, that were suitable for microstructural and mechanical properties evaluations. No attempt was made to evaluate pressureless sintering or nearnet-shape forming of the powders. Sintering to full density would require very high temperatures, i.e., $\geq 0.9 \mathrm{~T}_{\mathrm{m}}$, which could erase any benefits associated with RSP. Near-net-shape consolidation of the powders is very important economically and will require considerable attention for industrial utilization of the RSP technology. As described later in this chapter, significant improvements in properties and performance can be realized from RSP. It is recognized that significantly higher costs appear to be associated with RSP and powder consolidation and that further effort is required to reduce such processing costs. An important factor in cost issues is the "price-for-performance," which can only be determined by the user. 


\section{JOINING OF CONSOLIDATED RSP POWDERS}

Although weldability of rapidly solidified materials has received little attention, it is important because even with near-net-shape consolidation of powders joining may be required to fabricate large or complex components. However, processes that involve melting and resolidification, and their thermomechanical influence, can be expected to affect the unique properties derived from RSP. It is reasonable to assume that a useful guideline for joining RSP materials would be to choose processes that do not significantly exceed the thermomechanical cycles associated with powder consolidation. It is evident from the previous section that powder consolidation processes are indeed joining on the particle scale. For welding, the heat-affected zone (HAZ) thermal cycles should not significantly exceed those required for particle consolidation, and the fusion zone, if any, should resolidify in the RSP regime. This would, in principle, retain the benefits from RSP of the powders.

A fairly extensive study has been performed on joining consolidated ironbase RSP powders. ${ }^{30,31}$ Test specimens of extrusion consolidated CA Type 304 SS powders were used. Five welding processes were evaluated: (a) gas tungsten arc (GTA), (b) capacitor discharge, (c) electron beam, (d) inertia or friction, and (e) explosive joining. GTA welding was chosen as a baseline process because it is well understood, though it is atypical of RSP and could significantly alter the RSP characteristics.

\section{GTA Welding}

The GTA welding tests were performed on CA Type 304 SS extruded powders using spot welds. ${ }^{32}$ For these tests, the cladding (can) material, which was also Type $304 \mathrm{SS}$, was not removed. This configuration permitted spot weld evaluations for the conventionally processed as well as RSP Type 304 SS materials from a single test specimen. Most of the tests were performed at currents of 50 to $100 \mathrm{~A}$ and for durations of 1 to $10 \mathrm{~s}$. The major features of the CA Type 304 SS weldments were a large amount of porosity in the fusion zone (Figure 37 ) and very fine grain size (i.e., no grain growth) in the heataffected zone. The porosity was attributable to helium, which was entrained 
during the powder acomization and retained during powder consolidation (e.g., see figure 35). The resistance to grain growth in the HAZ is evident in Figure 38 [this photomicrograph shows an overlap of the spot weid onto the Type 304 SS can material (area on right)]. The GiA spot weld tests show that porosity from entrained helium is a major concern, more so than the retention of fine microstructures. As a result, techniques that suppress bubble growth should be used for the noble gas containing materials.

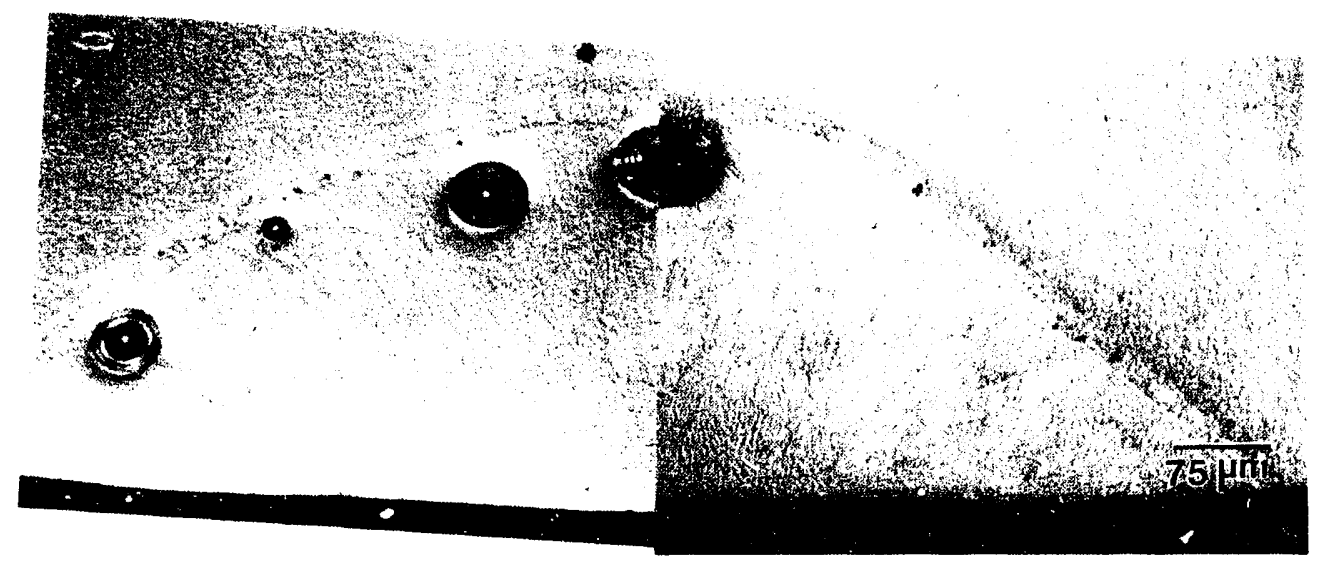

Figure 37. GTA spot weld on CA Type 304 SS extruded powder containing $~ 8$ appm entrained helium and showing porosity in fusion zone.

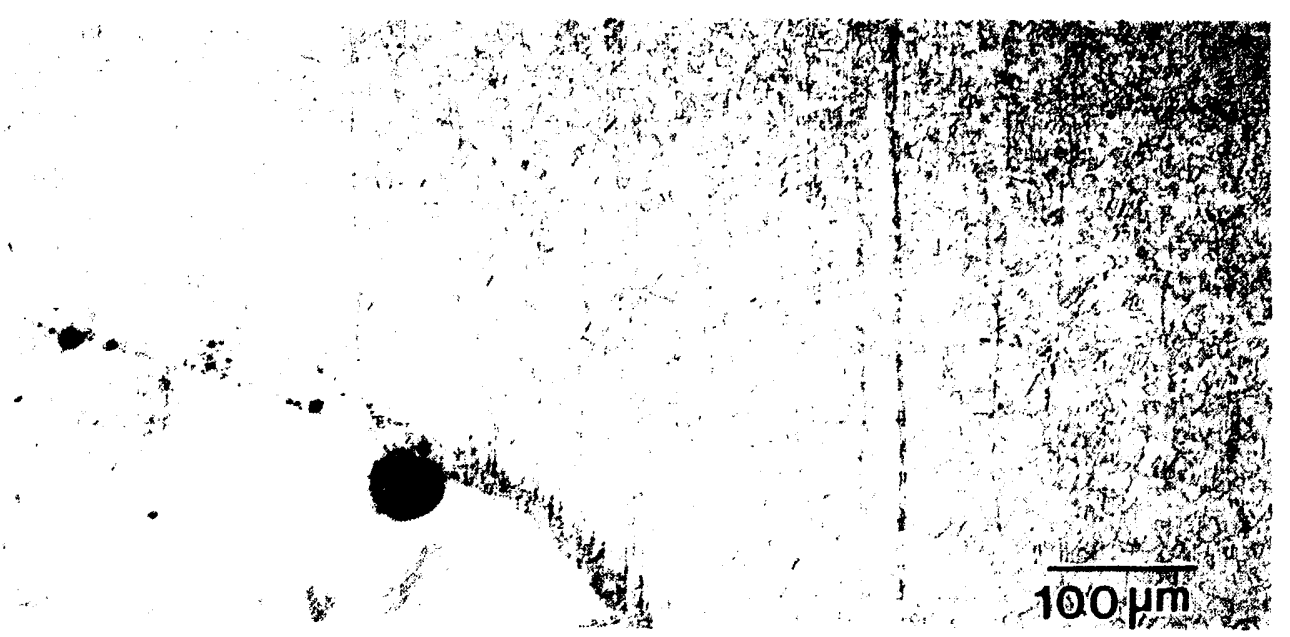

Figure 38. Grain behavior in HAZ for CA Type 304 SS extruded powder (upper left) and conventionally processed Type 304 SS cladding (right). 


\section{Capacitor Discharge Welding}

The capacitor discharge (CD) joining process appears attractive for RSP metals because its welding times are very short. In this process, the pieces are connected across a large capacitor after vertical alignment; a schematic of the process is shown in Figure 39. Key variables include the voltage, capacitance, drop height, drop weight, ignition tip geometry, and weld-face geometry. ${ }^{33-35}$ The cooling rate is primarily controlled with the ignition tip length and diameter, drop height, and the drop weight, e.g., faster cooling rates were obtained with a shorter ignition tip and higher drop heights and weights. During this process, some molten metal expulsion occurs, eliminating surface contamination (e.g., oxide films) on the workpiece.

A CD weld cross section is shown in Figure 40a for CA and HIPped Type 304 SS. This was a high cooling rate weld, and the weld extends uniformly (in thickness) across the entire diameter of the specimen without evidence of flaws near or at the bond line. The weld has a very fine cellular microstructure, with cellular growth being more towards the axis of contact than radially. There is little evidence of a heat-affected zone for this process. The bond strengths and ductility associated with the CD welds were reasonably good, but lower than those of the base metal. ${ }^{33}$

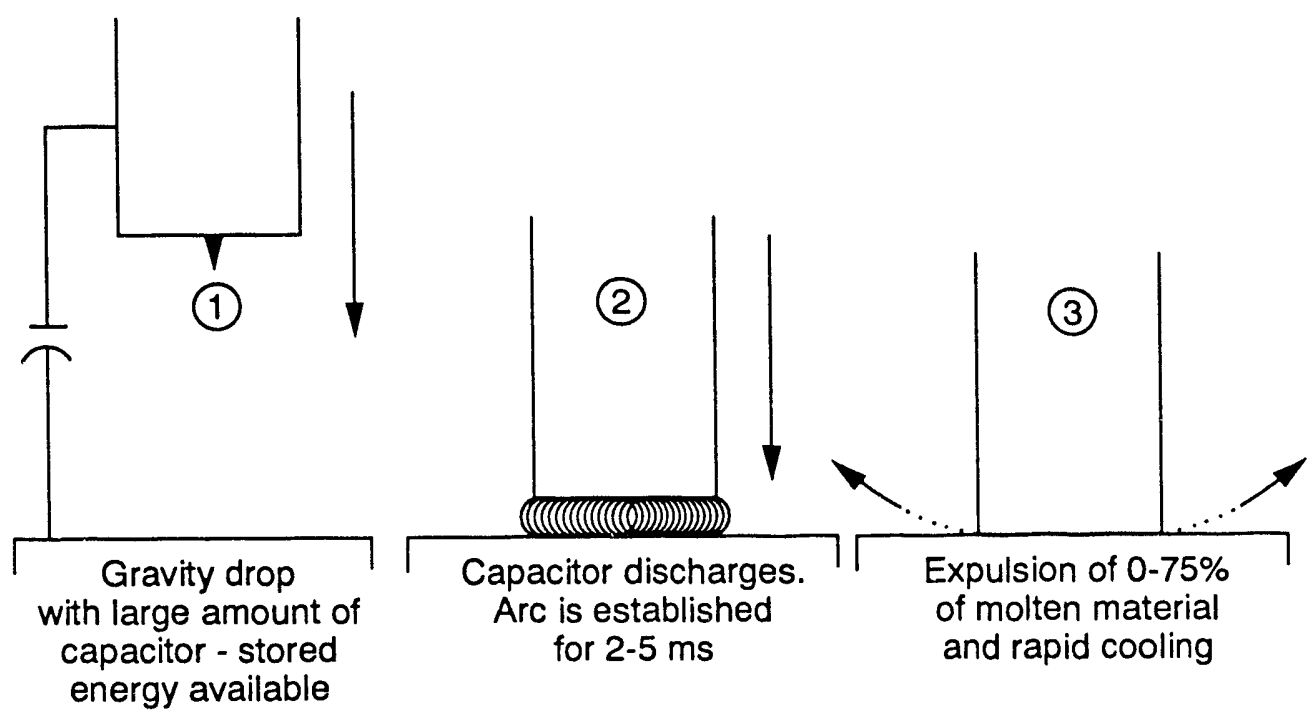

N91 0057

Figure 39. Schematic of capacitor discharge joining. 


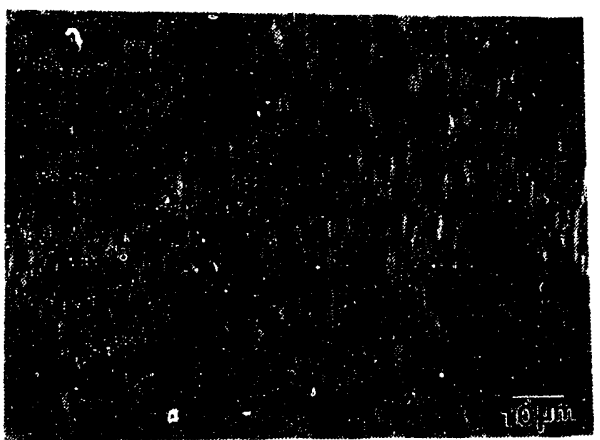

(a) At bond interface of capacitor discharge

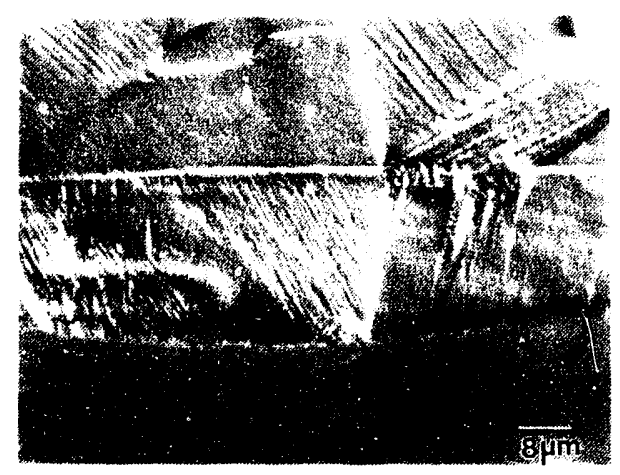

(b) Electron beam weld

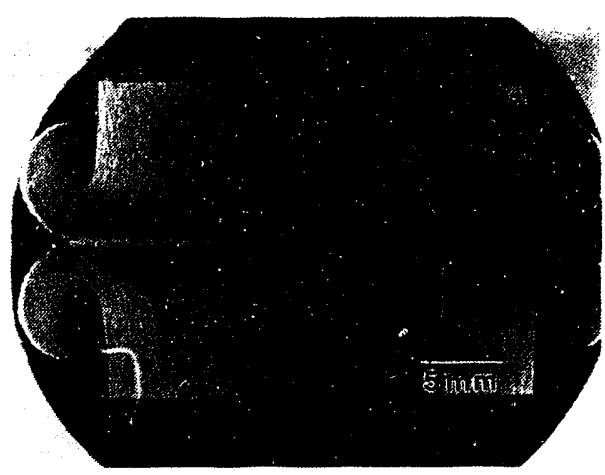

(c) Cross section intertia

Figure 40. Microstructure of CA Type 304 SS extruded powder after joining.

The CD joining process is fairly limited in terms of geometry. It is commonly used for joining studs onto plates. For structural RSP alloy applications, some use could be made of the CD process. An important finding from the CD study was that the fine microstructure is retained along the bond line. .33-35 $^{-30}$

\section{Electron Beam Welding}

Electron beam (EB) welding is a potentially attractive process for joining RSP alloys because of its high energy density and short interaction times. These two features can promote rapid solidification along the weld line. This process can produce a wide range of melt depth-to-width ratios, and is suitable for producing 1 inear joints or even surface modifications, e.g., glazing. The ER test welds produced a cellular solidification microstructure, as shown in Figure 40b. The cell spacing is very small, 
indicating that the solidification rate is very high. As with the CD process, there is no evidence of a HAZ region; however, there does appear to be some evidence of microporosity in the weld region. This porosity is believed to be caused by the helium entrained in the consolidated CA Type 304 SS powders.

\section{Inertia or Friction Welding}

Friction welding is a solid siate process that virtually eliminates the fusion zone and corresponding solidification. For this process, one of the workpieces to be $\mathrm{i}$ ined is held in the center of a flywheel and rotated at up to several thousand rpm. The flywheel and the workpiece are disconnected from the motor and the stationary workpiece is mechanically forced into the spinning one. The weld is made as the flywheel energy is dissipated, which occurs in a matter of a few seconds. For this process, a small volume of material is expelled as flash along with any surface contamination along the joint interface. A macroview of a friction weld performed on a bar specimen of CA Type 304 SS extruded powder is shown in Figure 40c. The weld had little effect on the grain size in the axial and radial directions. Some small voids/bubbles (<l $\mu \mathrm{m}$ in diameter) observed in the outer regions of the bond interface may be the result of the helium entrained in this RSP alloy. Bond strengths for this joining process were high and failures during tensile tests occurred outside of the weld interface. ${ }^{36}$

\section{Explosive Joining}

Explosive joining is similar to the dynamic consolidation of powders and also to inertia welding where friction assists in the solid state bonding. Although the mechanical deformation or "shock hardening" for this process can be quite high, the thermal effects can be quite small. The process uses explosives to propel one of the workpieces and create a rapidly moving angular contact with the other workpiece. A fluid jet from the intense friction at the apex cleans the surfaces and produces an undulating interlocking at the interface. Explosive joining offers considerably more flexibility in terms of joining configurations, sizes, etc., than the welding methods described previousiy. Expiosive joining studies have been performed on CA Type 304 SS consolidated powders for two configurations: plate-to-plate and RSP tubes to 
a header plate of conventionally processed Type 304 SS. $^{31}$ The test configurations for the two types of welds are shown in Figure 41. The weld interface for the plate-to-plate explosive weld is shown in Figure 42; the
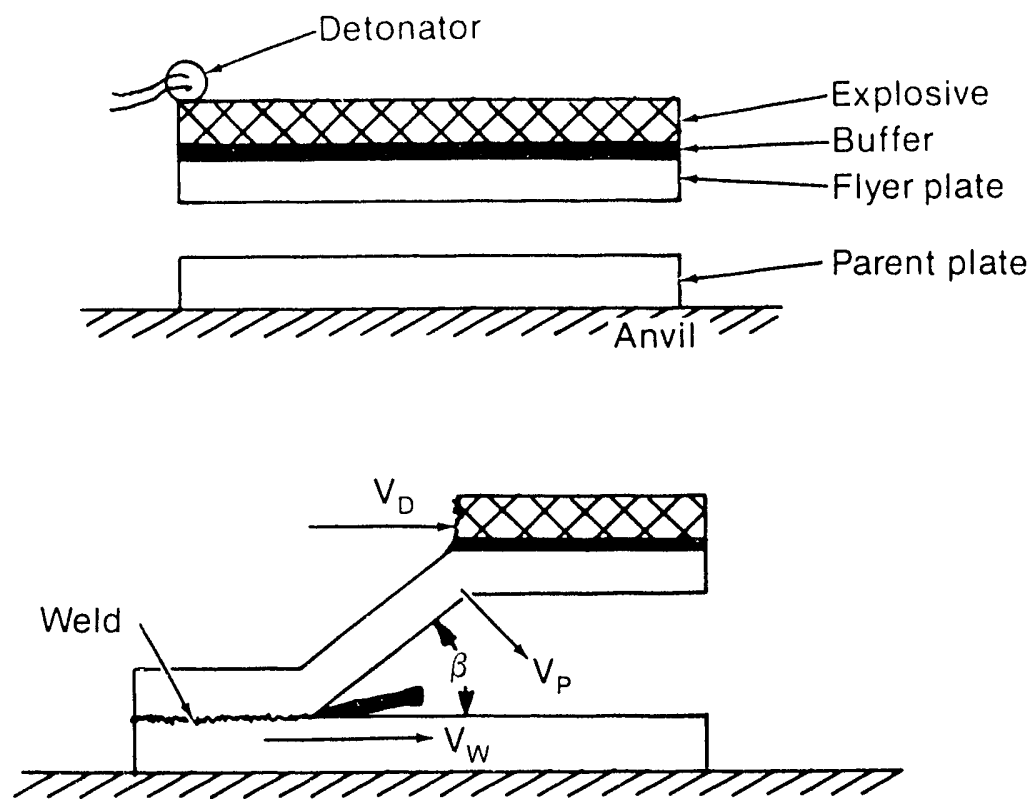

Plate to plate cladding weld
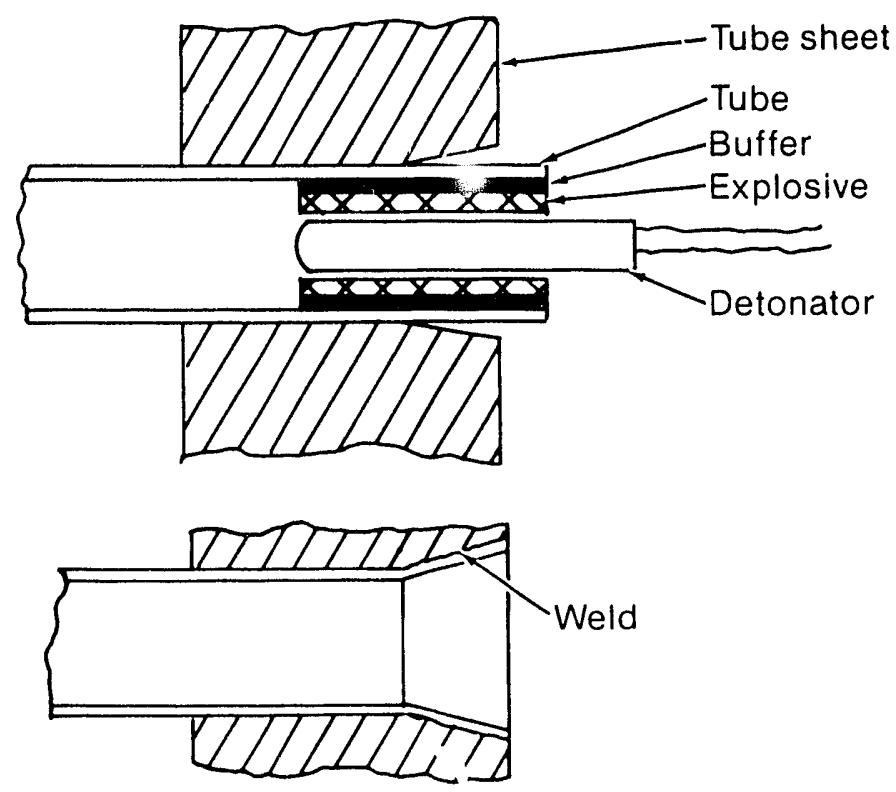

Cylindrical tube to tube sheet weld

Figure 4l. Test configurations for plate-lo-plate (ciaduing) and tube-to-tube sheet welds using explosives. 
undulating bond line is evident. The bond strength of the explosive welds for the plate-to-plate configuration was determined to be quite good - failure occurred in the base material and not along the bond line. The tube-sheet-toheader joining was also quite successful. A macro cross section of the test piece after explosive joining is shown in Figure 43.

\section{Issues Associated with Joining of RSP Iron-Base Alloys}

The joining studies just described for the CA Type 304 SS consolidated powders illustrate that there are techniques that can be used to join RSP iron-base alloys. These techniques are primarily associated with solid state bonding processes where the development of fusion zones during joining is kept to a minimum. For RSP alloys that contain significant levels of entrained

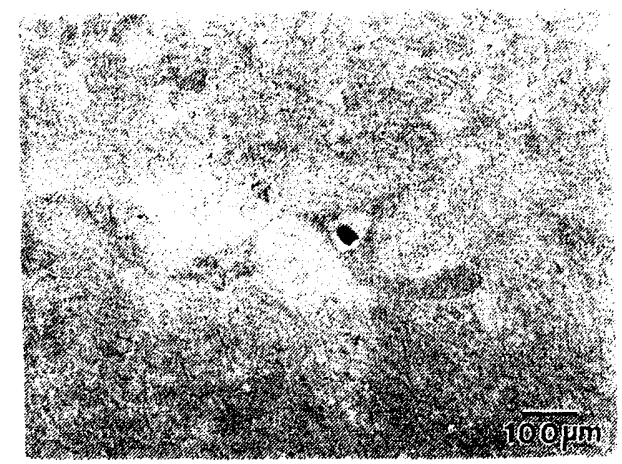

Figure 42. Bond region of plate-to-plate joint, made using explosives, in CA Type 304 SS consolidated powder.
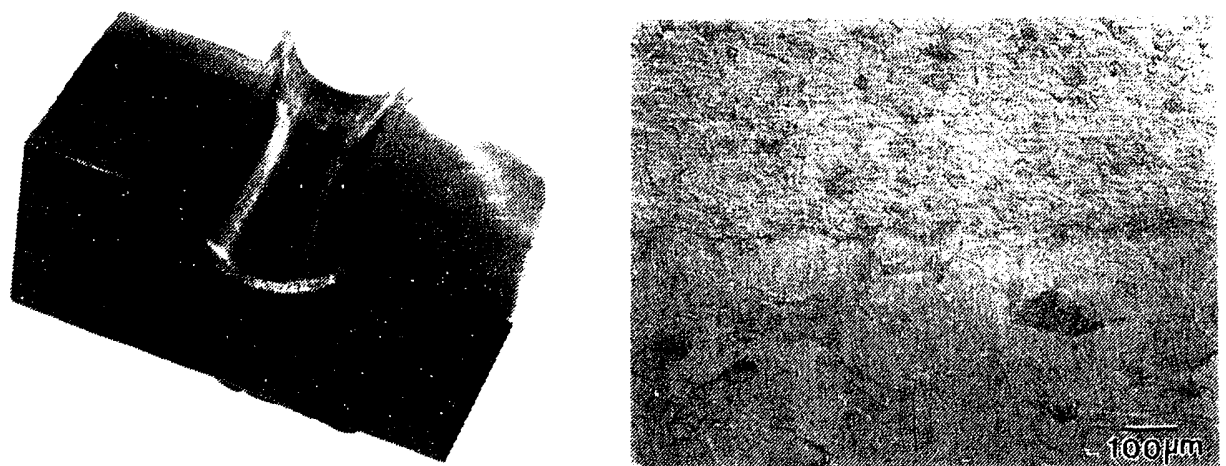

Figure 43. CA Type 304 SS tube explosively joined to a conventionally processed header; macro cross section (left) and micro view of bond region (right). 
noble gases, porosity development in the fusion zone can erase any potential benefits from rapid solidification if these zones are not rapidiy cooled. Although the joining studies indicate that effective joints between RSP materials can be achieved, additional studies are needed, particularly in terms of establishing economical production techniques. Such production studies must first identify a component or part produced from RSP powder that requires joining. It is quite possible that one of the solid state techniques described earlier could be used for production joining. 


\section{CHARACTERIZATION OF CONSOLIDATED RSP POWDERS}

The information presented so far has primarily covered the processing aspects associated with RSP of iron-base alloys. At this juncture there is little evidence of benefit from RSP aside from the fine grain size that remains after thermal-mechanical processing, including welding. Characterization of the consolidated RSP iron-base alloy powders, particularly after conventional heat treatments, and comparison with their conventionally processed counterparts (CPCS) should establish the potential of RSP to produce alloys with significant improvements in properties and performance. Furthermore, the microstructural development and properties (primarily mechanical) of the RSP consolidated iron-base alloys should indicate which processing parameters are important and can be controlled to improve alloy properties and performance. A database on the behavior of RSP consolidated iron-base alloys has been developed that is sufficient to enable the potential of this technology to be realized. These results will be summarized in this section.

\section{Evaluation of Particle Surface Films}

During powder atomization, surface films develop on the particles. Earlier, it was shown that the surface films are predominantly oxides for the iron-base alloy powders. A recent study of consolidated powders has provided some valuable insight on the surface films, particularly regarding the oxygen association. ${ }^{37}$ Powders of six stainless steels were processed by inert gas atomization, sieved into size fractions, and consolidated by hot extrusion. Analysis of the compositions of the consolidated powders and the melt stock material from which they were processed showed no evidence of compositional differences except for oxygen and, in some cases, nitrogen. Carbon levels appeared to be unaffected by powder processing. The oxygen content increased with decreasing particle size as shown in Figure 44.

The total oxygen content consists of contributions from the oxide films on the particles from powder processing and the oxygen entrained inside the particles. A rather simple model can be used to determine the contributions 


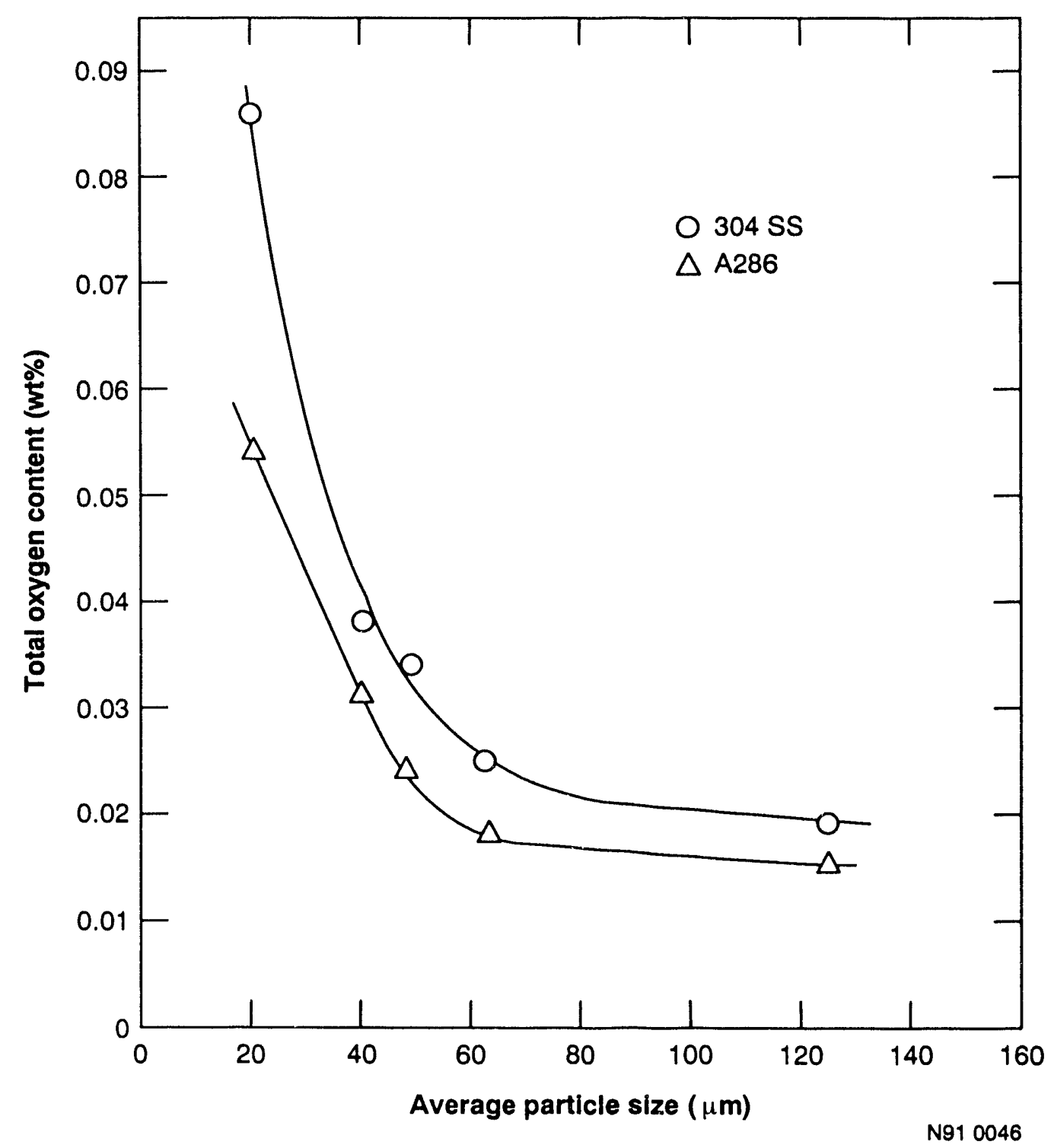

Figure 44. Influence of powder particle size on oxygen content for IGA A286 and Type 304 SS after consolidation.

to the total oxygen content from the films and particle interiors. ${ }^{37}$ This relationship is as follows:

$$
\left(O_{2}\right)_{T}=6(R \times 100)\left(\rho_{f} / \rho_{p}\right)(t / D)+I
$$

where $\left(0_{2}\right)_{T}$ is the total oxygen concentration in wt\%, R is the weight fraction of oxygen in the film, $\rho_{f}$ is the film density, $\rho_{p}$ is the particle density, $t$ is the oxide film thickness, $D$ is the average particle diameter, and $I$ is the weight fraction of entrained oxygen inside the particles. For the derivation of this expression, it was assumed that $D \gg t$. Because the total oxygen 
content is proportional to $1 / D$ (i.e., reciprocal of the particle diameter), a linear relation is expected if the oxide film thickness $(t)$ is constant. Some of the experimental observations are shown in Figure 45 for the IGA extrusion consolidated iron-base alloy powders. The results show the validity of the model and, furthermore, indicate that (1) the oxide film thickness is independent of particle size and (2) the residual oxygen entrained inside the particles is equivalent to the amount contained in the melt stock material. It should be noted that for some of the alloys (see Figure 45 top and center), there may be a deviation from linearity with the small particle sizes. The data points shown actually represent a range of the screened powder fractions used for consolidation. For example, the particle size of $20 \mu \mathrm{m}$ shown in Figures 44 and 45 is the midpoint of the screen fraction of $>10$ to $<30 \mu \mathrm{m}$. If this fraction contained a higher proportion of particles less than $20 \mu \mathrm{m}$, the oxygen content would actually be that of a smaller particle size. This could explain the apparent deviation from constant oxide film thickness shown in Figure 45 for the $20 \mu \mathrm{m}$ particle size of the Type $304 \mathrm{SS}$ and $\mathrm{Fe}-16 \mathrm{Ni}-9 \mathrm{Cr}$ extruded powders.

The IGA processing parameters for the stainless steel powders were very similar. For each alloy, the powders used for extrusion consolidation were screened from four to six atomization runs. Prior to each run the chamber was evacuated and backfilled with argon three to four times before atomizing the melt stream with helium. The film thickness was independent of particle size (constant) but dependent on the alloy. A correlation was observed between the nickel content and the oxide film thickness (see Figure 46). The calculated oxide film thicknesses were based on the assumption that the film was $\mathrm{Fe}_{2} \mathrm{O}_{3}$. As noted earlier in the discussion of Auger sputtering measurements, iron appears to be a major constituent of the oxide films on the particles. There appeared to be no consistent correlation with any other chemical constituent in the alloys, e.g., $\mathrm{Fe}, \mathrm{Cr}, \mathrm{Mn}, \mathrm{C}, \mathrm{Si}$.

The second important feature observed in this oxygen study is the apparent oxygen content in the particle interiors. This is represented by the intercept $(1 / D=0)$ shown in Figure 45 , and corresponds to the oxygen content of the melt stock material. To reduce the amount of oxygen entrained inside the particles, strong deoxidizers such as $\mathrm{Al}, \mathrm{Ti}$, and $\mathrm{Si}$ must be added to the 


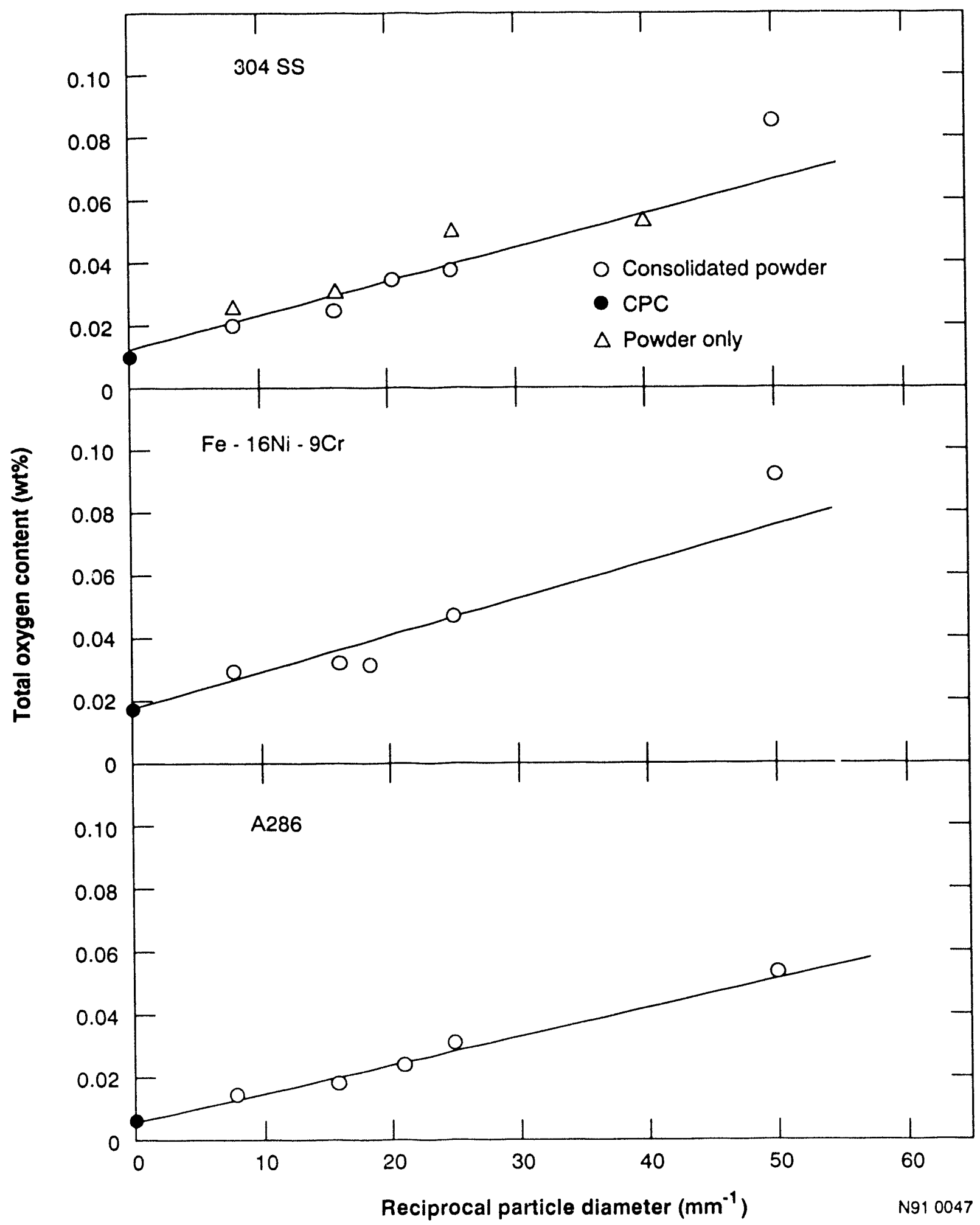

Figure 45. Influence of reciprocal particle diameter on total oxygen content for IGA processed stainless steels. 


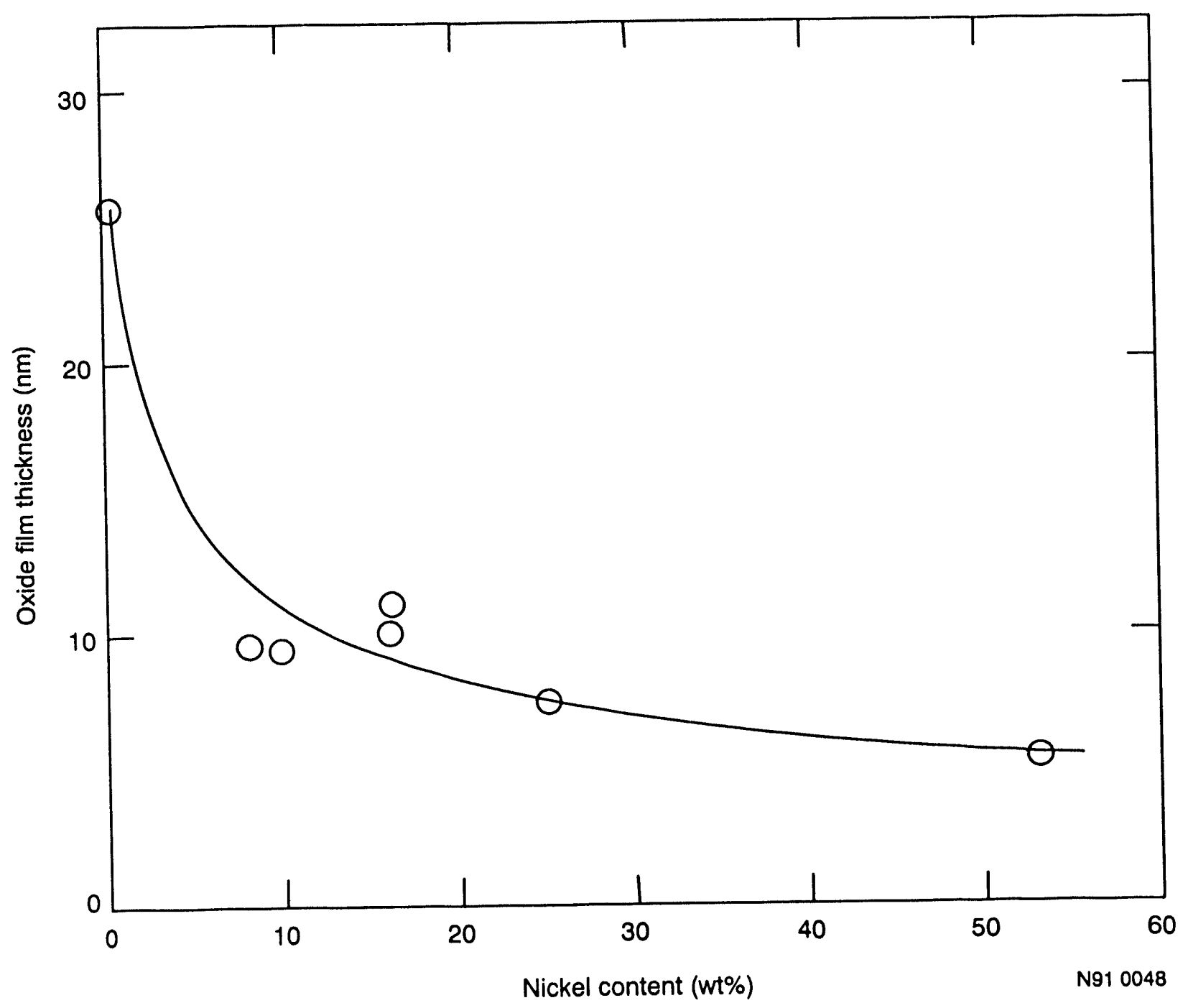

Figure 46. Influence of alloy nickel content on oxide film thickness for IGA powders.

melt. Conversely, in order to achieve relatively high levels of solubilized (i.e., dissociated) oxygen in the melt, the concentration of strong deoxidizers has to be very small. It will become evident later in this section that the dissociated oxygen can be very important for microstructure stabilization.

\section{Entrained Noble Gases and Porosity}

The powders, when atomized in the presence of noble gases, can entrain significant levels of the gas. It was shown earlier (see Figures 18-22) that several atomic parts per million (appm) of the noble gases are commonly entrained in the powders. These gases cannot be degassed from the powders 
without subjecting them to melting point temperatures. The solubility of the noble gases in iron-base alloys is very $10 \mathrm{w} ;^{16}$ therefore, levels in the appm range mean that the gases are entrained primarily as porosity. Thermalmechanical processing of the powders, such as consolidation, greatly reduces the size of the gas bubbles and increases their pressure. These bubbles would be expected to grow when exposed to temperatures that approach the alloy's melting point. It was shown earlier that bubbles can become quite large in GTA welding fusion zones (see Figure 37). The swelling/porosity behavior of several of the consolidated RSP iron-base alloy powders was examined after the specimens had been exposed for $1 \mathrm{~h}$ to temperatures up to $0.97 \mathrm{~T}_{\mathrm{m}}(38)$. These results are summarized below, along with some discussion of their implications for the properties and performance of the alloys.

Noble gas analyses have been performed on particles and consolidated powders of iron-based alloys processed with noble gases. There is no evidence that the noble gas content is affected by consolidation. A random selection of noble gas measurements on the alloys studied, before and after powder consolidation, is plotted in Figure 47; the consolidated specimens received $1 \mathrm{~h}$ exposures to $0.97 \mathrm{~T}_{\mathrm{m}}$. These measurements showed no evidence that noble gas was released during the heat treatment. ${ }^{38}$

After consolidation, several RSP iron-base alloys were machined into cylinders, heat treated for $1 \mathrm{~h}$ at various temperatures, and water quenched. The alloys and their noble gas contents are shown in Table 4 . After heat treating, immersion density measurements were performed; these results are shown in Figure 48 in terms of volume change (\%). It should be noted that the three alloys have nearly identical melting points, i.e., $-1450^{\circ} \mathrm{C}$, hence the nearly equivalent heat treating temperature and $T_{m}$ values. The most glaring aspect of the results is the "break-away" swelling of the CA Type 304 SS containing 8 appm of helium. The porosities of CA Type 304 SS after consolidation, by extrusion or HIPping, and high temperature heat treatments are shown in Figure 49; note that the shape of the bubbles is consistent with the consolidation deformation expected for spherical powders containing spherical gas-filled cavities. The CA Fe-40Ni alloy that contains 7.5 appm helium does not show break-away swelling after the 1300 and $1400^{\circ} \mathrm{C}$ heat 


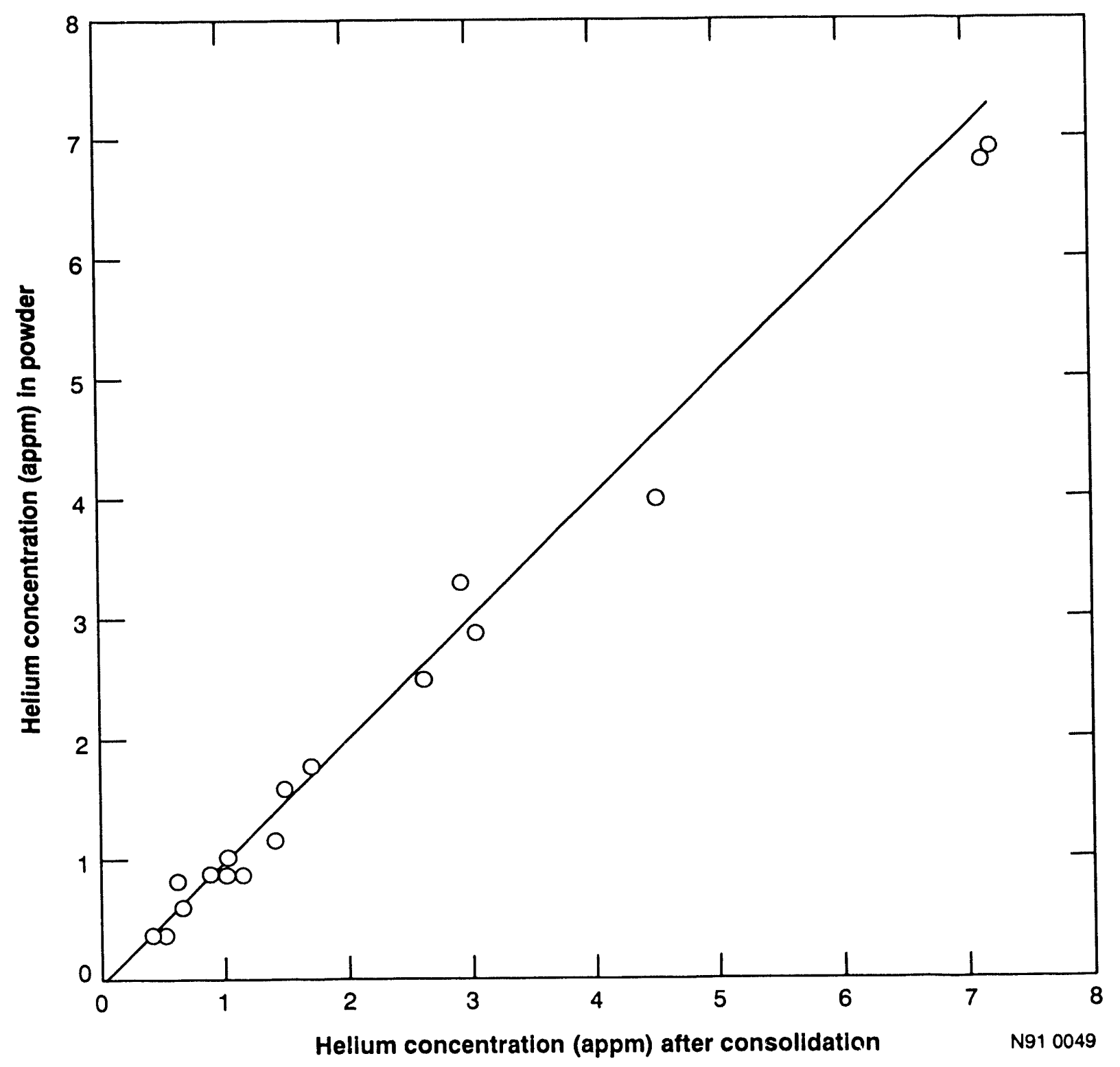

Figure 47. Noble gas contents of iron-base alloy powders before and after consolidation and exposure to $0.97 \mathrm{~T}_{\mathrm{m}}$ for $1 \mathrm{~h}$.

treatments. The IGA processed Type 304 SS extruded powder shows significant swelling at $1400^{\circ} \mathrm{C}$, with the specimen containing $1.8 \mathrm{appm}$ of helium having a volume increase of about a factor of two higher than the specimen with $1.2 \mathrm{appm}$ He.

The amount of swelling is small, and similar, for both the $\mathrm{Fe}-16 \mathrm{Ni}-9 \mathrm{Cr}$ with $3 \mathrm{appm} \mathrm{Ar}$ and the Fe-40Ni with $2.9 \mathrm{appm}$ helium. Even though the gas contents of these two specimens are larger than those of the IGA Type 304 SS 
Table 4. Iron-Base Alloys and Noble Gas Contents After Powder Consolidation

\begin{tabular}{|c|c|c|c|c|}
\hline \multirow[b]{2}{*}{ A $110 y$} & \multirow{2}{*}{$\begin{array}{c}\text { Median } \\
\text { Particle } \\
\text { Size }(\mu \mathrm{m})\end{array}$} & \multirow[b]{2}{*}{$\begin{array}{c}\text { Powder } \\
\text { Atomization }\end{array}$} & \multicolumn{2}{|c|}{ Noble Gas } \\
\hline & & & Type & $\begin{array}{l}\text { Amount } \\
\text { (appm) }\end{array}$ \\
\hline 304 SS & 80 & $C A$ & $\mathrm{He}$ & 8.0 \\
\hline 304 SS & 49 & IGA & $\mathrm{He}$ & 1.2 \\
\hline 304 SS & 125 & IGA & $\mathrm{He}$ & 1.8 \\
\hline $\mathrm{Fe}-16 \mathrm{Ni}-9 \mathrm{Cr}$ & 75 & VGA & $\mathrm{Ar}$ & 3.0 \\
\hline $\mathrm{Fe}-40 \mathrm{Ni}$ & 68 & $C A$ & $\mathrm{He}$ & 2.9 \\
\hline $\mathrm{Fe}-40 \mathrm{Ni}$ & 62 & $\mathrm{CA}$ & $\mathrm{He}$ & 7.5 \\
\hline
\end{tabular}

specimens, their swelling is significantly less than that of the IGA Type 304 SS specimen containing 1.2 appm helium.

An explanation for the sweiling behavior shown in Figure 48 can be deduced from the alloy structure at high temperatures. The CA Type 304 SS specimens show evidence that the alloy has entered into the ferrite (bcc) phase at temperatures $\geq 1300^{\circ} \mathrm{C}$, below which it is austenite. Evidence of ferrite around the austenite grains is shown in Figure 50 for the extruded and HIPped specimens after the 1300 and $1400^{\circ} \mathrm{C}$ heat treatments. Similarly, the IGA processed Type 304 SS extruded powders contained ferrite after the $1400^{\circ} \mathrm{C}$ heat treatment; however, after treatment at $1300^{\circ} \mathrm{C}$, the specimens appeared to be totally auster,te. The VGA Fe-16Ni-9Cr and the two CA Fe-40Ni alloys retained the austenite or $\mathrm{fcc}$ structure through the $1400^{\circ} \mathrm{C}$ h at treatment.

Another feature of the alloys that may influence the swelling is grain size. The austenitic alloys, $\mathrm{Fe}-16 \mathrm{Ni}-9 \mathrm{Cr}$ and $\mathrm{Fe}-40 \mathrm{Ni}$, showed marked grain growth at temperatures $>1200^{\circ} \mathrm{C}$ and small grain size $(\leq 20 \mu \mathrm{m})$ at temperatures $\leq 1200^{\circ} \mathrm{C}$. The Type 304 SS materials exhibit a fine grain size to $1200^{\circ} \mathrm{C}$; however, the IGA processed material shows marked grain growth at $1300^{\circ} \mathrm{C}$, but refined grains at $1400^{\circ} \mathrm{C}$. The CA Type 304 SS shows considerable grain growth retardation to $1400^{\circ} \mathrm{C}$. The grain growth retardation is attributed to ferrite phase formation at the grain boundaries as shown in Figure 50 . 


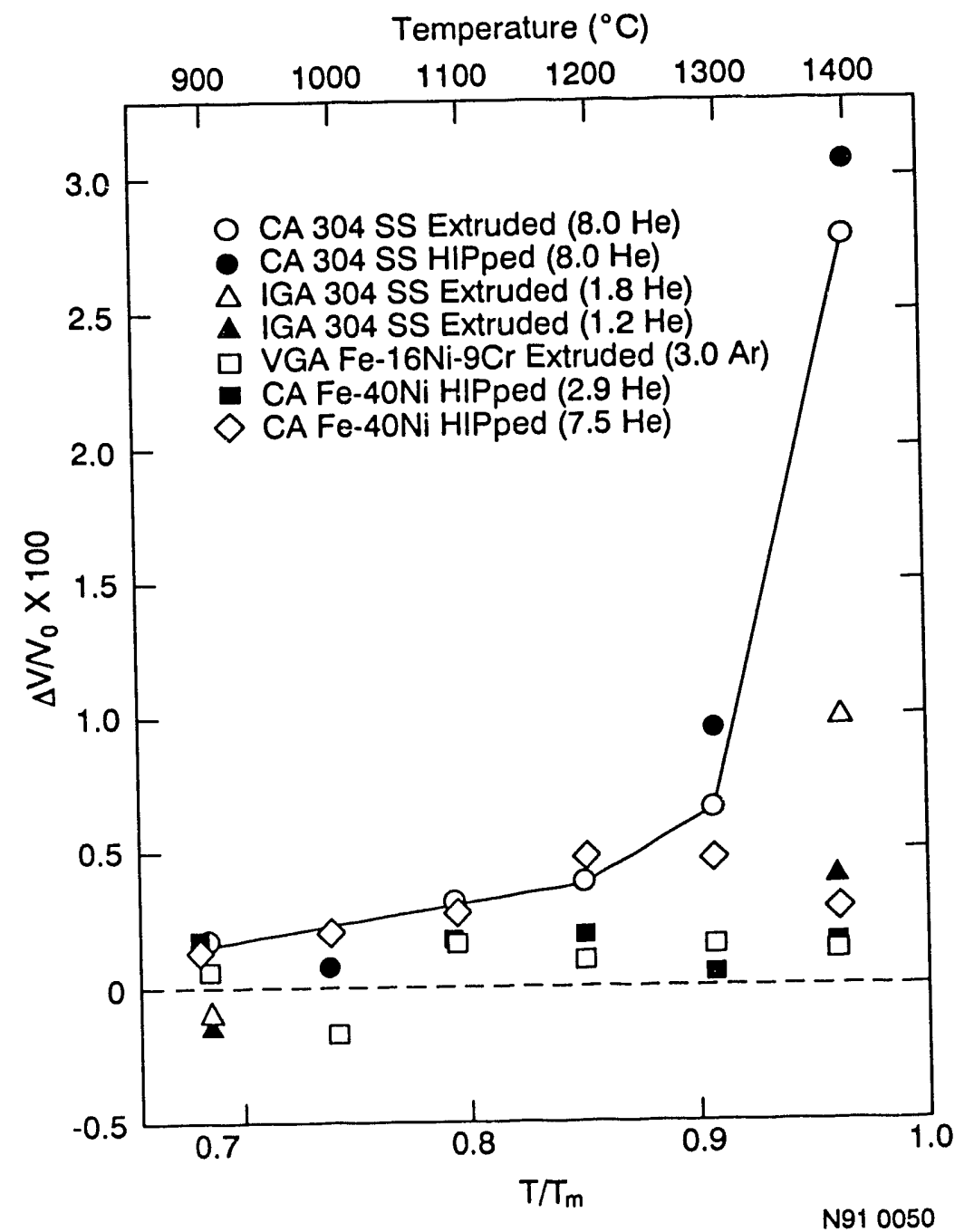

Figure 48. Volume increase arter $1 \mathrm{~h}$ heat treatment for RSP consolidated iron-base alloy powders containing noble gases.

The swelling can be explained by a density decrease or bubble growth (volume increase) due to Nabarro-Herring/Coble $(\mathrm{N}-\mathrm{H} / \mathrm{C})$ creep from the pressurized bubbles. ${ }^{39,40}$ Helle et al. proposed a combined $(\mathrm{N}-\mathrm{H} / \mathrm{C})$ expression for high temperature densification that results from hot isostatic pressing. ${ }^{23}$ This relation, which appears to be applicable to swelling/bubble growth, is given by

$$
\dot{\rho}=\frac{B \Omega}{k T \bar{d}^{2}}(\rho-1)\left[D_{v}+\frac{\pi \delta D_{b}}{\bar{d}}\right] P_{i}
$$




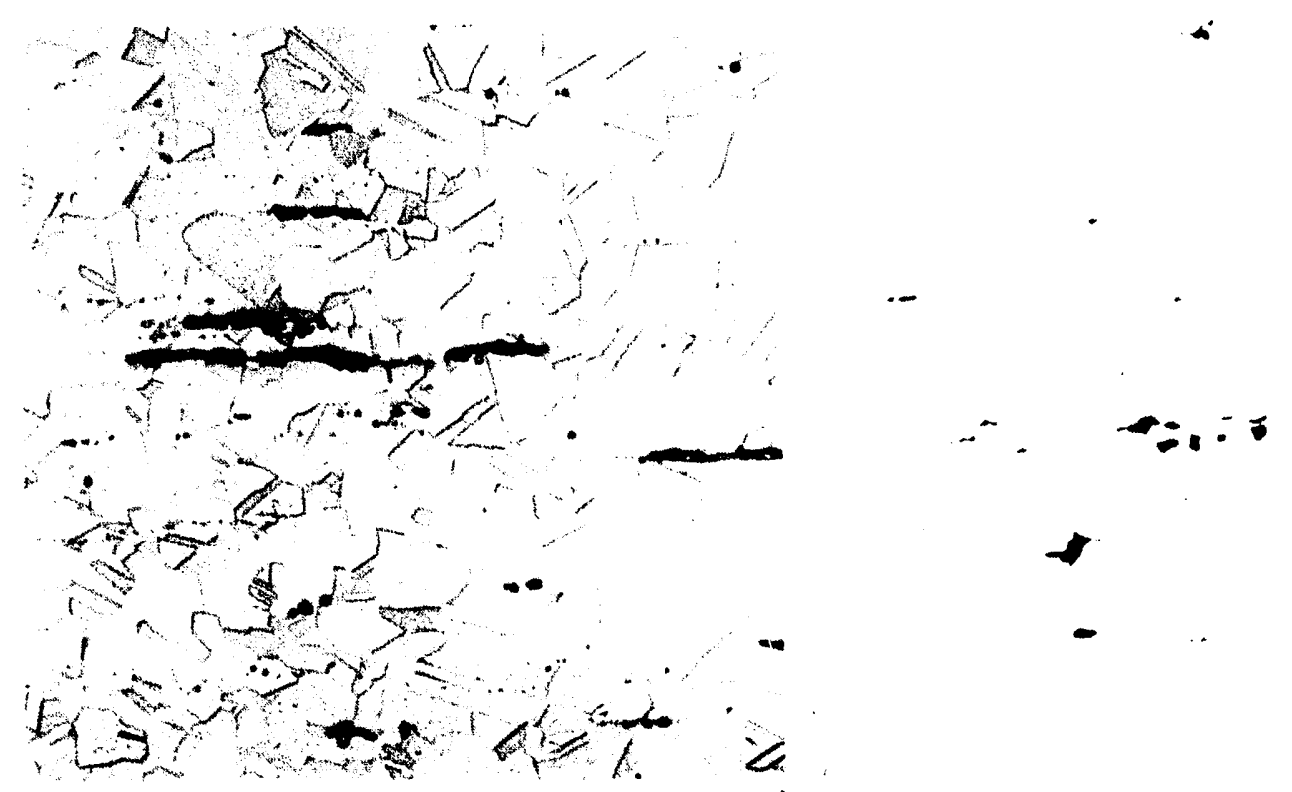
a.) $1200^{\circ} \mathrm{C}$
$40 \mu \mathrm{m}$ b.) $1300^{\circ} \mathrm{C}$
$100 \mu \mathrm{m}$

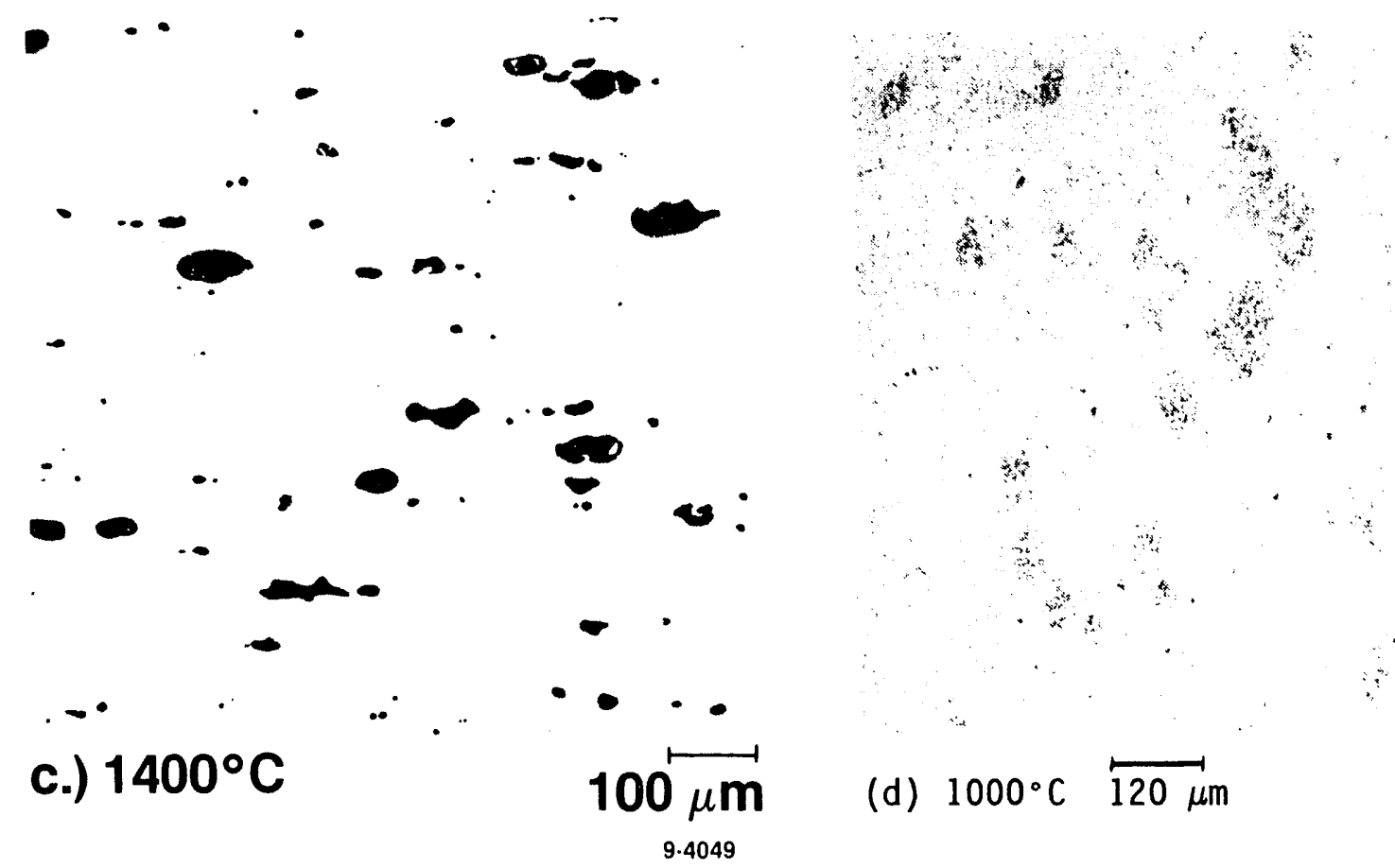

Figure 49. Porosity for CA Type 304 SS consolidated powder containing -8 appm of entrained helium after $1 \mathrm{~h}$ heat treatments. [ $(a-c)$ Extruded powder, (d-f) HIPped powder]

where $\dot{\rho}$ is the rate of density change, $B$ is a numerical constant, $\Omega$ is the atomic volume, $k$ is Boltzmann's constant, $T$ is the temperature $\left({ }^{\circ} \mathrm{K}\right), \bar{d}$ is the average grain size, $\rho$ is the relative density, $D_{v}$ is the volume diffusivity, $\delta$ is the grain boundary thickness, $D_{b}$ is the grain boundary diffusivity, and $P_{i}$ 

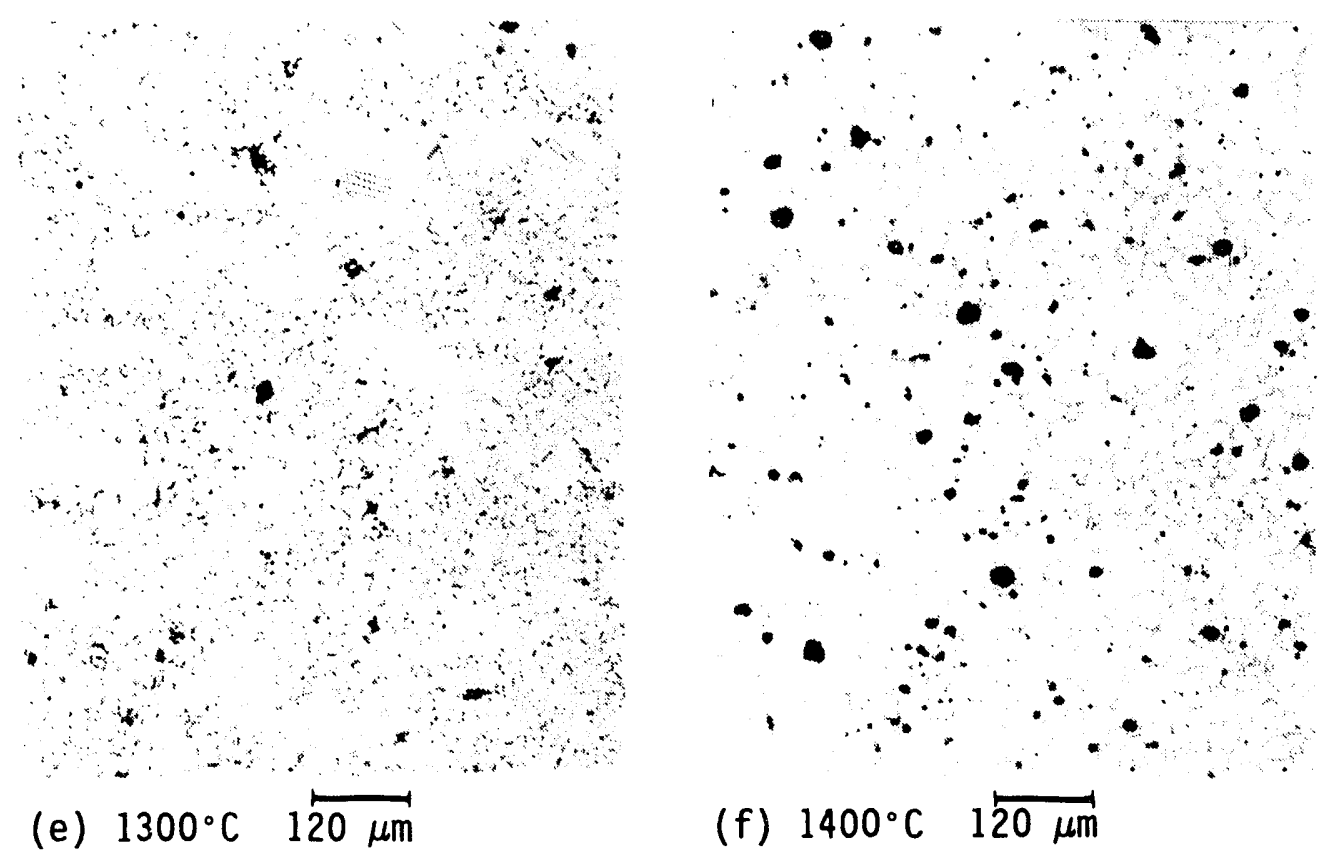

Figure 49. (Continued)

is the internal bubble pressure. Based on the microstructure and structural observations, the above $\mathrm{N}-\mathrm{H} / \mathrm{C}$ relation provides a qualitative explanation for the results shown in Figure 48 . Consider the behavior at $1400^{\circ} \mathrm{C}$ : the fine grain Type 304 SS specimens appear to be predominantly bcc and, because the diffusivities are substantially larger for bcc than $\mathrm{fcc}$, the combination of fine grain size and high diffusivities would promote high bubble growth rate (i.e., density change). The internal bubble pressure, $P_{i}$, depends on the noble gas content and, assuming equivalent microstructural/structure conditions, the increased swelling shown in Figure 48 for the IGA and CA Type 304 SS specimens with increasing helium content is consistent with the $\mathrm{N}$ $\mathrm{H} / \mathrm{C}$ model. The behavior of the chree austenitic ( $\mathrm{fcc}$ ) specimens (Fe-16Ni-9Cr and the two $\mathrm{Fe}-40 \mathrm{Ni}$ ) is also consistent with the model; at temperatures $\geq 1300^{\circ} \mathrm{C}$ they are large grained and the model predicts that the bubble growth would be low because of their large grain size and lower diffusivities.

Noble gases entrained in atomized powders can lead to significant porosity development after powder consolidation. Exposure of the consolidated powders to temperatures very near their melting point promotes significant bubble growth. Such high temperature exposures would be rare for iron-base structural alloys, except possibly during joining operations. The above study suggests that large grain size and retention of an fcc structure at high 

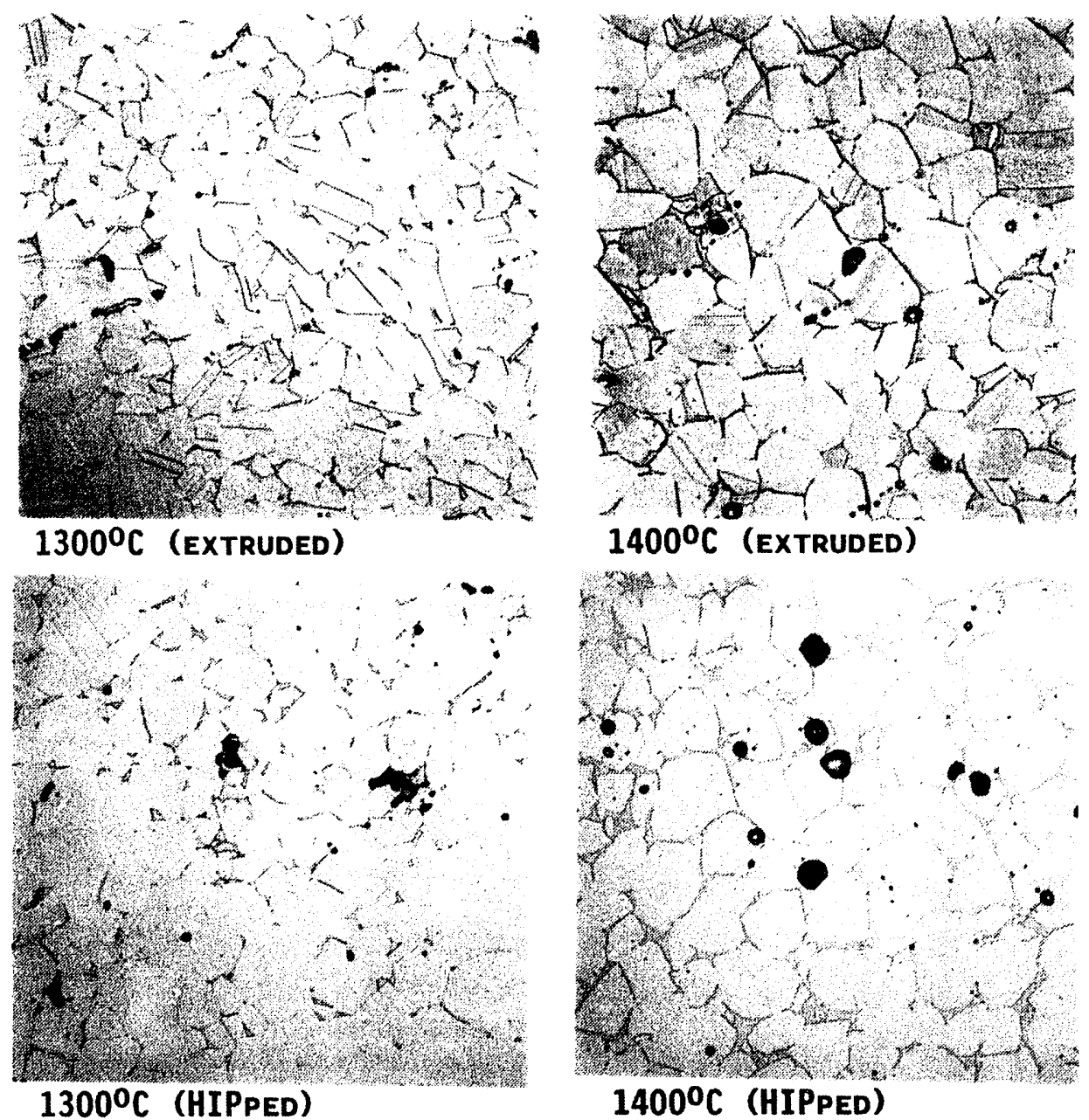

Figure 50. Ferrite formation around austenite grains after $1 \mathrm{~h}$ heat treatments for CA Type 304 SS consolidated powders.

temperatures will substantially reduce bubble growth. Also, use of smaller particle sizes will reduce the amount of entrained gas. The influences of the entrained noble gases on the properties of the alloy have not been given much consideration. It is important to note that they have no apparent effect on ductility, i.e., the noble gas is trapped in the bubbles and does not appear to migrate to the grain boundaries.

\section{Microstructure-Submicron Features}

In order to understand the effects and potential benefits from RSP, it is critical that a quantitative understanding of the microstructure be obtained, particularly the microstructure after thermal-mechanical exposures. For RSP to be effective, it must create very fine and stable microstructures 
in the alloys. An extensive effort has been devoted to understanding the microstructure of RSP iron-base alloys. The observations to date are providing a very significant insight into RSP and are revealing opportunities for using this processing approach to design iron-base alloys that will have substantial improvements in properties and performance.

This section will summarize the submicron microstructural features observed for several of the alloys shown in Table 1. The section to follow will address the grain size behavior. The submicron microstructural features were determined by extensive TEM/STEM examinations of consolidated and heat treated RSP alloys and their conventionally processed counterparts. The alloys that have undergone rigorous examinations are shown in Table 5. Examinations on some of the other alloys listed in Table 1 are in progress. The most complete microstructural database has been generated for Type 304 SS materials whose powders were processed by CA and IGA. The consolidated materials derived from the IGA powders also provide an opportunity to evaluate the effect of particle size on microstructural evolution and stability.

\section{Dislocation Behavior}

The TEM/STEM examinations have shown that RSP processing of Type 304 SS promotes very significant high temperature stabilization of dislocations. An example of the dislocation stability is shown in Figure 51 for the conventionally processed counterpart (CPC), CA Type 304 SS extruded powder, and IGA Type 304 SS extruded powders (two particle sizes, >30 to <50 and >100

Table 5. Quantitative TEM and STEM Examinations on RSP and CPC Alloys

\begin{tabular}{lll}
\hline Alloy & $\begin{array}{c}\text { Powder } \\
\text { Atomization }\end{array}$ & \multicolumn{1}{c}{$\begin{array}{c}\text { Consolidated Form } \\
\text { Type } 304\end{array}$} \\
CA & IGA & $\begin{array}{l}\text { Extruded } \\
\text { Extruded }\end{array}$ \\
$\mathrm{Fe}-16 \mathrm{Ni}-9 \mathrm{Cr}$ & VGA & Extruded \\
$\mathrm{Fe}-40 \mathrm{Ni}$ & $\mathrm{CA}$ & HIPped and cold worked \\
$\mathrm{Fe}-40 \mathrm{Ni}-0.3 \mathrm{Nb}-0.05 \mathrm{C}$ & $\mathrm{CA}$ & HIPped and cold worked \\
\hline
\end{tabular}




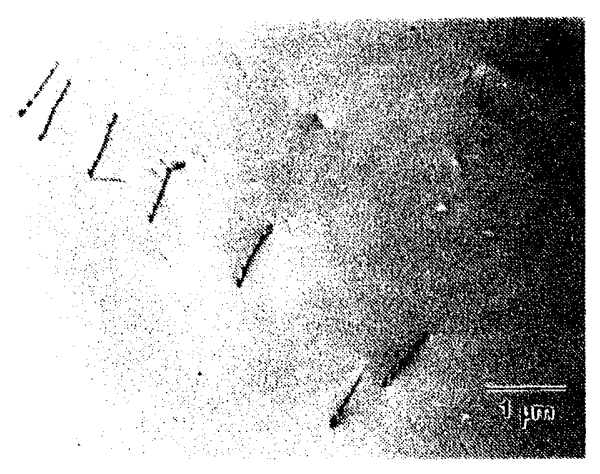

(a) CPC

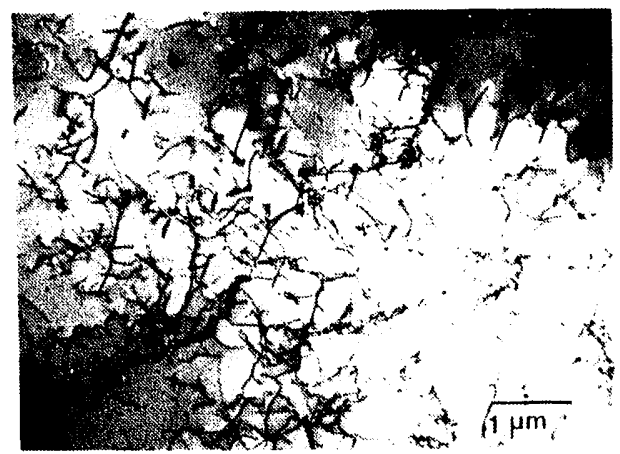

(c) Extruded IGA powder (30-50 $\mu \mathrm{m}$ particle size)

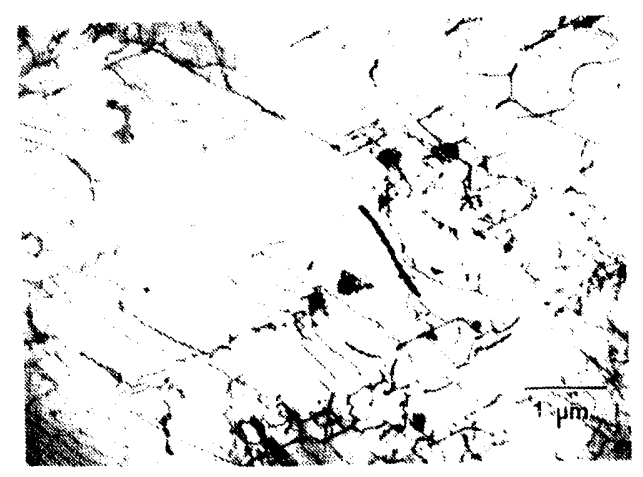

(b) Extruded CA powder

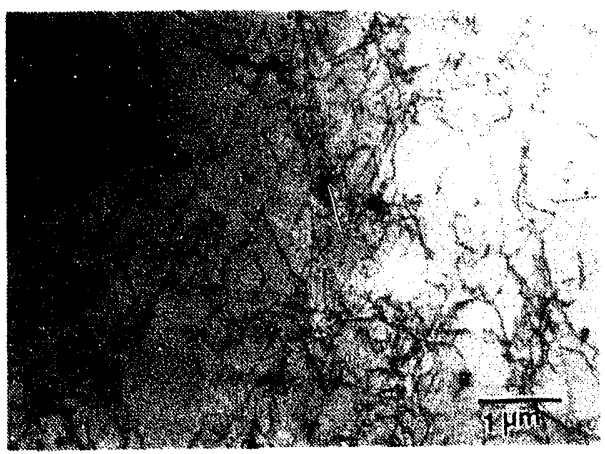

(d) Extruded IGA powder (100-150 $\mu \mathrm{m}$ particle size)

Figure 51. Dislocations (TEM) for Type 304 SS after $1 \mathrm{~h} 1100^{\circ} \mathrm{C}$ heat treatment.

to $<150 \mu \mathrm{m})$ after a $1 \mathrm{~h}$ heat treatment at $1100^{\circ} \mathrm{C}$. The influence of heat treatment temperature on the dislocation densities for the Type 304 SS materials is shown in Figure 52. The CA Type 304 SS extruded powder specimens show an apparent decrease in dislocation density with increasing temperature, but the dislocation density remains over a factor of 20 higher than that of the CPC material. The IGA processed Type 304 SS extruded powder ( $>30$ to $<50 \mu \mathrm{m})$ shown in Figure 52 exhibits a very high dislocation density, which is retained and independent of temperature to $1200^{\circ} \mathrm{C}$ (i.e., to $0.85 \mathrm{~T}_{\mathrm{m}}$ ). The RSP alloys show remarkable dislocation stability up to $1200^{\circ} \mathrm{C}$, which strongly suggests that the dislocations have become effectively pinned. For the IGA. alloy at $1300^{\circ} \mathrm{C}$, the dislocations have apparently suffered considerable depinning, allowing the microstructure to develop a more fully recovered condition. 


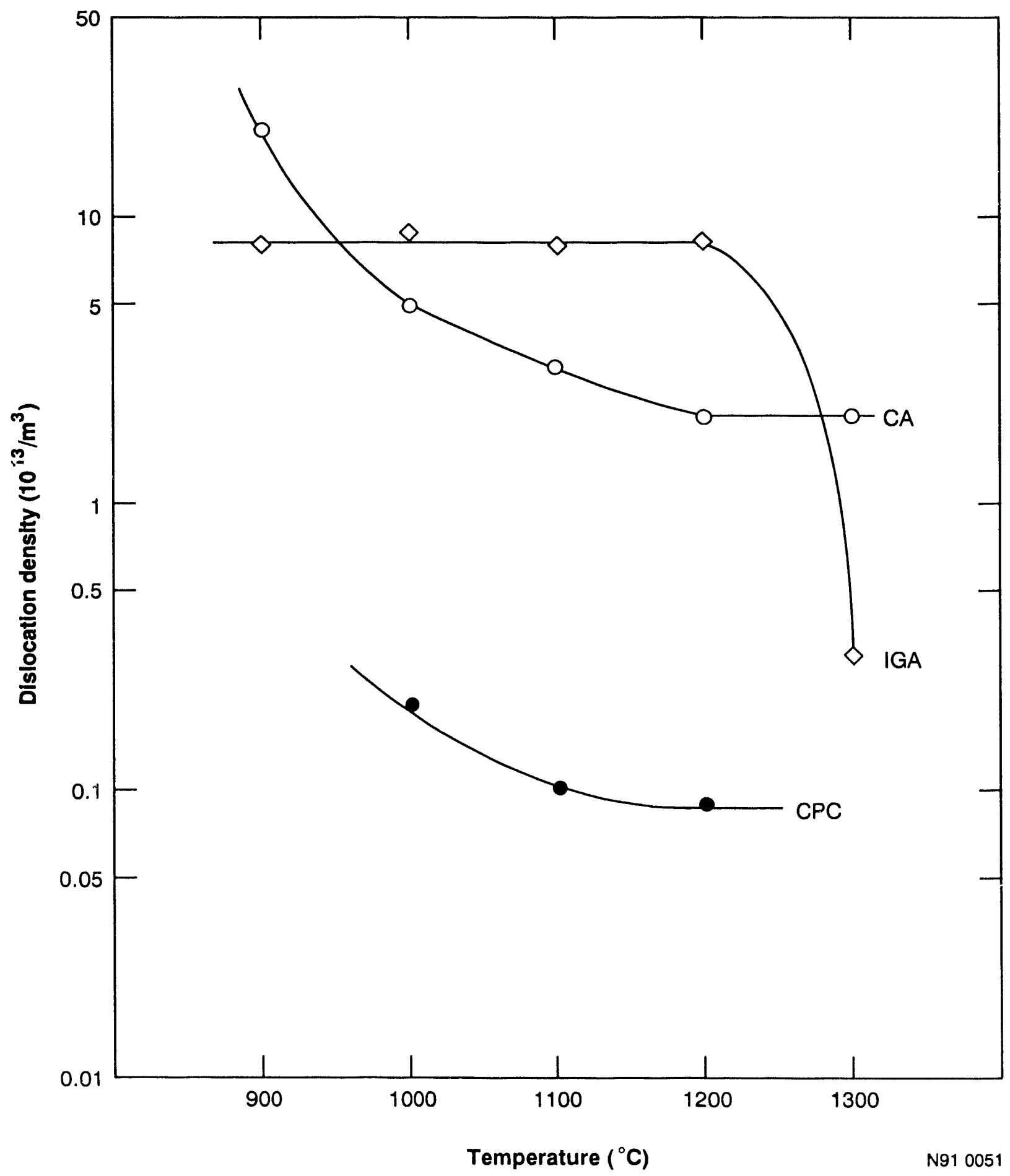

Figure 52. Influence of $1 \mathrm{~h}$ heat treatments on the dislocation density for CA and IGA Type 304 SS extruded powders and their CPC.

The IGA Type 304 SS extruded powders were from five particle size ranges (i.e., $>10$ to $<30,>30$ to $<50,>50$ to $<75,>100$ to $<150$, and $>10$ to $<150 \mu m$ with a median size of $48 \mu \mathrm{m})$. Specimens were examined after a $1 \mathrm{~h}, 1100^{\circ} \mathrm{C}$ 
heat treatment. The dislocation densities associated with the five particle sizes are shown in Table 6 . The results indicate a possible trend of increasing density with increasing particle size. However, because of the nature and number of the measurements, particularly in terms of average or global representaiion, the conclusion that dislocation density is dependent on particle size is not supported. Based on this view, the high residual dislocation density has no apparent dependence on the solidification rate associated with the particle size (see Figure 11).

The cause or reason for the dislocation stabilization observed for the CA and IGA Type 304 SS extruded powders has not been resolved. The results indicate that the pinning agent is very stable, below normal TEM resolution, probably a compound rather than impurity atoms, and is closely spaced along the dislocation lines. Another feature observed from the imaging and analyses is that the dislocations are primarily of the screw type. This suggests that the pinning defects are providing a strong, but attractive, nonspherical lattice strain field.

The dislocations observed for the Fe-16Ni-9Cr (VGA and CPC), Fe-40Ni (CA and $\mathrm{CPC}$ ), and $\mathrm{Fe}-40 \mathrm{Ni}-0.3 \mathrm{Nb}-0.05 \mathrm{C}$ (CA and $\mathrm{CPC}$ ) alloys show fairly stable behavior after the high-temperature heat treatments. ${ }^{41,42}$ The dislocation densities appear to be slightly higher for the powder-derived alloys than

Table 6. Influence of Particle Size on Dislocation Density After $1 \mathrm{~h}, 1100^{\circ} \mathrm{C}$ Heat Treatment for IGA Extruded Type 304 SS Powder

\begin{tabular}{cc}
$\begin{array}{c}\text { Particle Size } \\
(\mu \mathrm{m})\end{array}$ & $\begin{array}{c}\text { Dislocation } \\
\text { Density } \\
\left(10^{13} \mathrm{~m} / \mathrm{m}^{3}\right)\end{array}$ \\
\hline$>10$ to $<30$ & 6 \\
$>30$ to $<50$ & 8 \\
$>10$ to $<150(48)^{a}$ & 8 \\
$>50$ to $<75$ & 9 \\
$>100$ to $<150$ & 10
\end{tabular}

a. Median particle size. 
their CPCs, but the differences are nowhere near as large as those shown in Figure 52 for the Type 304 SS materials.

\section{Precipitate Behavior}

The precipitates observed for the alloys listed in Table 5 were primarily characterized using electron diffraction and energy dispersive spectroscopy (EDS) on TEM-type specimens. For the Fe-40Ni alloys, extraction replica techniques were also used. ${ }^{42}$ More effort is needed to quantify the composition and structure of the precipitates.

The examinations revealed that a large number of small precipitates are present, even after the high-temperature heat treatments, in the RSP consolidated powders. In comparison, their CPCs exhibit complete dissolution of precipitates at these temperatures, as expected. The precipitates are carbides and/or oxides. For the Type 304 SS materials, the primary precipitates after $1 \mathrm{~h}$ heat treatments at $\leq 1100^{\circ} \mathrm{C}$ are $\mathrm{M}_{23} \mathrm{C}_{6}$ carbides (where $\mathrm{M}$ is predominantly chromium). At temperatures $\geq 1100^{\circ} \mathrm{C}$, oxygen begins to appear as a significant component of the precipitates in the RSP alloys. The Type 304 SS CPC specimens have quite large $(>1 \mu \mathrm{m}) \mathrm{M}_{23} \mathrm{C}_{6}$ precipitates at temperatures $\leq 1000^{\circ} \mathrm{C}$ that are interconnected and located primarily along the grain boundaries. There was very little evidence of $M_{23} C_{6}$ in the matrix. At $1100^{\circ} \mathrm{C}$, neither $M_{23} C_{6}$ nor any other precipitate was observed in the CPC specimens, which is consistent with the solution annealing behavior of CPC Type 304 SS. The precipitates observed for the CA and IGA Type 304 SS extruded powders were predominately located inside the grains and not on the grain boundaries. The median size, number density, and volume fractions of the precipitates in the RSP Type 304 SS extruded powder specirens are shown in Figure 53. The CA specimens show little evidence of precipitate growth to $1100^{\circ} \mathrm{C}$; however, there is a significant increase in the volume fraction at this temperature. The precipitates appear to be mainly $\mathrm{M}_{23} \mathrm{C}_{6}$. At temperatures $>1100^{\circ} \mathrm{C}$, growth is observed as well as apparent dissolution, as indi ated by the decrease in volume fraction. The precipitates at 1200 and $130 C$ ' $c$ a:'e chromium-rich, but the examinations have not resolved whether they are carbides, oxides, or carbo-oxides. Examinations of the CA Type 304 SS powders after HIP consolidation and heat treatment at $1200^{\circ} \mathrm{C}$ for 1 h found 

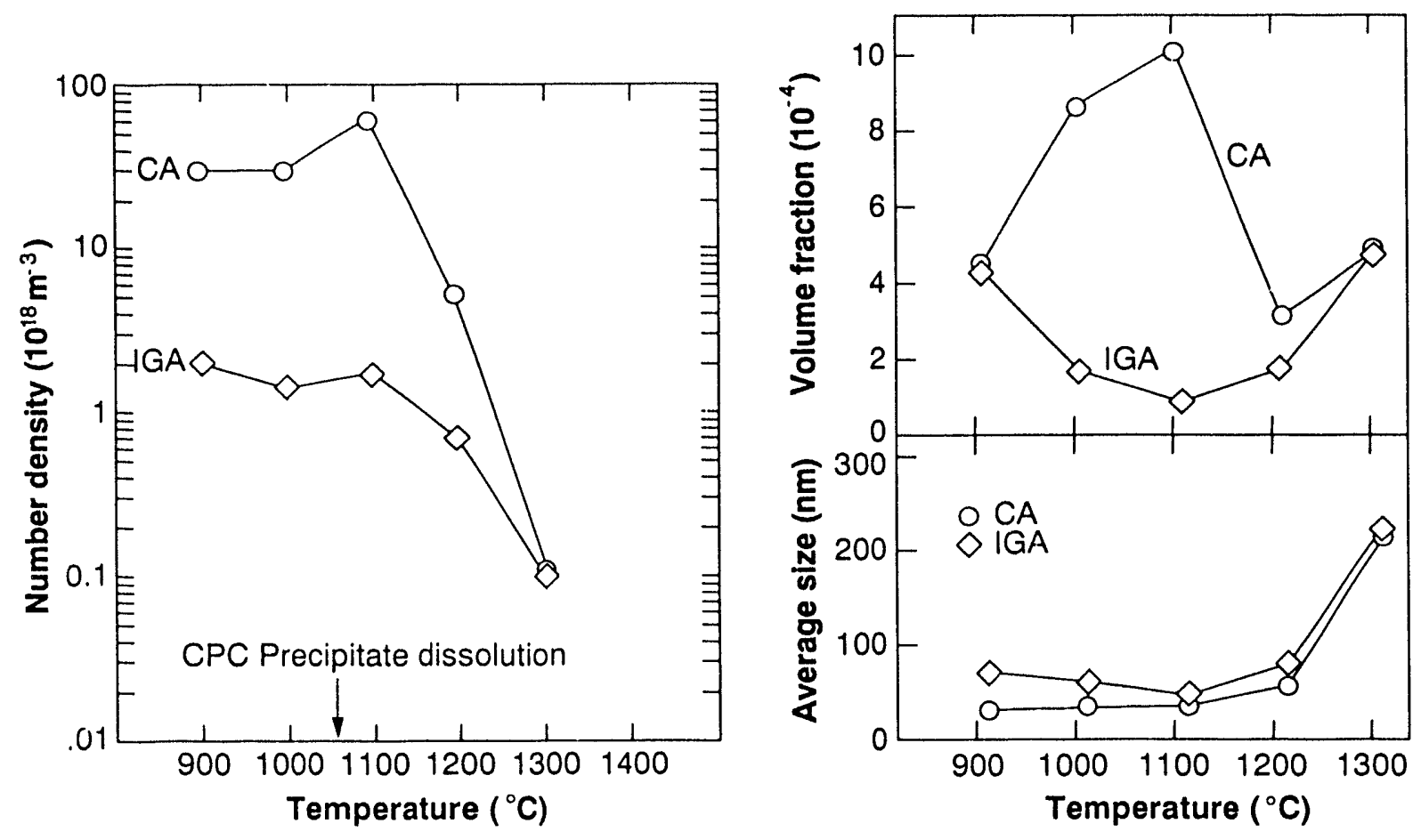

N91 0054

Figure 53. Influence of $1 \mathrm{~h}$ heat treatments on precipitate features for $C A$ and IGA extruded Type 304 SS powders.

chromium-rich precipitates with a larger median particle size and a smaller volume fraction than those in the extruded specimens after heat treatment at $1200^{\circ} \mathrm{C}$ for $1 \mathrm{~h}$. This comparison indicates that, for the CA Type 304 SS powder, the consolidation method influenced the precipitation behavior. Again, it should be pointed out that at temperatures $\geq 1100^{\circ} \mathrm{C}$, no precipitates were observed for the CPC specimens.

The IGA Type 304 SS extruded powders $(>30$ to $<50 \mu \mathrm{m}$ ) show a different precipitate behavior than the CA specimens (Figure 53). The precipitates observed from 900 to $1100^{\circ} \mathrm{C}$ were predominantly $M_{23} C_{6}$. Based on the size and volume fraction data in Figure 53, dissolution is occurring. However, at the higher temperatures $\left(1200\right.$ and $\left.1300^{\circ} \mathrm{C}\right)$, the size of the precipitates increases along with the volume fraction. Analysis of the precipitates after the 1200 and $1300^{\circ} \mathrm{C}$ heat treatments shows that they are $\mathrm{Al}$ - and $\mathrm{Mn}-\mathrm{rich}$ with little or no chromium. Furthermore, the EDS measurements indicate that the precipitates are oxides or possibly carbo-oxides. The precipitate size vs. frequency 
diagrams in Figure 54 show the influence of heat treatment on the size distributions.

The influence of particle size (i.e., used for extrusion consolidation) on the precipitate behavior of IGA Type 304 SS specimens was also evaluated for the $1100^{\circ} \mathrm{C} 1 \mathrm{~h}$ heat treatment. The results are shown in Table 7. Although trends in the data are apparent, the nature of the measurements prevents concluding that particle size significantly influences precipitate behavior.

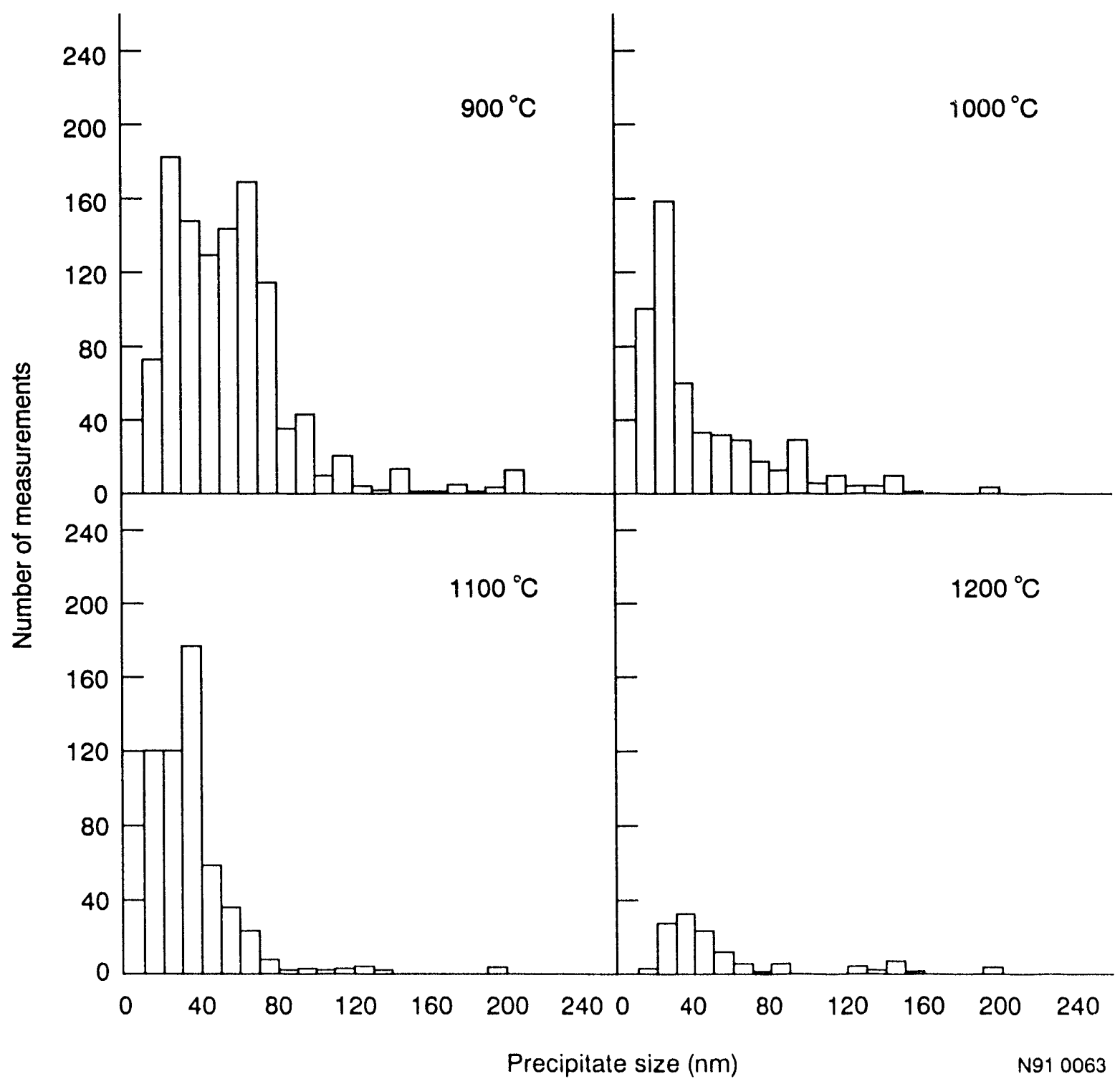

Figure 54. Precipitate size distributions for IGA Type 304 SS extruded powder (>30-50 $\mu \mathrm{m}$ ) after $1 \mathrm{~h}$ heat treatments. 
Table 7. Influence of Preconsolidation Particle Size on Precipitate Behavior for Extruded IGA Type 304 SS After $1100^{\circ} \mathrm{C} 1 \mathrm{~h}$ Heat Treatment

\begin{tabular}{cccc} 
Particle Size & $\begin{array}{c}\text { Median } \\
\text { Diameter } \\
(\mathrm{nm})\end{array}$ & $\begin{array}{c}\text { Number } \\
\text { Density } \\
\left(10^{18} / \mathrm{m}^{3}\right)\end{array}$ & $\begin{array}{c}\text { Volume } \\
\text { Fraction } \\
\left(10^{-4}\right)\end{array}$ \\
\cline { 2 - 2 }$>10$ to $<30$ & 44 & & 1.9 \\
$>30$ to $<50$ & $\frac{14}{4}$ & 1.7 & 0.8 \\
$>50$ to $<75$ & 51 & 1.2 & 0.8 \\
$>100$ to $<150$ & 50 & 1.4 & 0.8 \\
$>10$ to $<150$ & 54 & 1.1 & 0.9 \\
$(48 \mu$ m median) & & & 0.9
\end{tabular}

The precipitate behavior for the VGA Fe-16Ni-9Cr appears to be similar to that of the IGA Type 304 SS, where the median size and volume fraction decrease with increasing temperature to $1100^{\circ} \mathrm{C}$; however, at 1200 and $1300^{\circ} \mathrm{C}$, both size and volume fraction increase. Although not verified at this time, the precipitate behavior may involve the dissolution of carbides to $1100^{\circ} \mathrm{C}$ and the development and growth of oxides at the higher temperatures. Further studies are underway to sort out the apparent carbide and oxide behavior for this alloy. ${ }^{41}$ For the $\mathrm{Fe}-16 \mathrm{Ni}-9 \mathrm{Cr} C P C$, there were no apparent precipitates in the specimens heat treated at temperatures from 900 to $1300^{\circ} \mathrm{C}$.

The Fe-40Ni alloys with $\mathrm{Nb}$ and $\mathrm{C}$ additions had different precipitates than those without additions. ${ }^{42}$ Both alloys have a high population of precipitates, as shown in Table 8 for the CA and CPC materials. The precipitates have not been conclusively identified, particularly the nonmetallic constituents. The CPC Fe-40Ni precipitates were primarily $\mathrm{Fe}-\mathrm{Cr}$ and appear to be oxides, although carbo-oxides are a possibility. The precipitates in the $\mathrm{CA} \mathrm{Fe}-40 \mathrm{Ni}$ alloy after the 1000 and $1200^{\circ} \mathrm{C}$ heat treatments contain $\mathrm{Fe}-\mathrm{Cr}-\mathrm{V}$; some precipitates contain $\mathrm{Si}$ and $\mathrm{Al}$. For the $1400^{\circ} \mathrm{C}$ heat treatment, $\mathrm{Cr}$ was not detected in the precipitates but $\mathrm{Fe}, \mathrm{Al}$, and $\mathrm{Si}$ were present. As with the CPC material, the precipitates appear to be oxides, possibly even carbo-oxides. It should be noted that $\mathrm{Cr}, \mathrm{Al}, \mathrm{Si}, 0$, and $\mathrm{C}$ are impurities in this alloy. These precipitates in the CA processed alloy show considerable stability compared to those in its CPC material (see Table 8 ). For the $\mathrm{Fe}-40 \mathrm{Ni}-0.3 \mathrm{Nb}-0.05 \mathrm{C}$ alloy, the predominant precipitate is $\mathrm{NbC}$, and the 
Table 8. Precipitate Observations for CA and CPC Fe-40Ni Alloy Series After $1 \mathrm{~h}$ Heat Treatments

\begin{tabular}{|c|c|c|c|c|}
\hline \multirow[b]{2}{*}{ Parameters } & \multicolumn{2}{|c|}{$\mathrm{Fe}-40 \mathrm{Ni}$} & \multicolumn{2}{|c|}{$\mathrm{Fe}-40 \mathrm{Ni}-0.3 \mathrm{Nb}-0.05 \mathrm{C}$} \\
\hline & $C A$ & $C P C$ & CA & $C P C$ \\
\hline $\begin{array}{l}1000^{\circ} \mathrm{C} \\
\text { Average dia }(\mathrm{nm}) \\
\text { Number density }\left(\mathrm{m}^{-3}\right) \\
\text { Volume fraction }\end{array}$ & $\begin{array}{l}26 \\
2 \times 10^{20} \\
2 \times 10^{-3}\end{array}$ & $\begin{array}{l} \\
2 \times 13 \\
4 \times 10^{18} \\
4 \times 10^{-4}\end{array}$ & $\begin{array}{l}144 \\
1 \times 10^{19} \\
2 \times 10^{-2}\end{array}$ & $\begin{array}{l}23 \\
2 \times 10^{19} \\
1 \times 10^{-2}\end{array}$ \\
\hline $\begin{array}{l}1200^{\circ} \mathrm{C} \\
\text { Average dia (nm) } \\
\text { Number density }\left(\mathrm{m}^{-3}\right) \\
\text { Volume fraction }\end{array}$ & $\begin{array}{l}6 \times 10^{18} \\
3 \times 10^{-3}\end{array}$ & 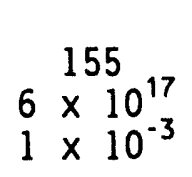 & $\begin{array}{ll} & 290 \\
1 \times 18 & 10^{18} \\
2 \times 10^{-2}\end{array}$ & $\begin{array}{l}320 \\
2 \times 10^{18} \\
3 \times 10^{-2}\end{array}$ \\
\hline $\begin{array}{l}1400^{\circ} \mathrm{C} \\
\text { Average dia }(\mathrm{nm}) \\
\text { Number density }\left(\mathrm{m}^{-3}\right) \\
\text { Volume fraction }\end{array}$ & $\begin{array}{ll} & 219 \\
2 \times 10^{18} & \times 10^{-3} \\
8 \times 1\end{array}$ & $\begin{array}{l}\text { None } \\
\text { None } \\
\text { None }\end{array}$ & $\begin{array}{ll} & 500 \\
5 & \times 10^{17} \\
3 & \times 10^{-2}\end{array}$ & $\begin{array}{l}2900 \\
5 \times 10^{15} \\
5 \times 10^{-3}\end{array}$ \\
\hline
\end{tabular}

precipitates are more stable in the CA processed alloy than in its CPC material.

These precipitate results have several interesting features. First, the precipitates in the RSP alloys are significantly more stable and usually finer than those of their CPCS; however, it must be recognized that the studies have not confirmed that the precipitates are compositionally identical for RSP and CPC materials. Second, the interstitial elements, carbon and probably oxygen, are important for precipitate development in the RSP materials, but do not appear to have the same influence in their CPCS. Third, impurity elements, particularly the high oxide formers such as Al, Si, Ti, and $v$, appear to be important for precipitate development.

An area that needs considerably more study is the role of oxygen in the iron-base RSP alloys. To properly assess its role, oxygen must be introduced into the alloy at the melt stage prior to powder atomization. It is important that the oxygen be retained in the melt in a dissociated form. This may require that strong deoxidizers, such as $\mathrm{Al}, \mathrm{Ti}$, and $\mathrm{Si}$, be controlled to low levels to preclude deoxidizing the melt. Initially, it is important that 
oxygen be entrained in the solid as a solute addition. Support for this concept will become more evident in the next section.

\section{Cavity Formation}

In a previous section, the role of entrained noble gases and their propensity for porosity/bubble formation was presented. There is another feature associated with rapid crystallization that can be very important for microstructural development and stabilization in RSP alloys: vacancy trapping. The liquid state of metals is significantly less dense (or of greater volume) than the solid. Extremely rapid crystallization of the liquid can introduce vacancy concentrations in the solid that substantially exceed the equilibrium concentration for the solid just below the melting point. Ideally, the excess vacancy concentration could approach the volume difference between the liquid and solid. ${ }^{43}$ However, in reality, finite crystallization rates, solid-liquid interface velocities, and the widths of the solid-liquid interfaces limit excess vacancy concentrations. A majority of the vacancies diffuse back into the liquid phase; however, supersaturation levels that significantly exceed equilibrium concentrations can still be trapped in the solid. Earlier it was shown (see Figure 13) that the CA Type 304 SS powders contained defect features, i.e., Frank loops and stacking faults, attributed to vacancy trapping.

TEM and STEM examinations for evidence of vacancy clusters after various $1 \mathrm{~h}$ heat treatments have been performed for the alloys shown in Table 5 . To detect small voids or large vacancy clusters, the specimen needs to be examined using through-focal imaging where under and overfocus conditions will show such features if they are present. ${ }^{44,45}$ The examinations of consolidated CA Type 304 SS powders have provided substantial evidence of nanometer size void/cavity evolution from RSP. ${ }^{46-48}$ These results are summarized below.

The through-focus examinations of the CA Type 304 SS extruded powders, heat treated at 900 to $1200^{\circ} \mathrm{C}$, show the presence of a high population of spherical cavities. Figure 55 presents representative TEM photographs of the cavities after $1 \mathrm{~h}$ heat treatments at 900 and $1200^{\circ} \mathrm{C}$; the cavities appear as light spots with dark rings in the underfocussed condition and dark spots with 


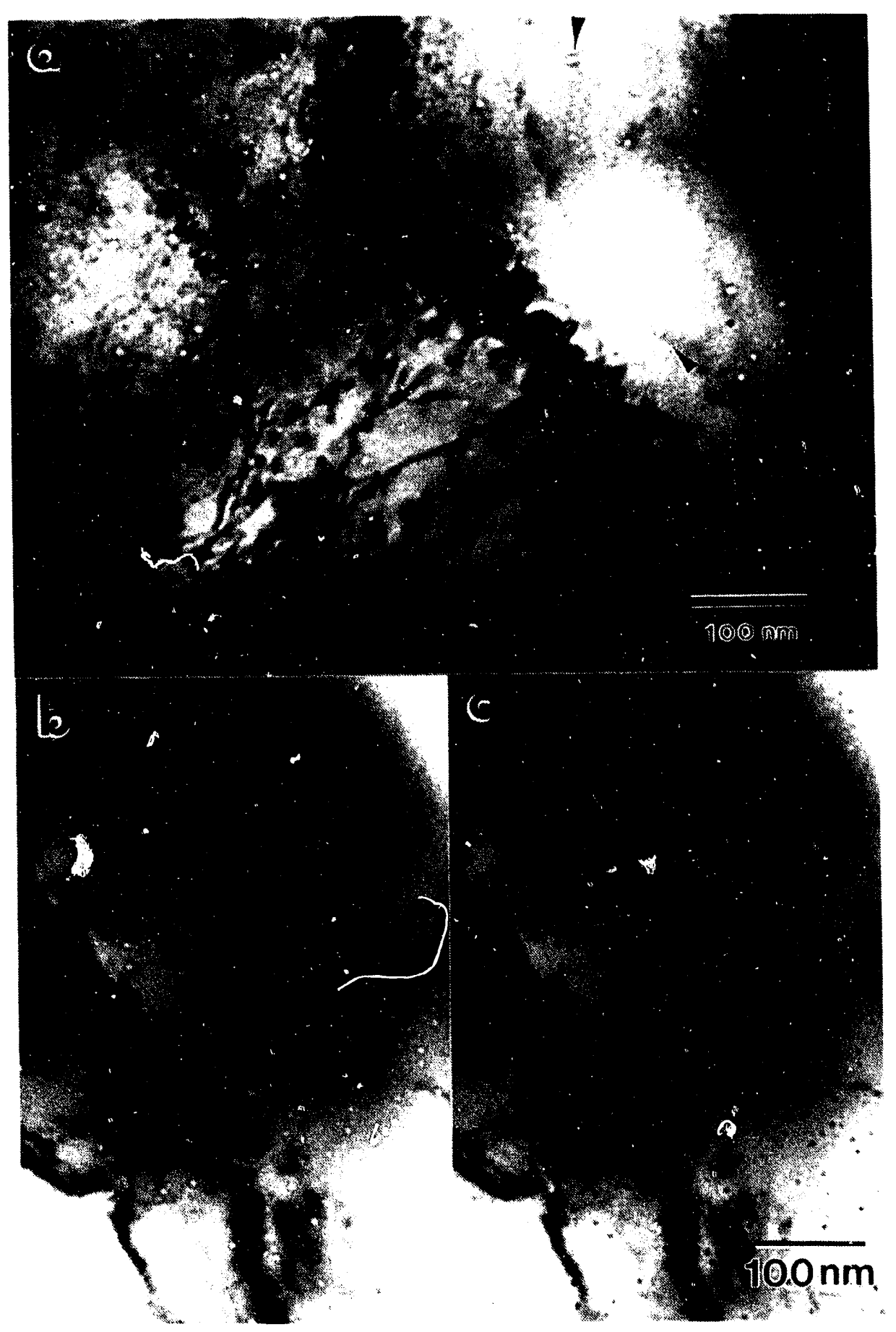

Figure 55. $8 \mathrm{~nm}$ cavities in CA Type $304 \mathrm{SS}$ extruded powder. (a) $900^{\circ} \mathrm{C}$, bright field, underfocus; (b) $1200^{\circ} \mathrm{C}$, bright field, underfocus; and (c) $1200^{\circ} \mathrm{C}$, bright field, overfocus. The arrows in (a) indicate cavities that are equally spaced along a smooth curve.

light rings in the overfocussed condition. The size distributions for these cavities were quite narrow and nearly identical over the 900 to $1200^{\circ} \mathrm{C}$ range. 
The cavity size (inner diameter) is $-8 \mathrm{~nm}$, and appears to be independent of temperature. Although cavity growth does not occur from 900 to $1200^{\circ} \mathrm{C}$, the number density increased with increasing temperature. The $8 \mathrm{~nm}$ cavities shown in Figure 55 appear to lie along dislocations. This is not obvious from the photographs due to differences in the contrast imaging conditions between cavities and dislocations; note that at-focus the dislocations have high contrast, but the cavities cannot be seen.

The HIPped Type 304 SS CA powders were also examined for $8 \mathrm{~nm}$ cavities. The cavities were not seen.

High resolution examinations were performed on the extruded and HIPped CA Type 304 SS powders using a VG HB 501 STEM. The behavior of the $8 \mathrm{~nm}$ cavities in the extruded and heat treated powders suggests that they have evolved from smaller cavities/vacancy clusters that were not seen during the more conventional TEM examinations. Representative high magnification photomicrographs from the STEM examinations are shown in Figures 56 and 57 for electropolished CA Type 304 SS extruded powder specimens with $1 \mathrm{~h}$ heat treatments at 900 and $1200^{\circ} \mathrm{C}$, respectively. The images in Figures 55 and 56 suggest that there is a second population of cavities with an average size of $-1.5 \mathrm{~nm} .{ }^{47,48}$ The cavities in the $1200^{\circ} \mathrm{C}$ heat treated specimens retained their $1.5 \mathrm{~nm}$ size; however, their number density was significantly reduced compared to the $900^{\circ} \mathrm{C}$ heat treatment specimens.

High resolution examinations of the CA Type 304 SS HIPped and heat treated powders revealed the presence of a very high population of $1.5 \mathrm{~nm}$ cavities as shown in Figure 58. However, the HIPped material differs from the extruded form in that it does not contain $8 \mathrm{~nm}$ cavities. Therefore, the $1.5 \mathrm{~nm}$ cavities appear to be a derivative of the CA powder processing, whereas the $8 \mathrm{~nm}$ cavities are derived from consolidation.

The number densities for the two cavity populations in the $C A$ Type 304 SS extruded powders were determined. With increasing temperature, the number density increases for the $8 \mathrm{~nm}$ cavities and decreases for the $1.5 \mathrm{~nm}$ cavities. These trends strongly suggest that the $8 \mathrm{~nm}$ cavities have evolved from the $1.5 \mathrm{~nm}$ cavities by an 0stwald ripening process, and that the 


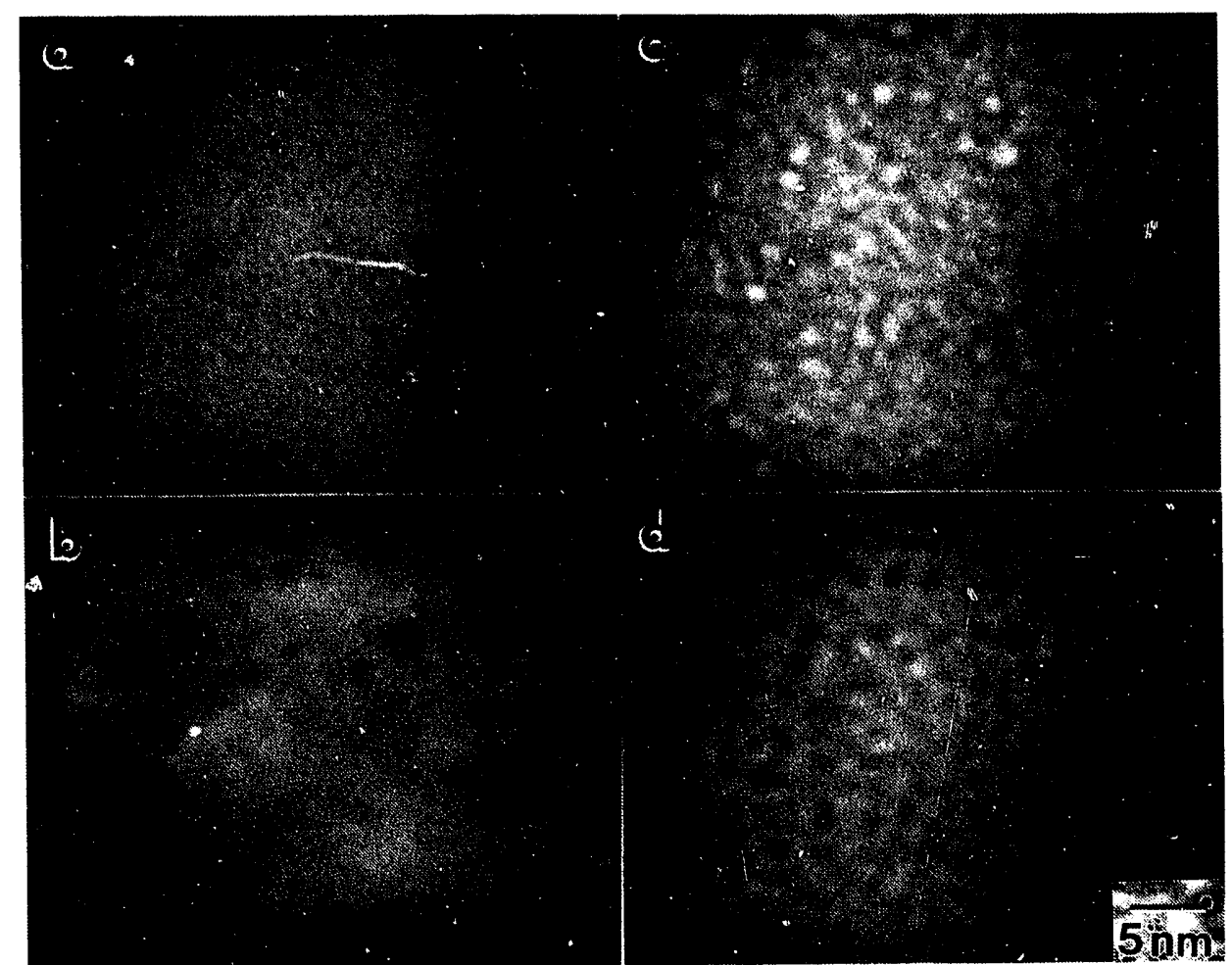

Figure 56. $1.5 \mathrm{~nm}$ cavities in CA Type $304 \mathrm{SS}$ extruded powder after $1 \mathrm{~h}$ at $900^{\circ} \mathrm{C}$. (a) Bright field, at focus; (b) annular dark field, at focus;

(c) bright field, underfocus, and (d) bright field, overfocus.
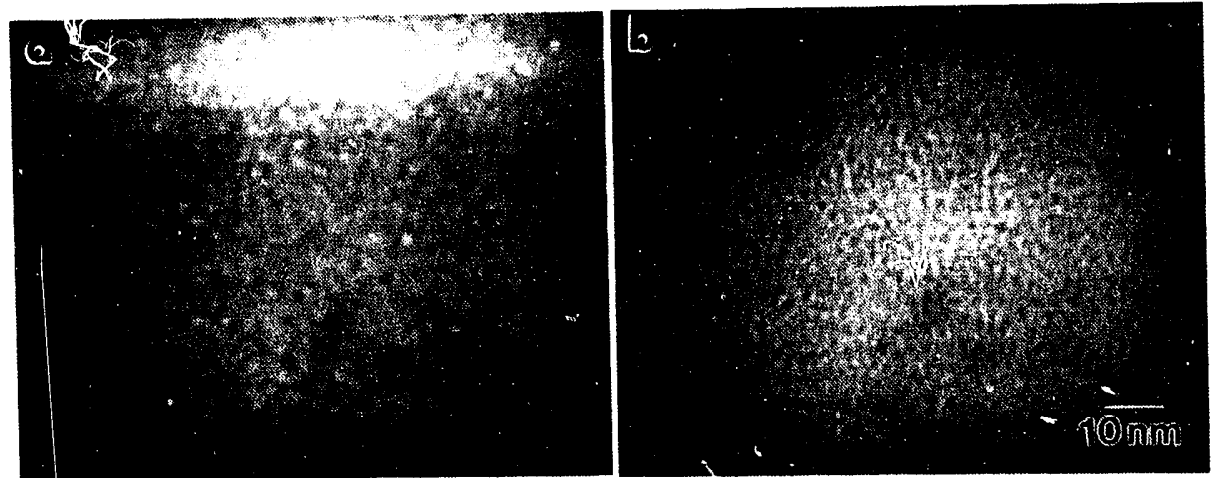

Figure 57. $1.5 \mathrm{~nm}$ cavities in CA Type $304 \mathrm{SS}$ extruded powder after $1 \mathrm{~h}$ at $1200^{\circ} \mathrm{C}$. (a) Bright field, underfocus, and (b) bright field, overfocus.

dislocations are playing an important role in this growth process.

Calculations indicate that the vacancy concentration between the two cavity populations is conserved. ${ }^{48}$ Furthermore, assuming that the atomic volume for a vacancy in Type 304 SS is $0.0168(\mathrm{~nm})^{3}$, the total vacancy concentration of the two cavity populations is -10 times the equilibrium number of vacancies at the melting point $(1723 \mathrm{~K}) \cdot{ }^{48}$ A similar level of vacancy supersaturation is 


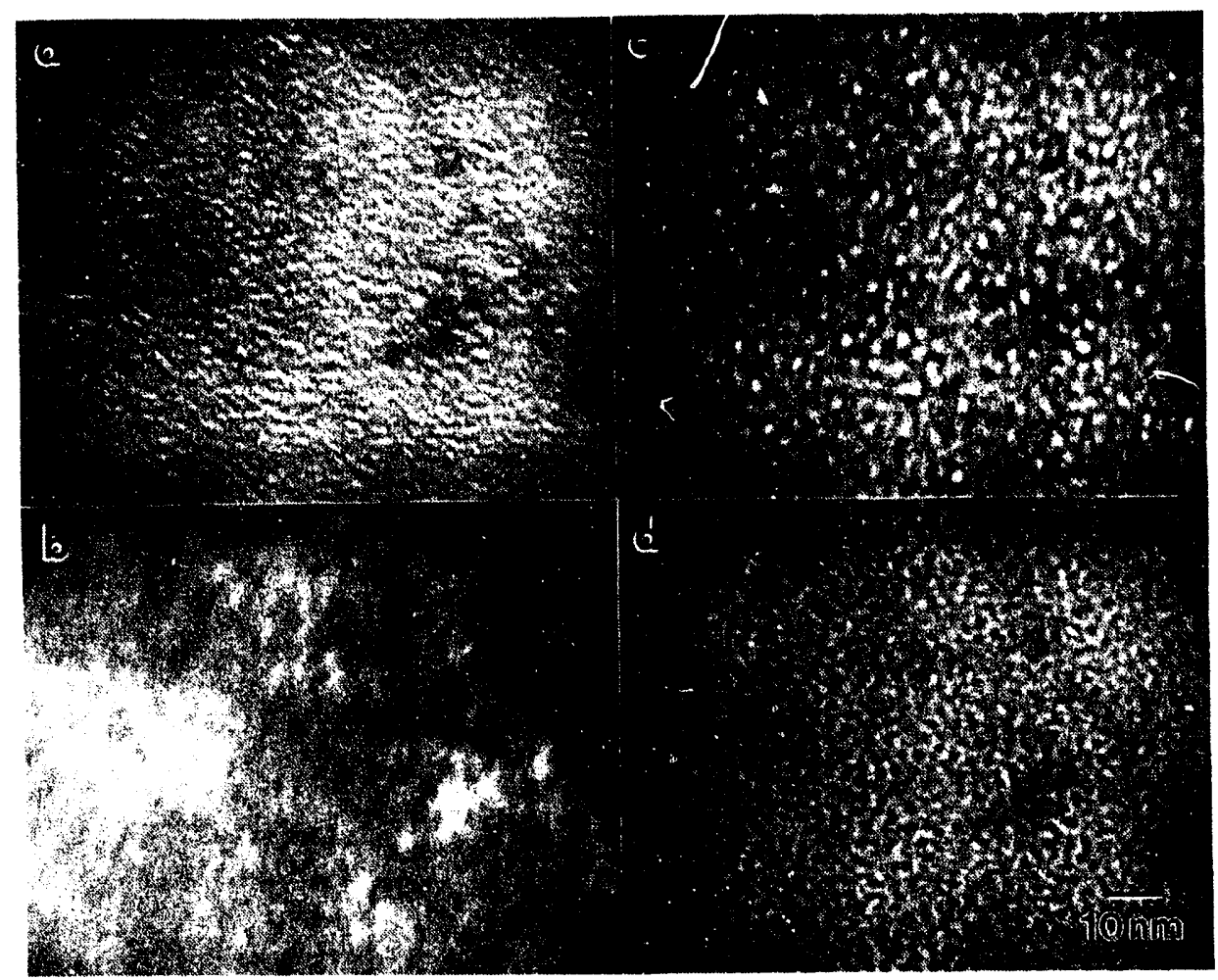

Figure 58. $1.5 \mathrm{~nm}$ cavities in CA Type 304 SS HIPped powders after $1 \mathrm{~h}$ at $1200^{\circ} \mathrm{C}$. (a) Bright field, at focus; (b) annular dark field, at focus; (c) bright field, underfocus, and (d) bright field, overfocus.

obtained for the $1.5 \mathrm{~nm}$ cavities observed for the HIP consolidated, CA Type 304 SS powders. ${ }^{48}$

The size stability of both the 1.5 and $8 \mathrm{~nm}$ cavities over the temperature range of $9 \mathrm{CO}$ to $1200^{\circ} \mathrm{C}$ is amazing. This behavior implies that impurities are associated with the cavities, and that there is a synergistic relationship between the vacancies and impurities for the growth of the $1.5 \mathrm{~nm}$ cavities to the $8 \mathrm{~nm}$ size. X-ray analysis was performed on the $8 \mathrm{~nm}$ cavities in very thin foil regions using the VG HB 501 STEM. The cavity ceniers as well as the matrix $\sim 4 \mathrm{~nm}$ away from the cavity were analyzed. The $x$-ray spectrum from the matrix was normalized to that of the cavity and subtracted from the cavity. The results, shown in Figure 59, confirm that the $8 \mathrm{~nm}$ cavities contain large amounts of oxygen with oxide-forming elements such as $\mathrm{A} 1, \mathrm{Ti}, \mathrm{Si}, \mathrm{V}, \mathrm{Mn}$, and $\mathrm{Cr}$ ( $\mathrm{A} 1, \mathrm{Ti}$, and $\mathrm{V}$ are impurities). In essence, the cavities are hollow oxides. It is suspected, based on their relative size 


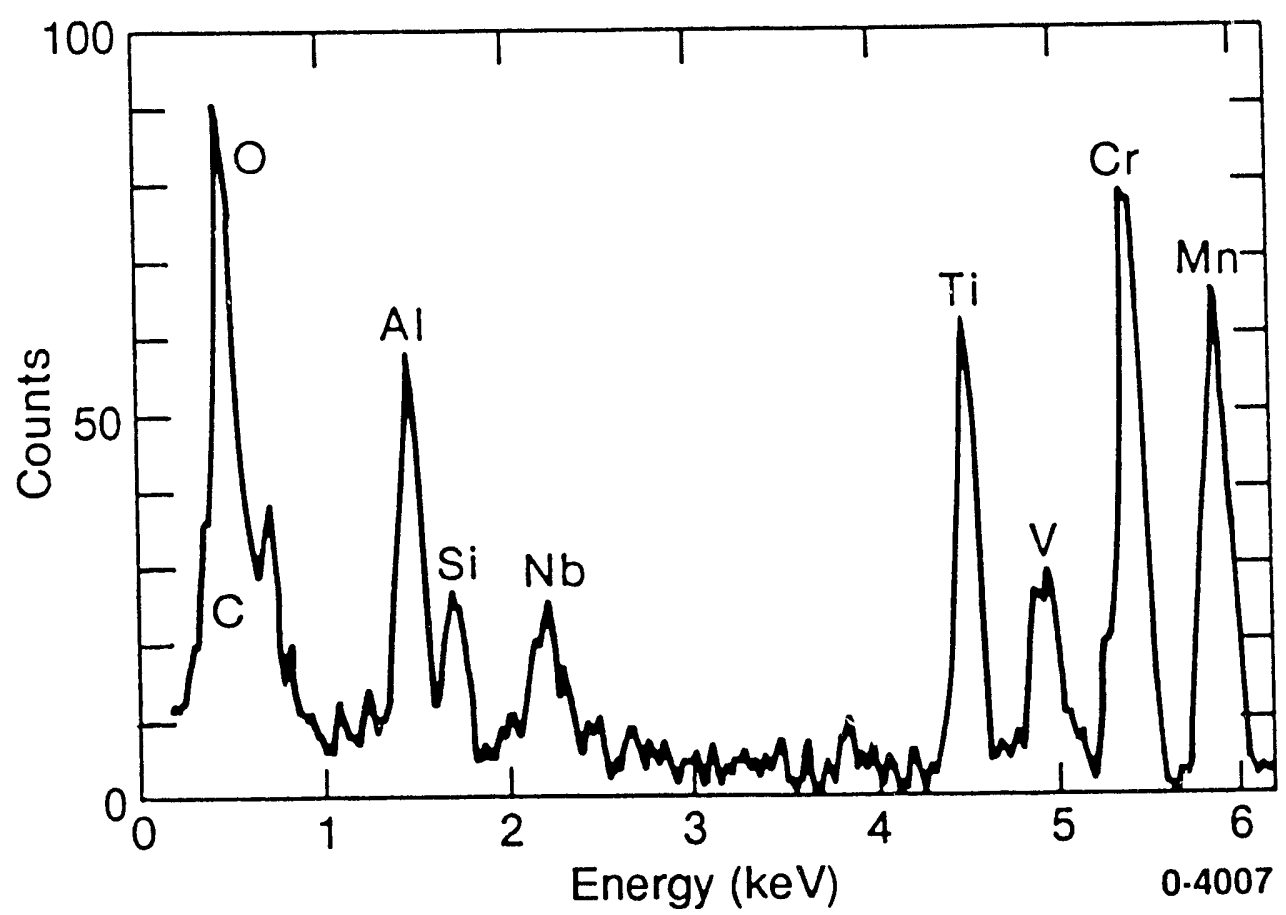

Figure 59. X-ray spectrum from $8 \mathrm{~nm}$ cavities in CA Type 304 SS extruded powder.

stability, that the $1.5 \mathrm{~nm}$ cavities also have associated oxygen, but its detection is beyond the resolution limits of the STEM.

The mechanism by which oxygen stabilizes large vacancy clusters or voids is based on chemisorption of oxygen on the void-matrix interface, which results in significant reduction of the surface energy. ${ }^{49-56}$ Calculations for Type 316 SS suggest that a partial coating (half coverage) of chemisorbed oxygen on a void will reduce the surface energy by a factor of 2 , making the void the most stable form of the vacancy cluster types. ${ }^{53,55}$ However, the size stability, particularly in the $8 \mathrm{~nm}$ cavities, suggests that chemisorbed oxygen must have evolved from the molecular dissociated form to a state of oxidation, i.e., a metal oxide film has formed around the cavities. Furthermore, the hollow oxide configuration remains stable at high temperatures (to $1200^{\circ} \mathrm{C}$ ), without further growth or collapse, which would imply that the oxide film is several monolayers thick.

Potentially, there is sufficient dissociated oxygen inside the CA Type 304 SS powders to provide a partial oxide coating around the $1.5 \mathrm{~nm}$ 
cavities and several monolayer thick oxide films around the $8 \mathrm{~nm}$ cavities. ${ }^{48}$ The role of oxygen in vacancy cluster or cavity stabilization means that relatively high levels of dissociated oxygen should be introduced into the melt prior to powder atomization and that the levels of deoxidizing elemental additions (impurities) such as $\mathrm{Al}, \mathrm{Ti}$, and $\mathrm{Si}$ should be controlled.

IGA Type 304 SS extruded powder and its CPC, VGA Fe-16Ni-9Cr extruded powder, and CA Fe-40Ni HIPped powder have been examined for cavities. No evidence of cavities, even on the order of $1 \mathrm{~nm}$ in size, was observed in the IGA and CPC Type $304 \mathrm{SS}$ or in the VGA Fe-16Ni-9Cr alloys. It was particularly surprising that cavities were not observed in the IGA Type 304 SS extruded powders, because the powder solidification rate appears to be higher than that of the CA Type 304 SS powder (see Figure 11). The effects of undercooling and recoalescence on vacancy trapping are not clear, and the degree of undercooling and amount of recoalescence could be significantly different between the IGA and CA processes. Also, there could be significant differences in the minor elements of the Type 304 SS melt stock materials used for $C A$ and IGA processing that influenced cavity development. Although there was no evidence of nanometer size cavities in the IGA Type 304 SS, something as yet unresolved, perhaps very small defect clusters, is pinning the dislocations as noted in Figures 51 and 52 and Table 6.

That nanometer size cavities were not observed in the VGA FE-iuivi-9Cr is not surprising because the solidification rate for this process is considerably lower than those for CA and IGA. High resolution examinations of the CA Fe-40Ni HIPped, cold worked, and heat treated powders show evidence of $-20 \mathrm{~nm}$ cavities. ${ }^{42}$ The number density of these cavities was significantly lower than that of the cavities in CA Type 304 SS extruded powders.

The nanometer size cavities, particularly the $8 \mathrm{~nm}$ size, offer new opportunities for dispersion strengthening. Another important function of the $8 \mathrm{~nm}$ cavities is to serve as nucleation sites for other precipitates. The CA Type $304 \mathrm{SS}$ extruded powder was given a $1200^{\circ} \mathrm{C}, 1 \mathrm{~h}$ anneal followed by a $600^{\circ} \mathrm{C}, 1000 \mathrm{~h}$ aging treatment. A fine and relatively uniformly spaced dispersion of carbides $\left(\mathrm{M}_{23} \mathrm{C}_{6}\right)$, shown in Figure $60 \mathrm{a}$, was produced on the dislocations. Through-focal imaging of the carbides revealed that inside each 


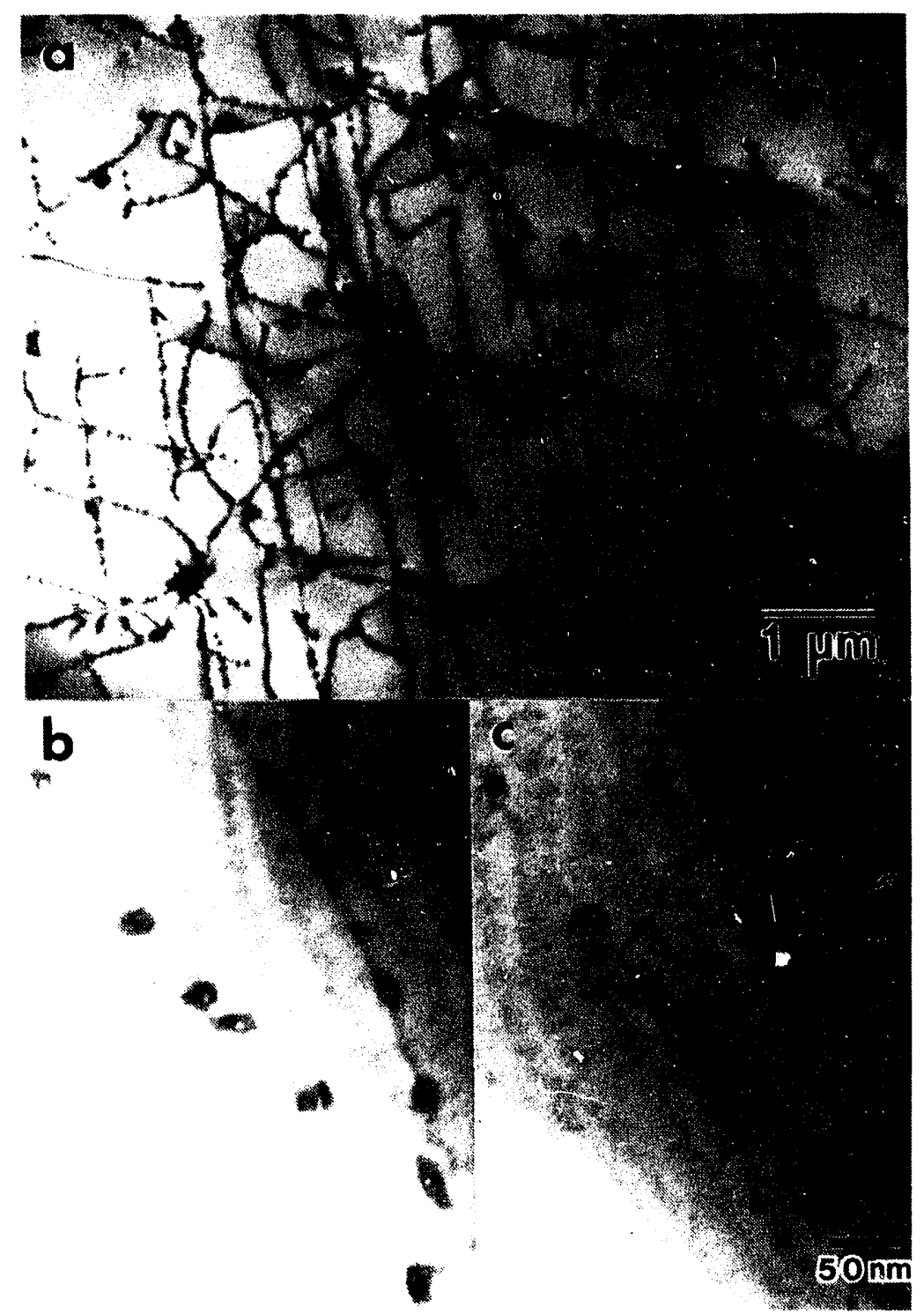

Figure 60. CA Type $304 \mathrm{SS}$ extruded powder after ? $\mathrm{h}, 1200^{\circ} \mathrm{C}$ and $1000 \mathrm{~h}, 600^{\circ} \mathrm{C}$ heat treatments. (a) Overview of cavity-carbide-dislocation morphology; (b) underfocus; and (c) overfocus, bright field image of details of cavity-carbide-dislocation interactions.

carbide is an $8 \mathrm{~nm}$ cavity (Figure $60 \mathrm{~b}$ ). This observation also supports the conclusion that the $8 \mathrm{~nm}$ cavities lie along the dislocations. Precipitate size distribution histograms are shown in Figure 61. Although the distribution of carbide-cavity complexes after aging is comparable to that of the precipitates after the $1200^{\circ} \mathrm{C}, 1 \mathrm{~h}$ anneal without aging, there is an apparent population increase in carbide-cavity complexes. 


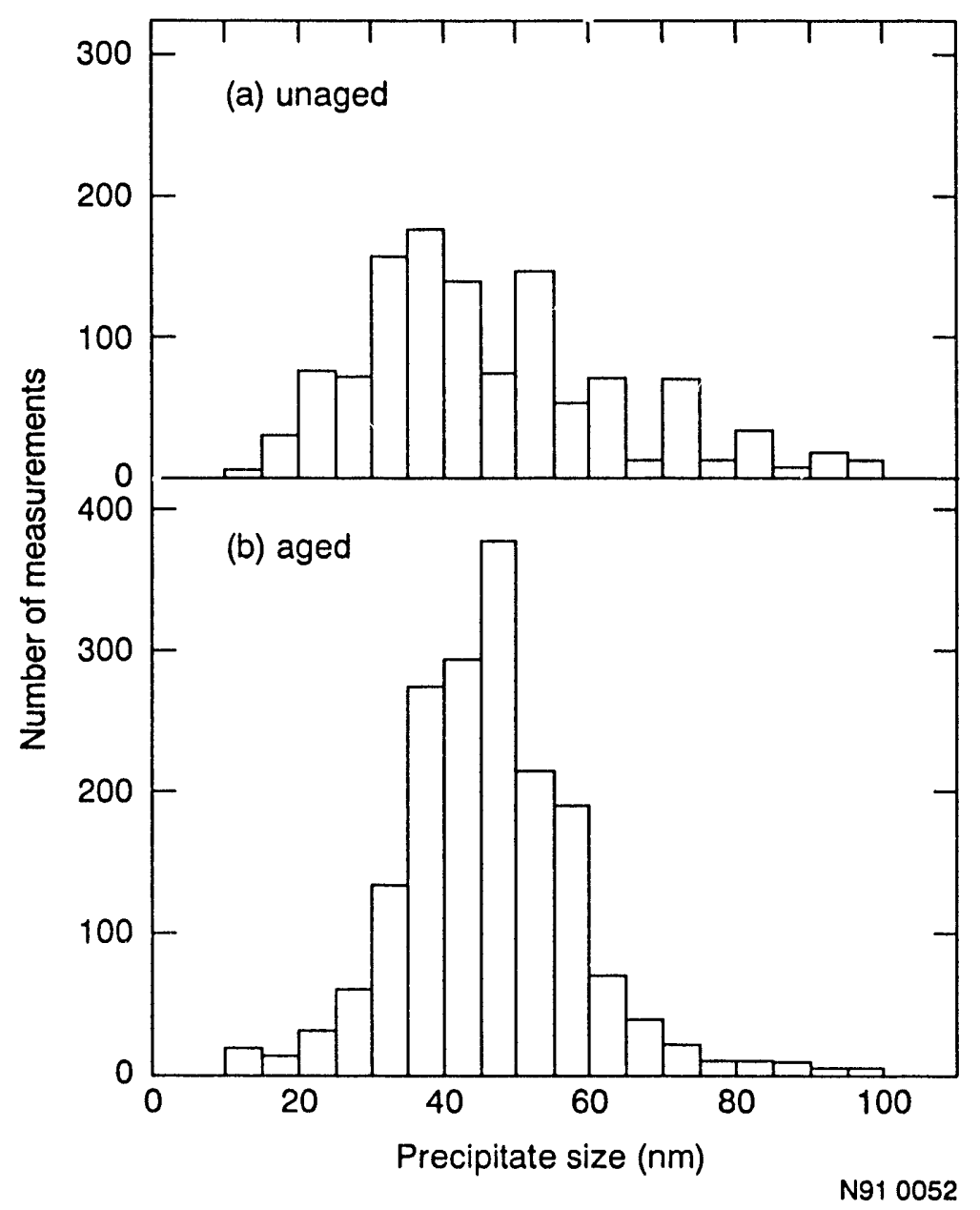

Figure 61. Precipitate size distribution for CA Type 304 SS extrured powder after $1 \mathrm{~h}$ heat treatment at $1200^{\circ} \mathrm{C}$. (a) Unaged and (b) aged $1000 \mathrm{~h}$ at $600^{\circ} \mathrm{C}$.

\section{Microstructure-Grain Size Behavior}

Rapid solidification processing of iron-base alloys promotes fine grain sizes that show significant grain growth retardation. ${ }^{19,57-60}$ The iron-base alloys investigated in this study (see Table 1) are no exception. What the current study offers is an evaluation of the parametric influences on the grain growth behavior of these alloys. This section will address the influences of powder processing, powder consolidation, thermal-mechanical processing, particle size, and composition on grain growth. From these results and the submicron microstructural features summarized in the previous section, arguments will be presented on the cause for the fine and stable grain sizes observed in the RSP iron-base alloys. 


\section{Powder "rocessin's}

The primary atomization methods used for powder processing were CA, IGA, and VGA. Powders for one alloy, Type 304 SS, were prepared by all three methods, consolidated, heat treated for $1 \mathrm{~h}$ at 900 to $1400^{\circ} \mathrm{C}$, and examined for grain size. A "grab-type" particle distribution was used. Grain size was determined by the linear intercept method, primarily from longitudinal cross sections. The results for heat treatments to $1200^{\circ} \mathrm{C}$ are shown in Figure 62 ,

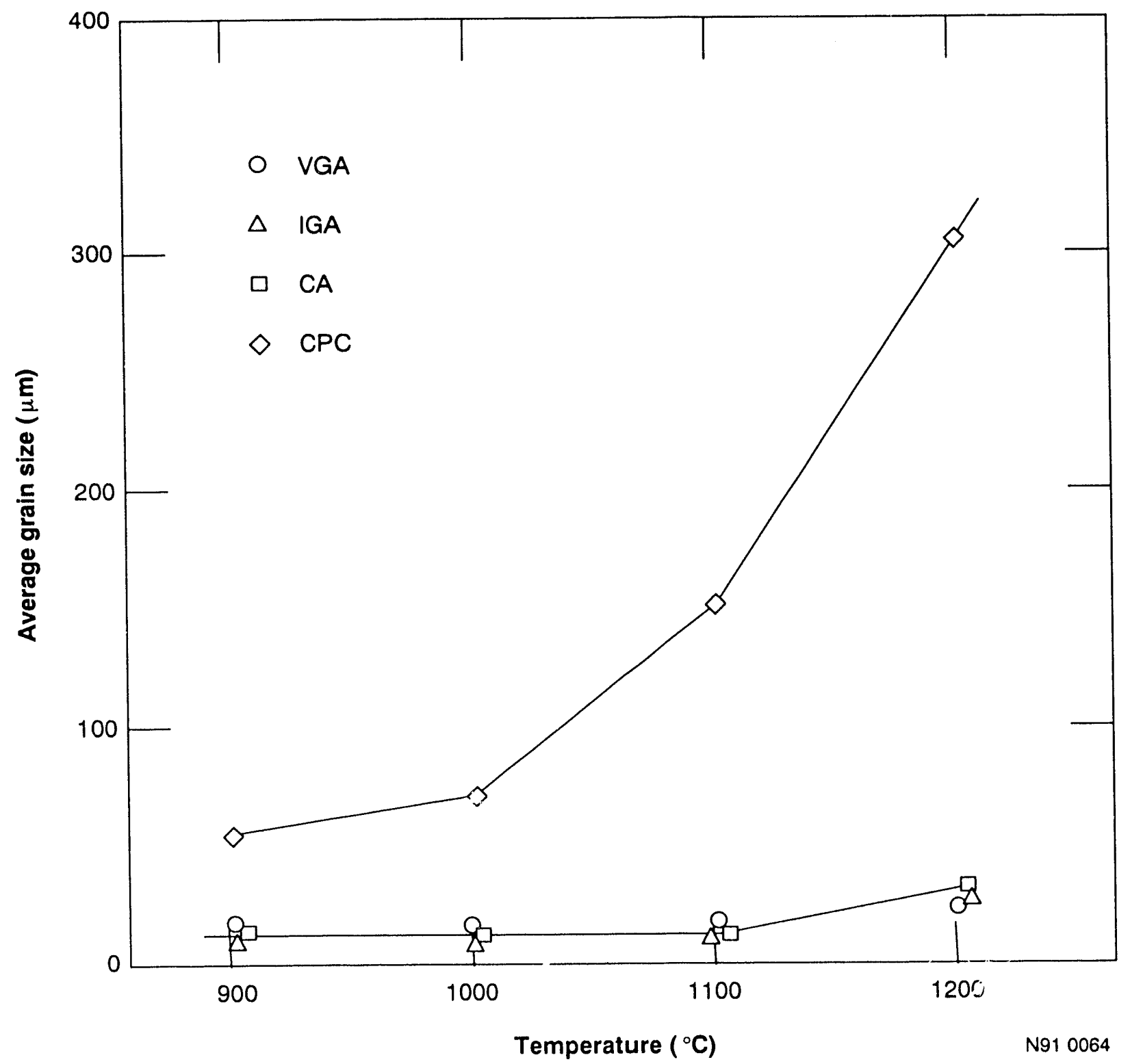

Figure 62. Influence of atomization method on grain growth behavior of Type 304 SS consolidated powders. 
along with those for the CPC. It is apparent that the three powder-derived Type 304 SS materials experienced considerable grain growth retardation compared to the CPC. Also, there was no apparent influence from the powder processing method, even though there was a significant difference in the powder microstructures before conso?idation (see Figure 11). Heat treatments above $1200^{\circ} \mathrm{C}$, i.e., at 1300 and $1400^{\circ} \mathrm{C}$, were performed on the CA and IGA Type 304 SS consolidated powders. At $1300^{\circ} \mathrm{C}$, the IGA Type 304 SS retained an austenitic microstructure, but suffered from a loss in grain growth resistance; an increase of more than a factor of 10 in grain size occurred between 1200 and $1300^{\circ} \mathrm{C}$. However, for the CA Type 304 SS, ferrite formed around the grain boundaries and substantially retarded growth of the austenitic grains (see Figure 50 ). At $1400^{\circ} \mathrm{C}$, both IGA and CA materials showed a fine grain size with the ferrite phase along the grain boundaries.

The studies on the $\mathrm{Fe}-40 \mathrm{Ni}$ alloy series have included several variations in the powder processing parameters. ${ }^{5}$ Among these are using several helium flow rates for convective cooling in CA and using both helium and argon for VGA. The powders from this series were consolidated by HIPping "grab-type" powder distributions, followed by cold rolling. The grain growth behavior of the Fe-40Ni consolidated powders and their CPC is shown in Figure 63. The results clearly show grain growth retardation for the entire RSP series. There may be a correlation between the powder atomization method and grain size for the consolidated specimens. The grain sizes are slightly larger for VGA than for CA specimens, which follows the same pattern as the boundary spacings in the powder microstructure (Figure 9a). At $1300^{\circ} \mathrm{C}$, marked grain growth occurs for all specimens (data not shown in figure).

In summary, these studies demonstrated that the powder-processing method had little effect on the grain growth behavior of PSP iron-base alloys. The influence of powder processing on the powder characteristics (i.e., solidification rate effects on morphology and fineness of the microstructure) apparently has no significant relation to grain growth. However, all of the powder processing methods investigated (i.e., CA, JGA, and VGA), are associated with fine and stable grain sizes after powder consolidation. 


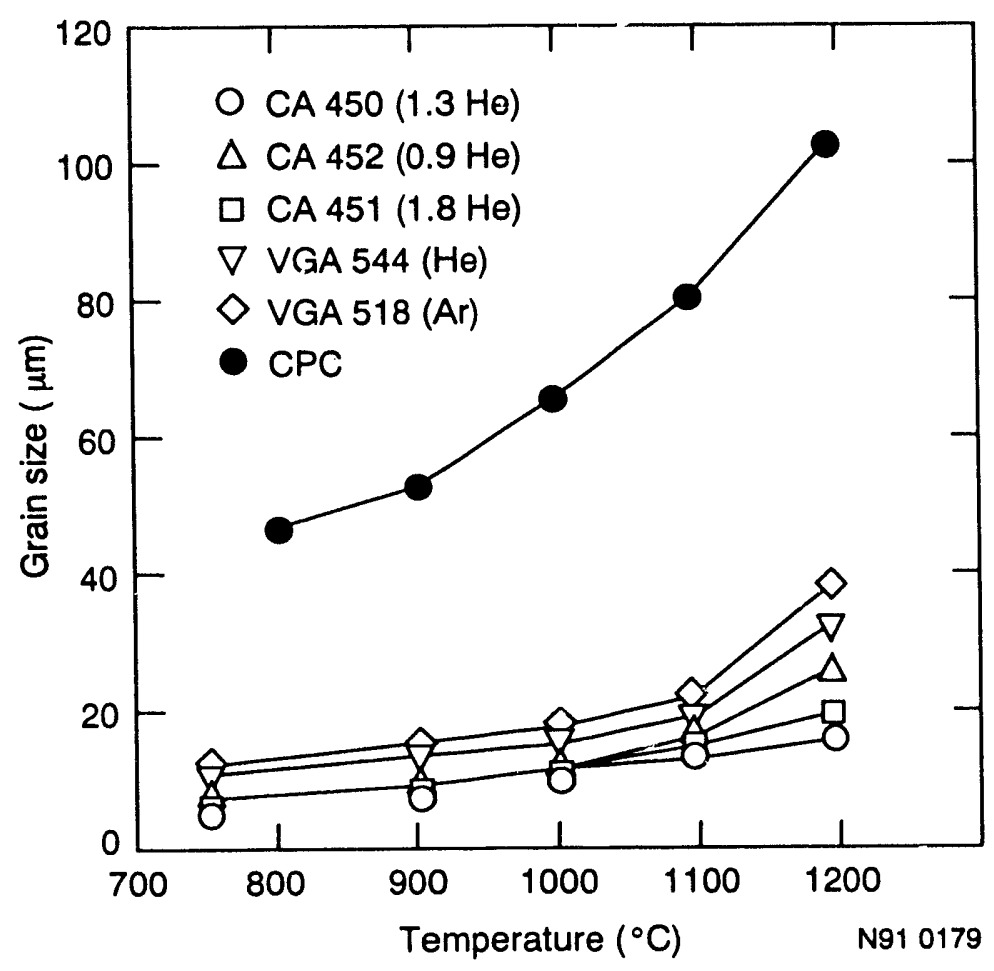

Figure 63. Influence of $1 \mathrm{~h}$ heat treatments on the grain size for CPC Fe-40Ni and for $C A$ and VGA Fe-4ONi powders with different atomization parameters after HIP consolidation and cold working.

\section{Powder Consolidation}

From the section summarizing the consolidation aspects for RSP iron-base alloy powder, it was evident that most of the evaluation was performed on CA Type 304 SS. The grain size was determined from extruded, dynamically consolidated, HIPped, and HIPped plus cold worked specimens after $1 \mathrm{~h}$ heat treatments at 900 to $1200^{\circ} \mathrm{C}$. These measurements show that the consolidation method has very little effect on the grain growth (see Figure 64).

\section{Thermal-Mechanical Processing}

Powder consolidation is obviously a form of thermal-mechanical processing, and it appears to have no influence on the grain growth behavior. Additional studies were performed on extrusion consolidated CA Type 304 SS powders that were heat treated at 1100 and $1200^{\circ} \mathrm{C}$ for $1 \mathrm{~h}$ followed by cold rolling $(-50 \%)$, arid then reheat treated for $1 \mathrm{~h}$ at various temperatures to 


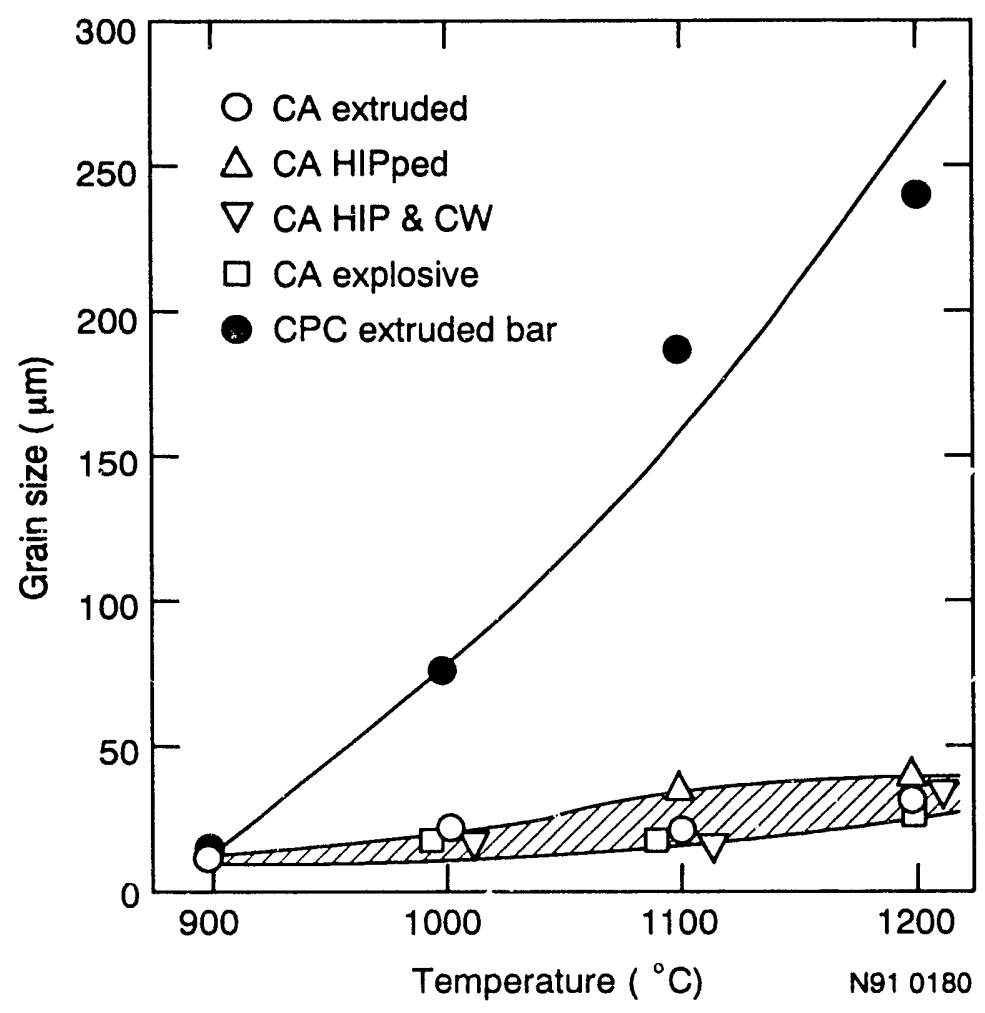

Figure 64. Influence of $1 \mathrm{~h}$ heat treatments on the grain size for CPC and CA Type 304 SS powders after consolidation by different methods.

$1300^{\circ} \mathrm{C}$. The grain sizes observed, as well as those observed after heat treatments on as-extruded powders without prior cold work, are shown in Figure 65 . The data in Figure $65 \mathrm{a}$ show that between 1100 and $1200^{\circ} \mathrm{C}$ a significant increase in grain size (approximately a factor of three, except for the $1200^{\circ} \mathrm{C}, 1 \mathrm{~h}$ preconditioned series, which shows an apparent memory effect to be discussed below) occurs, but the grains remain substantially smaller than those in the CPC (see Figure 64). The structure at 1100 and $1200^{\circ} \mathrm{C}$ is austenitic. As noted earlier, at $1300^{\circ} \mathrm{C}$ ferrite is observed around the grain boundaries (see Figure 50). The factor of three increase in grain size between 1100 and $1200^{\circ} \mathrm{C}$ indicates that grain boundary destabilization is starting.

The $1100^{\circ} \mathrm{C}, 1 \mathrm{~h}$ preconditioned specimen series, after cold rolling and annealing, shows a grain size behavior that is nearly identical to the annealing behavior of the as-extruded material. The specimen preconditioned at $1200^{\circ} \mathrm{C}$ for $1 \mathrm{~h}$, cold worked, and annealed (Figure 65a) shows an apparent memory effect. The starting grain size prior to cold working was about 


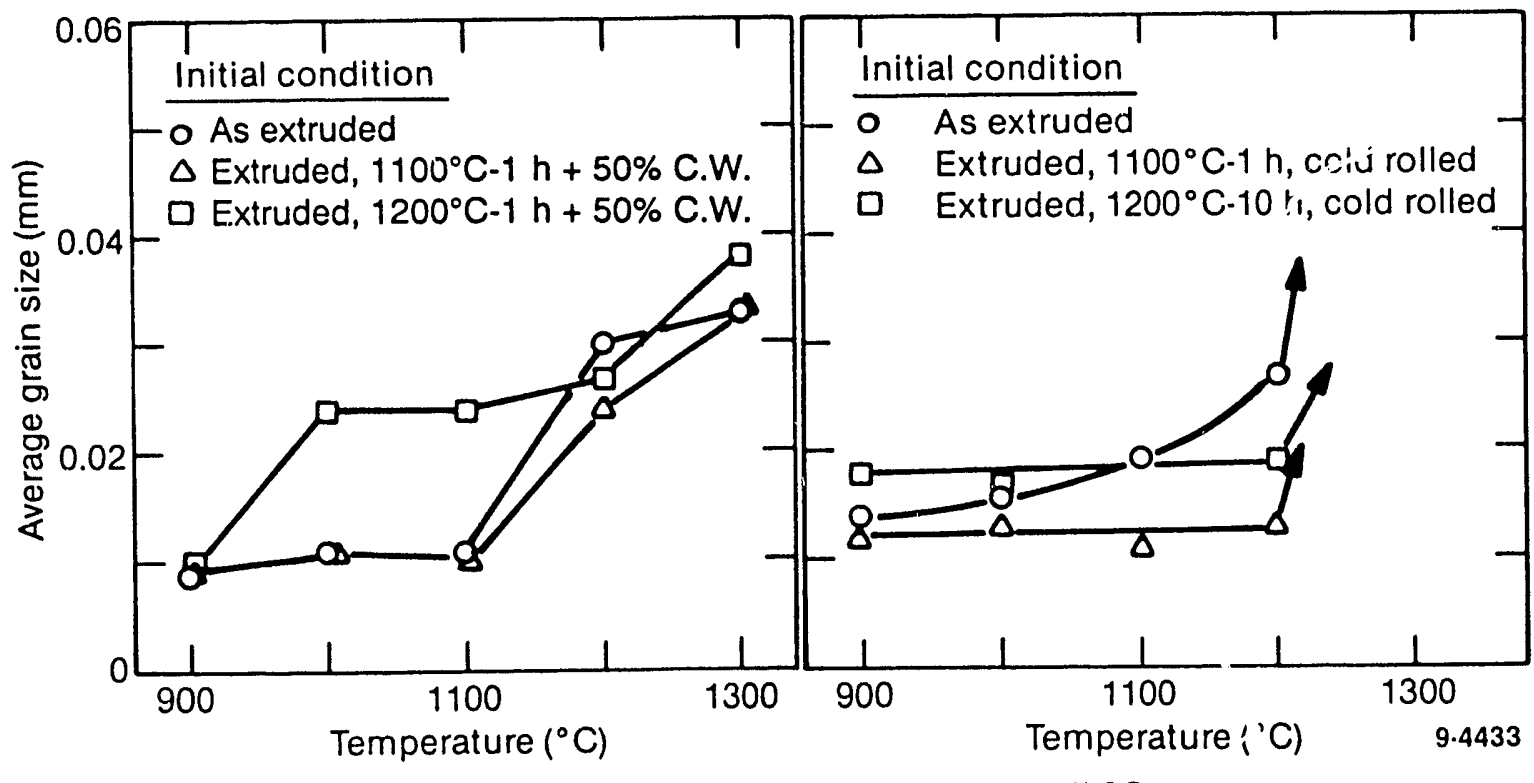

a) CA $304 \mathrm{SS}$

b) VGA Fe-16Ni-9Cr

Figure 65. Influence of $1 \mathrm{~h}$ reheat treatments on grain size for extruded $C A$ Type 304 SS and VGA Fe-16Ni-9Cr powders with two thermal-mechanical processing conditions. (Note: grain sizes for $\mathrm{Fe}-16 \mathrm{Ni}-9 \mathrm{Cr}$ are $0.02 \mathrm{~mm}$ for $1100^{\circ} \mathrm{C} / 1 \mathrm{~h}$ and $-1 \mathrm{~mm}$ for $1200^{\circ} \mathrm{C} / 10 \mathrm{~h}$ initial conditions, prior to reheat treatment.)

$0.030 \mathrm{~mm}$. After cold working, annealing at $900^{\circ} \mathrm{C}$ produced a recrystallized grain size $(0.010 \mathrm{~mm})$ equivalent to those of the other two specimen series. However, at $1000^{\circ} \mathrm{C}$ the grain size jumped to $\sim 0.025 \mathrm{~mm}$, which is nearly equivalent to its starting grain size prior to the cold working, and it retains this grain size through the $1200^{\circ} \mathrm{C}$ anneal. This behavior implies that this specimen series has a memory of its prior history.

Another interesting thermal-mechanical treatment study involved the VGA Fe-16Ni-9Cr extruded powder. Portions of an extruded bar were heat treated at $1100^{\circ} \mathrm{C}, 1 \mathrm{~h}$, and $1200^{\circ} \mathrm{C}, 10 \mathrm{~h}$. The grain sizes were 0.020 and $-1.0 \mathrm{~mm}$, respectively. Each section was then cold rolled to $-50 \%$ reduction in thickness and reannealed for $1 \mathrm{~h}$ at various temperatures. The grain size results for these two specimen series, as well as for the heat treatments performed on the as-extruded powder material, are shown in Figure 65b. Neither preconditioned specimen series shows a history influence; this is particularly surprising for a specimen series that started with a very large grain size (i.e., $-1 \mathrm{~mm}$ ) prior to cold rolling and annealing. The $1300^{\circ} \mathrm{C}, 1 \mathrm{~h}$ heat treatments produced greatly enlarged grairs for all three conditions. 


\section{Particle Size Effects}

The influence of powder particle size on grain growth was investigated using IGA stainless steels; the only influence noted was for A286 at the higher temperatures. The alloys discussed below were extruded $\left(\right.$ at $900^{\circ} \mathrm{C}$ ) from the following screened particle sizes (in $\mu \mathrm{m}$ ): $>10$ to $<30,>30$ to $<50,>50$ to $<75,>100$ to $<150$, and $>10$ to $<150$ (grab distribution).

The grain sizes determined for the IGA Type 304 SS extruded powders after $1 \mathrm{~h}$ heat treatments are shown in Figure 66. There was no grain growth after the 900 to $1100^{\circ} \mathrm{C}$ heat treatments, but at $1200^{\circ} \mathrm{C}$ the increase in grain size was nearly a factor of three [similar to that observed for the CA Type 304 SS (see Figure 65a)] for all size fractions. At $1300^{\circ} \mathrm{C}$, abnormal grain growth with over a factor of 10 increase in grain size is observed, whereas for the CA Type 304 SS extruded powder, a ferrite phase had formed at the grain boundaries and retarded the grain growth. For the IGA series, there was no evidence of ferrite after the $1300^{\circ} \mathrm{C}$ heat treatment, but ferrite was prevalent after treatment at $1400^{\circ} \mathrm{C}$ and the resulting grain growth inhibition is evident in the figure. The results shown in Figure 66 do not indicate an influence of powder particle size on grain size/growth. Powder characteristics that are observed to be dependent on particle size (oxygen content from oxide film and dendrite arm spacing) are also showr in Figure 67. These results clearly show that break up and redistribution of the oxide film on the particles during extrusion and solidification rate effects associated with the powder processing have no apparent influence on the grain growth behavior of this IGA processed alloy.

The results for the IGA processed $\mathrm{Fe}-16 \mathrm{Ni}-9 \mathrm{Cr}$ alloy (see Figure 68) also show no influence of particle size on grain size. This alloy also shows that the solidification microstructure and oxygen content associated with powder particle films are similar to those of the IGA Type 304 SS shown in Figure 67. The grain size behavior for the IGA Fe-16Ni-9Cr series is similar to that of the VGA Fe-16Ni-9Cr (see Figure $65 \mathrm{~b}$ ), except at $1300^{\circ} \mathrm{C}$ where abnormal grain growth occurs for the VGA alloy but not the IGA (Figure 68). This difference is apparently associated with the $1.5 \mathrm{wt} \%$ Mn content in the VGA alloy; Mn was not added to the IGA material. 


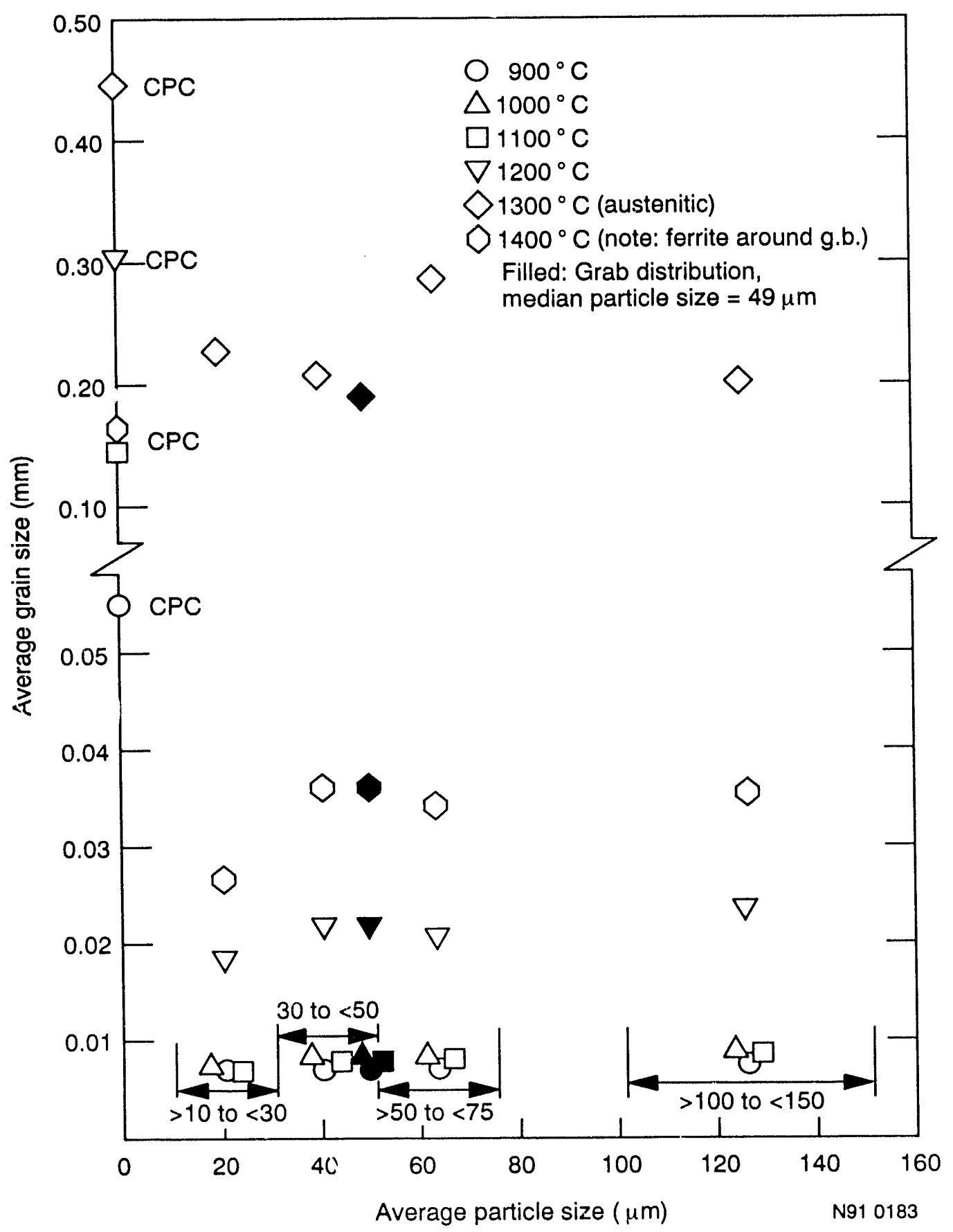

Figure 66. Influence of powder particle size on grain size after $1 \mathrm{~h}$ heat treatments for IGA Type 304 SS extruded powders.

The grain size results for the IGA A286 superalloy are shown in Figure 69. As with the other alloys, IGA A286 shows a substantial resistance to grain growth compared to its CPC. However, unlike the previous two IGA alloy examples, powder particle size does appear to influence the grain growth at the higher temperatures. The particle size influence is attributed to the 
Influence of Particle Characteristics on Grain Growth for IGA Type 304SS Extruded Powders

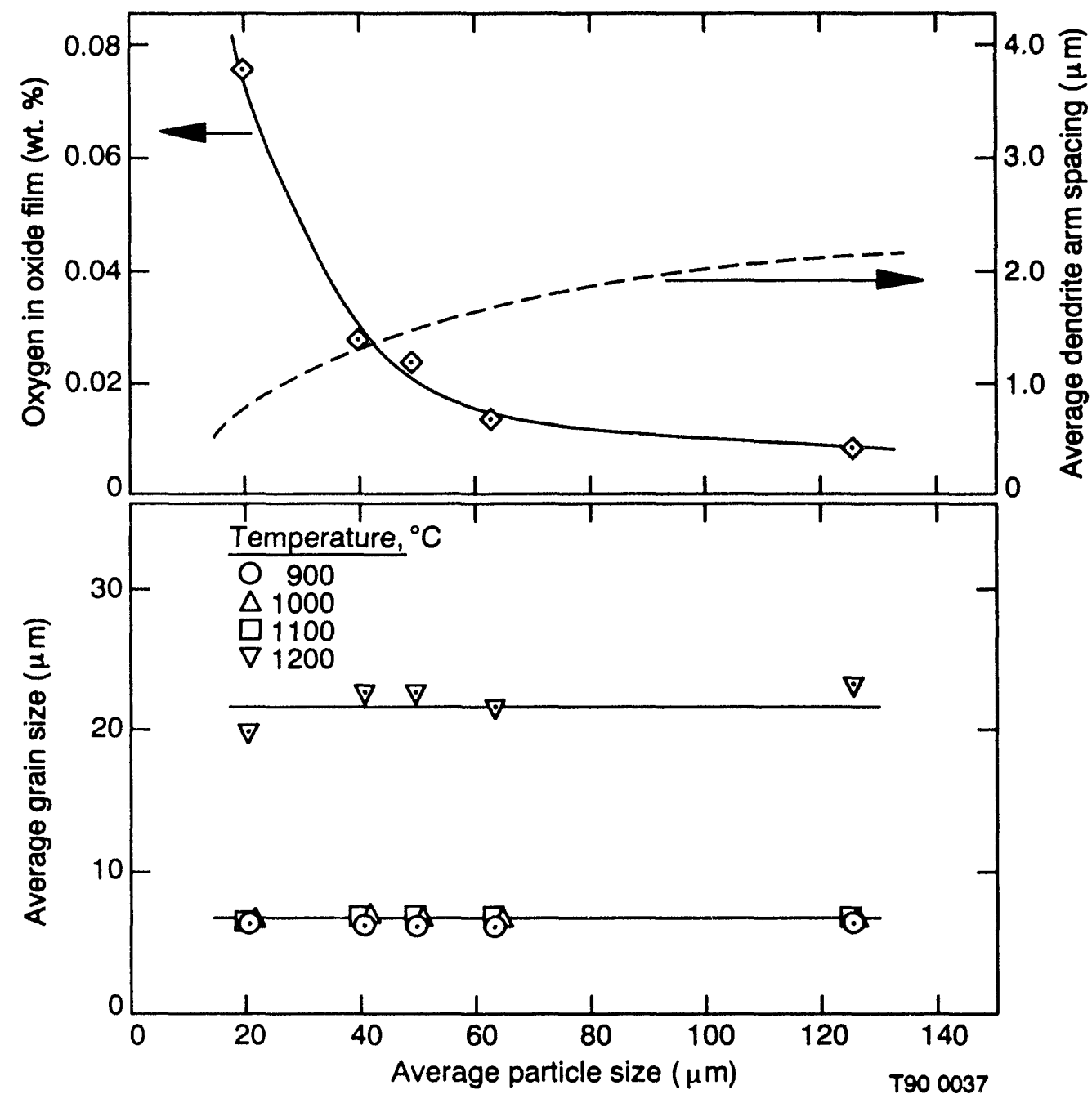

Figure 67. Influence of powder particle size on oxide film, dendrite arm spacing, and grain size after $1 \mathrm{~h}$ heat treatments for IGA Type 304 SS extruded powders.

oxide surface film on A286 IGA powders, although the surface film had no effect on the two stainless steel IGA materials discussed previously. The oxide film on this alloy contained significant levels of titanium (Figure 16) with the film thickness independent of particle size (Figure 45). The titanium-iron oxide film caused banding in the extrusion consolidated alloy, as is evident in the microstructures shown in Figures 25 and 70 . The IGA Fe$16 \mathrm{Ni}-9 \mathrm{Cr}-2 \mathrm{Mo}-1.5 \mathrm{Mn}-1 \mathrm{Si}-0.5 \mathrm{Ti}$ extruded powders behaved similarly. Titanium migration to the particle surface during powder processing is a form of chemical segregation that may be unpreventable. When banding is detrimental, 


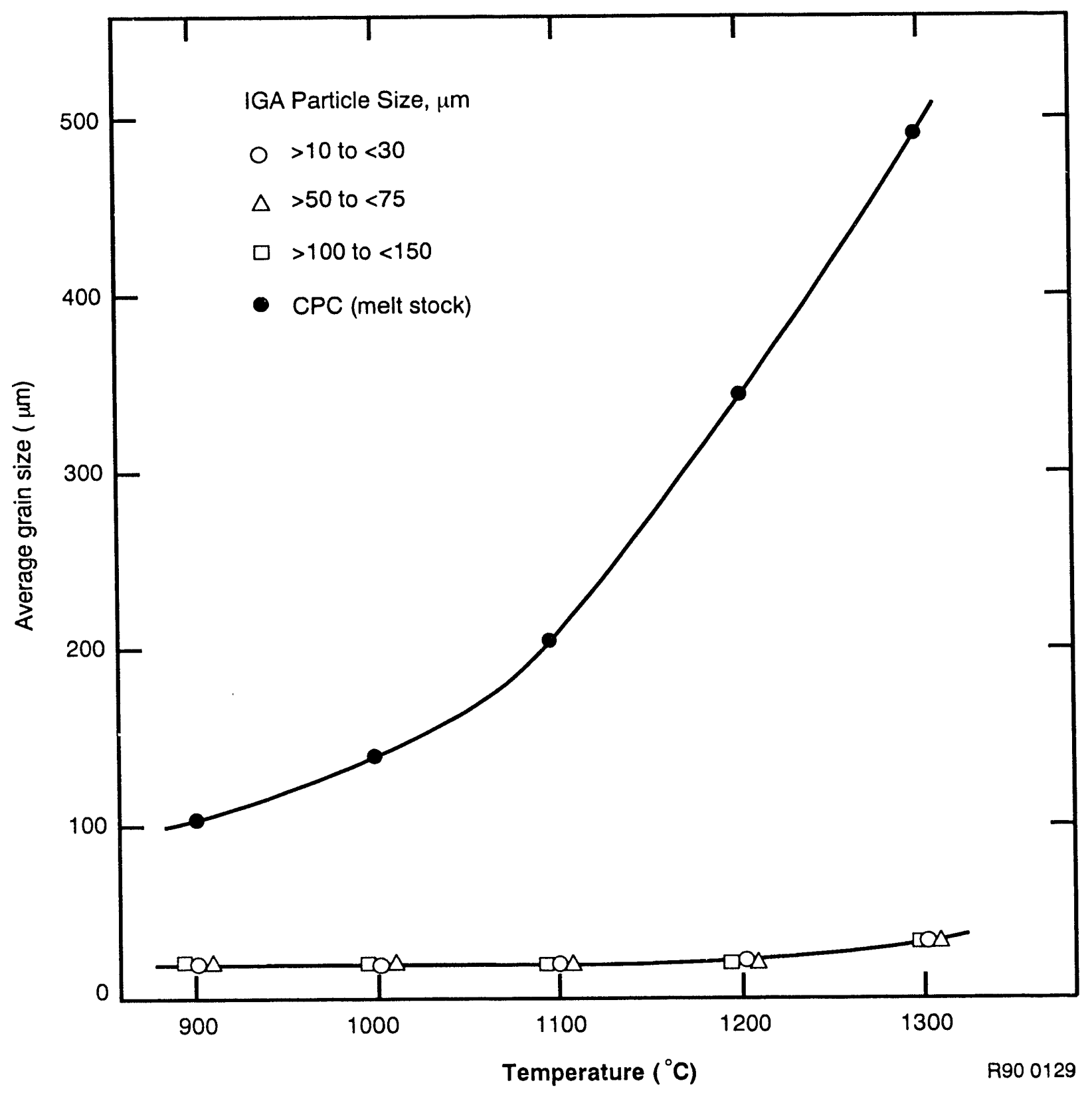

Figure 68. Grain size after $1 \mathrm{~h}$ heat treatments for IGA Fe-16Ni-9Cr extruded powders of different particle sizes and the CPC material.

a forging treatment on the consolidated powder may be needed to break up or disperse the surface films on the particles:

\section{Composition Influences}

The grain size results shown in Figures 62-69 are from different alloys, and it is interesting to note that for a given temperature the grain sizes are 


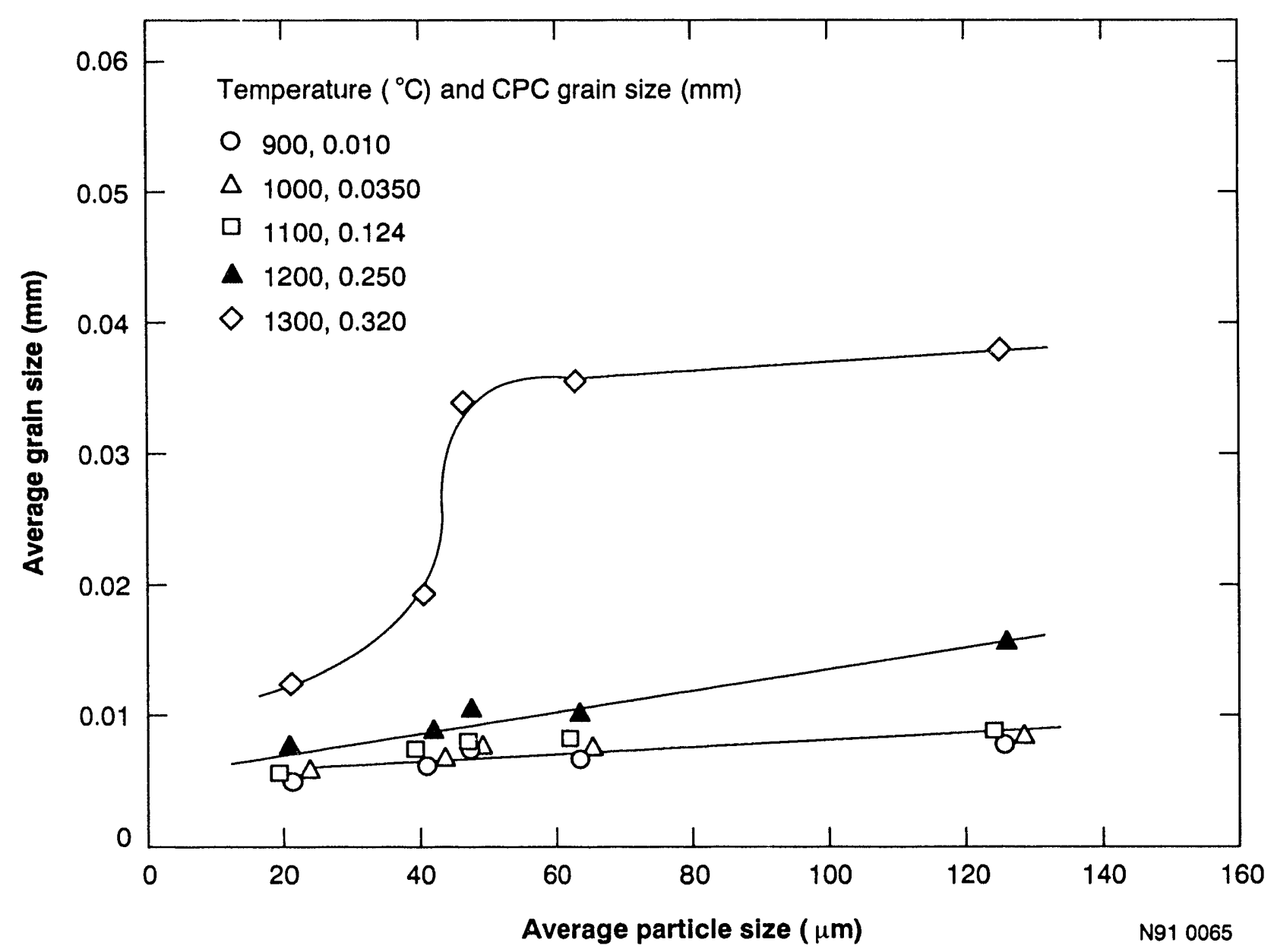

Figure 69. Influence of powder particle size on grain size for IGA extruded A286 after $1 \mathrm{~h}$ heat treatments.

surprisingly similar. Two additional examples are presented to illustrate the effects of minor elemental additions on grain size. Figure 71 presents the grain size results for $\mathrm{CA}$ and consolidated $\mathrm{Fe}-40 \mathrm{Ni}$ and Fe-40Ni-0.3Nb-0.05C. For temperatures to $1200^{\circ} \mathrm{C}$, it appears that the $\mathrm{Nb}$ and $\mathrm{C}$ additions ( $\mathrm{NbC}$ dispersions) have no influence on the grain size. Above $1200^{\circ} \mathrm{C}$, these additions appear to have a significant influence on the grain size.

The second example is the CA Fe-20Ni-20Cr alloy with three carbon levels. The grain sizes observed are shown in Figure 72 as a function of carbon content for several heat treating temperatures; the CPC material is included for comparison. The results show a possible, but modest, influence

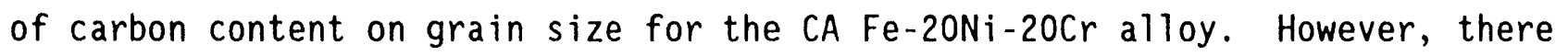



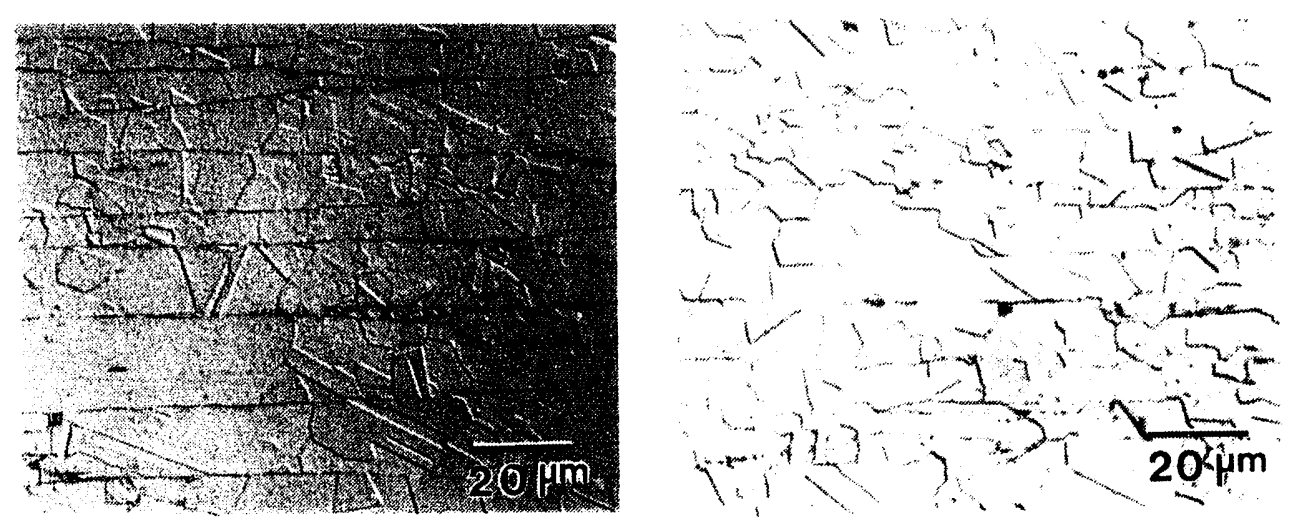

Figure 70. Microstructure (longitudinal view) of 30-50 $\mu \mathrm{m}$ (1eft) and 100-150 $\mu \mathrm{m}$ (right) IGA A286 particles after extrusion and heat treatment at $1200^{\circ} \mathrm{C}$ for $1 \mathrm{~h}$.

appears to be a strong dependence on carbon for the CPC specimens, particularly below 0.04 wt\% carbon.

\section{Grain Growth Retardation Mechanisms}

It is well recognized that the most important driving force for grain growth is the surface energy of the grain boundaries. The evidence from the RSP iron-base alloys clearly shows that, in comparison to their CPCs, they all display fine grains and substantial grain growth resistance, particularly in the 1100 to $1200^{\circ} \mathrm{C}$ range. These temperatures are normally considered to be more than adequate for solution annealing. Obviously, RSP has substantially influenced the grain boundaries; this influence will be addressed in this section. The following is a summation of the parametric influences on the observed grain growth of the RSP iron-base alloys.

1. The powder atomization method does not appear to influence grain growth. However, the atomization method may affect the recrystallized grain size because the processes with lower solidification rates tend to yield larger initial grain sizes in the consolidated products.

2. The consolidation method used does not appear to influence grain growth. 


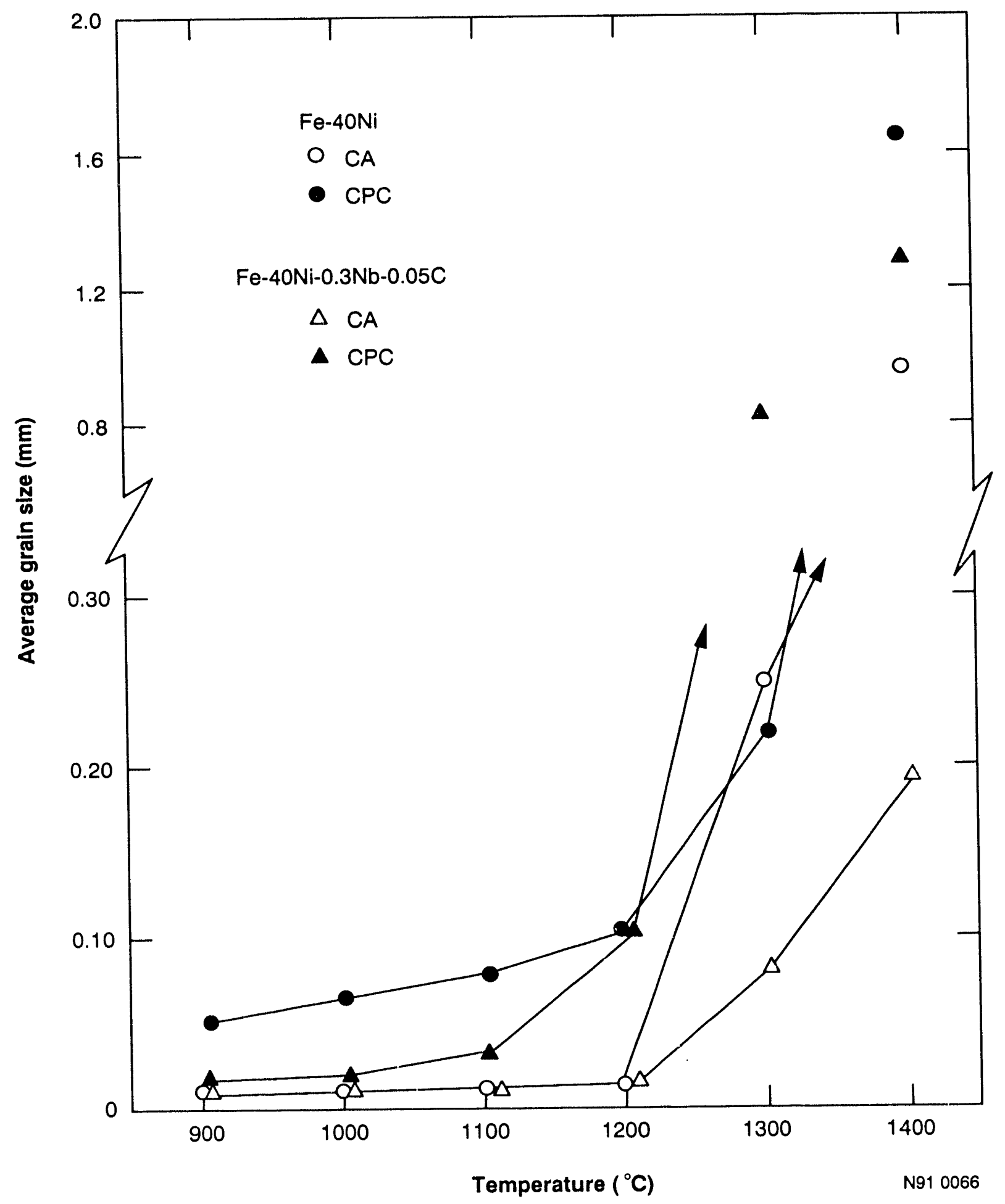

Figure 71. Grain growth behavior of CA, HIPped, and cold worked Fe-40Ni and Fe$40 \mathrm{Ni}-0.3 \mathrm{Nb}-0.05 \mathrm{C}$ powders and the ir CPC. 


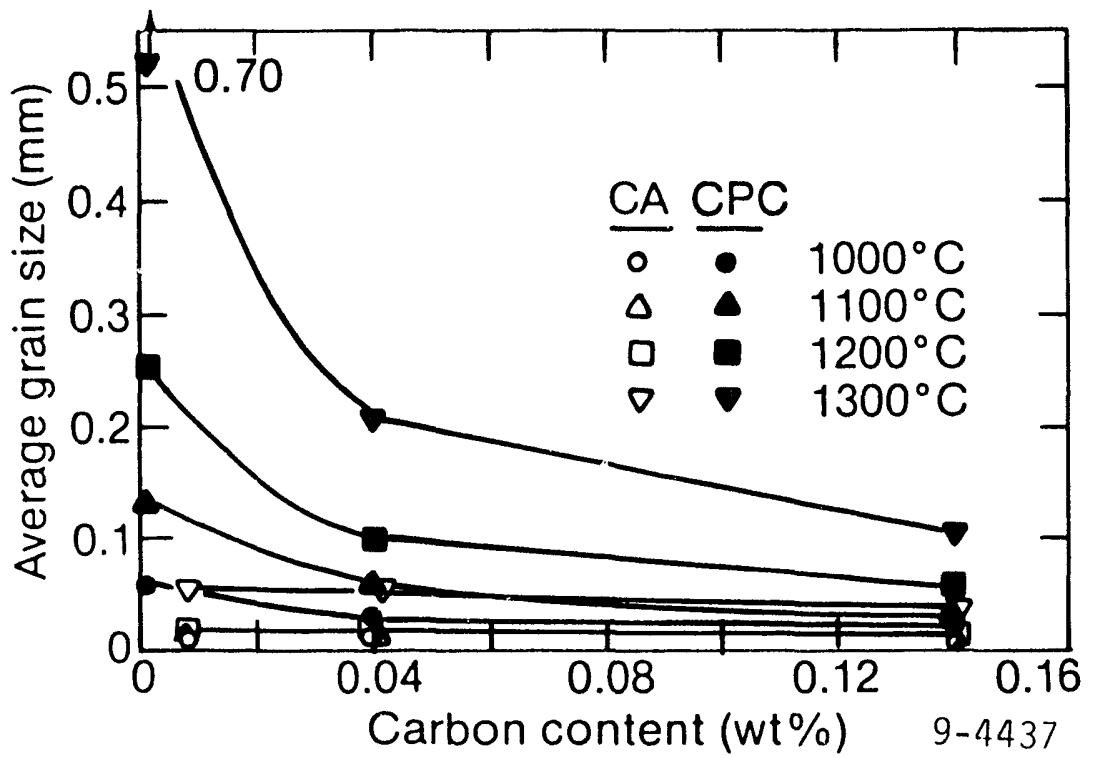

Figure 72. Influence of carbon content on grain size for CA Fe-20Ni-20Cr HIPped and cold worked powders and their CPC.

3. Under certain circumstances, thermal-mechanical processing of the consolidated powders may have a modest influence on the grain growth behavior.

4. Particle size and associated characteristics, such as oxygen contribution from the oxide film and solidification rate, have no apparent influence on the grain growth, with the possible exception of alloys containing titanium.

5. Alloy chemistry, including the highly reactive minor elements such as carbon, has only a modest influence on the recrystallized grain size and subsequent growth.

These observations do not directly explain why fine and stable grain size appears to be a fundamental feature of the atomized iron-base alloy powders after consolidation. The results suggest that the same mechanism for grain growth retardation may operate in all the alioys examined. There appear to be two leading candidates, one of which can be evaluated while the other remains speculative. The first candidate is associated with dispersion pinning. Zener ${ }^{61}$ has put forth the basis for the majority of the theories pertaining to dispersion pinning of grain boundaries. Dispersion pinning as 
the mechanism retarding grain growth can be evaluated from the TEM examinations of precipitates,'dispersions. Using a median/average precipitate size and volume fraction, the dispersion pinning theories permit calculation of an expected grain size for comparison to that observed. The TEM examinations (see Tables 7 and 8 and Figures 53 and 54 ) have provided a good database for precipitate behavior over a large temperature range for $C A$ and IGA Type 304 SS and the CA Fe-40Ni (with and without Nb and C additions). A fairly recent dispersion pinning model, ${ }^{62}$ a modification to the original Zener theory, was used to compute grain size based on matrix-dispersed precipitate data. The expression used for these calculations is

$$
\overline{\mathrm{d}}=\frac{2}{9}(2 \mathrm{r})\left(\frac{1}{\mathrm{f}^{0.93}}\right)
$$

where $\bar{d}$ is the calculatec average grain diameter, $2 r$ is the average particle (precipitate) diameter, and $f$ is the volume fraction of the precipitate.

The results from these calculations, based on the experimental data for precipitates, are shown in Tables 9 and 10 along with measured grain sizes. The extruded CA Type 304 SS powders show reasonable correlations between the calculated and measured grain sizes. A HIPped Type 304 SS specimen had significant deviation between calculated and measured grain sizes. Although the HIPped and extruded CA powders show the same grain size after the $1 \mathrm{~h}$, $1200^{\circ} \mathrm{C}$ heat treatment, the $i r$ precipitate characteristics were considerably different. The results for the IGA Type 304 SS show a fairly large difference between the calculated and measured grain sizes. For example, calculations for the 1100,1200 , and $1300^{\circ} \mathrm{C}$ specimens predict a constant grain size of about $60 \mu \mathrm{m}$, yet the observed grain sizes range from 8 to $210 \mu \mathrm{m}$.

The precipitate data shown in Table 8 were used to calculate the grain sizes for the $\mathrm{Fe}-4 \mathrm{ONi}$ and $\mathrm{Fe}-40 \mathrm{Ni}-0.3 \mathrm{Nb}-0.05 \mathrm{C}$ alloys. The results are shown in Table 10. The differences between the calculated and measured grain sizes (calculation based on the dispersion pinning model) are substantial for the CA as well as CPC alloys. 
Table 9. Correlation of Grain Sizes Calculated From Dispersion Pinning Model and Measured Grain Sizes for RSP and Extruded Type 304 SS

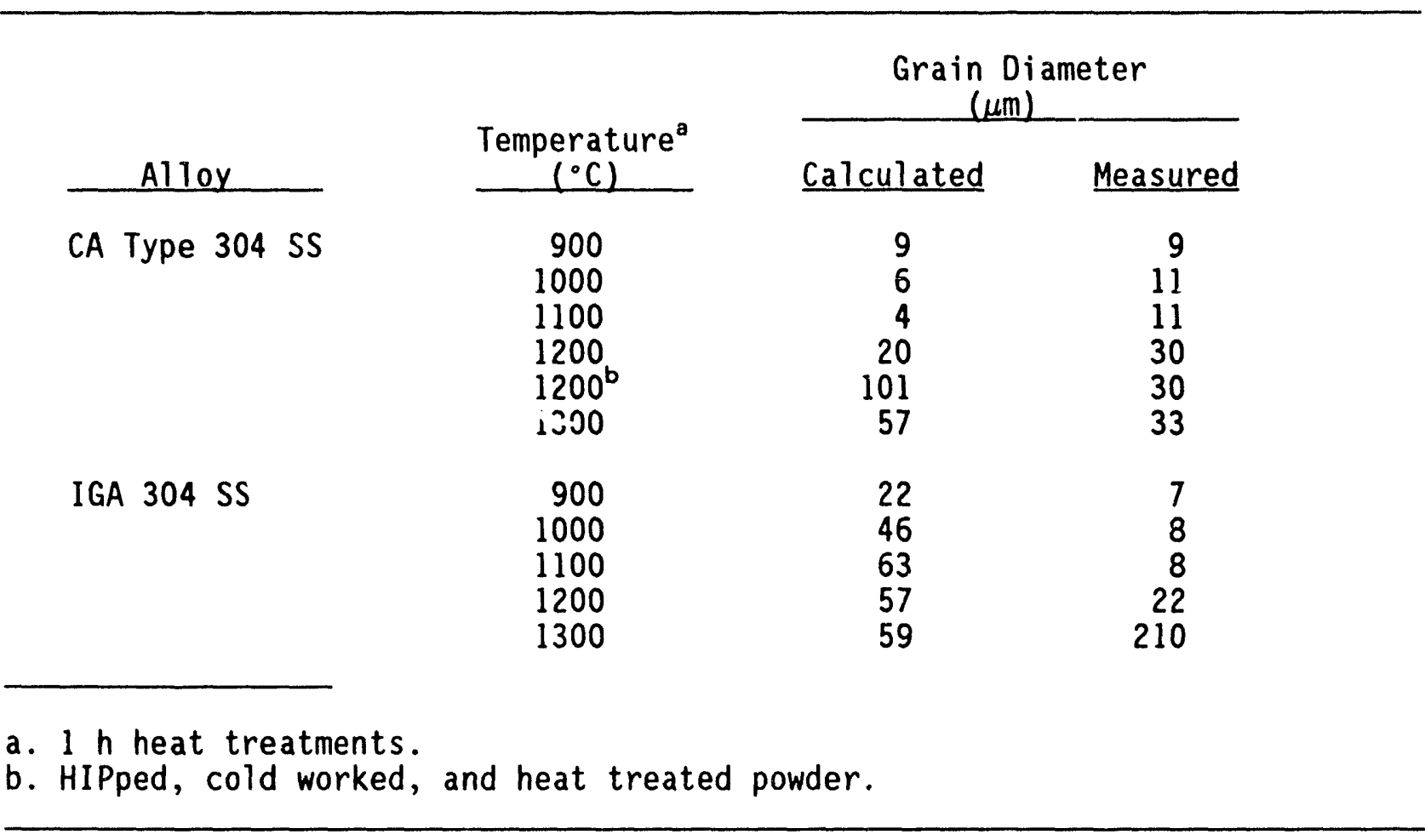

An added important observation comes from the TEM examinations, which occasionally found some precipitates at the grain boundaries: the numbers of grain boundary precipitates have been quite small for the RSP alloys compared to the numbers of matrix precipitates. It is also important to note that, for the alloys examined to date, it is not apparent that the precipitates observed at the grain boundaries have a pinning effect. The comparisons shown in Tables 9 and 10 challenge the more common belief that dispersion pinning is responsible for the grain growth retardation observed in RSP alloys. The comparisons cannot prove that dispersion pinning is not responsible, but they certainly are an incentive to explore other explanations for the observed grain growth retardation. The unanimity of the experimental observations strongly suggests a common mechanism for all of the RSP iron-base alloys.

One common feature of these alloys appears to be oxygen, though its role is not understood at this time. This leads to the second, speculative, explanation of the mechanism for grain growth retardation. Oxygen's 
Table 10. Correlation of Grain Sizes Calculated From Dispersion Pinning Model and Measured Grain Sizes for RSP Fe-40Ni Alloys and their CPCS

\begin{tabular}{|c|c|c|c|}
\hline \multirow[b]{2}{*}{ Alloy } & \multirow{2}{*}{$\begin{array}{c}\text { Temperature } \\
\left({ }^{\circ} \mathrm{C}\right)\end{array}$} & \multicolumn{2}{|c|}{$\begin{array}{c}\text { Grain Diameter } \\
(\mu \mathrm{m})\end{array}$} \\
\hline & & Calculated & Measured \\
\hline $\mathrm{CA} \mathrm{Fe}-40 \mathrm{Ni}$ & $\begin{array}{l}1000 \\
1200 \\
1400\end{array}$ & $\begin{array}{l}2 \\
5 \\
4\end{array}$ & $\begin{array}{r}11 \\
15 \\
950\end{array}$ \\
\hline CPC Fe-40Ni & $\begin{array}{l}1000 \\
1200 \\
1400\end{array}$ & $\begin{array}{l}27 \\
21 \\
-.-9\end{array}$ & $\begin{array}{r}66 \\
102 \\
1650\end{array}$ \\
\hline $\begin{array}{l}\text { CA Fe-40Ni- } \\
0.3 \mathrm{Nb}-0.05 \mathrm{C}\end{array}$ & $\begin{array}{l}1000 \\
1200 \\
1400\end{array}$ & $\begin{array}{l}1.4 \\
3 \\
3\end{array}$ & $\begin{array}{r}9 \\
15 \\
192\end{array}$ \\
\hline $\begin{array}{l}\text { CPC Fe-40Ni- } \\
0.3 \mathrm{Nb}-0.05 \mathrm{C}\end{array}$ & $\begin{array}{l}1000 \\
1200 \\
1400\end{array}$ & $\begin{array}{l}1.5 \\
2 \\
95\end{array}$ & $\begin{array}{r}20 \\
100 \\
1270\end{array}$ \\
\hline
\end{tabular}

contribution to the grain boundaries might be the lowering of surface/grain boundary energy, similar to what appears to be occurring for the nanometer size cavities as discussed previously. The form of oxygen at the grain boundaries is not known, e.g., dissociated state, film, and/or molecular compound (or dispersion) whose size is <l nm. The latter is too small to have been detected during the high resolution examination of the $1.5 \mathrm{~nm}$ cavities.

The parametric studies of grain growth do not provide any evidence against oxygen being a major factor in grain growth retardation in RSP ironbase alloys. Because the mechanistic role of oxygen is not known, the following discussion of the influence of the processing parameters on oxygen and its effects is viewed as speculative, but providing a basis for further analysis.

Powder processing: 0xygen dispersion in the melt and during atomization should be fairly homogeneous with no gross segregation. Conceptually, the 
cooling rate of the molten droplet and subsequent solidification rate would influence oxygen segregation. For example, this, in conjunction with boundary spacing (Figure 9), could explain the apparent influence from powder processing shown in Figure 63 for the Fe-40Ni series, i.e., larger grain size for the VGA powders than the CA. However, because the iron-base alloys investigated all show licicle influence of powder processing on grain growth retardation, even the VGA process appears to have a high enough level of cooling to curtail oxygen segregation.

Powder consolidation. The mechanical deformation associated with powder consolidation should not influence the internally entrained oxygen, although it could affect the oxide films on the particles. The powder consolidation temperatures were relatively low, primarily $900^{\circ} \mathrm{C}$, which would reduce oxygen segregation. Certainly the results presented earlier on the stability of the submicron-microstructural features, as well as grain size, support the view that the consolidation temperatures used for this study should not have a major effect on oxygen segregation.

Thermal-mechanical effects. The results shown for CA Type 304 SS and VGA Fe-16Ni-9Cr in Figure 65 have some very interesting implications regarding possible oxygen effects. This figure could be interpreted as illustrating grain boundary destabilization and grain boundary breakaway phenomena. The CA Type 304 SS shows a factor of three increase in grain size between the 1100 and $1200^{\circ} \mathrm{C}$ heat treatments. The larger grain size (at $1200^{\circ} \mathrm{C}$ ) is remembered after subsequent mechanical processing and heat treatment, suggesting that the $1200^{\circ} \mathrm{C}$ heat treatment has produced an instability at the grain boundaries. The pinning effects of oxygen could have been chemically reduced between 1100 and $1200^{\circ} \mathrm{C}$ because a significant amount of carbon has apparently been released by carbide dissolution (see Figure 53). The carbon could be reacting with oxygen, causing the oxygen to be removed and unavailable for restabilizing the grain boundaries after cold working and reannealing. For the $1100^{\circ} \mathrm{C}, 1 \mathrm{~h}$ heat treatment followed by cold working and reannealing, the oxygen, or at least a significant amount of oxygen, has not been removed from the original grain boundaries, and hence remains available for continued stabilization of the grain boundaries until heat treated at $1200^{\circ} \mathrm{C}$. 
The VGA Fe-16Ni-9Cr alloy has no apparent memory of the large grains produced by the $1200^{\circ} \mathrm{C}, 10 \mathrm{~h}$ heat treatment followed by cold working and reannealing (Figure $65 \mathrm{~b}$ ). This would imply that the heat treatments $\geq 1200^{\circ} \mathrm{C}$, $1 \mathrm{~h}$, produced a grain boundary breakaway from oxygen influences at the grain boundaries, and that the oxygen fields from the prior grains have not been removed. As a result, the cold-worked, large grain material could use the residual oxygen fields for grain growth retardation during reannealing.

Particle size influences. The IGA Type 304 SS extruded powder showed no evidence that particle size influenced grain growth (see Figure 67). The amount of oxygen entrained and its morphology would be expected to be independent of particle size because the solidification rates are quite high for all particle sizes (Figure 11). The grain growth behavior for the IGA Type 304 SS series is very similar to that of the CA Type 304 SS, where a threefold increase in grain size occurs between 1100 and $1200^{\circ} \mathrm{C}$. This suggests that some form of oxygen destabilization has occurred at the grain boundaries. The IGA alloy series, however, shows that marked grain growth occurs at $1300^{\circ} \mathrm{C}$ (approximately a tenfold increase compared to the $1200^{\circ} \mathrm{C}$ heat treatment). Tests are underway to evaluate the thermal-mechanical (history) effects on the IGA material. The tests will involve a preconditioning heat treatment at $1300^{\circ} \mathrm{C}, 1 \mathrm{~h}$, which will produce $\sim 0.25 \mathrm{~mm}$ grain size, followed by cold rolling and reannealing.

The banding behavior associated with the titanium-iron oxide films that form on atomized powders of alloys such as A286 and $\mathrm{Fe}-16 \mathrm{Ni}-9 \mathrm{Cr}-2 \mathrm{Mo}-1.5 \mathrm{Mn}-1 \mathrm{Si}-$ $0.5 \mathrm{Ti}$ requires further evaluation. For residual oxygen to be effective for microstructural stability, the quantities of strong deoxidizers, such as titanium, must be controlled, probably to low levels, to preclude melt deoxidation. The banding phenomenon needs to be further studied, particularly using high resolution analytical electron microscopy techniques. Conventional thinking would interpret the banding behavior (e.g., Figure 70) as strictly a form of dispersion pinning from a linear array of titanium oxide particles. It is possible that the band zones contain some residual uncombined oxygen, i.e., not all of the oxygen is tied up as titanium-iron oxides. 


\section{Microstructural Issues}

Although this section has provided considerable evidence for the microstructural stability of the RSP iron-base alloys, further effort is required to understand microstructural development and control. The importance of vacancy trapping during rapid crystallization and oxygen solute addition are issues that have arisen from this study. Future developments in RSP of iron-base alloys should focus on optimum use of these two features.

\section{Mechanical Behavior.}

A considerable effort has been devoted to correlating mechanical property behavior with microstructure for the RSP iron-base alloys and their CPCS. These correlations have provided insight on the effects of powder processing and consolidation on the alloy. In this section, some of the results from the mechanical property tests will be presented; correlations of these results with the microstructural observations will be presented in the following section.

\section{Tensile Properties}

Tensile properties have been determined for all of the iron-base alloys shown in Table 1. Stress-strain curves for the VGA Fe-16Ni-9Cr extruded powder's and their CPC are shown in Figure 73 . It is apparent that significant strengthening has occurred with some reduction in ductility. However, substantial ductility remains. The influences of annealing temperature and test temperature on the yield and uitimate tensile stresses and on ductility for this alloy are shown in Figures 74 and 75 , respectively.

Stress-strain curves for the CA Type 304 SS extruded powders and their $C P C$ are shown in Figure 76. The strengthening for the $C A$ alloy compared to its CPC is apparent. Its ductility has been reduced, but the reduction is modest. The influence of the powder consolidation methods on the room temperature tensile properties ofCA Type 304 SS is shown in Figure 77 . Prior to testing, the $C A$ specimens were given $1-h$ pre-condition heat treatments (PCHis) at 900 and $1100^{\circ} \mathrm{C}$. The $900^{\circ} \mathrm{C}$ heat treatment did not produce a fully 


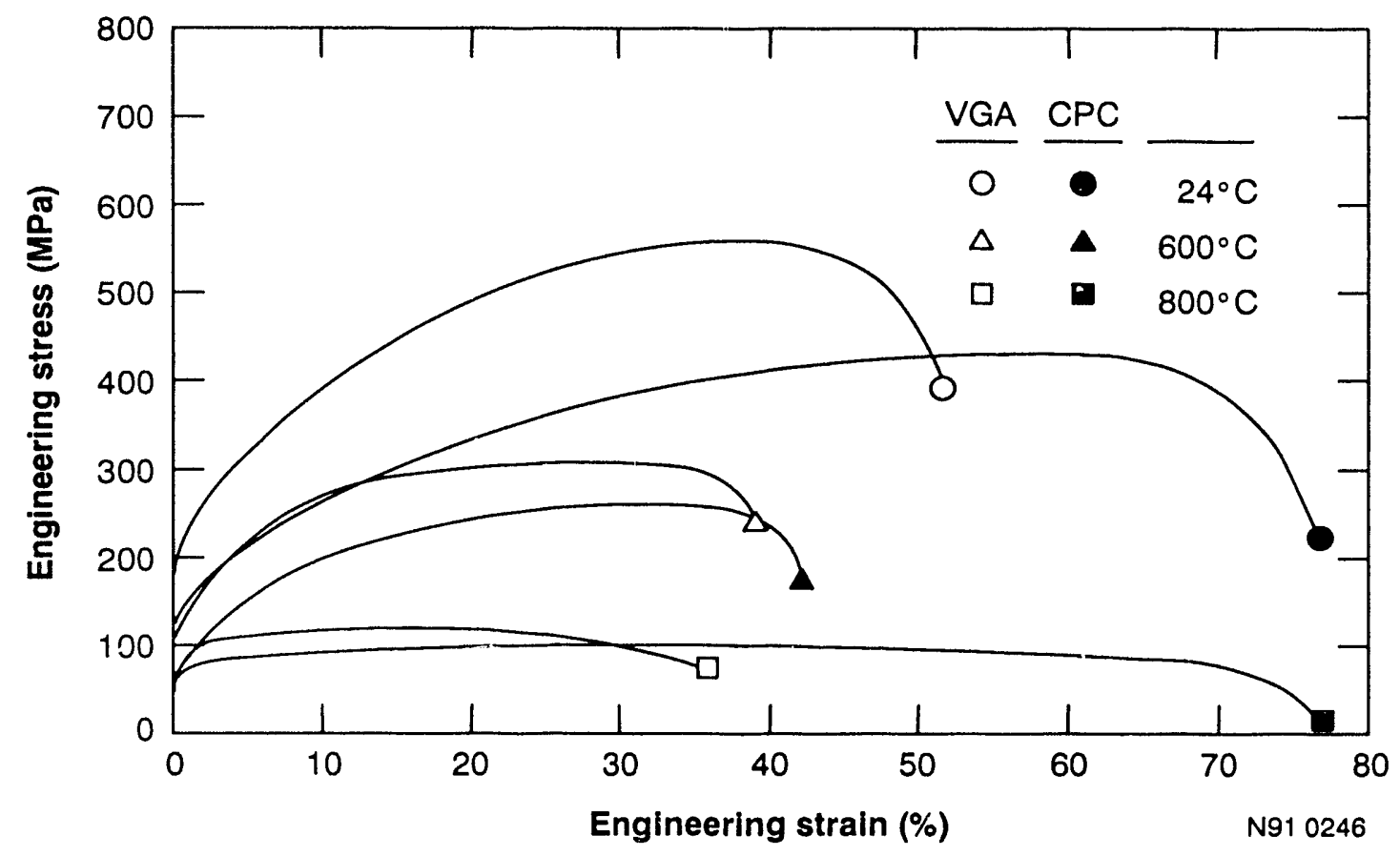

Figure 73. Engineering stress-strain curves at various temperatures after $1 \mathrm{~h}, 1100^{\circ} \mathrm{C}$ heat treatments for CPC and VGA extruded $\mathrm{Fe}-16 \mathrm{Ni}-9 \mathrm{Cr}$ powder.

annealed condition, which is evident from the properties shown in the figure. After the $1100^{\circ} \mathrm{C}$ heat treatments, the tensile behavior appears to be relatively insensitive to the consolidation method. The studies of che IGA Type 304 SS extruded powders addressed the influence of powder particle size. Tensile properties at $600^{\circ} \mathrm{C}$ are shown in Table 11 , along with the results for the CA Type 304 SS extruded powder and the CPC. The IGA and CA processed and consolidated powders have equivalent tensile properties. Their strengths are significantly greater than that of the CPC material and their ductilities are only slightly reduced. Prior particle size had no apparent influence on tensile properties (based on the IGA series). The IGA processed $\mathrm{Fe}-16 \mathrm{Ni}-9 \mathrm{Cr}$ extruded powder series, with five different particle sizes, also showed no influence of particle size on tensile properties. ${ }^{63}$

The two alloys that contain significant levels of titanium (A286 and the experimental $\mathrm{Fe}-16 \mathrm{Ni}-9 \mathrm{Cr}-2 \mathrm{Mo}-1.5 \mathrm{Mn}-1 \mathrm{Si}-0.5 \mathrm{Ti}$ ) do show an apparent influence of particle size on tensile properties. Figure 78 illustrates the influence of $1 \mathrm{~h}$ isothermal anneals on the room temperature yield and ultimate tensile stresses for three particle sizes from the A286 series. Although powder particle size appears to influence the yield and ultimate stresses, the 


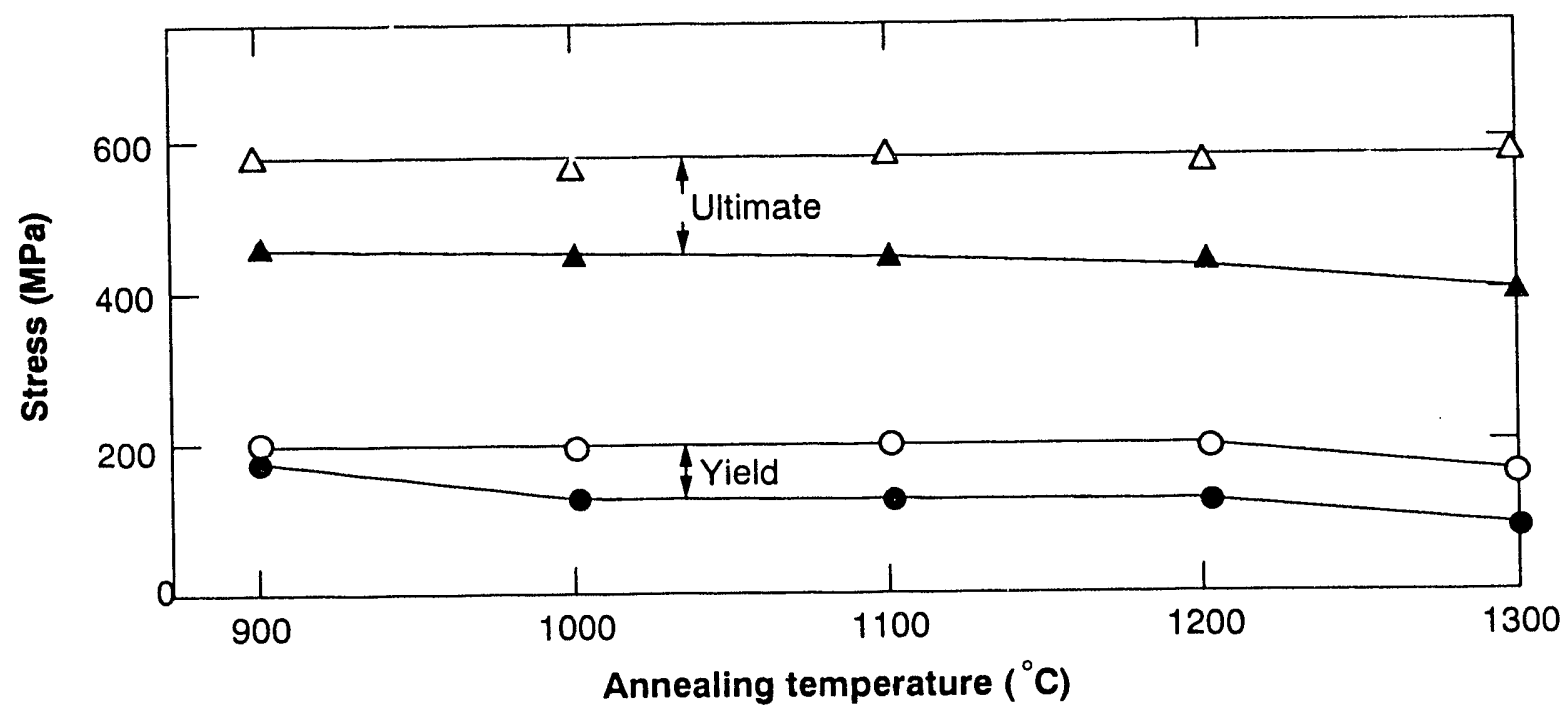

(a) Room temperature tests

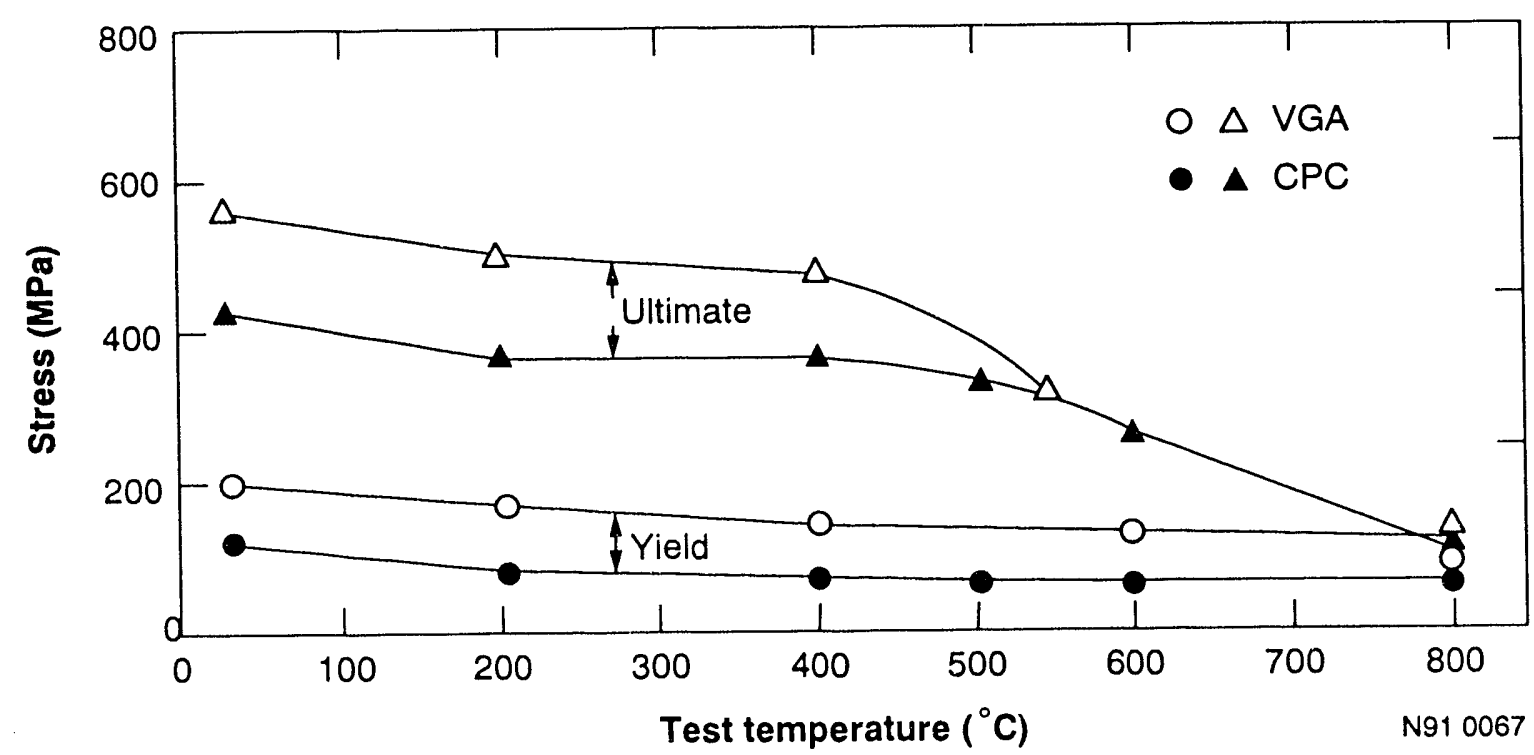

(b) After $1100^{\circ} \mathrm{C}, 1 \mathrm{~h}$ heat treatment

Figure 74. Influence of temperature on yield and ultimate tensile stresses for $C P C$ and VGA Fe-16Ni-9Cr extruded powder.

ductility behavior (elongation and reduction in area) showed very little influence from particle size. ${ }^{64}$ Annealing temperature significantly influenced yield stress but had less influence on ultimate stress, except for the CPC specimens. It is also apparent from these results that the IGA processed and extruded powders had significantly greater strength than the $C P C$. The influerice of powder particle size on the room temperature yield stress after $1 \mathrm{~h}$ anneals at $1100^{\circ} \mathrm{C}$ for the unaged and aged $\left(700^{\circ} \mathrm{C}, 100 \mathrm{~h}\right.$ ) 


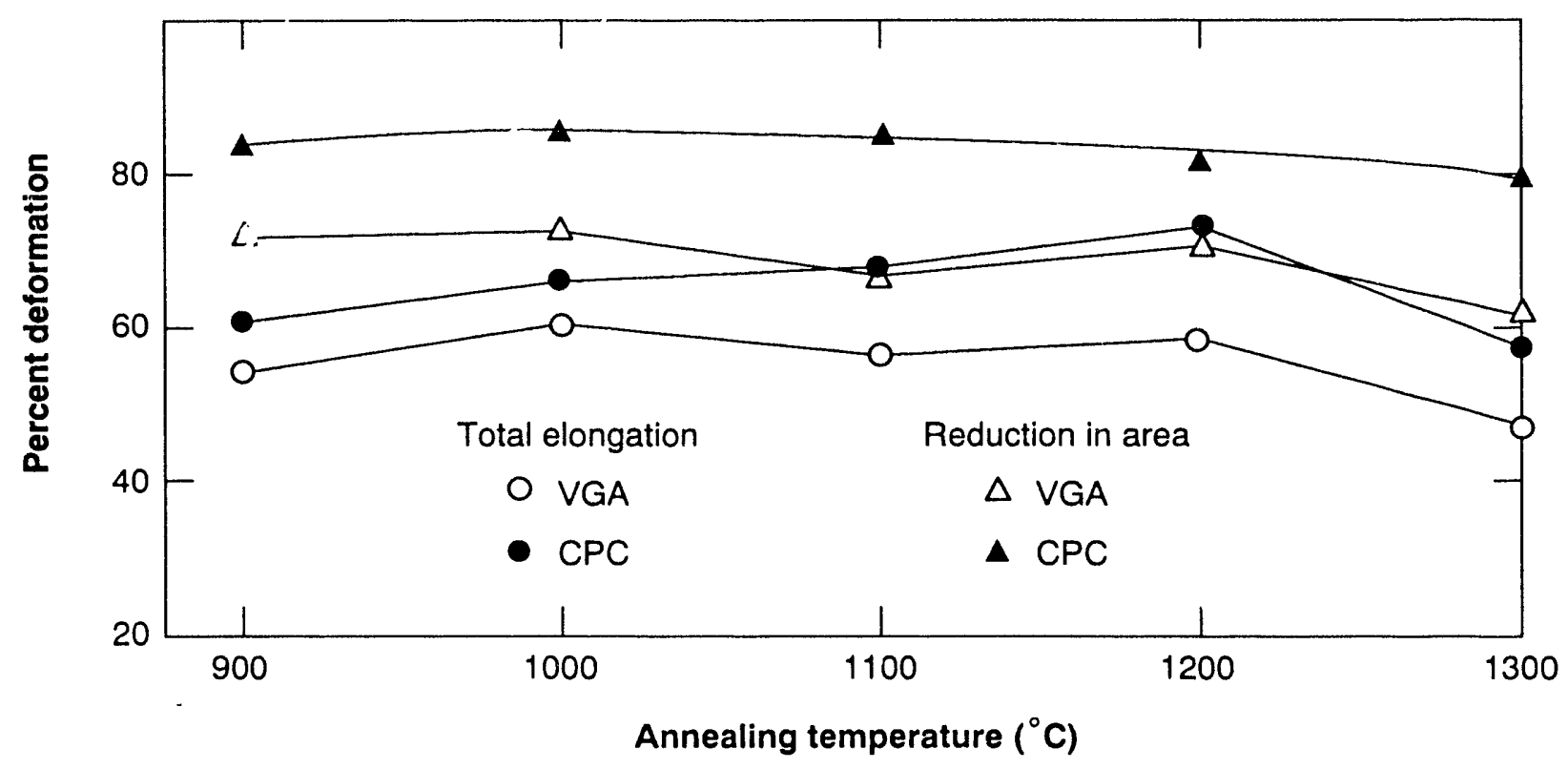

(a) Room temperature tests

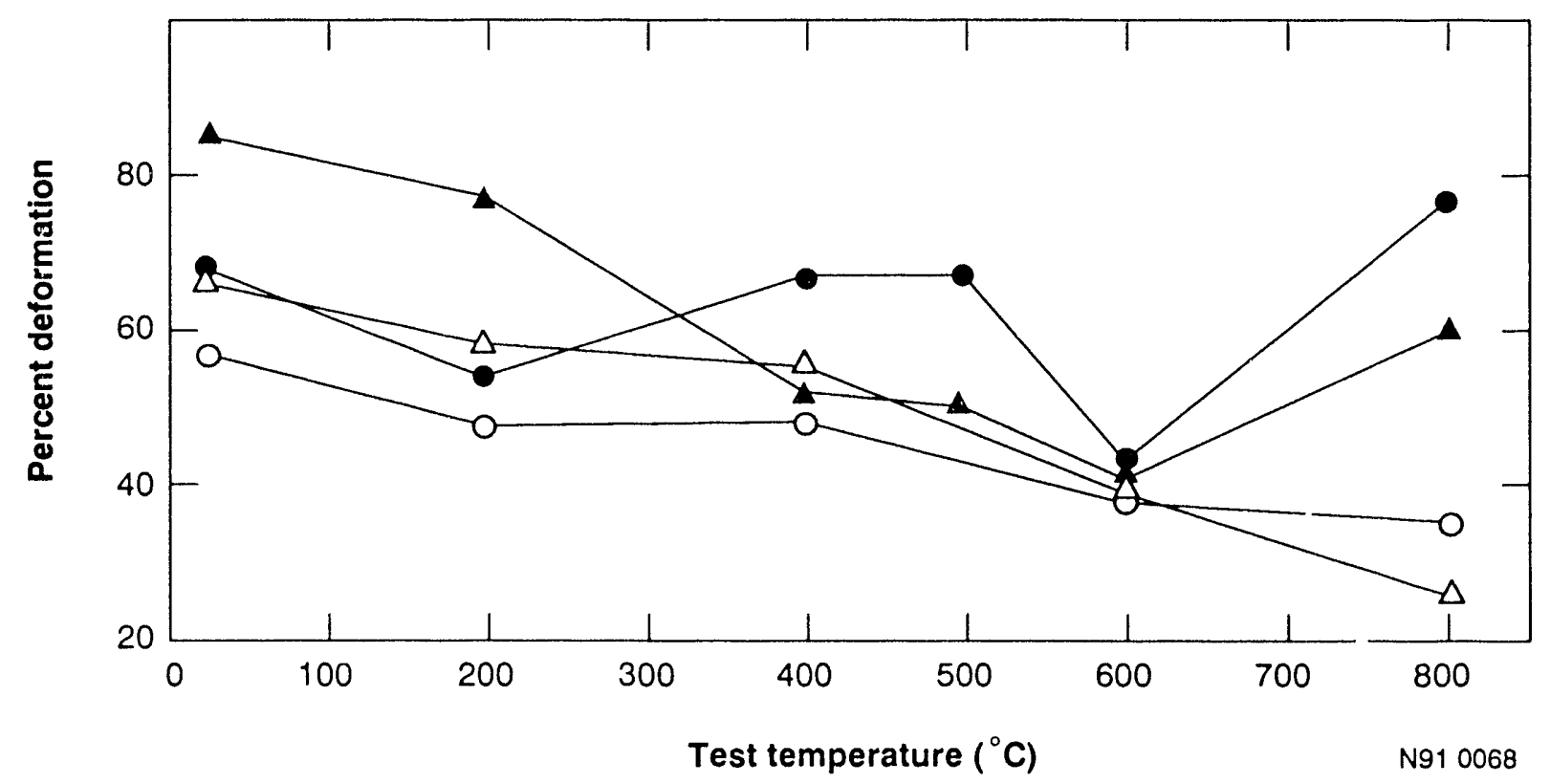

(b) After $1100^{\circ} \mathrm{C}, 1 \mathrm{~h}$ heat treatment

Figure 75. Influence of temperature on total elongation and reduction in area for CPC and VGA Fe-16Ni-9Cr extruded powder.

conditions is shown in Figure 79. The influence of test temperature on the tensile stresses for A286 specimens (i.e., IGA grab-sample extruded particles and $(P C)$ is shown in Figure 80 . Significant strengthening from IGA powder processing is certainly apparent up to $600^{\circ} \mathrm{C}$. 


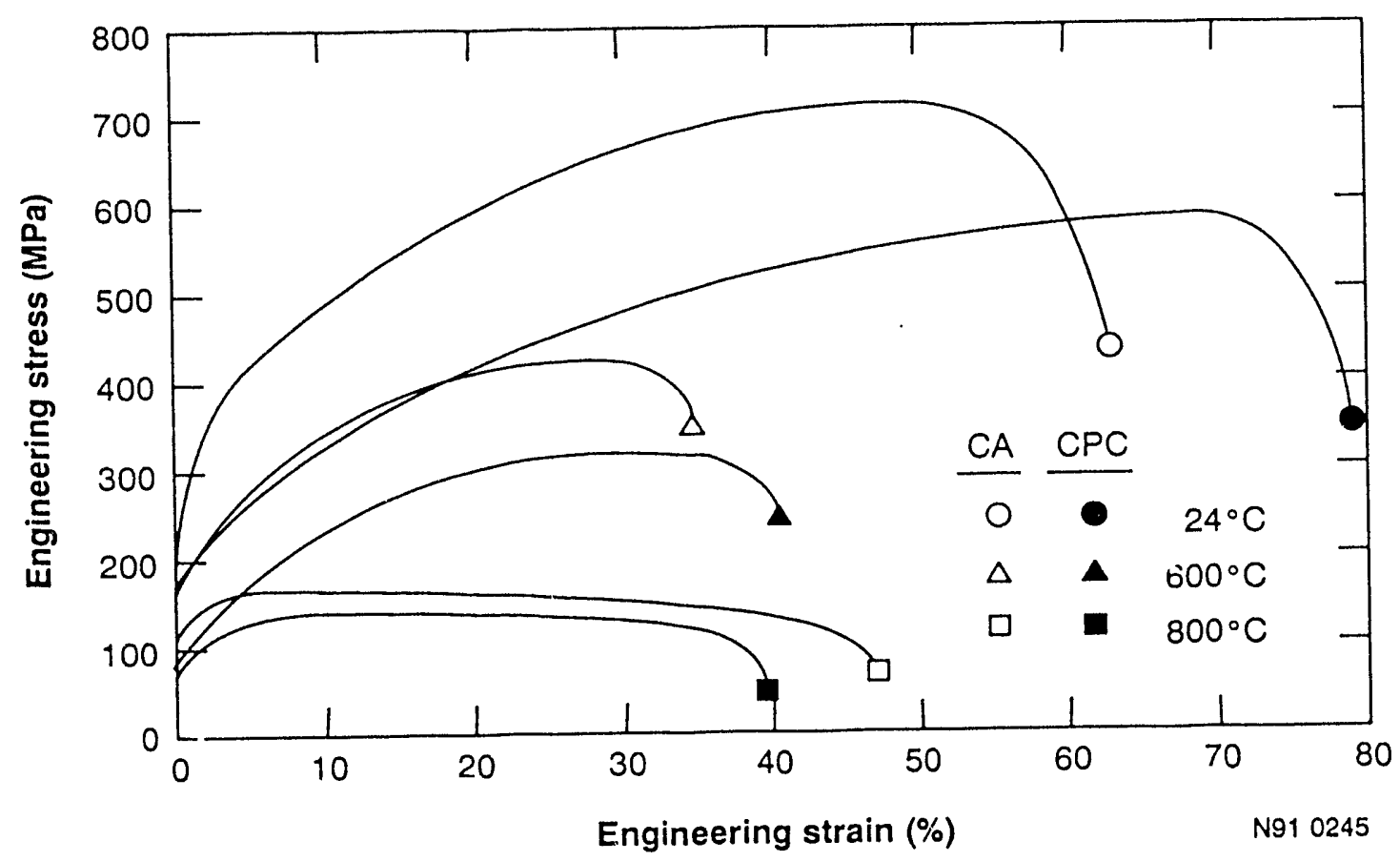

Figure 76. Engineering stress-strain curves at various test temperatures for CA Type $304 \mathrm{SS}$ extruded powders and CPC after a $1 \mathrm{~h}, 1100^{\circ} \mathrm{C}$ heat treatment.
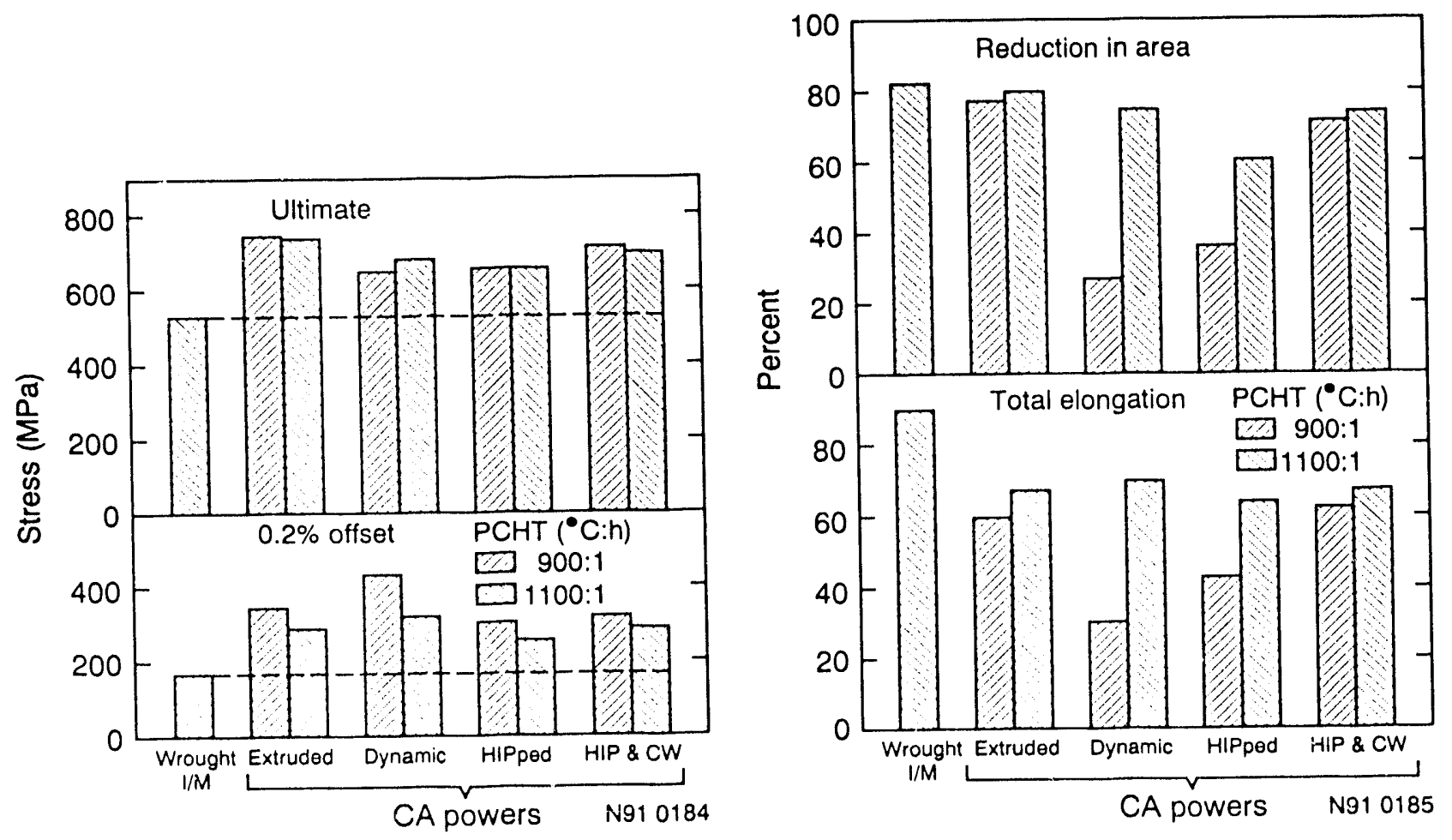

Figure 77. Influence of powder consolidation method on room temperature tensile properties for CA Type 304 SS and CPC (I/M) after $1 \mathrm{~h}$ heat treatments (PCHT) at 900 and $1100^{\circ} \mathrm{C}$. 
Table 11. Tensile Properties at $600^{\circ} \mathrm{C}$ for Type $304 \mathrm{SS}$

\begin{tabular}{|c|c|c|c|c|}
\hline Material ${ }^{a}$ & $\begin{array}{l}\text { Yield } \\
\text { Stress } \\
\text { (MPa) }\end{array}$ & $\begin{array}{l}\text { U1timate } \\
\text { Stress } \\
\text { (MPa) } \\
\end{array}$ & $\begin{array}{l}\text { Total } \\
\text { Elongation } \\
(\%) \\
\end{array}$ & $\begin{array}{c}\text { Reduction } \\
\text { in Area } \\
(\%) \\
\end{array}$ \\
\hline CPC & 81 & 320 & 45 & 52 \\
\hline$C A^{c}$ & 161 & 420 & 37 & 39 \\
\hline IGA $(10-30 \mu \mathrm{m})$ & 168 & 414 & 37 & 47 \\
\hline $\operatorname{IGA}(30-50 \mu \mathrm{m})$ & 161 & 422 & 38 & 48 \\
\hline $\operatorname{IGA}(50-75 \mu \mathrm{m})$ & 163 & 405 & 42 & 51 \\
\hline IGA $(100-150 \mu \mathrm{m})$ & 158 & 409 & 40 & 51 \\
\hline$I_{G A}{ }^{c}$ & 157 & 409 & 39 & 50 \\
\hline \multicolumn{5}{|c|}{$\begin{array}{l}\text { a. Specimens annealed at } 1100^{\circ} \mathrm{C}, 1 \mathrm{~h} \text {. } \\
\text { b. } 0.2 \% \text { offset. }\end{array}$} \\
\hline \multicolumn{5}{|c|}{ c. Grab particle size distribution. } \\
\hline
\end{tabular}

The tensile properties for the IGA processed and extruded powders of the Fe-16Ni-9Cr-2Mo-1.5Mn-1Si-0.5Ti alloy series and their CPC at three test temperatures $\left(24,600\right.$, and $800^{\circ} \mathrm{C}$ ) are shown in Figure 81 . The $>10$ to $<30 \mu \mathrm{m}$ (20 $\mu \mathrm{m}$ average) powder particle size exhibits a rather substantial increase in strength compared to both the larger powder particle sizes and the CPC. (Note that the yield stress at $800^{\circ} \mathrm{C}$ of the $>10$ to $<30 \mu \mathrm{m}$ IGA extruded powder is equivalent to that of its CPC at room temperature.) The yield and ultimate stresses of the larger powder particle sizes (i.e., $>30$ to $<150 \mu \mathrm{m}$ ) are significantly higher than those of the CPC; however, they show no evidence of dependence on particle size. The $>10$ to $<30 \mu \mathrm{m}$ extruded powder specimen shows some loss in ductility compared to the other powder particle sizes and the $C P C$, but its ductility is quite acceptable.

The tensile property tests of all the iron-base alloys studied have shown that RSP significantly increases the tensile stresses, even to 


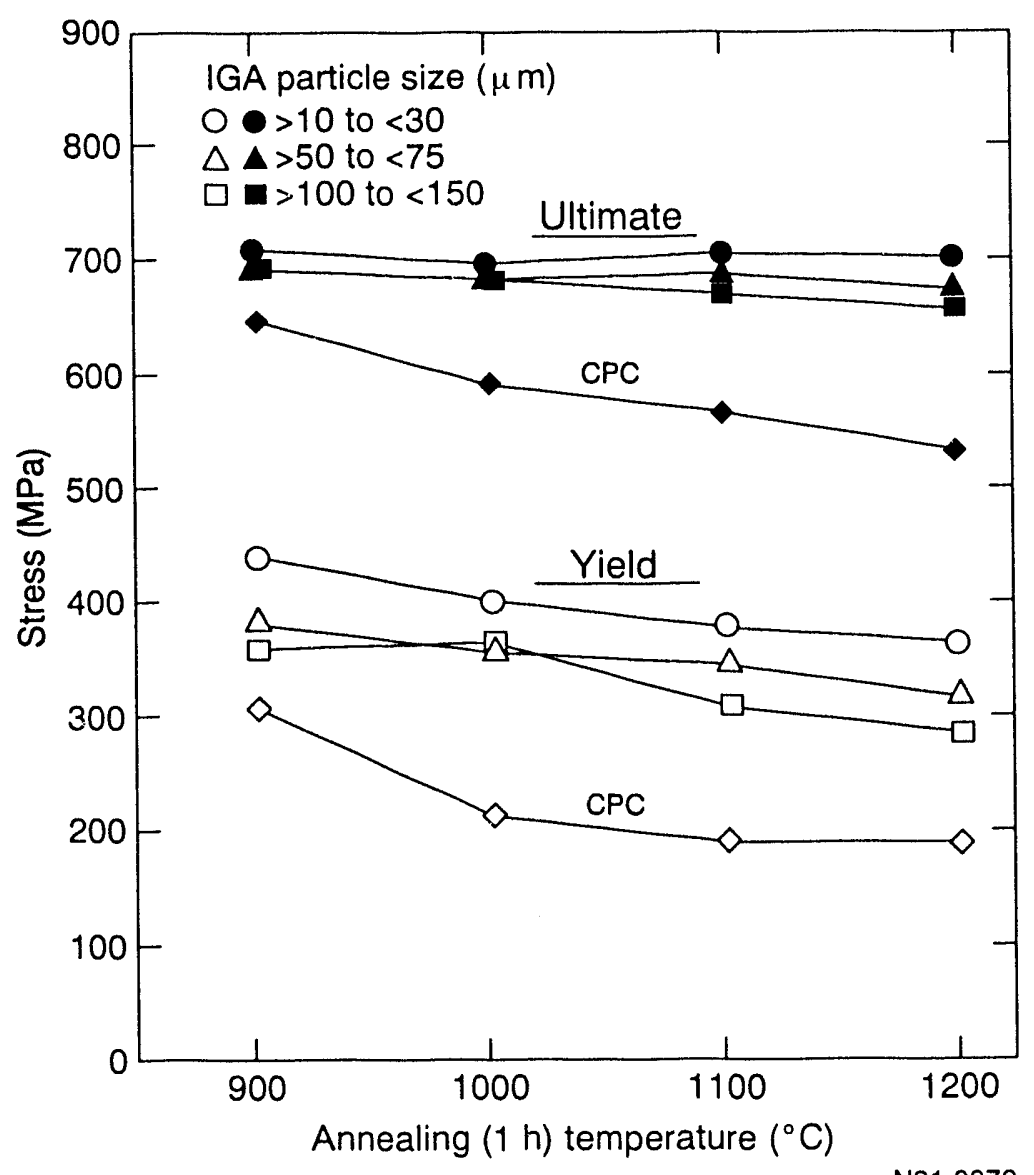

Figure 78. Influence of annealing temperature on room temperature yield and ultimate tensile stresses for IGA A286 extruded powders of three particle sizes and CPC.

relatively high temperatures, compared to the CPCS. Some loss in ductility was also observed for the RSP alloys, compared to their CPCS; however, the ductilities were still quite acceptable. In this study, powder processing and powder consolidation methcds had no obvious influence on the tensile properties.

\section{Creep Properties}

Evaluation of the creep behavior of the iron-base RSP alloys and their CPCS has also been an important part of property studies. A representative cross section of the creep observations will be covered. Unlike the tensile behavior, there is evidence that some powder atomization and consolidation parameters can influence the creep behavior. Significant improvement in 


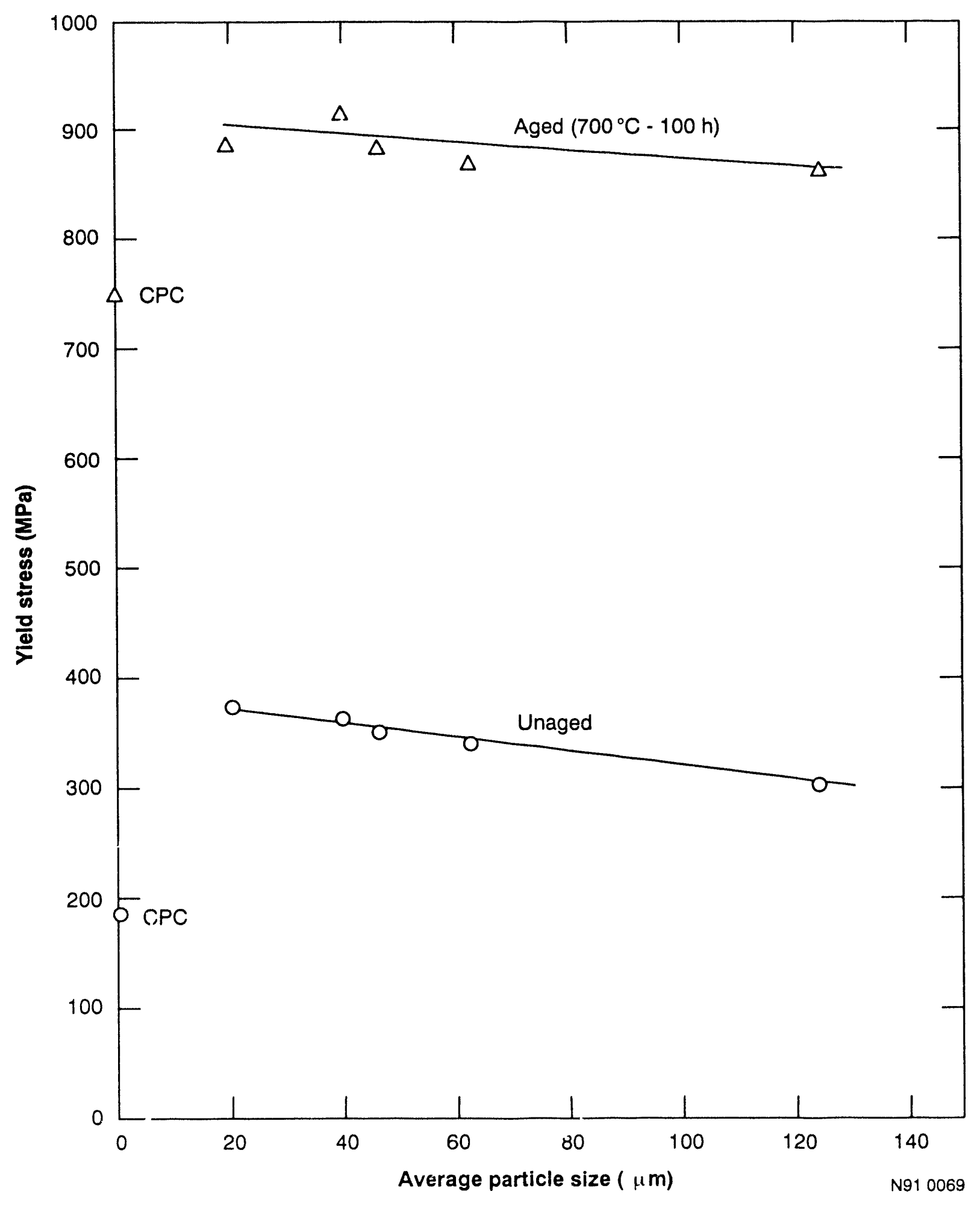

Figure 79. Influence of powder particle size on yield stress after extrusion consolidation and $1100^{\circ} \mathrm{C}, 1 \mathrm{~h}$ heat treatment on A286 IGA powders with and without a $100 \mathrm{~h} 700^{\circ} \mathrm{C}$ aging treatment. 


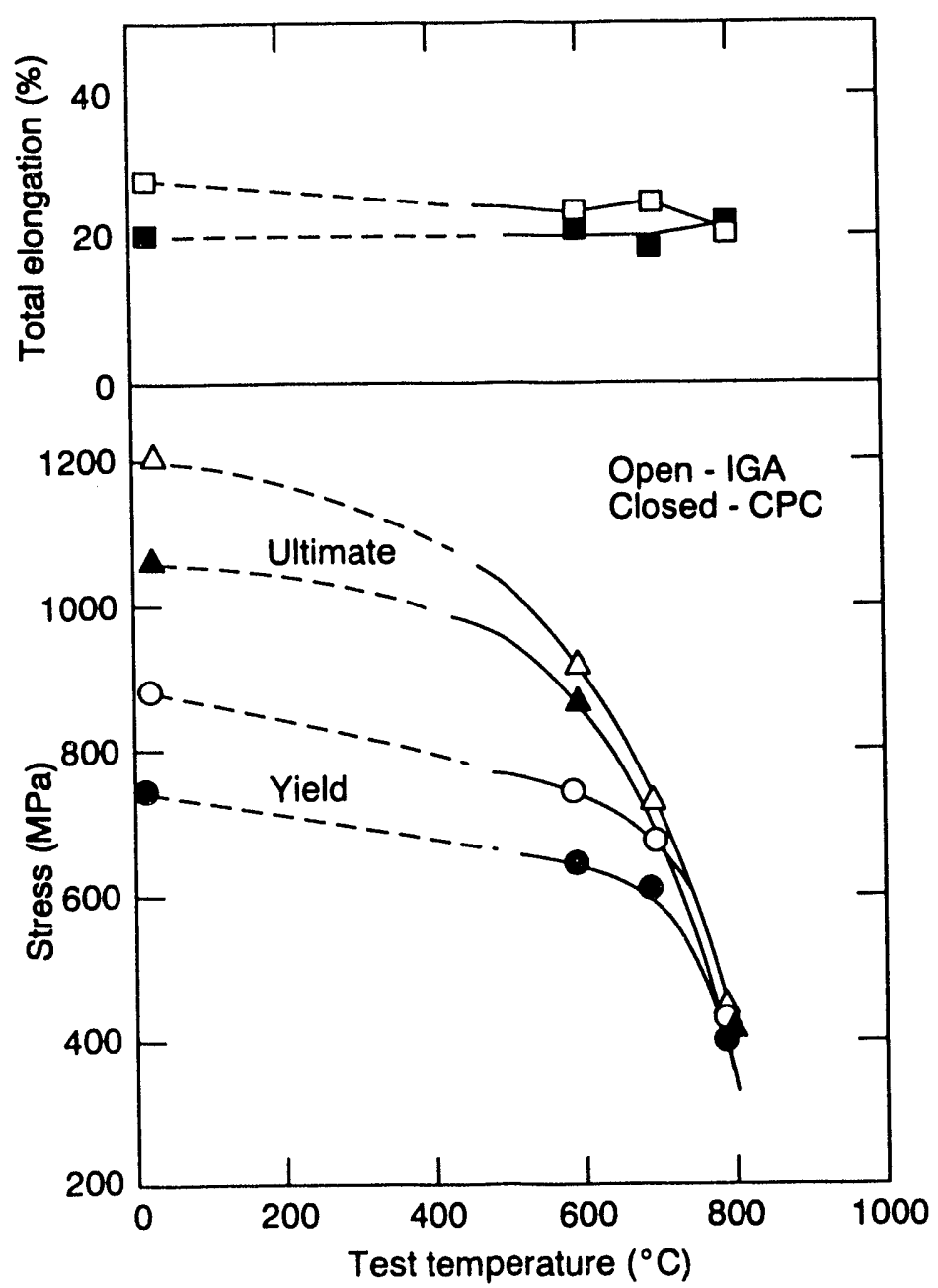

N91 0071

Figure 80. Influence of test temperature on tensile properties of A286 IGA extruded powder and $C P C$ after $1100^{\circ} \mathrm{C} 1 \mathrm{~h}$ heat treatment and $700^{\circ} \mathrm{C} 100 \mathrm{~h}$ aging treatment.

creep resistance was observed only for CA processed alloys that contained a high population of nanometer-size hollow oxides.

The stress vs. time to rupture behavior at 500 and $600^{\circ} \mathrm{C}$ for the RSP Fe-40Ni powders after HIP consolidation, cold working, and heat treating at $1100^{\circ} \mathrm{C}$ for $1 \mathrm{~h}$ is shown in Figure $82 \mathrm{a}$. These data are for various powder processing parameters, i.e., CA with different helium flow rates for convective cooling and VGA with either argon or helium for atomization. There is no apparent influence of powder processing on stress-rupture for this alloy. The stress-rupture behavior of the Fe-40Ni alloy series with $\mathrm{Nb}$ and $\mathrm{C}$ 


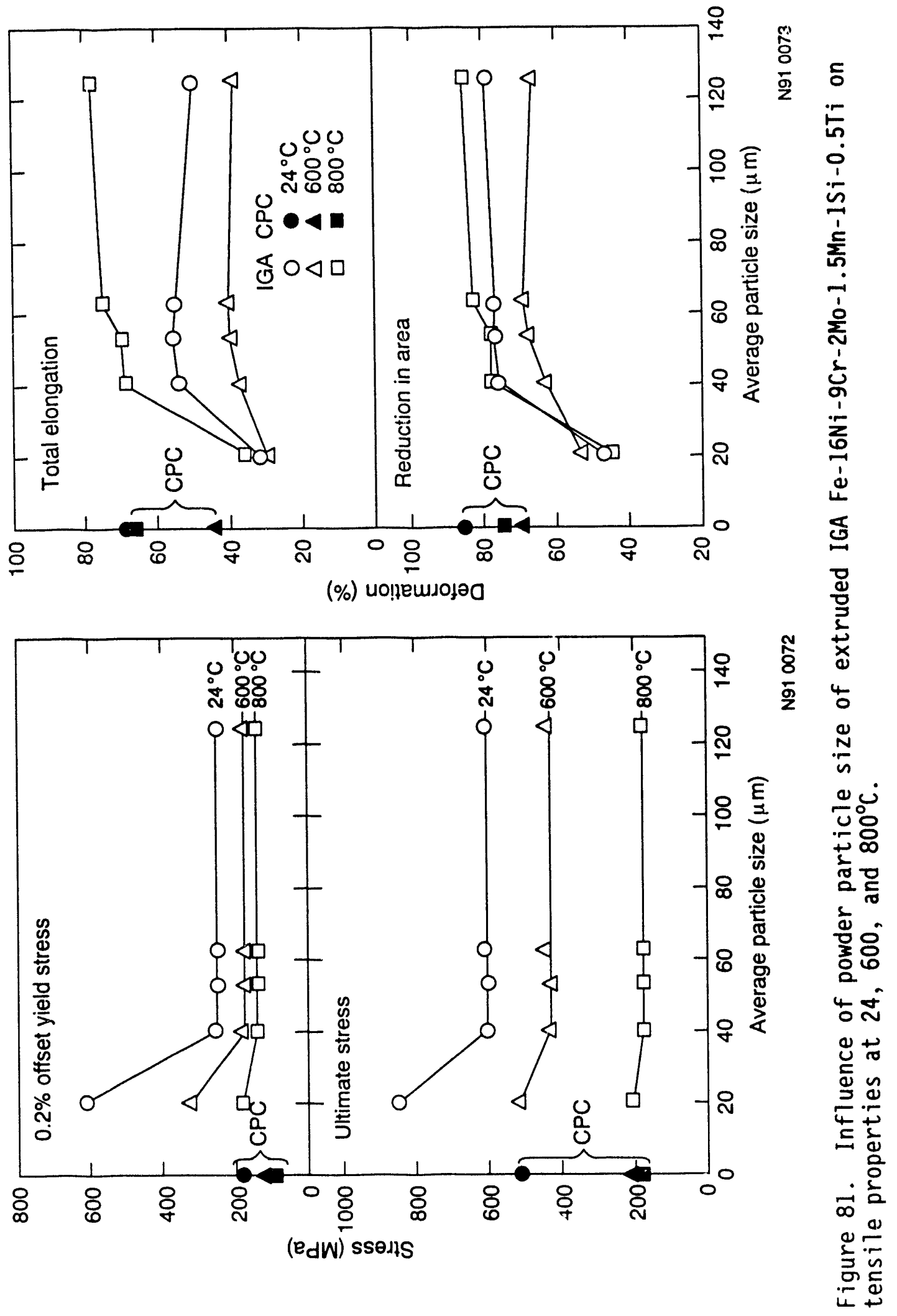




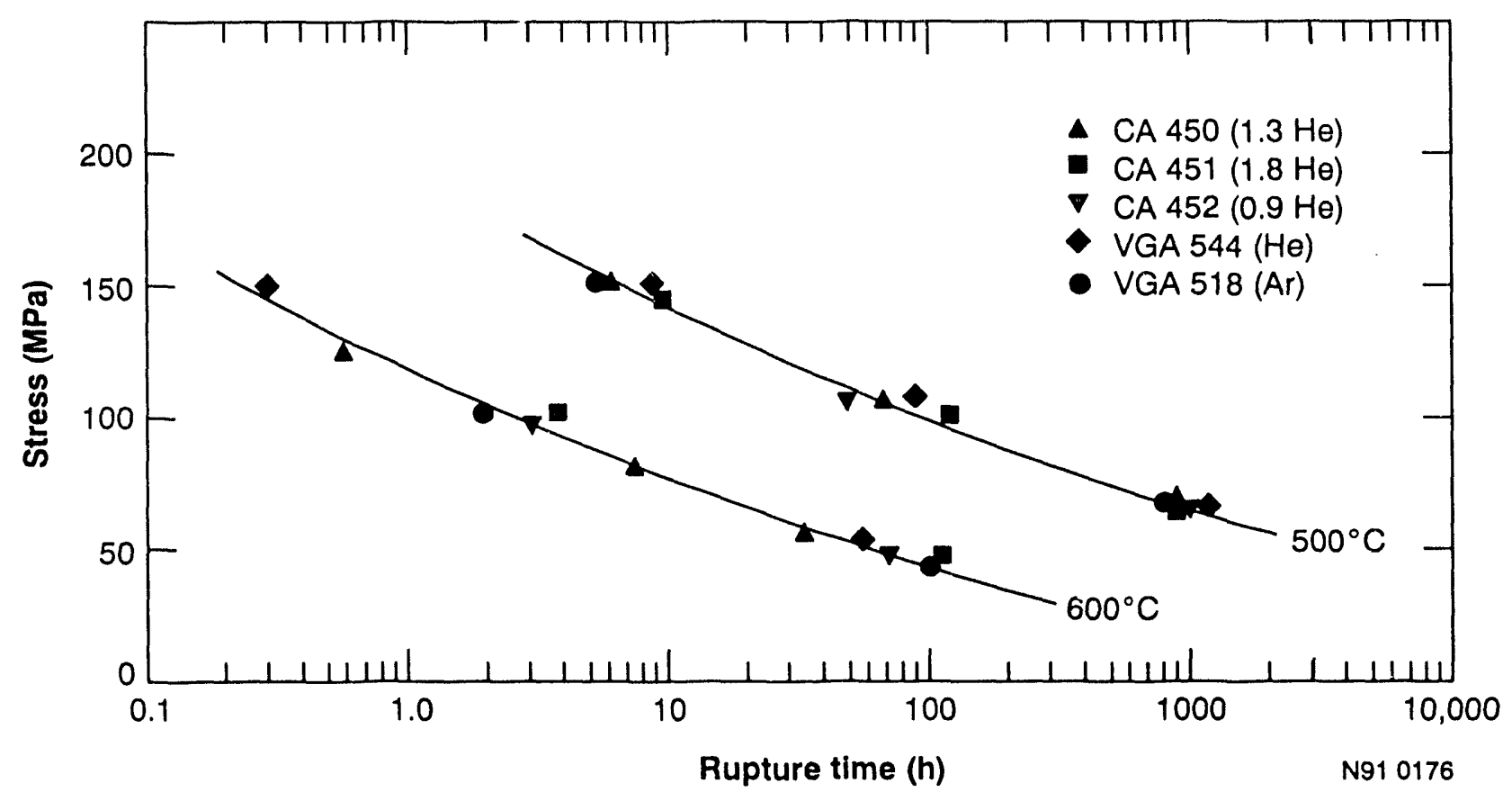

(a) $\mathrm{Fe}-40 \mathrm{Ni}$

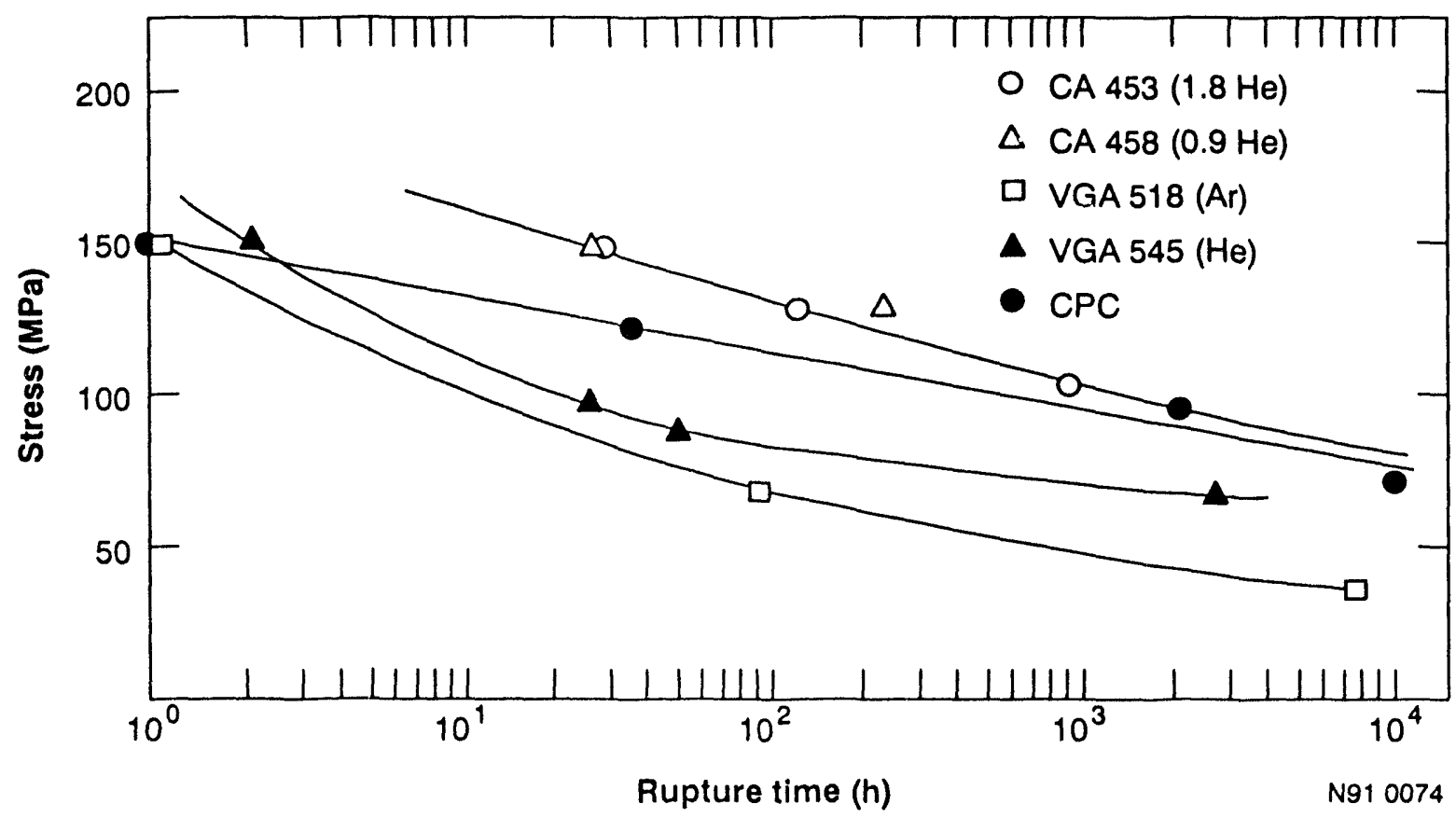

(b) Fe- $40 \mathrm{Ni}-0.3 \mathrm{Nb}-0.05 \mathrm{C}\left(600^{\circ} \mathrm{C}\right)$

Figure 82. Stress-rupture behavior for CA and VGA HIPped, cold worked, and heat treated $\left(1100^{\circ} \mathrm{C}, 1 \mathrm{~h}\right)$ powders.

additions did show some significant influences from powder processing. As seen in the results for the $600^{\circ} \mathrm{C}$ tests, Figure $82 \mathrm{~b}$, CA processing apparently gives better creep resistance than VGA. There is some indication that 


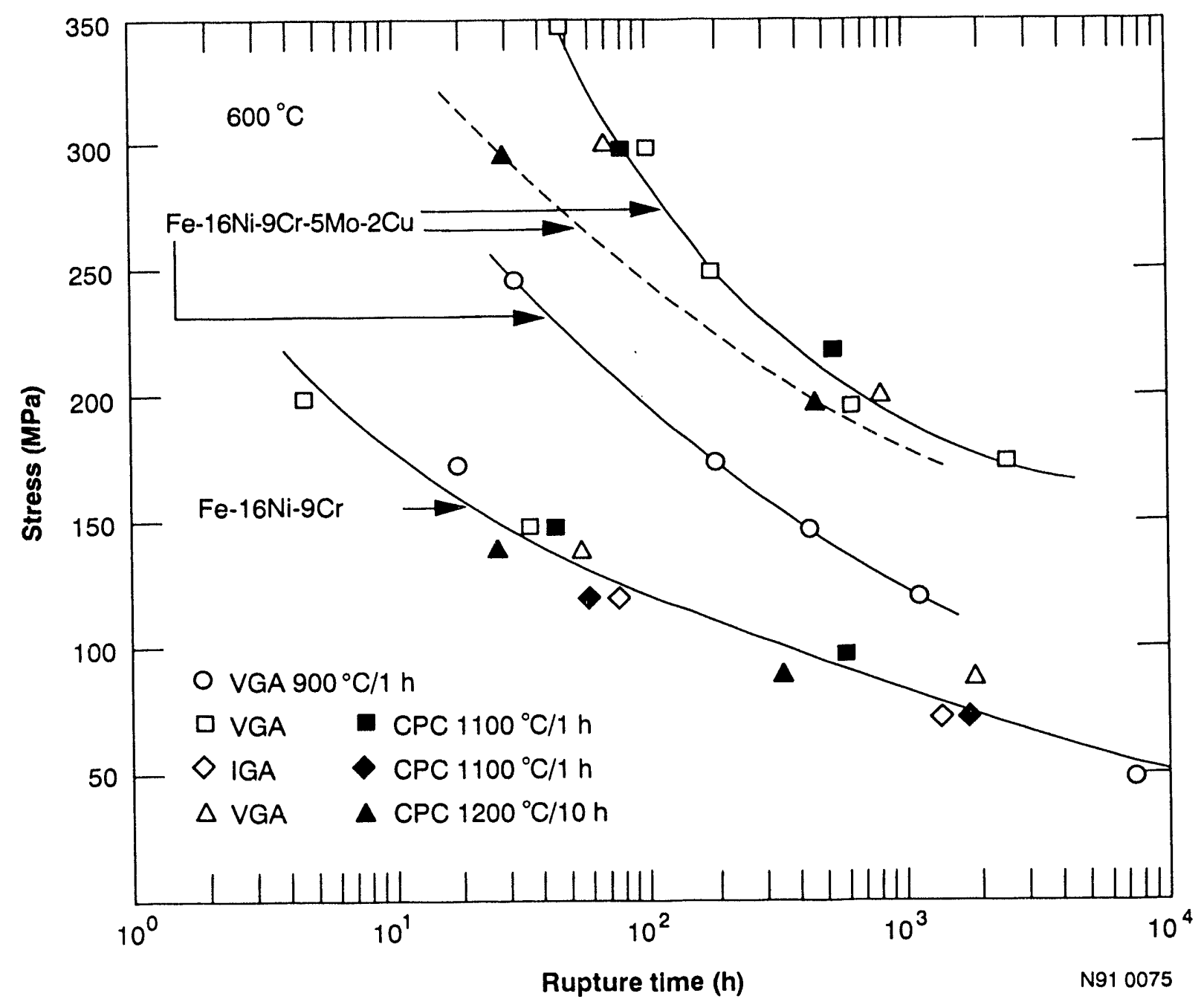

Figure 83. Stress-rupture behavior at $600^{\circ} \mathrm{C}$ for VGA and IGA extruded Fe-16Ni$9 \mathrm{Cr}$ and VGA extruded $\mathrm{Fe}-16 \mathrm{Ni}-9 \mathrm{Cr}-5 \mathrm{Mo}-2 \mathrm{Cu}$ powders and their CPCs after various heat treatments.

preaging the $\mathrm{CA} F-40 \mathrm{Ni}-0.3 \mathrm{Nb}-0.05 \mathrm{C}$ substantially improves creep resistance compared to the VGA and CPC material. ${ }^{65}$

The stress-rupture behavior at $600^{\circ} \mathrm{C}$ for two exploratory stainless steels, Fe-16Ni-9Cr and $\mathrm{Fe}-16 \mathrm{Ni}-9 \mathrm{Cr}-5 \mathrm{Mo}-2 \mathrm{Cu}$, is shown in Figure 83 . The powders for these two alloys were consolidated by hot extrusion. The VGA specimens and their CPCs received various heat treatments prior to creep testing. The results for the $\mathrm{Fe}-16 \mathrm{Ni}-9 \mathrm{Cr}$ alloy series (lower curve) show no apparent effect of processing method (VGA, IGA and CPC) or of prior heat treatment on the rupture time, even though a substantial difference in grain size was observed between the $1100^{\circ} \mathrm{C}, 1 \mathrm{~h}$ and $1200^{\circ} \mathrm{C}, 10 \mathrm{~h}$ heat treatments. 


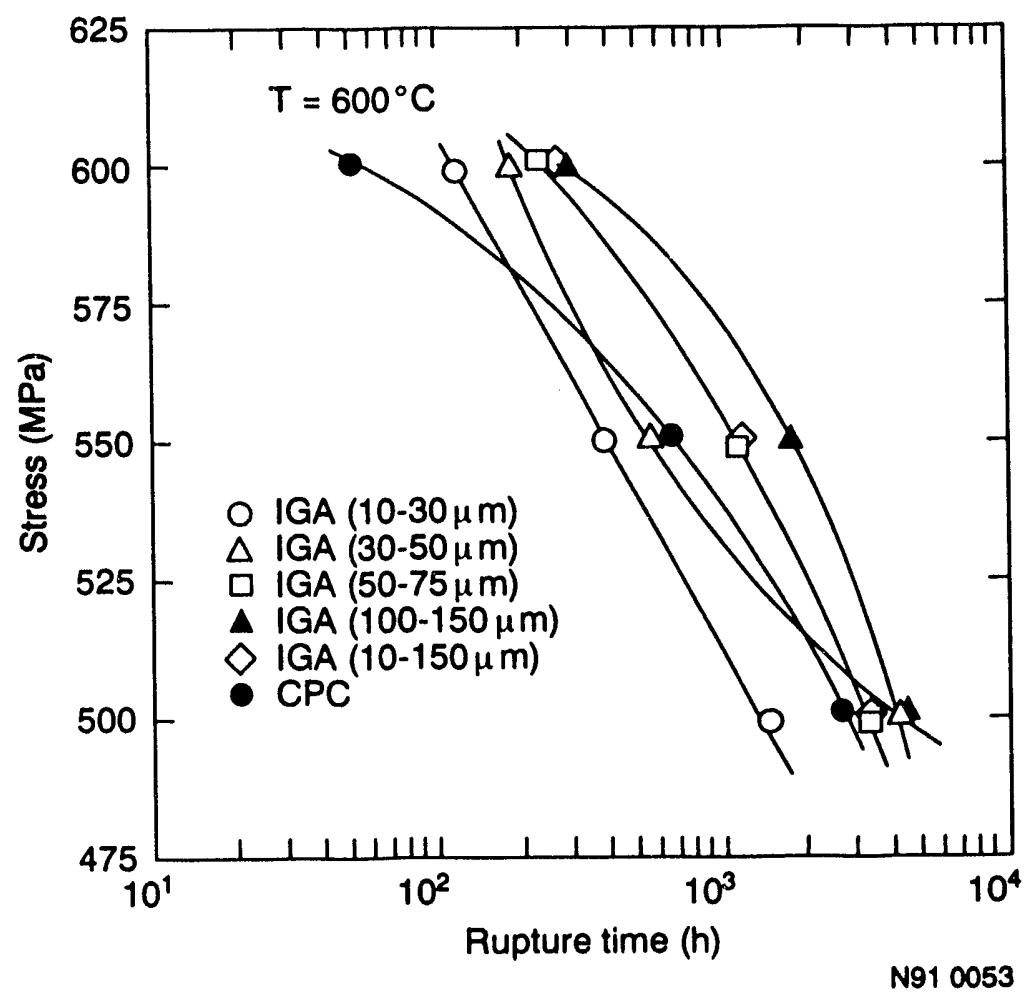

Figure 84. Stress-rupture behavior at $600^{\circ} \mathrm{C}$ for IGA extruded A286 powders of different particle sizes and their CPC.

For the VGA Fe-16Ni-9Cr-5Mo-2Cu extruded powders (upper three curves in Figure 83), prior heat treatment does influence the creep behavior, although the results suggest that there is little influence from grain size (the $1100^{\circ} \mathrm{C}, 1 \mathrm{~h}$ material had relatively small grains while the $1200^{\circ} \mathrm{C}-10 \mathrm{~h}$ material had large ones). However, these two heat treatments appear to have a modest influence on the creep properties of the CPC.

The discussion of the next two alloys illustrates the influence of powder particle size on stress-rupture behavior. Figure 84 shows the results from tests at $600^{\circ} \mathrm{C}$ of the IGA and CPC A286 specimens after heat treatment at $1100^{\circ} \mathrm{C}, 1 \mathrm{~h}$, followed by a $100 \mathrm{~h}, 700^{\circ} \mathrm{C}$ aging treatment. The five powder particle sizes $(>10$ to $<30,>30$ to $<50,>50$ to $<75,>100$ to $<150 \mu \mathrm{m}$, and grab distribution with a median particle size of $46 \mu \mathrm{m}$ ) reveal a definite particle size dependence. The rupture time increases significantly with increasing particle size, suggesting an influence from the apparent banding effects (Figure 25) from the titanium-iron oxide film on the particles (see Figures 16, 44, and 45). Oxide particles from the powder surface film are 
expected to be incoherent and not contribute to strengthening. The CPC specimens show less creep resistance than the IGA A286 extruded powder specimens derived from the larger particle sizes. Although not shown, the IGA extruded powder specimens exhibited a fivefold increase in ductility compared to their CPC. ${ }^{64}$

The CA Type 304 SS extruded powders show substantial improvements in creep resistance compared to the IGA and CPC materials. Figure 85 gives the test results iur the IGA and CPC specimens with three heat treatments; the increased creep resistance of CA specimens is shown in Figure 86 for one of these heat treatments $\left(1100^{\circ} \mathrm{C}, 1 \mathrm{~h}\right)$. As can be seen in Table 12, which summarizes the creep properties for the CA arid IGA Type 304 SS (both extruded grab particle sizes) and CPC specimens, not only has the rupture time been substantially extended for the CA Type 304 SS, but there is also a substantial reduction in minimum creep rate.

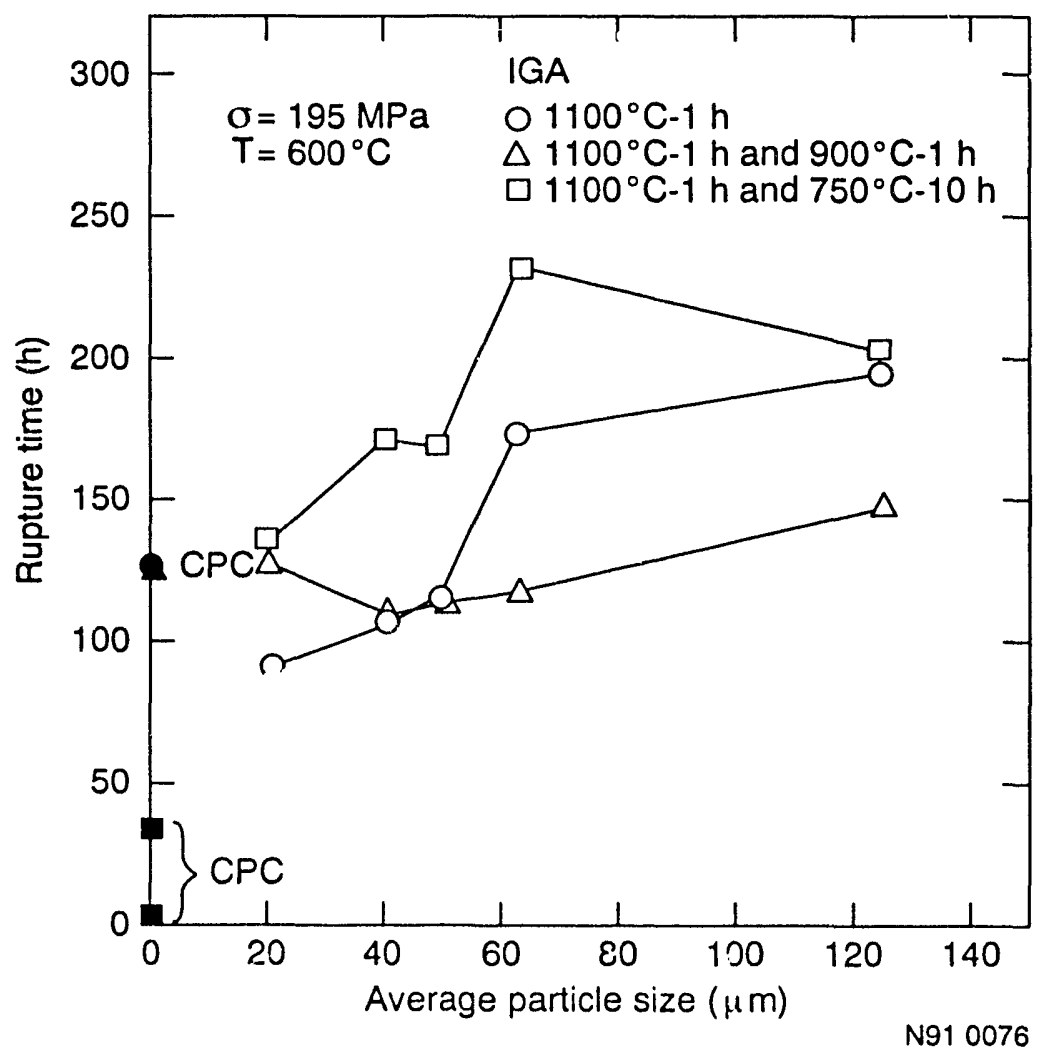

Figure 85. Influence of powder particle size on stress-rupture behavior at $600^{\circ} \mathrm{C}$ and $195 \mathrm{MPa}$ for Type 304 SS IGA extruded powders and CPC material. (Open and closed symbols of the same shape denote the same heat treatment.) 


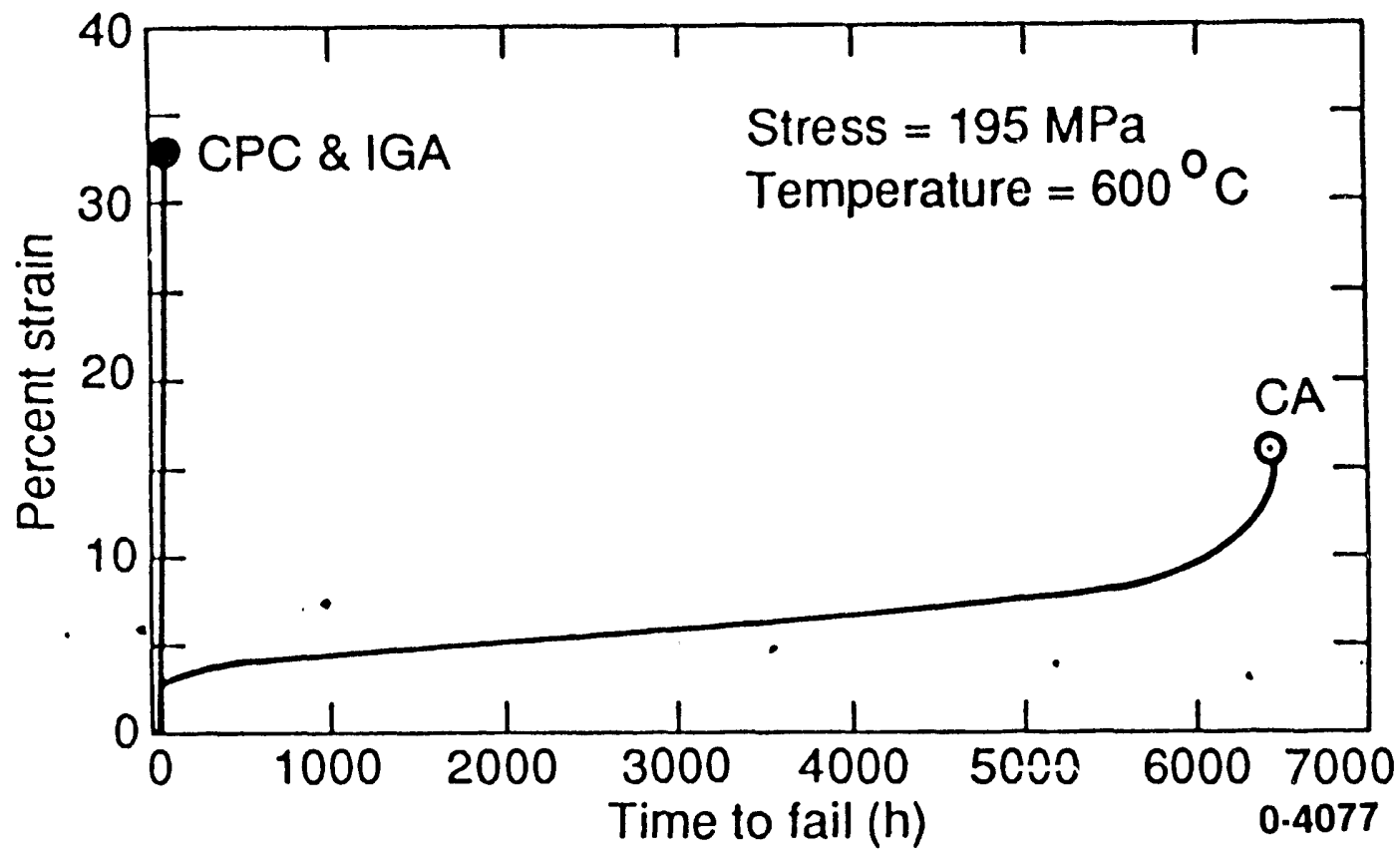

Figure 86. Creep curves at $600^{\circ} \mathrm{C}$ and $195 \mathrm{MPa}$ for CA Type 304 SS extruded powder and $\mathrm{CPC}$ after a $1100^{\circ} \mathrm{C} 1 \mathrm{~h}$ heat treatment.

The creep behavior of the CA Type 304 SS consolidated powders was also evaluated for influences from the consolidation method. The creep curves in Figure 87 show that heat treatment and consolidation method do affect the material's creep resistance.

\section{Fatique Properties}

Fatigue testing of the RSP iron-base alloys in this study (see Table 1) has been very limited to date. Room temperature test data have only been obtained for Type 304 SS and A286. Future testing will address fatigue behavior at higher temperatures. The preliminary findings are summarized below.

Fatigue testing of the CA Type 304 SS extruded powder disclosed a disturbing feature from powder metallurgy processing. Most of the specimens showed evidence of premature failure (see Figure 88 ), which is attributed to the presence of foreign hard particles from an earlier batch of powder processed in the CA system because failure initiated at impurity defects (Figure 89). 
Table 12. Creep Results for Type 304 SS Materials Tested at $600^{\circ} \mathrm{C}$ and $195 \mathrm{MPa}$

\begin{tabular}{|c|c|c|c|c|}
\hline Material & $\begin{array}{c}\text { Rupture Time } \\
\text { (h) }\end{array}$ & $\begin{array}{c}\text { Minimum } \\
\text { Creep Rate } \\
(\% / h) \\
\end{array}$ & $\begin{array}{c}\text { Total } \\
\text { Elongation } \\
(\%) \\
\end{array}$ & $\begin{array}{c}\text { Reduction in } \\
\text { Area } \\
(\%) \\
\end{array}$ \\
\hline$C P C$ & 126 & 0.064 & 23 & 23 \\
\hline IGA & 116 & 0.062 & 18 & 14 \\
\hline$C A$ & 6430 & 0.0007 & 26 & 17 \\
\hline
\end{tabular}

a. Heat treątment $-1100^{\circ} \mathrm{C}$ for $1 \mathrm{~h}$.

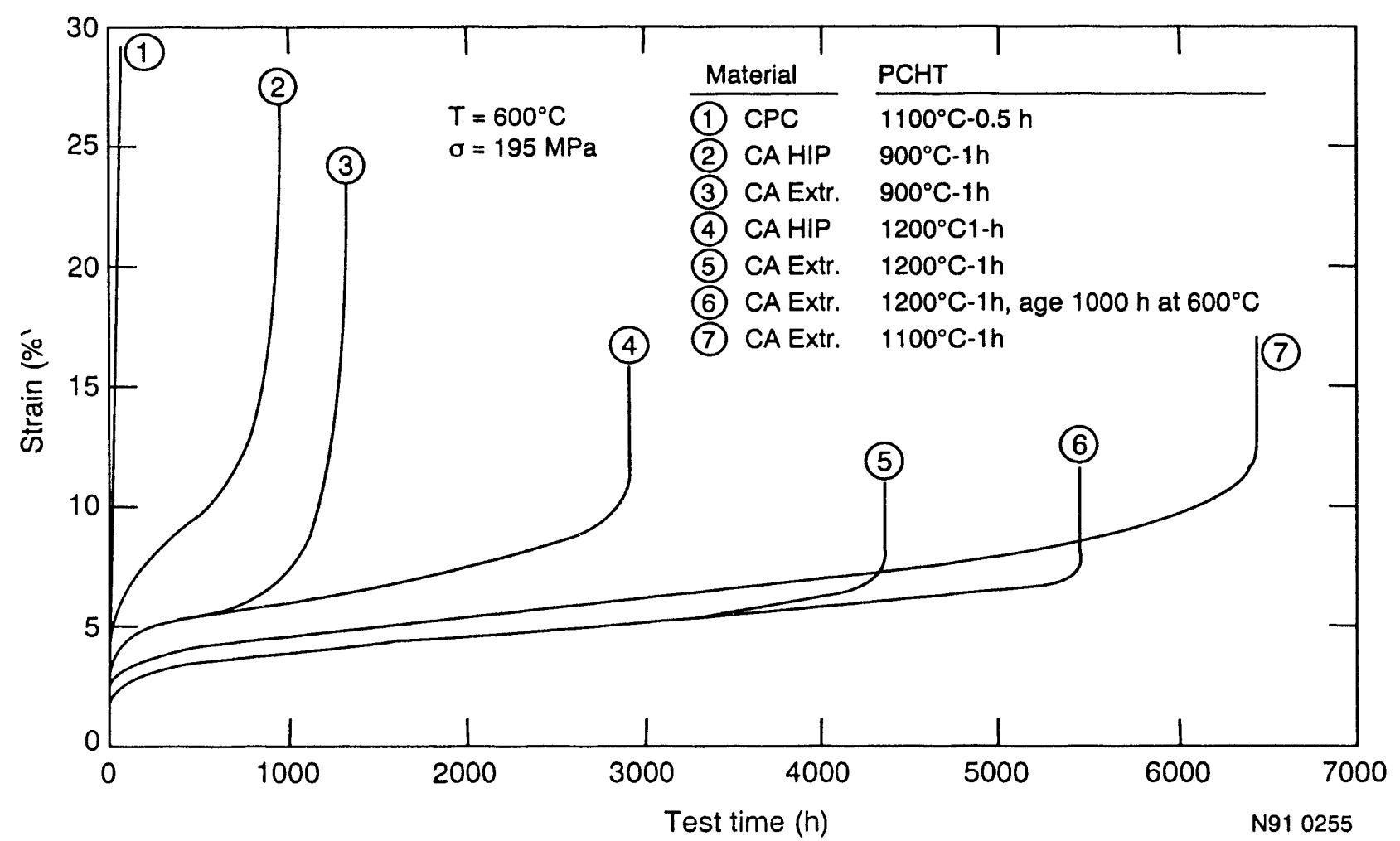

Figure 87. Creep curves at $600^{\circ} \mathrm{C}$ and $195 \mathrm{MPa}$ for consolidated CA Type 304 SS powders and CPC with different thermal-mechanical treatments.

Even with these premature failures, the CA Type 304 SS extruded powder shows cycle lifetimes comparable to those of conventionally processed austenitic stainless steels. Processing practices that eliminated the foreign particles would reduce the number and size of defects and thus further improve fatigue properties. 


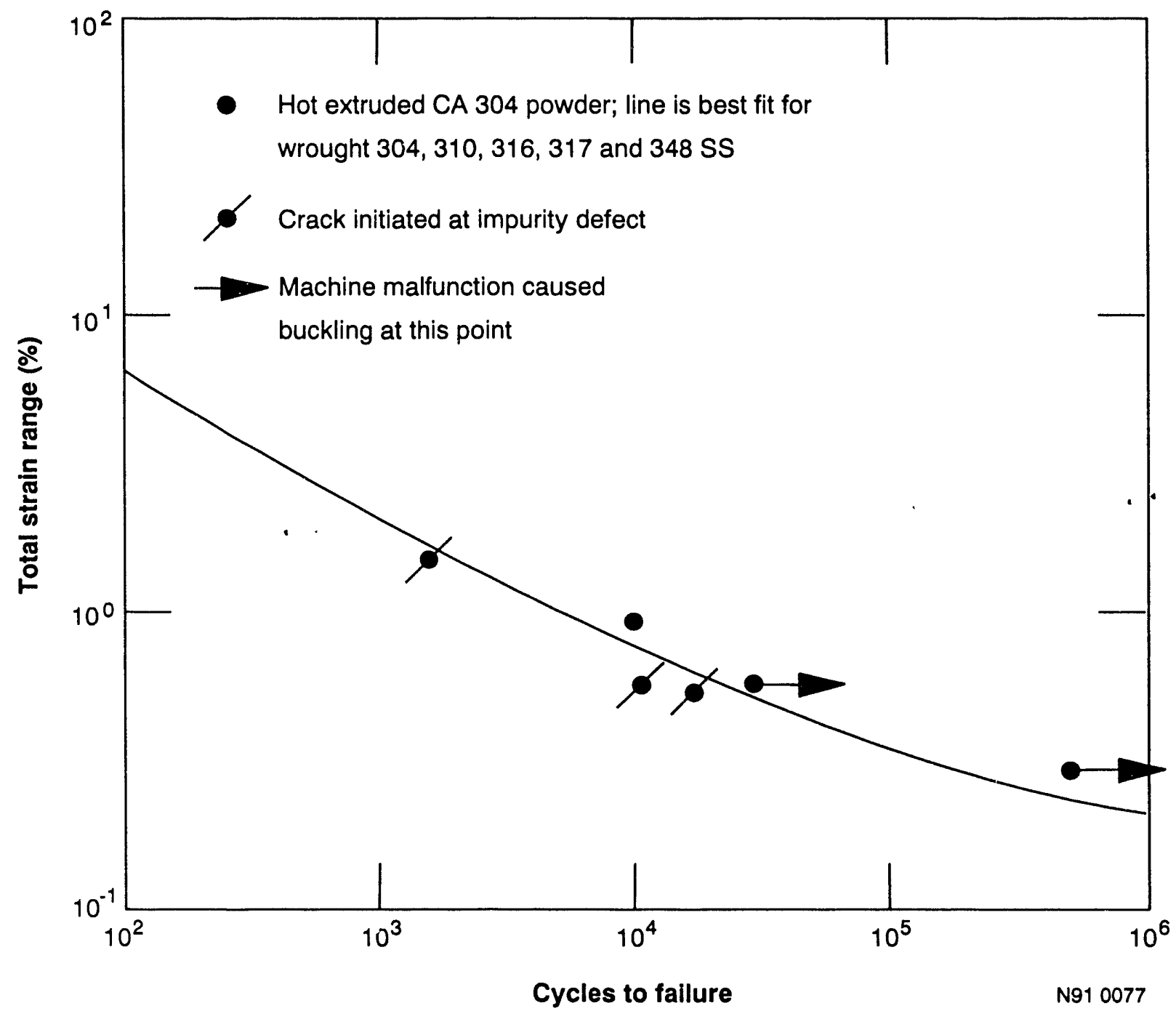

Figure 88. Room temperature fatigue behavior of CA Type 304 SS extruded powder with comparison to wrought austenitic stainless steels.
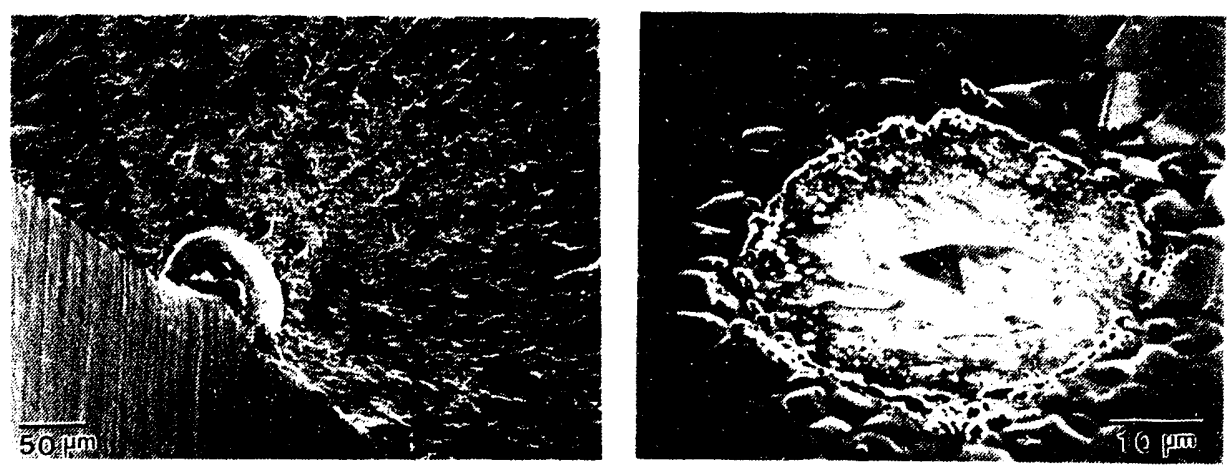

Figure 89. Foreign hard particles from prior powder processing caused premature fatigue failure for extruded CA Type 304 SS. Left--particle on specimen surface; right--same particle in interior. 
Room temperature fatigue data for the IGA Type 304 SS extruded powder series are shown in Figure 90a, where the number of cycles to failure is plotted against the peak tensile stress of the plastic strain cycle. These results show that the fatigue resistance of the IGA Type 304 SS is superior to that of its CPC at room temperature. Also, there is no obvious influence of

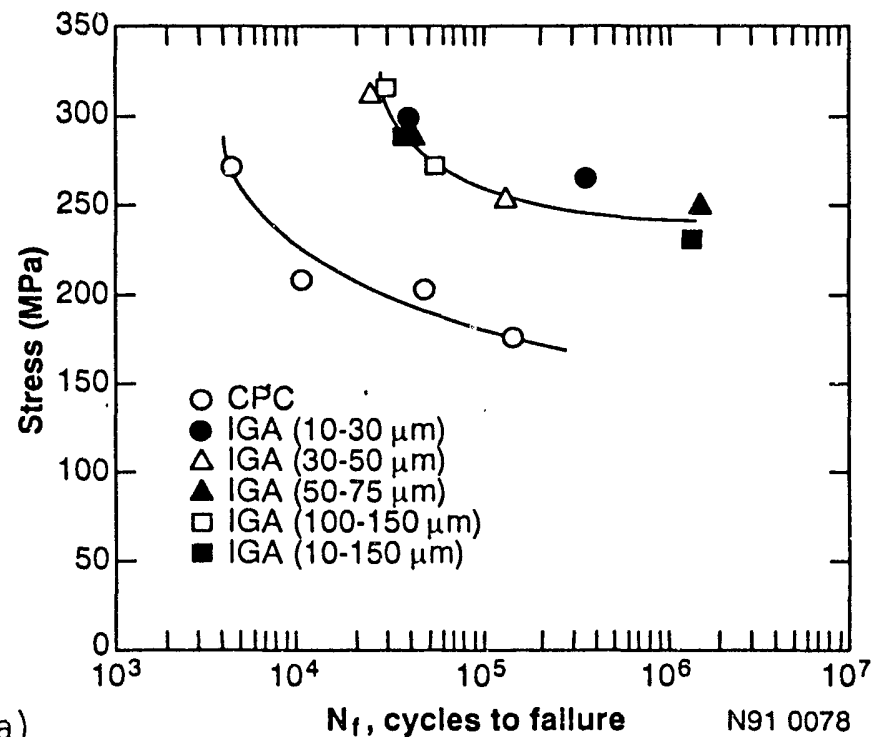

a)

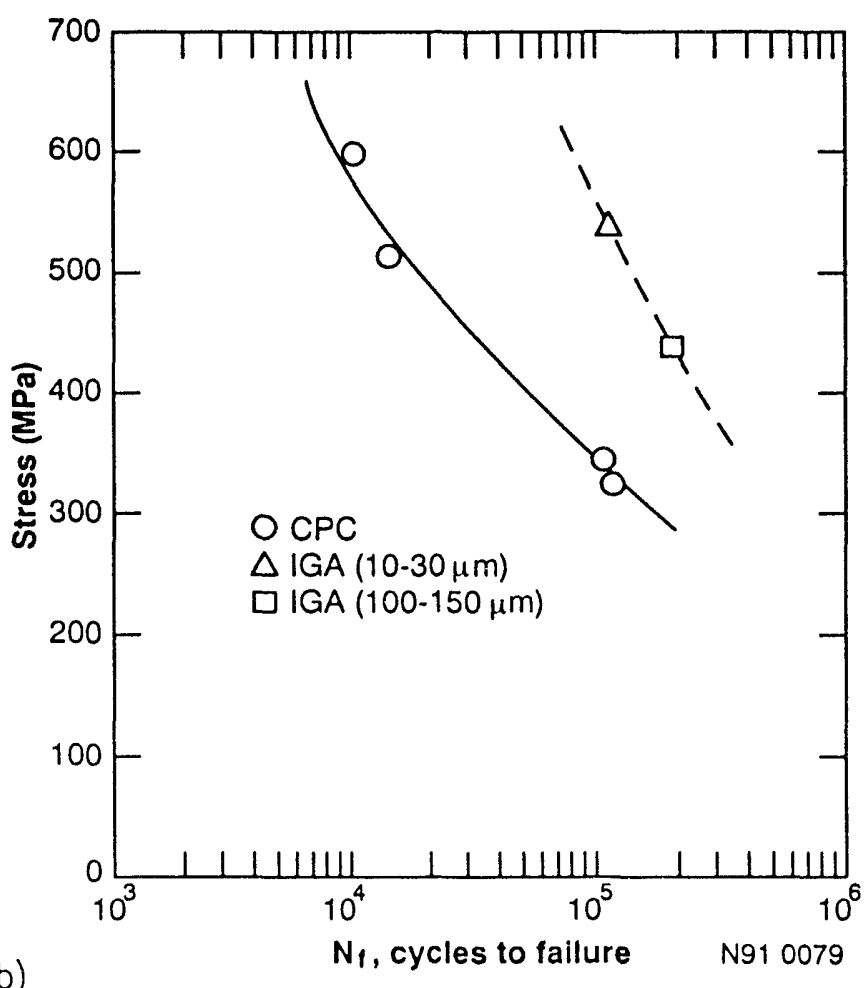

Figure 90. Room temperature fatigue behavior for IGA extruded powders with different particle sizes. 
powder particle size on room temperature fatigue for the IGA series; this could change at higher test temperatures. Tests performed at room temperature on $\mathrm{A} 286$ IGA extruded powders and their $\mathrm{CPC}$, heat treated at $1100^{\circ} \mathrm{C}$ for $1 \mathrm{~h}$ and aged at $700^{\circ} \mathrm{C}$ for $100 \mathrm{~h}$, indicate that there are improvements in fatigue lifetime for the RSP materials. The preliminary test results for these materials are shown in Figure $90 \mathrm{~b}$.

\section{Microstructure-Mechanical Property Correlation}

The section on microstructural behavior of the RSP and CPC iron-base alloys showed that the RSP alloys possess fine and stable microstructural features comparead to their CPCS. Such features should account for the observed improvements in mechanical properties. The correlation between microstructure and the mechanical properties, summarized in this section, will be used to propose guidelines for designing RSP processes for structural ironbase alloys.

\section{Tensile Correlations}

The most obvious of the microstructural features expected to influence the tensile properties is grain size. All the RSP iron-base alloys examined in this study (see Table 1) have fine grain sizes, even after high temperature exposures, compared to their CPCS. Hall-Petch type influences 66,67 on properties such as yield stress would be expected for the iron-base alloys, i.e., $\sigma_{y}=\sigma_{0}+\mathrm{kd}^{-1 / 2}$, where $\sigma_{y}$ is the yield or flow stress, $\sigma_{0}$ is the internal or matrix stress (represented as an intercept), $k$ is the slope, and $d$ is the average grain size.

Figure 91 a presents the yield-stress behavior as a function of $d^{-1 / 2}$ for the $\mathrm{Fe}-40 \mathrm{Ni}$ alloy series. These results show several interesting effects. First, yield stress is totally independent of the powder processing parameters for this series, except for relatively small, but significant, variations in grain size after equivalent heat treatments. Second, a substantial amount of the strengthening observed for the RSP materials is due to their inherent fine grain size. Third, after secondary recrystallization or marked grain growth 


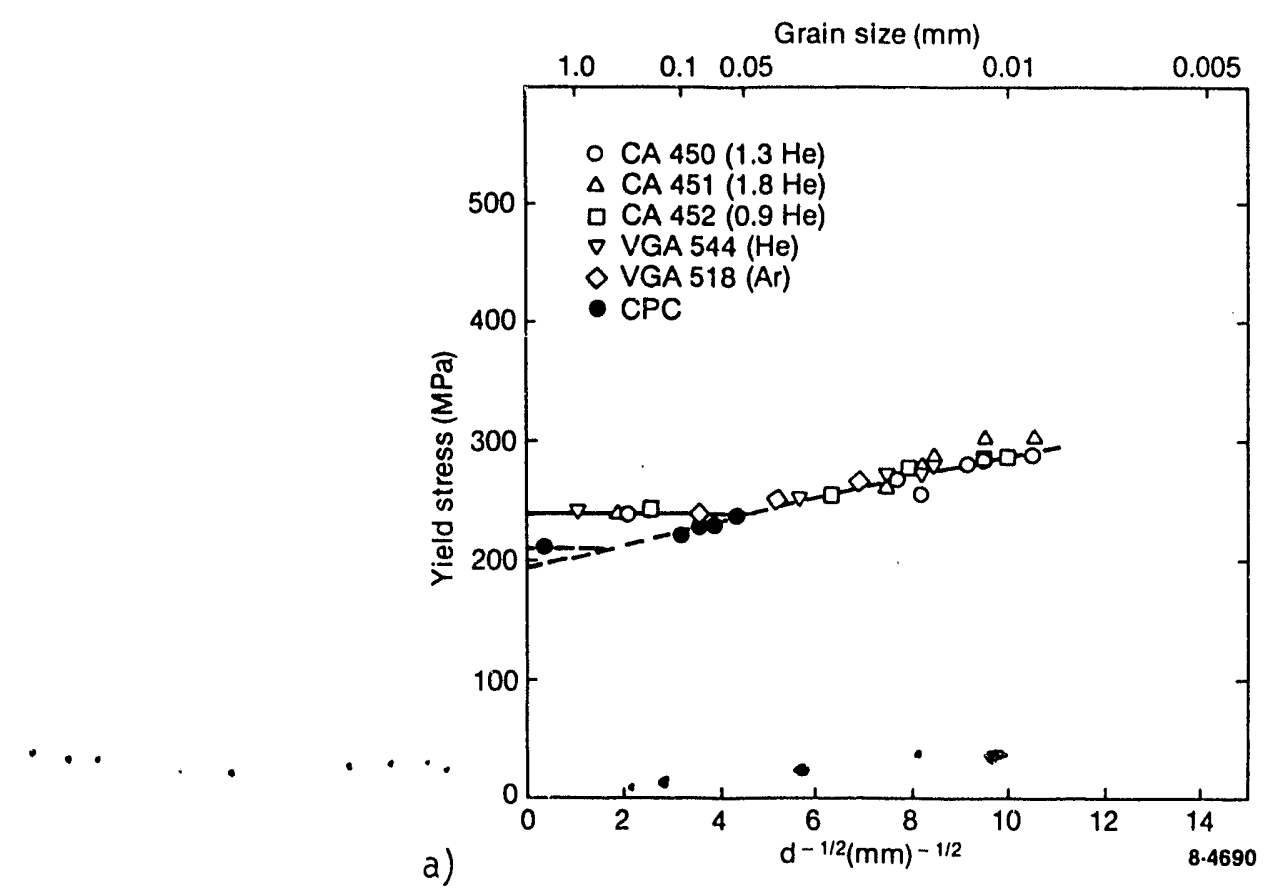

a)

Grain size $(\mathrm{mm})$

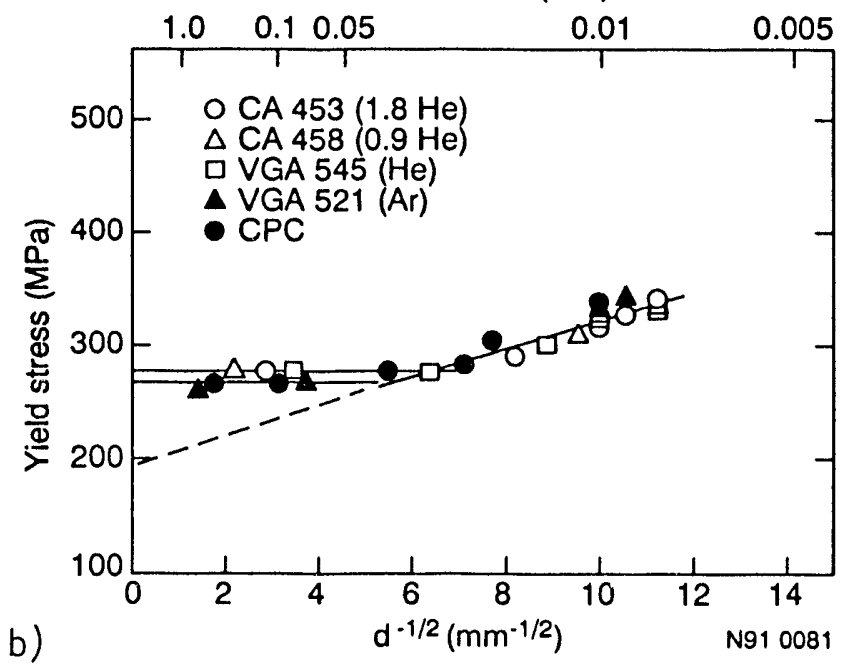

Figure 91. Influence of grain size on room temperature yield stress.

occurs, yield stress is independent of grain size. Finally, the apparent matrix or internal stress $\left(\sigma_{0}\right)$ corresponding to the intercept associated with infinite grain size is significantly higher for the RSP materials than the CPC. The cause of the higher matrix stress in the RSP materials is not fully understood, but is independent of the powder processing parameters. The RSP alloys as well as their CPC contain relatively high levels of residual oxygen. ${ }^{5}$ The conventionally processed Fe-40Ni has micron-size oxides that persist to high temperatures; ${ }^{65}$ finer oxides are observed for the RSP 


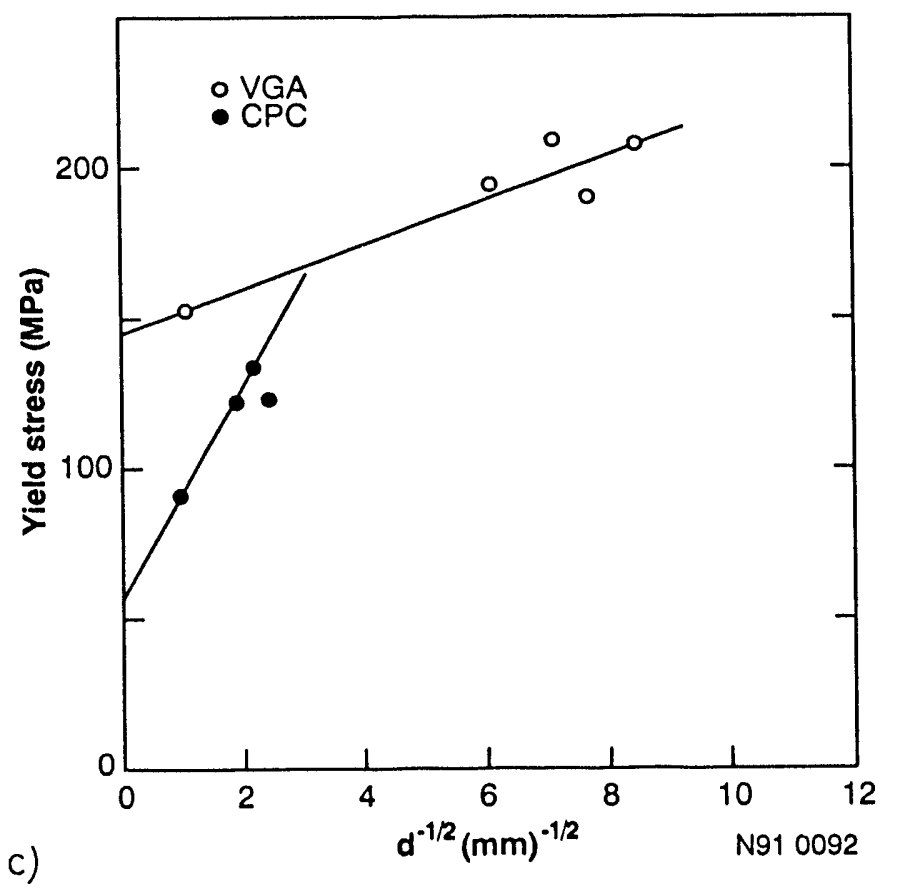

Figure 91. (Continued)

materials. ${ }^{42}$ It is believed that the enhanced matrix stress for the RSP Fe-40Ni series is due to oxygen in dispersions and/or solute/interstitial oxygen.

Another example of the influence of grain size on the yield stress behavior of $\mathrm{Fe}-40 \mathrm{Ni}$ alloys is shown in Figure $9 \mathrm{lb}$, which gives the results for the alloy containing $\mathrm{Nb}$ and $\mathrm{C}$ additions. The behavior is nearly identical to that of the relatively pure $\mathrm{Fe}-40 \mathrm{Ni}$ (Figure $91 \mathrm{a}$ ), but there are three notable differences. The $\mathrm{Fe}-40 \mathrm{Ni}$ with $\mathrm{Nb}$ and $\mathrm{C}$ has a higher slope, larger intercept $\left(\sigma_{0}\right)$, and smaller difference between the internal or matrix stress components of the RSP and CPC specimens in the large grain region where there appears to be no dependence on grain size. The higher Hall-Petch slope for this alloy series could be due to the presence of carbon, which is believed to interact with the grain boundaries and result in higher slopes. ${ }^{68-70}$ A larger $\sigma_{0}$ intercept would be expected from the $\mathrm{Nb}$ and $\mathrm{C}$ additions, probably as a result of solute strengthening rather than from $\mathrm{NbC}$ precipitates. This view is based on the fact that the strengthening occurs after the high-temperature heat treatments. The apparent small difference in $\sigma_{0}$ between three of the RSP materials and their CPC is attributed to the relatively small oxygen content of this alloy series. ${ }^{5}$ 
The VGA and extruded $\mathrm{Fe}-16 \mathrm{Ni}-9 \mathrm{Cr}$ powders exhibit significant strengthening, compared to their CPC, from grain size effects and from the matrix stress component $\left(\sigma_{0}\right)$. These results are shown in Figure 9lc. Unlike the $\mathrm{Fe}-40 \mathrm{Ni}$ (with and without $\mathrm{Nb}$ and $\mathrm{C}$ additions), these CPC specimens have a significantly steeper slope than the VGA extruded powder specimens. However, like the Fe-40Ni alloys, the difference between the slopes for the two Fe$16 \mathrm{Ni}-9 \mathrm{Cr}$ materials could be associated with carbon/grain boundary control. There is a fairly high volume fraction of precipitates, even after hightemperature heat treatments, in the VGA processed $\mathrm{Fe}-16 \mathrm{Ni}-9 \mathrm{Cr}$ but not in its $C P C .{ }^{41}$ These precipitates may be tying up a significant amount of carbon. The relatively high matrix stress component $\left(\sigma_{0}\right)$ for the VGA alloy may be related to its high oxygen content. ${ }^{41}$

The influence of grain size on the yield stress behavior of the Fe-20Ni$20 \mathrm{Cr}$ and $\mathrm{Fe}-20 \mathrm{Ni}-20 \mathrm{Cr}-2 \mathrm{Mo}$ alloys, each with three carbon levels, is shown in Figure 92. The strengthening observed for the CA specimens, compared to their CPCS, appears to be only a grain size effect. There is no evidence of a difference in the intercepts $\left(\sigma_{0}\right)$ for the CA material and its CPC, with the possible exception of the high carbon Fe-20Ni-20Cr-2Mo alloy. However, there is some question regarding the homogeneity of this CPC material after plate fabrication. ${ }^{71}$ The Hall-Petch parameters for these alloys, shown in Table 13, reflect the Mo and $C$ additions. It should be noted that the oxygen contents for these alloys were $10 w^{71}$ compared to those of the other alloys investigated.

The influence of microstructure on tensile properties has been extensively studied for the CA Type 304 SS extruded powder and its CPC. ${ }^{72,73}$ The influence of grain size on the yield stress is shown in Figure 93 . It is apparent from this figure that the retarded grain growth of the CA Type 304 SS material has a pronounced effect on its strengthening; note that the two data sets do not overlap. An interesting trait of the CA material shown in Figure 93 is that it has only two grain sizes: $0.011 \mathrm{~mm}$ for the 1000 and $1100^{\circ} \mathrm{C}$ heat treatments and $-0.030 \mathrm{~mm}$ for the 1200 and $1300^{\circ} \mathrm{C}$ heat treatments. This grouping provides a unique opportunity to distinguish other microstructural features that strengthen the CA material, i.e., submicron microstructural features that increase matrix stress $\left(\sigma_{0}\right)$. This research 


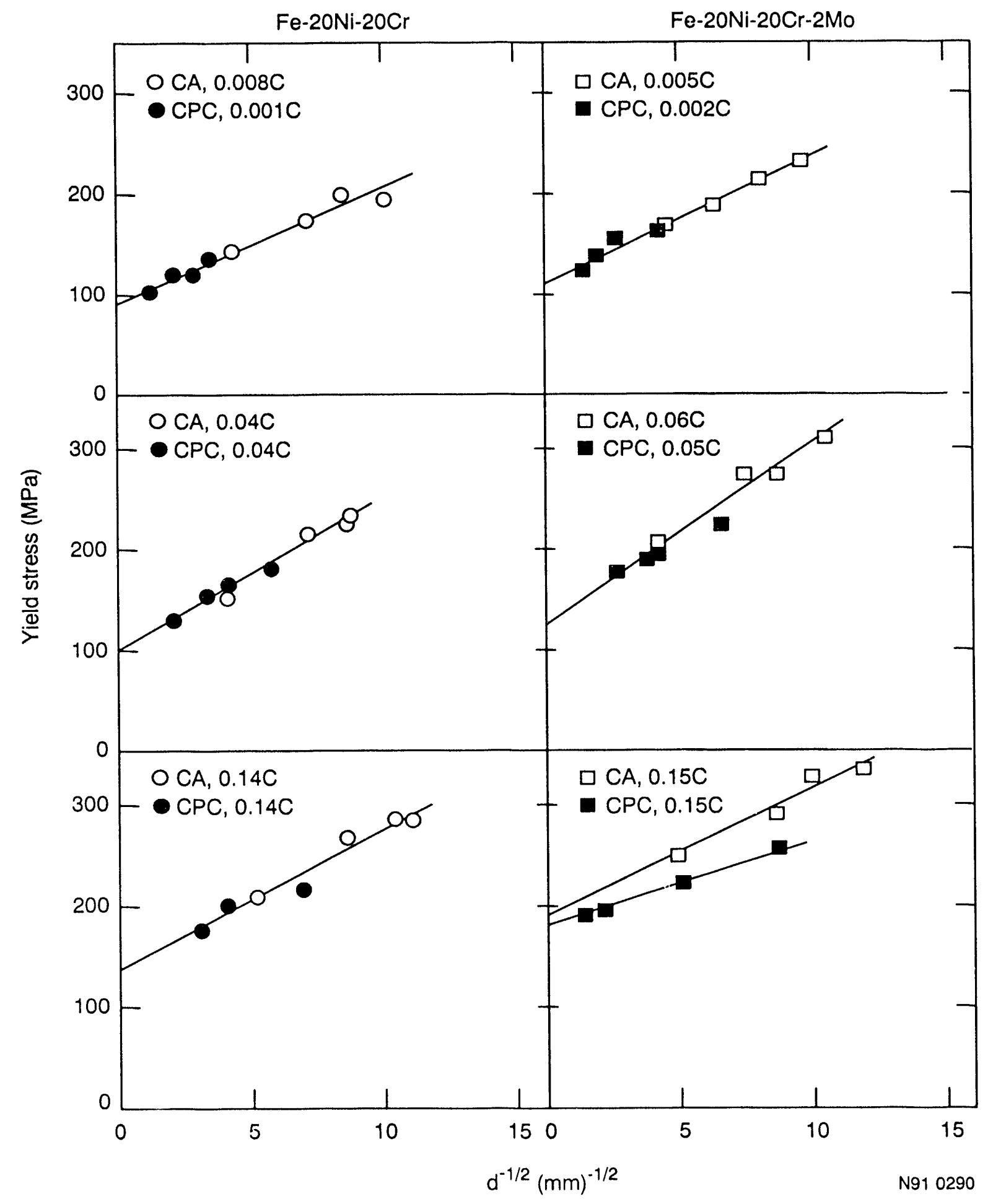

Figure 92. Yield stress dependence on grain size for CA HIPped Fe-20Ni-20Cr and $\mathrm{Fe}-20 \mathrm{Ni}-20 \mathrm{Cr}-2 \mathrm{Mo}$ powders with different carbon contents and their CPCs. 
Table 13. Parameters Associated with the Grain Size Influence on Yield Stress for CA Processed $\mathrm{Fe}-20 \mathrm{Ni}-20 \mathrm{Cr}$ and $\mathrm{Fe}-20 \mathrm{Ni}-20 \mathrm{Cr}-2 \mathrm{Mo}$ Alloys and their CPC

Al10y

$\mathrm{Fe}-20 \mathrm{Ni}-20 \mathrm{Cr}-0.005 \mathrm{C}$

$\mathrm{Fe}-20 \mathrm{Ni}-20 \mathrm{Cr}-0.04 \mathrm{C}$

$\mathrm{Fe}-20 \mathrm{Ni}-20 \mathrm{Cr}-0.14 \mathrm{C}$

$\mathrm{Fe}-20 \mathrm{Ni}-20 \mathrm{Cr}-2 \mathrm{Mo}-0.005 \mathrm{C}$

$\mathrm{Fe}-2 \mathrm{ONi}-20 \mathrm{Cr}-2 \mathrm{Mo}-0.06 \mathrm{C}$

$\mathrm{Fe}-20 \mathrm{Ni}-20 \mathrm{Cr}-2 \mathrm{MO}-0.15 \mathrm{C}$

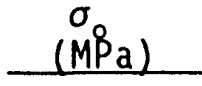

90

95

135

110

122

$188(173)^{a}$ $k$
$\left(\mathrm{MPa} \cdot \mathrm{mm}^{1 / 2}\right)$

11.4

15.9

13.8

12.7

17.8

$13.0(9.0)^{\mathrm{a}}$

${ }^{\mathrm{a} C P C}$ values.

has shown that the $C A$ material contains high dislocation densities (see Figure 52), a large number of fine precipitates, and nanometer size cavities. Recent analysis of the influence of these microstructural features on yield stress has shown that the high dislocation density provides the most consistent correlation with the results shown in Figure 93.72,73 However, the origin of the dislocations and how to stabilize them are still unknown. It is believed that oxygen could be playing an important role in stabilizing the dislocation structure.

Figures 91 through 93 clearly show that the fine grain size retained in the RSP iron-base alloys after high temperature heat treatments has provided a substantial portion of the tensile strengthening. This behavior is typical of all the iron-base alloys investigated. There was no obvious influence of powder processing or powder consolidation parameters or of powder particle size on tensile properties, except in the case discussed below. The variations observed were primarily related to alloy composition, particularly those compositional variations that contribute to matrix strengthening.

The final example of microstructural effects on tensile properties for the RSP alloys is the substantial increase in strengthening for the $>10$ to 


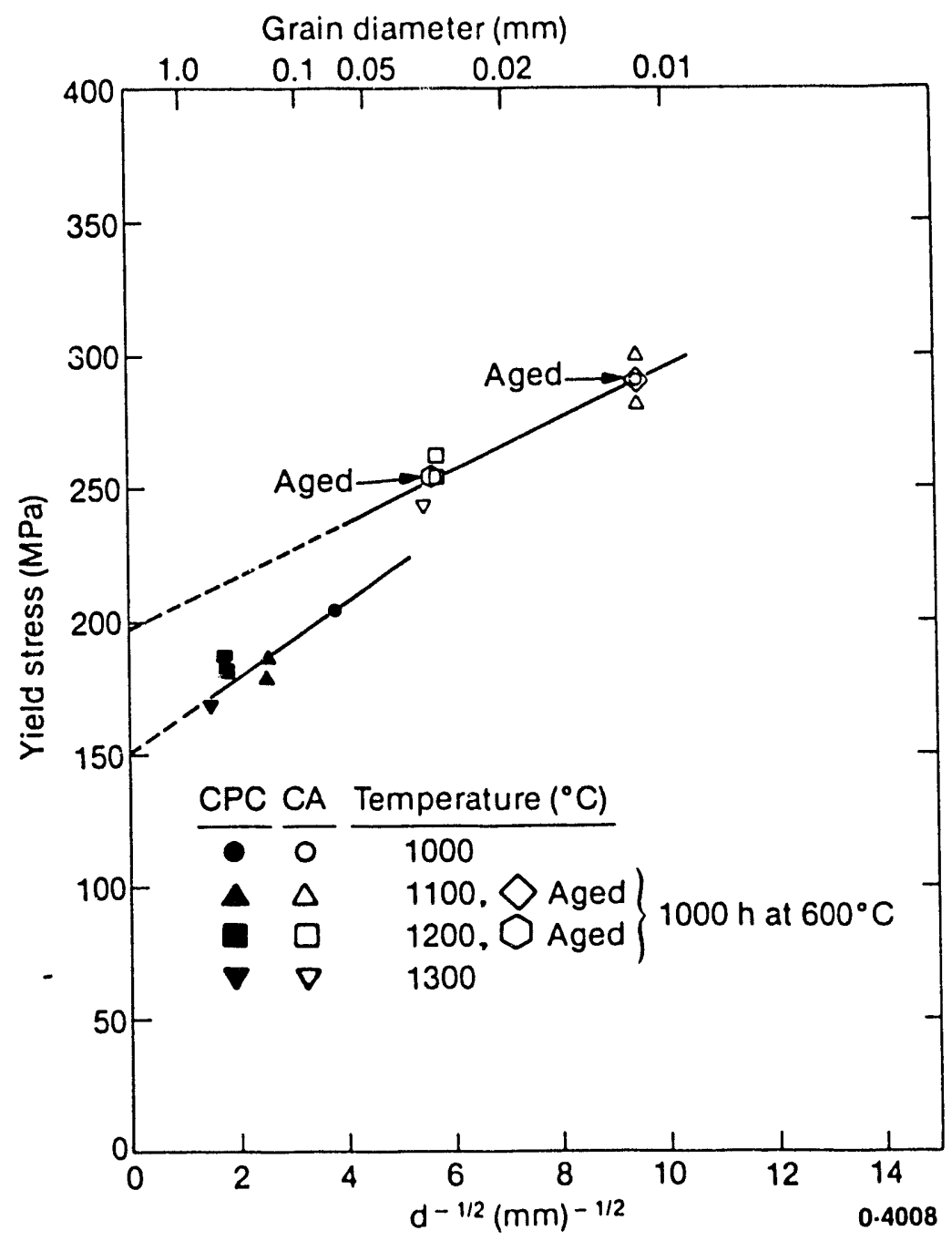

Figure 93. Influence of grain size on room temperature yield stress for CA Type 304 SS extruded powder and its CPC.

$<30 \mu \mathrm{m}$ powder particle size of the IGA and extruded $\mathrm{Fe}-16 \mathrm{Ni}-9 \mathrm{Cr}-2 \mathrm{Mo}-1.5 \mathrm{Mn}-1 \mathrm{Si}-$ $0.5 \mathrm{Ti}$ alloy. An explanation for the behavior shown in Figure 81 is still being sought; however, preliminary results indicate that particles in this size range have acquired, during atomization with helium, a relatively large amount of nitrogen compared to the other particle sizes and their CPC. ${ }^{74}$ The mechanism of nitrogen entrainment for the $>10$ to $<30 \mu \mathrm{m}$ particle size range is currently under investigation. This material has a very high population of fine titanium nitrides in the matrix. The other particle sizes and the CPC show no evidence of nitride precipitates. It is surmised that the titanium nitrides are responsible for the rather remarkable increase in strength observed for the $>10$ to $<30 \mu \mathrm{m}$ extruded powders. 


\section{Creep Correlations}

The creep behavior of most of the RSP iron-base alloys investigated shows either no or only slight improvement over that of their CPCS. Two of the CA alloys, Fe-40Ni-0.3Nb-0.05C and Type 304 SS, are notable exceptions. These $C A$ alloys show marked improvement in creep resistance compared to their CPCs. Microstructural examinations of the CA Fe-40Ni-0.3Nb-0.05C alloys are not extensive enough to conclusively identify the cause of their creep strengthening, but it is believed to be associated with the stabilization of niobium carbides. ${ }^{65}$ This is not the case for the CA Type 304 SS extruded powder; the cause of its creep strengthening has been identified to be the large population of fine carbide dispersions that nucleated on the $8 \mathrm{~nm}$ cavities (see Figure 60) during the creep test or after preaging at $600^{\circ} \mathrm{C}$. The microstructural features of the IGA and CA Type 304 SS extruded powders are very similar. However, in the IGA material, nanometer size cavities did not develop, so precipitation of carbides on such cavities could not occur. (The creep results for CA and IGA Type 304 SS materials were shown earlier in Table 12.) Analysis of the minimum creep behavior in terms of the effective stress for the CA Type 304 SS extruded powder and its CPC shows a significantly higher obstacle stress for the CA material. ${ }^{75}$ The obstacle stress for a range of test cemperatures is shown in Figure 94 . The increase in obstacle stress for the CA material is attributed to the fine cavitycarbide matrix dispersions (see figure 60). The dispersion strengthening allows the applied or load-bearing stress to be significantly increased, or the operating temperature to be raised about $100^{\circ} \mathrm{C}$, compared to the limits for the CPC material.

\section{Fatigue Correlations}

Fatigue testing on the RSP iron-base alloys and their CPCS has been quite limited to date. The initial results (Figure 90) show that significant improvements in fatigue resistance can be expected for many of the iron-base alloys; however, the research is still too incomplete to discern the microstructural characteristics responsible for these improvements. The fine grain size observed for the RSP alloys and the matrix strengthening, when it occurred, would be expected to have a positive effect on the fatigue behavior. 


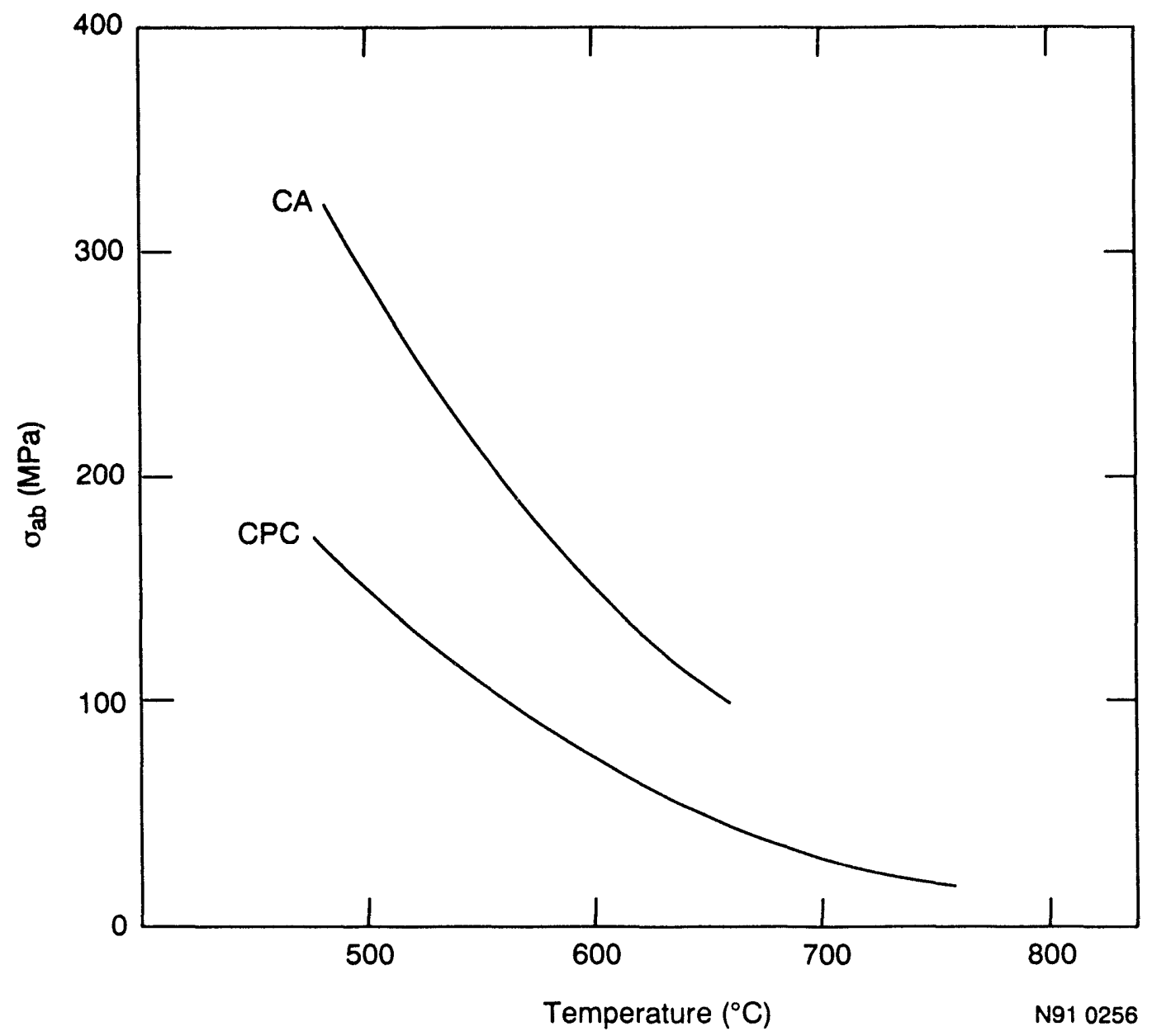

Figure 94. Temperature influence on creep obstacle stress for CA Type 304 SS extruded powder and its CPC.

Improved Microstructural Stability and Strengthening by Designed Rapid Solidification Processing

It is fairly well accepted that fine and stable microstructures will significantly improve mechanical properties, as well as other properties such as corrosion resistance. ${ }^{60}$ The results of this study on iron-base alloys provide evidence that RSP can achieve mechanical property improvements. The study has also identified areas that need further research in order to realize the full potential of RSP: control and proper use of the interstitial elements oxygen, carbon, and nitrogen, as well as of vacancy trapping. This is essential for designing the desired microstructures in improved, RSP, ironbase alloys. It is well known that carbon and nitrogen play very important roles in the strengthening of iron-base alloys. However, their effect as 
precipitates in conventionally processed alloys at high temperatures is questionable because of coarsening. Normally, the presence of oxygen in ironbase alloys is viewed as detrimental because of inclusion development, and measures are taken to reduce the oxygen content. This study indicates that oxygen can be very beneficial and, in fact, may be the most important ingredient for microstructural stabilization. Extracting the maximum benefit from the interstitial elements requires a better understanding of their role and how to control them during RSP and subsequent thermal-mechanical treatments. Before addressing guidelines for using interstitial elements, we need to summarize their apparent roles, or at least the implications of the observations of this study.

1. Oxygen. The results for the iron-base alloys imply that this element has a dominant influence on microstructural refinement and stabilization.

- Retards grain growth, apparently more through reduction in grain boundary energy and drag effects than from dispersion pinning.

- Stabilizes vacancy clusters to form stable, nanometer size, cavities or hollow oxides that are matrix nucleation sites for strengthening precipitates such as carbides.

- Interacts with dislocations, preventing their recovery.

- Promotes solute (solution) strengthening.

2. Carbon. This study does not indicate that carbon enhances the RSP alloys, except possibly in combination with oxygen as carbooxides. In support of this view, consider the $\mathrm{Fe}-20 \mathrm{Ni}-2 \mathrm{OCr}$ and $\mathrm{Fe}-20 \mathrm{Ni}-20 \mathrm{Cr}-2 \mathrm{Mo}$ alloys that contained various carbon concentrations (see Figures 72 and 92). Although not confirmed, there is reason to suspect that carbo-oxide development, through RSP, can be important. This illustrates the need for quantitative determination of the compositions of the submicron precipitates. 
3. Nitrogen. The use of entrained nitrogen in RSP has not received much attention; however, that may be the major thrust for ironbase structural alloys in the near future. The results shown in Figure 81 , in conjunction with the observation that the $>10$ to <30 $\mu \mathrm{m}$ particle size for this alloy contains four to five times more nitrogen than the other consolidated powder particle sizes and the $C P C$, are most encouraging.

Effective use of the interstitial elements requires that they be introduced into the melt as dissociated solutes before powder atomization. Significant superheat may be needed to eliminate or minimize compound development. It is very important that compound formers in the alloy do not tie up the interstitial elements and thus "kill" the melt prior to crystallization. It is equaliy important that the interstitial elements be uniformly distributed and chemically dissociated during crystallization of the atomized droplets. The amounts of strong compound formers (i.e., those having high heats of formation) must be controlled, probably to low levels. It is doubtful, for example, that alloys that have significant concentrations (intentionally or as impurities) of elements such as $\mathrm{Al}, \mathrm{Ti}, \mathrm{Si}, \mathrm{Zr}$, and some of the rare earths, will be able to realize the full benefits of dissociated oxygen.

In conjunction with control of the interstitial elements, vacancy trapping at supersaturation levels during crystallization needs to be promoted. Entrainment of a very large population of vacancy clusters and their subsequent stabilization by an oxygen coating can lead to a homogeneous distribution of closely spaced, nanometer sized, hollow oxides that can substantially increase dispersion strengthening. Achieving this requires that the oxygen find and stabilize the vacancy clusters or voids during rapid crystallization. The opportunities for substantial improvements in properties and performance appear to be associated with composition control of the highly reactive elements during the melting process and with atomization practices that produce powders that have experienced high crystallization rates. 
A considerable number of powder metallurgy ( $P / M)$ parts are produced annually from iron-base alloys, the majority of which are for the automotive industry. The powders used are produced primarily by water atomization, and consolidated to the desired near-net-shapes (NNS) by pressing and sintering. These parts commonly fall into the category of "low value," i.e., structural integrity is not a critical factor in their performance. It is not the intent of this review to cover the current practices and commercial uses of iron-base $P / M$ parts, because, in principle, they are not viewed as RSP. However, it is recognized that some of the benefits of RSP observed in this study might also occur in these parts. For high performance structural applications of RSP alloys, the consolidated powder forms must be fully dense and fully metallurgically bonded.

Commercial use of RSP iron-base alloys depends on a number of factors. The bottom line for the $P / M$ products is cost competitiveness with conventionally processed alloys, often referred to as ingot metallurgy (I/M) products. $P / M$ products have successfully competed with $I / M$ for low value applications, mainly by eliminating many of the forming and fabrication steps required for shaping the I/M parts. Because full density is not required, water atomization of powders and subsequent NNS forming by pressing and sintering are adequate for these applications.

\section{Powder Processing}

The RSP approach requires some changes in commercial powder atomization practices. Melt chemistry must be closely controlled and the liquid droplets require high rates of cooling after atomization. The latter necessitates the use of rather expensive noble gases, i.e., argon or helium. To reduce costs, the noble gases used for atomization and/or cooling could be recycled. The primary factor in recovering the capital costs is utilization, i.e., heavy use of the atomization system with minimal downtime.

Further steps can be taken to improve powder atomization economics. For example, it is obvious that usable powder yields, in terms of melt through- 
put, need to be as high as possible and flakes (splats) and shards kept to a minimum. For atomization processes such as IGA, nozzle design and melt stream delivery must provide a high ratio of atomizing gas to molten metal flow to maximize breakup of the melt stream into fine droplets and produce a high yield of fine particles. The advantage of atomizing to produce finer powders lies in higher crystallization rates, which promote trapping of supersaturation levels of vacancies and a more homogeneous distribution of the reactive elements, such as oxygen, in the solid to stabilize vacancy clusters.

Admittedly, most of the iron-base alloys investigated in this study showed very little evidence of microstructural and mechanical property dependence on powder particle size. The reason for this behavior is not well understood, but could be due to a lack of reactive elements for vacancy stabilization. The current study has shown the importance of vacancy supersaturation and stabilization with oxygen. Additional research is required to better understand the vacancy trapping behavior and melt chemistry control needed to promote the development of large populations of nanometer size, hollow oxides. Intuitively, the concentration of entrained vacancies should increase with decreasing particle size, i.e., higher cooling rates. Vacancy stabilization as small voids will depend on the availability of dissociated oxygen, which is likely to be independent of particle size (see Figures 44 and 45 ). Since vacancy entrapment is important, sufficient oxygen needs to be available to allow the particle size to influence microstructural stability and strengthening.

In addition to high yields of fine particles, improved atomization practices would produce high quality powders suitable for powder injection molding (PIM). This would expand opportunities for alloy selection. However, PIM for high value parts (defined primarily from a performance viewpoint) will depend on the effectiveness of consolidation, i.e., the density and particle bonding achieved. Consolidation will be discussed in the next section.

Nitrogen shows promise for powder processing and/or atomization, but more study is required. Blanketing the melt with $>1 \mathrm{~atm}$ of nitrogen just prior to atomization provides an opportunity to entrain relatively high levels 
of nitrogen. A variety of iron-base alloys could benefit from high nitrogen concentrations. It has been demonstrated that pressurization of iron-base alloy melts with $>1$ atm nitrogen can provide supersaturation levels of nitrogen in the solidified alloy. ${ }^{76,77}$ An example was given earlier (see Figure 81) in which $0.1 \mathrm{wt} \%$ nitrogen in the IGA and extruded Fe-16Ni-9Cr-2Mo$1.5 \mathrm{Mn}-1.0 \mathrm{Si}-0.5 \mathrm{Ti}$ alloy produced outstanding tensile properties. A stabilized microstructure was retained to $1100^{\circ} \mathrm{C}$, and the yield stress was a factor of 3 higher than that of the CPC and twice as high as those of the other extruded particle sizes that possessed four to five times less nitrogen. The microstructure had a large population of small (20 to $50 \mathrm{~nm}$ ) titanium nitride precipitates.

To realize these benefits, the optimum conditions for homogeneous entrainment of nitrogen need to be determined. Potentially, atomization of a nitrogen-enriched melt stream with helium would provide high crystallization rates and a more homogeneous distribution of the nitrogen in the droplets/particles. Atomization with nitrogen, due to lower convective cooling, may result in less nitrogen homogeneity. However, if the latter is disproved, i.e., there is no apparent difference between using helium and nitrogen for atomization, then nitrogen should be used for the nitrogenenriched iron-base alloys. An obvious advantage of using nitrogen for atomization is that it is considerably less expensive than the noble gases. Another potential benefit of nitrogen atomization is that mechanically entrained nitrogen is fairly soluble in most iron-base alloys and its use could eliminate the gas porosity that can result from entrained noble gases.

\section{Powder Consolidation}

Full densification and particle bonding are needed to maximize the properties of the consolidated product and realize the full benefits from RSP. This level of consolidation requires techniques beyond conventional pressing and sintering, e.g., hot isostatic pressing or extrusion. Some economic benefits may be obtained by applying near-net-shape consolidation practices, thus reducing subsequent forming and shaping operations. While less than fully dense products can be made from the high quality RSP powders, the value 
of these products in terms of performance would have to be weighed against any additional cost of powder processing.

The results from this study indicate that there is flexibility in the method of consolidating RSP iron-base alloy powders. A possible exception was the CA Type 304 SS powders, for which hot extrusion led to the development of $8 \mathrm{~nm}$ hollow oxides but HIPping did not. These oxides provided nucleation sites for a fine dispersion of matrix carbides, which resulted in substantial increases in creep resistance (see Figure 87 ).

Temperature is an important parameter in powder consolidation. Higher temperatures than those of conventional processing practices can be used, but this study indicates that consolidation temperatures should not exceed $1200^{\circ} \mathrm{C}$ to ensure retention of the RSP benefits. Consolidation of RSP iron-base alloy powders can be achieved at lower temperatures, as has been demonstrated in this work by extrusion and HIPping at $900^{\circ} \mathrm{C}$.

This study has focused on the underlying basis for the improved microstructural stability and strength of RSP iron-base alloys and has not targeted specific product lines. Powder consolidation practices will necessarily be tailored to the particular end product. It is obvious that near-net-shape practices are needed for economic reasons, and NNS methods will be developed by industry as RSP is adopted.

Earlier, the potential for producing RSP powders that could be used for powder injection molding was mentioned. Another aspect of the RSP iron-base alloy powders that may aid in powder consolidation and shape forming is superplastic behavior. Although this study has not addressed their superplastic behavior, it is expected that many of these alloys have this tendency. This belief is based on the fine grain size and submicron microstructural features observed in the consolidated powders.

Another type of particulate NNS forming that has not been addressed in this study, but could potentially benefit from RSP, is spray casting. Spray deposition of metallic droplets to NNS has economic benefits that allow it to compete with conventional processing. However, there is concern that spray 
casting may not be able to realize the full potential of RSP as this process may not be able to achieve crystallization rates comparable to those of atomized and convectively cooled powders. The crystallization rates for spray casting depend on the substrate and the thickness of the deposited powder. Studies are needed to establish the microstructure-property behavior for spray cast alloys and to compare it with that of consolidated products from atomized and convectively cooled powders. It is anticipated that some improvements in microstructural stability and strengthening will be attained by spray cast products even if the full potential of RSP cannot be achieved.

\section{Potential Product Applications}

The preceding two sections addressed economic aspects of powder processing and consolidation that must be considered before adopting the RSP technology as a commercial practice. A major, and possibly governing, factor that needs to be addressed is the cost for performance, i.e., what price is the user willing to pay for superior performance? Addressing this issue requires a rather thorough evaluation of the specific application for the RSP product. These applications will fall into two categories: (1) a suitable product cannot be obtained by other means (i.e., there is no other way to achieve the required properties), and (2) replacement and associated downtimes are critical or expensive and the RSP product provides the longest lifetime. This study has shown that RSP of iron-base alloys has the potential for a major, positive, impact in such applications. Admittedly, more research and development is needed to realize the full potential of RSP of iron-base alloys.

The development iron-base alloys prepared by RSP requires more attention from researchers and industry. This will involve further testing on actual parts or components in service environments. These field tests will provide the information necessary to establish performance differences between the RSP iron-base alloys and their CPCS. If the differences are substantial, users of the product forms can determine if the additional value of the RSP products justifies their cost. 
Some potential end uses for RSP iron-base alloys are shown in Table 14 . It should be recognized that the list is not inclusive, but rather suggests areas where future research and development could be focused. It is also probable that RSP iron-base alloys can replace nickel-base superalloys in applications where high temperature mechanical properties are important.

Table 14. Potential End Uses for RSP Iron-Base Alloy Products

\begin{tabular}{|c|c|c|}
\hline \multirow[b]{2}{*}{ Sector } & $\begin{array}{l}\text { Near Term } \\
(<5 \text { y) }\end{array}$ & $\begin{array}{r}\text { Mid Term } \\
(<15 y)\end{array}$ \\
\hline & & \\
\hline Transportation & $\begin{array}{l}\text { Drive train } \\
\text { Engine components } \\
\text { Gears } \\
\text { Fasteners }\end{array}$ & $\begin{array}{l}\text { Turbine system } \\
\text { Lightweight structures } \\
\text { Springs } \\
\text { Bearings }\end{array}$ \\
\hline Industry & $\begin{array}{l}\text { Burners } \\
\text { Sour gas systems } \\
\text { Thermal and electrical } \\
\text { resistance }\end{array}$ & $\begin{array}{l}\text { Valves } \\
\text { Pressure vessels } \\
\text { High temperature } \\
\text { filters }\end{array}$ \\
\hline
\end{tabular}




\section{SUMMARY}

A review of the status of rapid solidification processing (RSP) of ironbase alloys for structural applications is provided. The review is based on several years of research at the Idaho National Engineering Laboratory. The focus of this review is on the cause of the improved microstructural fineness and stability of the RSP alloys and on correlation of the microstructural features with the observed improvements in mechanical properties. The primary variables evaluated were powder atomization and consolidation methods, and alloy composition.

After powder processing and consolidation, all of the alloys investigated had a fine and stable grain size that prevailed to $1200^{\circ} \mathrm{C}$. This was not the case for their conventionally processed counterparts (CPCs). Not only is grain stability fairly independent of alloy composition, but little evidence exists to support the theory that the methods used for powder atomization (with their associated differences in solidification rates) or for powder consolidation have much influence on grain size or grain growth.

The reason for the fine and stable grain size has not been resolved, but the collective results seem to indicate that oxygen is important in stabilizing the grain boundaries. Stable submicron microstructural features observed in these RSP iron-base alloys appear to show some dependence on alloy composition and on powder atomization and consolidation processes. A major finding of the study of the submicron microstructural behavior was the supersaturation of vacancies trapped during rapid crystallization and their stabilization by oxygen to form nanometer-sized cavities/hollow oxides. These cavities were observed to be nucleation sites for matrix carbides. Findings from microstructural studies showed that entrained oxygen, particularly when introduced into the RSP alloy in dissociated form, can have a very positive influence on the development and stabilization of fine microstructures.

Significant improvements in mechanical properties were observed for the RSP alloys compared to their CPCS. The fine grain sizes provided very significant increases in tensile stresses for all of the RSP alloys without causing significant losses in ductility. The fine grain size is also credited 
with the improvements in fatigue resistance. Improvements in creep resistance were observed only for the alloy containing a high population of nanometersize hollow oxides. Their ability to provide effective nucleation sites for small and stable matrix carbides resulted in substantial improvement in creep resistance.

The study shows that rapid solidification processing of iron-base alloys should be designed to optimize the control and utilization of the interstitial elements, oxygen, nitrogen, and carbon, and of vacancy trapping during crystallization. These appear to be necessary ingredients for designing a new generation of RSP iron-base alloys with substantial improvements in performance and reliability. Achieving a new generation of alloys will require further research and development. The results presented in this review should provide useful guidelines for further development and realization of the full potential of RSP. Resolution of some economic issues is also necessary for commercial adoption of the RSP approach. 


\section{REFERENCES}

1. Cohen, M., Kear, B. H., Mehrabian R., in Proceedings of the Second

International Conference on Rapid Solidification Processing: Principles and Technologies II, eds. Mehrabian, R., Kear, B. H., and Cohen, M., (Claitors Publ. Div., Baton Rouge, LA) (1980) 1-23.

2. Flinn, J. E., Rapid Solidification Technology for Reduced Consumption of Strategic Materials (Noyes Publ., Park Ridge, NJ) (1985).

3. Mehrabian, R., International Metallurgical Reviews, 27 (1982) 184-208.

4. Korth, G. E., Storhok, V. W., and Burch, J. V., in Rapidly Solidified Materials: Properties and Processing, eds. Lee, P. W., and Moll, J. H., (ASM International, Metals Park, OH) (1988) 213-220.

5. Flinn, J. E., and Smolik, G. R., Mater. Sci. and Eng., Al24 (1990) 39-48.

6. Kelly, T. F., Cohen, M., and Vander Sande, J. B., Metal1. Trans. A, 15A (1984) 819-833.

7. Wright, R. N., Bae, J. C., Kelly, T. F., Flinn, J. E., and Korth, G. E., Metall. Trans. A, 19A (1988) 2399-2405.

8. Bae, J. C., Kelly, T. F., Flinn, J. E., and Wright, R. N., Scripta Metal1., 22 (1988) 691-696.

9. Kim, Y-W., Kelly, T. F., and Flinn, J. E., "Submicron Defect

Characteristics of Type 304 SS Powders Produced by Inert Gas Atomization" (to be published).

10. Fredriksson, H., Metall. Trans., $\underline{3}$ (1972) 2989-2997.

11. Masumoto, I., Tamaki, K., and Kutsuna, M., J. Japan Welding Society, 41 (1972) 1306-1314.

12. Brooks, J. A.: Ph.D. Thesis, Carnegie-Mellon, Pittsburgh, PA (1981).

13. David, S., Welding J., 60 (1981) 635-715.

14. Smolik, G. R., and Delmore, J. E., Mater. Sci. Eng., Al24 (1990) 15-19.

15. Rabin, B. H., Smolik, G. R., and Korth, G. E., Mater. Sci. Eng., A124, (1990) 1-7.

16. Wolfer, W. G., Van Siclen, C. D., Foiles, S. M., and Adams, J. B., Acta Metall., 37 (1989) 579.

17. Korth, G. E., Flinn, J. E., and Burch, J. V., Advances in Powder Metallurgy - 1990, eds. Andreotti, E. R., and McGeehan, P. J., (Metal Powder Industries Federation, Princeton, NJ) (1990) 49-63.

18. Sidda11, R. J., U.S. Patent No. 4,233,062 (November 11, 1980). 
19. Flinn, J. E., Korth, G. E., and Wright, R. N., Rapidly Solidified Materials: Properties and Processing, eds. Lee, P. W., and Moll, J. H., (ASM International, Metals Park, OH) (1988) 153-162.

20. Kim, W-W., Ph.D. Thesis, University of Utah, Salt Lake City, UT (August 1988).

21. Kim, W-W., Byrne, J. G., and Flinn, J. E., "Particle Densification and Bonding During HIP Consolidation of Type 304 SS Powder" (to be publ ished).

22. Arzt, E., Ashby, M. F., and Easterling, K. E., Metall. Trans. A, 14A (1983) 211 .

23. Helle, A. S., Easterling, K. E., and Ashby, M. F., Arta Metall., 33 (1985) 2163-2174.

24. Helle, A. S., Ph.D. Thesis, Lulea University, Sweden (1986).

25. Korth, G. E., Flinn, J. E., and Green, R. C., Metallurgical Applications of Shock-Wave and High-Strain-Rate Phenomena, eds. Murr, L. E., Staudhammer, K. P., Meyers, M. A., (Marcel-Dekker, New York, NY) (1986) 129-147.

26. Flinn, J. E., Korth, G. E., and Doyle, T. E., Shock Waves in Condensed Matter - 1987, eds. Schmidt, S. C., and Holmes, N. C., (Elsevier Sci. Pub1., New York, NY) (1988) 415-418.

27. Korth, G. E., Flinn, J. E., and Wright, R. N., Ibid (Ref. 19) 177-182.

28. Wright, R. N., Korth, G. E., and Flinn, J. E., Metall. Trans. A, 20A (1989) 2449-2457.

29. Flinn, J. E., Williamson, R. L., Berry, R. A., Wright, R. N., Gupta, Y. M., and Williams, M., J.Appl. Phys., 64 (1988) 1446-1457.

30. Clark, D. E., and Korth, G. E., Ibid (Ref. 19) 9-19.

31. Flinn, J. E., Clark, D. E., and Korth, G. E., "Consolidation and Joining of Rapidiy Solidified Alloys, " U.S. Bureau of Mines Research Investigation Report (to be published).

32. Clark, D. E., Einerson, C. J., and Loop, R. B., The Gas Tungsten ArC Weldability of Rapidly Solidified Alloys, Idaho National Engineering Laboratory Report: EGG-SCM-7196 (September 1986).

33. Clark, D. E., Einerson, C. J., and Loop, R. B., Capacitor Discharge Welding for Joining of Rapidly Solidified Materials, Idaho National Engineering Laboratory Report: EGG-SCM-7220 (September 1987).

34. Einerson, C. J., Clark, D. E., and Devletian, J. H., in Proceedings of the 1987 ASME JSME Thermal Engineering Joint Conference, $\underline{3}$ (1987) 217 224. 
35. Devletian, J. H., Oregon Graduate Center, Beaverton, OR, personal communication (1987).

36. Loop, R. B., and Clark, D. E., Idaho National Engineering Laboratory, Idaho Falls, ID, personal communication (1987).

37. Flinn, J. E., "Influence of Particle Size on Entrained Gases from Powders Processed by Inert Gas Atomization" (to be published).

38. Flinn, J. E., Bae, J. C., and Kelly, T. F., "Swelling/Porosity Behavior of Iron-Base Alloys Containing Noble Gases from Powder Processing" (to be published).

39. Herring, C., J.Appl. Phys., 21 (1950) 437.

40. Coble, R. L., J. Appl. Phys., 41 (1970) 4798.

41. Flinn, J. E., and Bae, J. C., "Mechanical Properties and Microstructures for Vacuum Gas Atomized and Conventionally Processed $\mathrm{Fe}-16 \mathrm{Ni}-9 \mathrm{Cr}$ and $\mathrm{Fe}-$ $16 \mathrm{Ni}-9 \mathrm{Cr}-5 \mathrm{Mo}-2 \mathrm{Cu}$ Alloys" (to be published).

42. Shin, Keesam, Masters Thesis, University of Wisconsin, Madison, WI (1991).

43. Webb, W. W., J.Appl. Phys., 33 (1962) 1961.

44. Ruhle, M., Radiation Induced Voids in Metals (Proc. Conf. held at Albany, NY, June 1971), USAEC (1972) 255.

45. Ruhle, M., and Wilkens, M., Crystal Lattice Defects, $\underline{6}$ (1975) 129-140.

46. Bae, Jung Chan, Ph.D. Thesis, University of Wisconsin, Madison, WI (1988).

47. Kelly, T. F., Shin, K., Bae, J. C., Noll, R. K., and Flinn, J. E., HighResolution Electron Microscopy of Defects in Materials, eds. Dahmen, U., Sinclair, R., and Smith, D. J., (Matls. Res. Soc., Pittsburgh, PA) (in press).

48. Kelly, T. F., Flinn, J. E., and Bae, J. C., "Nanometer-Size Cavity Formation and Stability from Rapid Solidification Processing of Austenitic Steels" (to be published).

49. Zinkle, S. J., Seitzman, L. E., and Wolfer, W. G., Phil. Mag. A, $\underline{55}$ (1987) $111-125$.

50. Wang, L. M., Dodd, R. A., and Kulcinski, G. K., J. Nucl. Mater, $141-143$ (1986) $713-717$.

51. Seitzman, L. E., Wang, L. M., Kulcinski, G. L., and Dodd, R. A., J. Nucl. Mater., 141-143 (1986) 279-286.

52. Wang, L. M., Dodd, R. A., and Kulcinski, G. L., J. Nucl. Mater., 155-157 (1988) 1241-1248. 
53. Seitzman, L. E., Kulcinski, G. L., and Dodd, R. A., ASTM Spec. Tech. Publ. 955 (1987) 279-286.

54. Sindelar, R., Kulcinski, G. L., and Dodd, R. A., J. Nucl. Mater., 133134 (1985) 246.

55. Zinkle, S. J., and Lee, E. H., Metall. Trans. A, 21A (1990) 1037.

56. Seitzman, L. E., Dodd, R. A., and Kulcinski, G. L., Metall. Trans. A, 21A (1990) 1839 .

57. Kelly, T. F., and Vander Sande, J. B., Ibid (Ref. 1) 120-111.

58. Suga, M., Goss, J. L., 01 son, G. B., and Vander Sande, J. B., Ibid (Ref. 1) $364-371$.

59. 01son, G. B., and Bourdeau, R. G., in Rapidly Solidified Crystalline Alloys, eds. Das, S. K., Kear, B. H., and Adam, C. M., (Metall. Soc. Pub1., Warrendale, PA) (1985) 185-201.

60. Yurek, G. J., Eisen, D., and Garratt-Reed, A., Metall. Trans. A, 13A (1982) 473-485.

61. Smith, C. S., Trans. Am. Inst. Min. Engrs., 175 (1948) 15.

62. Hillert, M., Acta Metall., 36 (1988) 3177-3181.

63. Flinn, J. E., "Influence of Powder Particle Size on the Mechanical Properties of IGA Processed and Extruded Fe-16Ni-9Cr Powders" (to be published).

64. Flinn, J. E., Shin, K., and Kelly, T. F., "Influence of Powder Particle Size on the Microstructure and Mechanical Properties of IGA Processed and Extruded A286 Powder" (to be published).

65. Flinn, J. E., Shin, K., and Kelly, T. F., "Mechanical Property Behavior of CA and VGA Processed and Consolidated Fe-40Ni and Fe-40Ni-0.3Nb-0.05C Powders" (to be putlished).

66. Ha11, E. 0., Proc. Phys. Soc., B64 (1951) 747.

67. Petch, N. J., J. Iron Steel Inst., 174 (1953) 25.

68. Li, J. C. M., Trans. TMS, AIME, 227 (1963) 239-247.

69. Li, J. C. M., and Chou, Y. T., Metall. Trans., 1, (1970) 1145-1159.

70. Mintz, B., Metals Tech., 11 (1984) 265-272.

71. Flinn, J. E., "Influence of Carbon Content on the Mechanical Properties of Centrifugally Atomized and Consolidated $\mathrm{Fe}-20 \mathrm{Ni}-20 \mathrm{Cr}$ and $\mathrm{Fe}-20 \mathrm{Ni}-20 \mathrm{Cr}$ 2Mo Powders" (to be published). 
72. Flinn, J. E., Bae, J. C., Kelly, T. F., and Korth, G. E.,

"Microstructural Stabilization in a Rapidly Solidified Type 304 Stainless Steel: Influence on Tensile Properties" (to be published, Metall. Trans. A).

73. Flinn, J. E., Bae, J. C., and Kelly, T. F., "Flow Stress Behavior of Rapidiy Solidified Type 304 SS Extruded Powder with Conventionally Processed Type 304 SS Comparisons" (to be published).

74. Flinn, J. E., Bae, J. C., and Kelly, T. F., "Influence of Powder Particle Size on the Microstructural and Mechanical Properties of IGA Processed and Extruded Fe-16Ni-9 $\mathrm{Cr}-2 \mathrm{Mo}-1.5 \mathrm{Mn}-1.0 \mathrm{Si}-0.5 \mathrm{Ti}-0.05 \mathrm{C}$ Powder" (to be published).

75. Flinn, J. E., Bae, J. C., and Kelly, T. F., "Improved Creep Strengthening of Type 304 SS from Rapid Solidification Processing" (to be published).

76. Stein, G., Menzel, J., and Dorr, H., High Nitrogen Steels, eds. Foot, J. and Hendry, A., (The Institute of Metals), (1984), 32-38.

77. Rawers, J. C., Dunning, J. S., Petty, A. V., and Reed, R. P., Advanced Materials and Processes, 138, (1990), 50-52. 

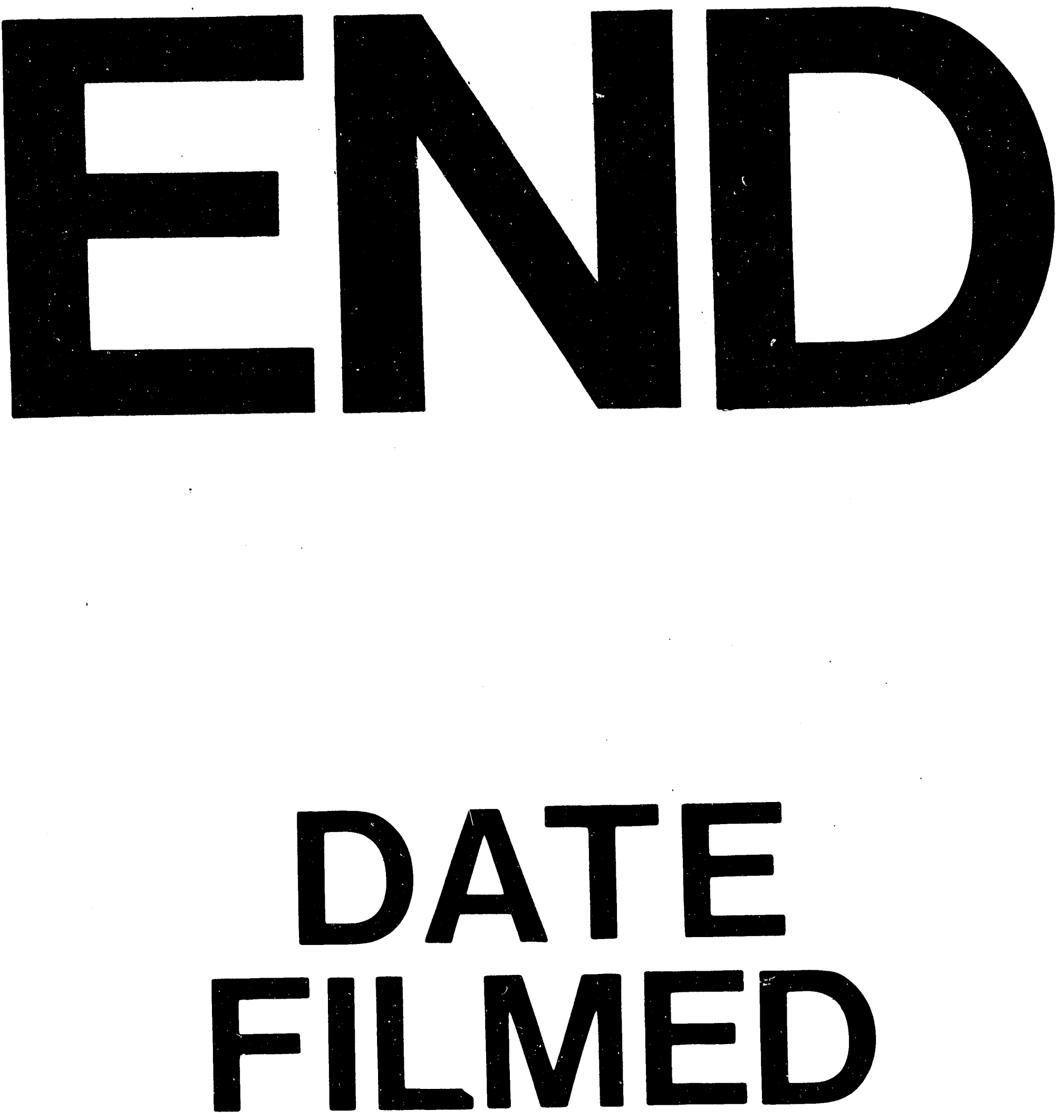

1

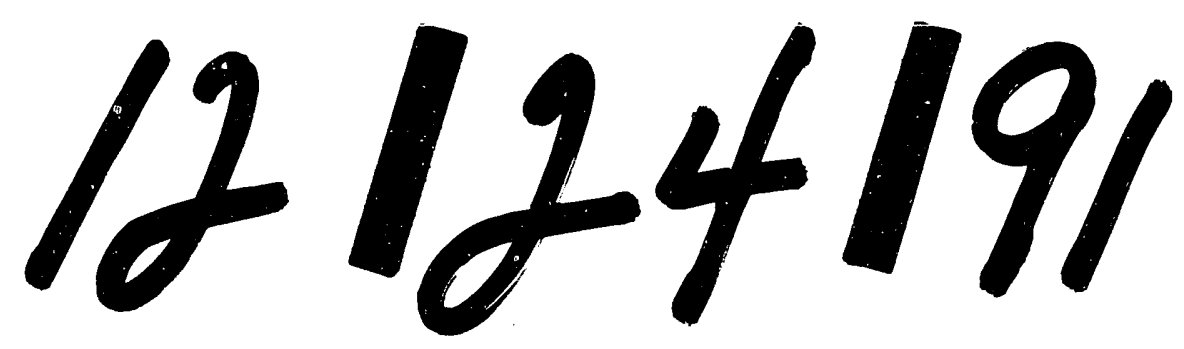


$-$

-
-
$\overline{=}$ 